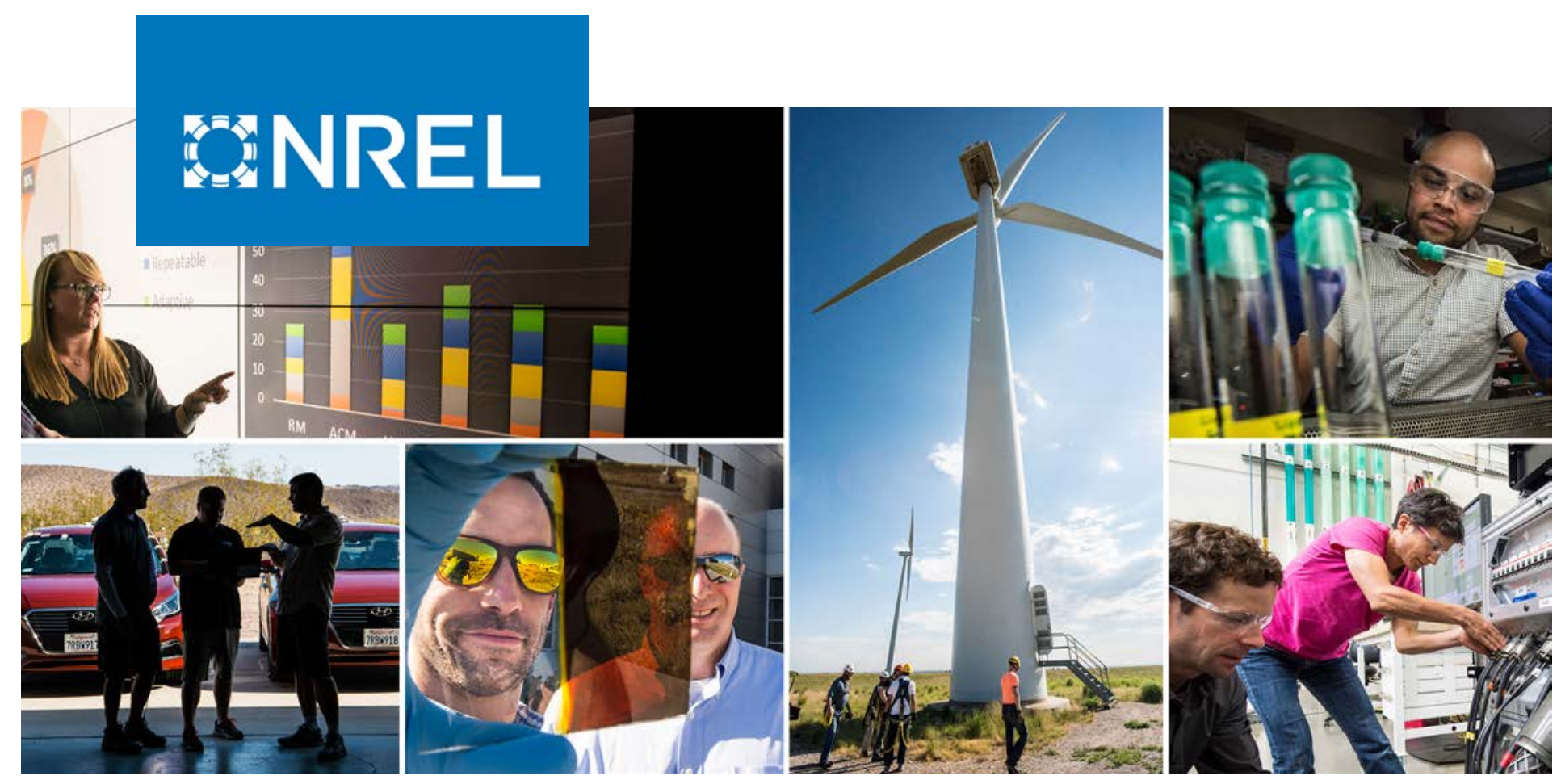

\title{
Best Practices for Operation and Maintenance of Photovoltaic and Energy Storage Systems; 3rd Edition
}

National Renewable Energy Laboratory, Sandia National Laboratory, SunSpec Alliance, and the SunShot National Laboratory Multiyear Partnership (SuNLaMP) PV O\&M Best Practices Working Group

NREL is a national laboratory of the U.S. Department of Energy Office of Energy Efficiency \& Renewable Energy

Operated by the Alliance for Sustainable Energy, LLC

This report is available at no cost from the National Renewable Energy Laboratory (NREL) at www.nrel.gov/publications.

\section{Technical Report}

NREL/TP-7A40-73822

December 2018 


\title{
BNREL
}

\section{Best Practices for Operation and Maintenance of Photovoltaic and Energy Storage Systems; 3rd Edition}

\author{
National Renewable Energy Laboratory, \\ Sandia National Laboratory, SunSpec Alliance, \\ and the SunShot National Laboratory Multiyear Partnership \\ (SuNLaMP) PV O\&M Best Practices Working Group
}

\section{Suggested Citation}

National Renewable Energy Laboratory, Sandia National Laboratory, SunSpec Alliance, and the SunShot National Laboratory Multiyear Partnership (SuNLaMP) PV O\&M Best Practices Working Group. 2018. Best Practices for Operation and Maintenance of Photovoltaic and Energy Storage Systems; 3rd Edition. Golden, CO: National Renewable Energy Laboratory. NREL/TP-7A40-73822. https://www.nrel.gov/docs/fy19osti/73822.pdf.

NREL is a national laboratory of the U.S. Department of Energy Office of Energy Efficiency \& Renewable Energy Operated by the Alliance for Sustainable Energy, LLC

This report is available at no cost from the National Renewable Energy Laboratory (NREL) at www.nrel.gov/publications.

Contract No. DE-AC36-08GO28308
Technical Report NREL/TP-7A40-73822

December 2018

National Renewable Energy Laboratory 15013 Denver West Parkway Golden, CO 80401 303-275-3000 • www.nrel.gov 


\section{NOTICE}

This work was authored by the National Renewable Energy Laboratory, operated by Alliance for Sustainable Energy, LLC, for the U.S. Department of Energy (DOE) under Contract No. DE-AC36-08GO28308. Funding provided by the U.S. Department of Energy Office of Energy Efficiency and Renewable Energy Solar Energy Technologies Office and SuNLaMP Agreement 32315. The views expressed herein do not necessarily represent the views of the DOE or the U.S. Government.

This report is available at no cost from the National Renewable Energy Laboratory (NREL) at www.nrel.gov/publications.

U.S. Department of Energy (DOE) reports produced after 1991 and a growing number of pre-1991 documents are available free via www.OSTI.gov.

Cover Photos by Dennis Schroeder: (clockwise, left to right) NREL 51934, NREL 45897, NREL 42160, NREL 45891, NREL 48097, NREL 46526.

NREL prints on paper that contains recycled content. 


\section{Acknowledgments}

The National Renewable Energy Laboratory (NREL), Sandia National Laboratories (SNL), SunSpec Alliance, and Roger Hill were supported by the U.S. Department of Energy (DOE) Solar Energy Technologies Office (SETO) under Agreement 32315 in the production of this report. The authors would like to thank the following working group contributors to this report.

\section{Working Group Coordinator}

Dylan Tansy, SunSpec Alliance

\section{Support Team}

Ammar Qusaibaty, SETO

Andy Walker, NREL

Eric Lockhart, NREL

Travis Lowder, NREL

Kari Burman, NREL, ret.

Geoff Klise, SNL

Roger Hill, consultant

Tom Tansy, SunSpec Alliance

Tim Keating, SunSpec Alliance

Olga Lavrova, SNL

Anil Pochiraju, SunSpec Alliance

Jessie Deot, SunSpec Alliance

Bob Fox, SunSpec Alliance

Chuck Kurnik, NREL

\section{Interviewees}

Greg Sellers, Clean Power Finance

Jean Paul La Marche, Main Street Power

Dirk Michaels, K \& L Gates

Rue Philips, True South

David Kenny, Sunrun

Leigh Zanone, Meteocontrol

Paul Lanning, Lightbox Energy

Sarah Disch, Wells Fargo

Andrew Truitt, Distributed Resource Ventures

Marco Lopez, Alectris

Ross Biesemeyer, First Solar

Laks Sampath, Alectris

Mark Berger, NextGrid Technologies 


\section{Working Group Roster}

Eric Alderman, Airphrame

Carlos Alves, Nextera Energy Services

Rob Andrews, Queen's University

John Balfour, High Performance PV

Stephen Barkaski, FLS Energy

Jimmy Bergeron, SolarCity

Michael Bolen, Electric Power Research Institute

Peter Bostock, VDE Americas

Alex Bradley, DuPont

Bill Brooks, Brooks Engineering

Paul Brucke, Brucke Engineering

Jon Budreski, Air Shark

Kari Burman, NREL

Joe Cain, Solar Energy Industries Assoc.(SEIA)

Nathan Charles, Enphase Energy

Daisy Chung, Solar Electric Power Assoc. (SEPA)

Joe Cunningham, Centrosolar

Jessie Deot, SunSpec

Skip Dise, Clean Power Research

Ron Drobeck, System Operations Live View (SOLV)

Nadav Enbar, Electric Power Research Institute

Cary Fukada, OpTerra Energy Services

Cyrille Godenot, Schneider Electric

Danya Golan, Solar Edge

Steve Hanawalt, Power Factors LLC

Chris Henderson, Ameresco

Martin Herzfeld, independent consultant

Roger Hill, consultant

Bill Hoffer, Sunergy Engineering Services

Rebekah Hren, Solar Energy International

Sandeep Jadhav, Mahindra Susten

Dirk Jordan, NREL

Raymond Kaiser, Amzur Technologies

Joe Kastner, Radian Generation

Tim Keating, SunSpec

Jason Kechijian, SolBright

George Kelly, Sunset Technology, Inc.

Geoff Klise, SNL

Pramod Krishnani, Terraform Power

Bhushan Kunjeer, Enersaas

Sarah Kurtz, NREL

Paul Lanning, Lightbox Energy
Olga Lavrova, SNL

Richard Lawrence, Institute for Building Technology and Safety (IBTS)

Eric Lockhart, NREL

Mike Loeser, Strata Solar

Jaya Mallineni, Nexamp Inc.

Joseph McCabe, Renewable Energy Champion

Ryan McCauly, Tritium3

Dirk Michels, Ballard Spahr

Reegan Moen, SOLV

Jamie Mordarski, SMA America

Jesse Moses, Swinerton Renewable Energy

Matt Murphy, Borrego Solar

Sean Murphy, SolBright Renewable Energy, LLC

Eric Nessl, Strata Solar

Christina Nichols, DOE

Don Nista, Cypress Creek Renewables

Angelo Purpura, SOLV

Michael Rogerson, Solar Edge

AJ Rossman, Smart Resource

Mary Rottman, Rottman Associates

Laks Sampath, Alectris

Jadhav Sandeep, Mahindra Susten

Rudy Saporite, IBTS

Kenneth Sauer, DNVGL

Thomas Sauer, Exxergy

Ulrich KW Schwabe, SEGIS-AC awardees

Bill Shisler, NRG

Jeff Southard, Juniper Unmanned Inc.

Jeff Spies, North American Board of Certified Energy Professionals (NABCEP)

Kristy Straiton, American Society of Testing and Materials (ASTM)

Dylan Tansy, SunSpec

Tom Tansy, SunSpec

Abhay Tilwankar, Mahindra Susten

Ernest (Ernie) Tom, Salt River Project

Will Troppe, Power Factors LLC

Andrew Truitt, Dividend Finance

Andy Walker, NREL

Carter Wall, Franklin Beach Energy

John Williamson, Array Technologies

Gordon Woodcock, Taitem Engineering, PC

Leigh Zanone, 8minutenergy 


\section{Working Group Roster}

Eric Alderman, Airphrame

Carlos Alves, Nextera Energy Services

Rob Andrews, Heliolytics Inc.

John Balfour, High Performance PV

Jimmy Bergeron, SolarCity

Michael Bolen, Electric Power Research

Institute (EPRI)

Peter Bostock, VDE Americas

Alex Bradley, DuPont

Bill Brooks, Brooks Engineering

Paul Brucke, Brucke Engineering

Jon Budreski, Air Shark

Ben Compton, NextPhase Solar

Joe Cunningham, Centrosolar

Skip Dise, Clean Power Research

Ron Drobeck, SOLV

Nadav Enbar, EPRI

Cary Fukada, OpTerra Energy Services

Jeff Gilbert, Vigilant Energy Management

Danya Golan, SolarEdge

Shannon Grein, Empyrean Electric

Steve Hanawalt, Power Factors LLC

Chris Henderson, Ameresco

Martin Herzfeld, consultant

Roger Hill, consultant

Bill Hoffer, Sunergy Engineering Services PLLC

Rebekah Hren, Solar Energy International

Joe Kastner, Radian Generation

Jason Kechijian, SolBright

George Kelly, Sunset Technology, Inc.

Ken Kostok, Alectris

Pramod Krishnani, Terraform Power

Bhushan Kunjeer, SunEdison

Sarah Kurtz, NREL

Paul Lanning, Lightbox Energy

Olga Lavrova, SNL
Richard Lawrence, National Accreditation Board

for Certified Energy Professionals (NABCEP)

Mike Loeser, Strata Solar

Jaya Mallineni, Nexamp Inc.

Joseph McCabe, Renewable Energy Champion

Ryan McCauly, Tritium3

Scott McWilliams, Sematech

Dirk Michels, Ballard Spahr

Reegan Moen, Swinerton Renewable Energy

Jamie Mordarski, SMA America LLC

Jesse Moses, Swinerton Renewable Energy

Matt Murphy, Borrego Solar

Sean Murphy, SolBright Renewable Energy, LLC

Eric Nessl, Strata Solar

Christina Nichols, DOE

Don Nista, Cypress Creek Renewables

Rue Phillips, True South Renewables

Angelo Purpura, Swinerton Renewable Energy

Michael Rogerson, SolarEdge

AJ Rossman, Smart Resource

Mary Rottman, Rottman Associates

Laks Sampath, Alectris

Jadhav Sandeep, Mahindra Susten

Rudy Saporite, IBTS

Ulrich Schwabe, SEGIS-AC awardees

Bill Shisler, NRG

Jeff Spies, NABCEP

Kristy Straiton, ASTM

Abhay Tilwankar, Mahindra Susten

Ernest Tom, Salt River Project

Will Troppe, Power Factors LLC

Andrew Truitt, Dividend Finance

Carter Wall, Franklin Beach Energy

David Walter, Hartford Steam Boiler

Gordon Woodcock, Taitem Engineering, PC

Leigh Zanone, Meteocontrol 


\section{List of Acronyms}

AC

AMI

AMR

ANSI

ASNT

ASTM

BLAST

CAD

CT

DAS

DC

DOD

DOE

EAM

EPC

EPDM

EPRI

ERP

EVA

FEMP

FERC

GFI

GHI

GO

GOP

GSU

IBTS

IEC

IECRE

IEEE

IGBT

IP

IRR

IT

$\mathrm{I}-\mathrm{V}$

KPI

kVAR

LC

LCOE

LFP

LLC

LMO

LTO

$\mathrm{MC}$ alternating current

advanced metering infrastructure

automated meter reading

American National Standards Institute

American Society of Non-destructive Testing

American Society for Testing and Materials

Battery Lifetime Analysis and Simulation Tool

computer-aided design

current transformer

data acquisition system

direct current

depth of discharge

U.S. Department of Energy

enterprise asset management

engineering, procurement, and construction

ethylene propylene diene monomer

Electric Power Research Institute

enterprise resource planning

ethylene vinyl acetate

Federal Energy Management Program

Federal Energy Regulatory Commission

ground fault interruption

global horizontal insolation

generator owner

generator operator

generator step-up

Institute for Building Technology and Safety

International Electrotechnical Commission

IEC Renewable Energy

Institute of Electrical and Electronics Engineers

insulated-gate bipolar transistor

Internet Protocol

internal rate of return

information technology

current voltage

key performance indicator

thousands of Volts-Amps Reactive

lithium carbon

levelized cost of energy

lithium iron phosphate

limited liability corporation

lithium manganese oxide

lithium titanate

multi-crystalline or multiple-connector 


\begin{tabular}{|c|c|}
\hline MFS & maximum foreseeable loss \\
\hline MLPE & module-level power electronics \\
\hline MPPT & maximum power-point tracking \\
\hline NABCEP & North American Board of Certified Energy Practitioners \\
\hline $\mathrm{NCA}$ & Nickel cobalt aluminum \\
\hline $\mathrm{NCU}$ & Network Control Unit \\
\hline NERC & North American Electric Reliability Corporation \\
\hline NFPA & National Fire Protection Agency \\
\hline NLE & normal loss expected \\
\hline NMC & nickel-manganese-carbon \\
\hline NREL & National Renewable Energy Laboratory \\
\hline OEM & original equipment manufacturer \\
\hline O\&M & operations \& maintenance \\
\hline $\mathrm{OMC}$ & outside management control \\
\hline OSHA & Occupational Safety and Health Administration \\
\hline PML & probable maximum loss \\
\hline POA & plane of array \\
\hline PPA & power purchase agreement \\
\hline PPE & personal protective equipment \\
\hline PR & performance ratio \\
\hline PV & photovoltaics \\
\hline PVC & polyvinyl chloride \\
\hline PVPS & Photovoltaic Power Station \\
\hline RCRA & Resource Conservation and Recovery Act \\
\hline REC & renewable energy certificate \\
\hline RMS & root mean square \\
\hline ROI & return on investment \\
\hline SAM & System Advisor Model \\
\hline SAPC & Solar Access to Public Capital \\
\hline SBS & styrene butadiene styrene \\
\hline SCADA & Supervisory Control and Data Acquisition \\
\hline SDO & standards developing organization \\
\hline sf & square foot \\
\hline STC & standard test condition \\
\hline TOD & Time of Day \\
\hline ТPO & thermoplastic polyolefin \\
\hline UAV & unmanned aerial vehicle \\
\hline UL & Underwriters Laboratories \\
\hline UN & United Nations \\
\hline UPS & Uninterruptible Power Supply \\
\hline UV & ultraviolet \\
\hline VLA & vented lead acid \\
\hline VRLA & valve regulated lead acid \\
\hline
\end{tabular}




\section{Table of Contents}

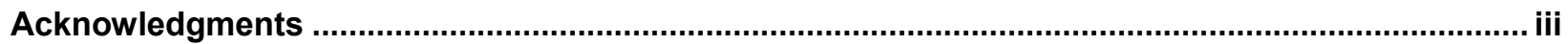

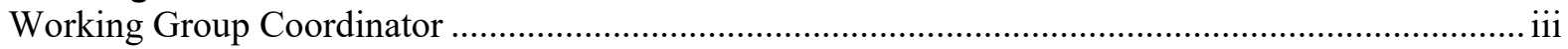

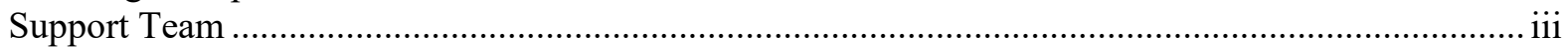

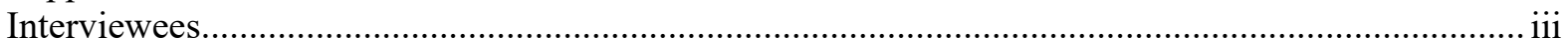

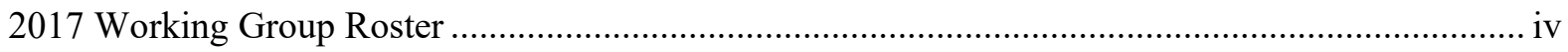

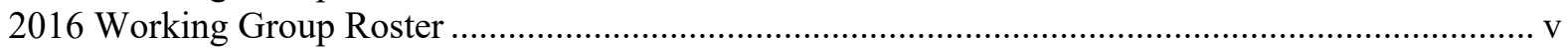

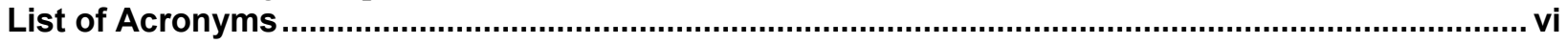

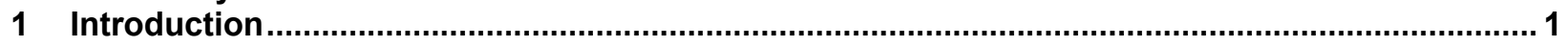

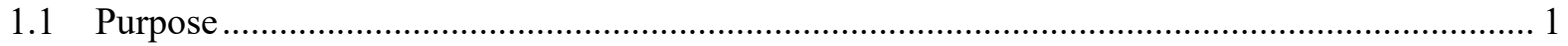

1.2 Background-The PV O\&M Working Group ...................................................................... 1

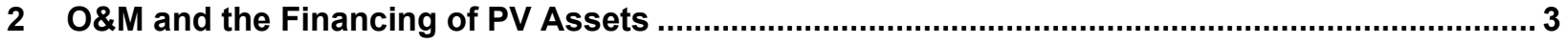

3 Scope and Prerequisites for a Successful O\&M Program ......................................................... 5

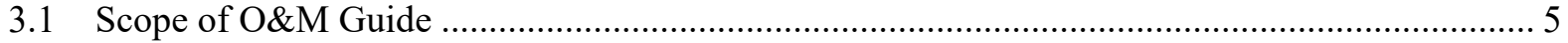

3.2 Prerequisites for a Successful O\&M Program ….............................................................. 5

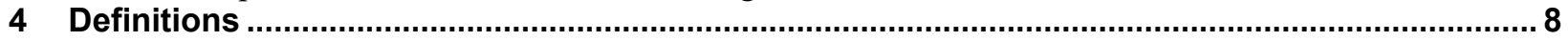

5 Dependencies on PV System Type, Site, and Environmental Condition.................................... 11

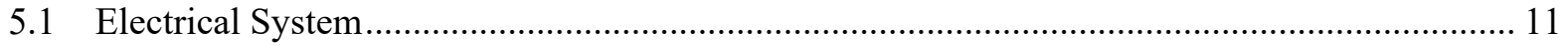

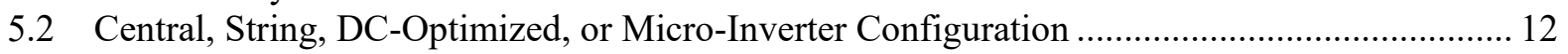

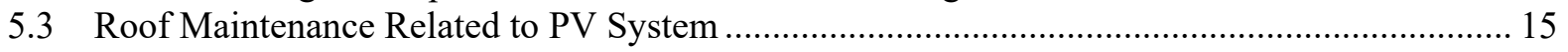

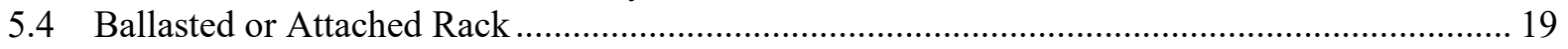

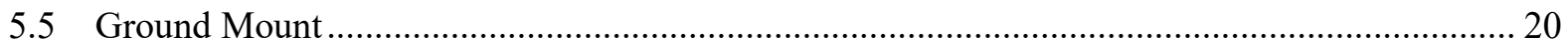

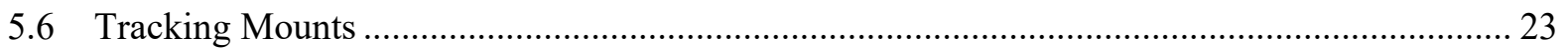

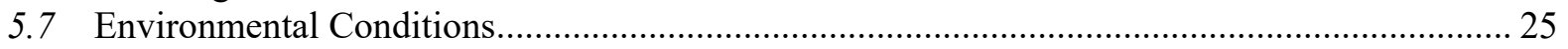

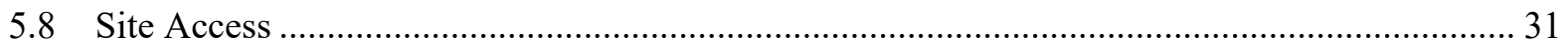

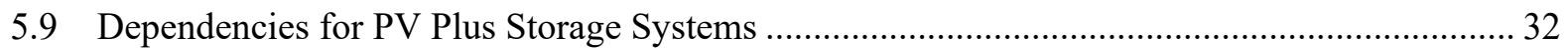

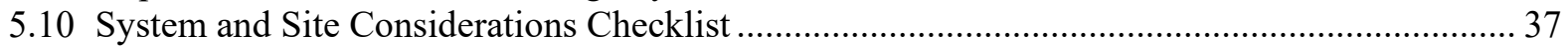

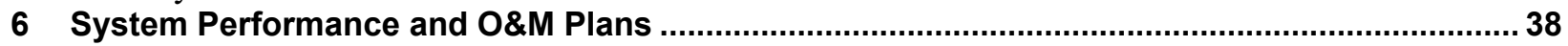

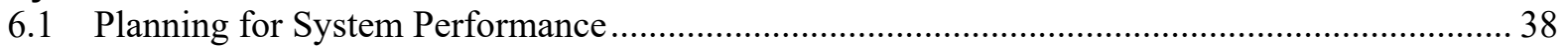

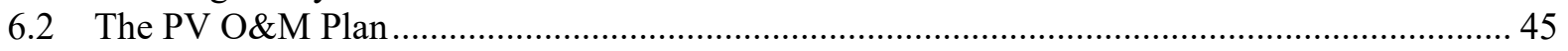

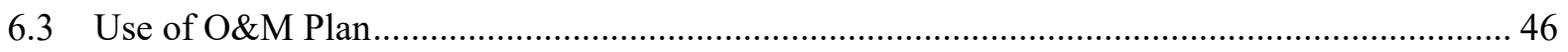

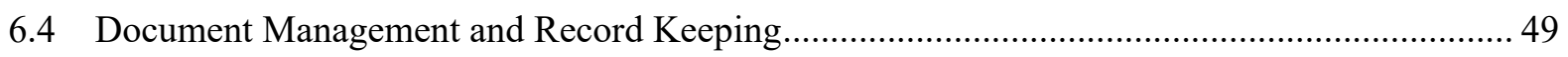

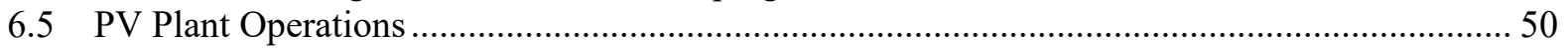

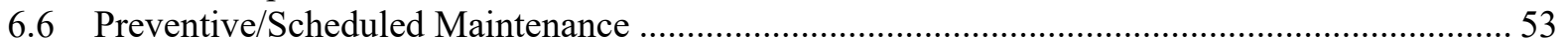

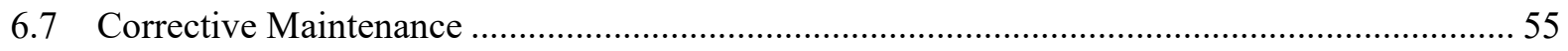

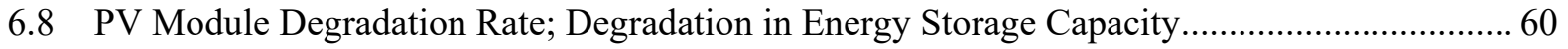

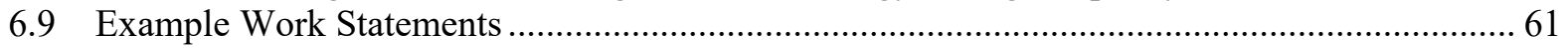

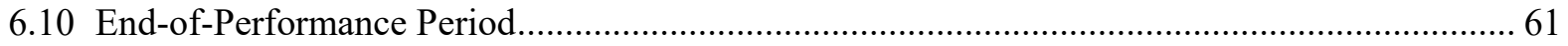

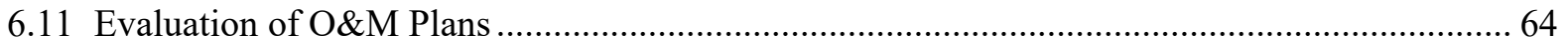

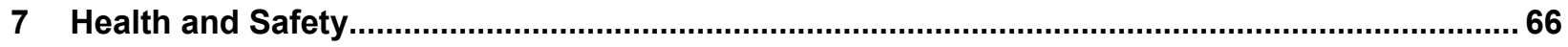

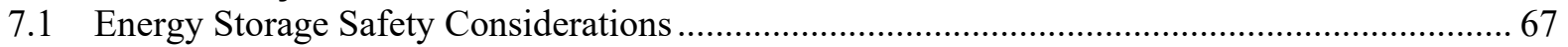

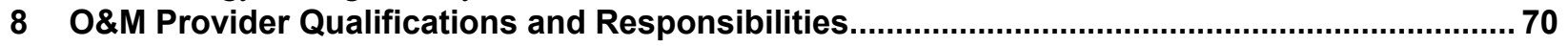

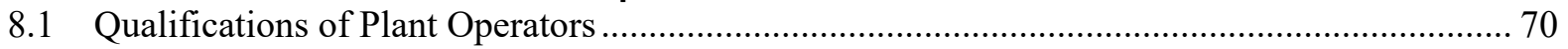

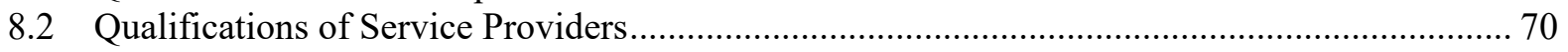

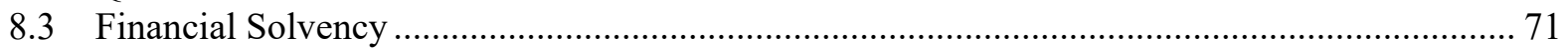

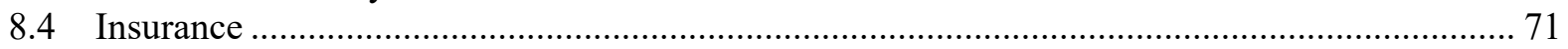

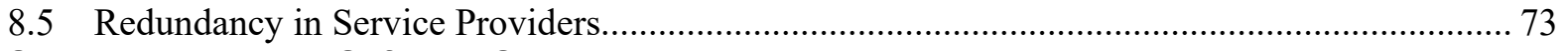

9 System Monitoring, Software Solutions, and Data Management ................................................74

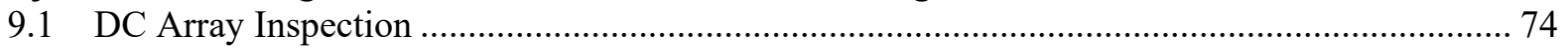

9.2 Energy Storage System Inspection and Testing ........................................................... 78 


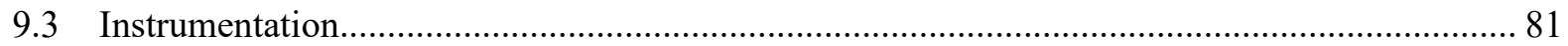

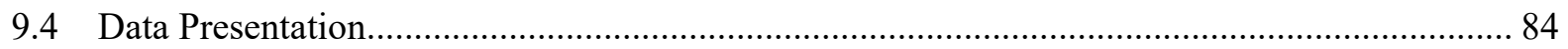

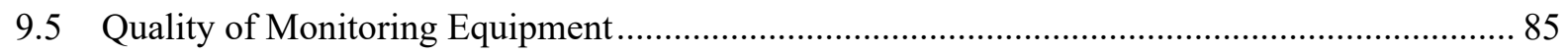

9.6 Transparency of Measurement Protocols and Procedures........................................................ 85

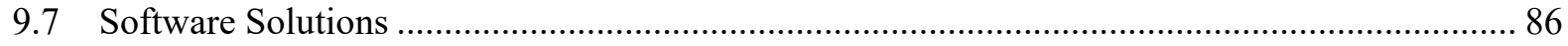

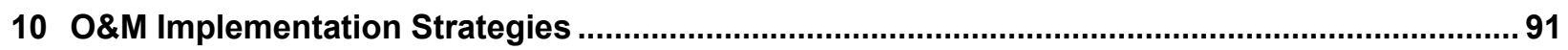

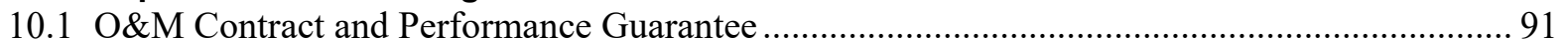

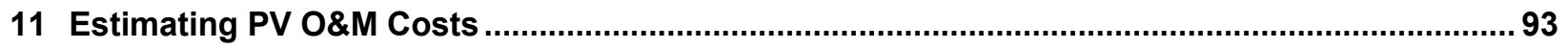

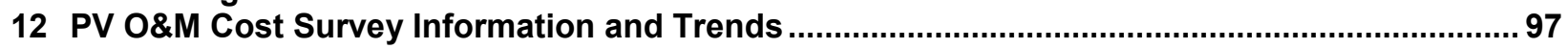

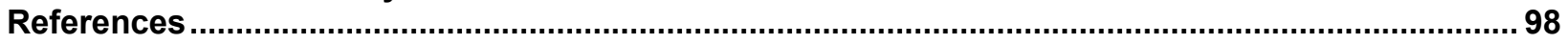

Appendix A. System Performance Guarantee Example Calculation (Without Shade Correction). 103

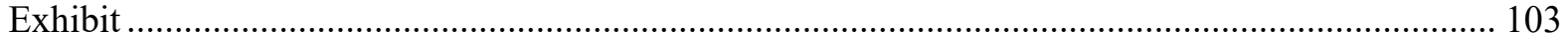

Appendix B. PV O\&M Cost Model Preventive Maintenance Service Descriptions .......................... 107

Appendix C. PV O\&M Cost Model Corrective Maintenance Service Descriptions...........................116

Appendix D. PV O\&M Scope of Work, Salary, and Qualifications ….............................................. 121

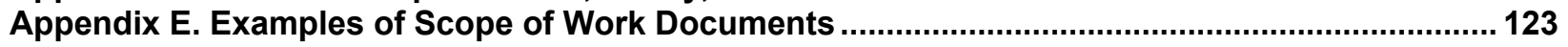

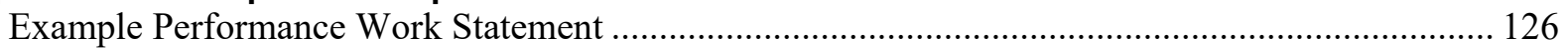

Example Description of Maintenance Services for Commercial Rooftop Installations ..................... 126

Example Description of Maintenance Services for Commercial Ground Mount Installations .......... 129

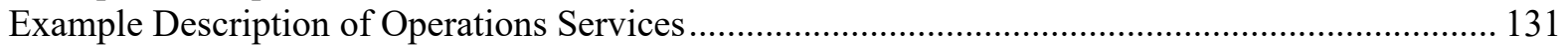

Appendix F. Using Model PV System Availability Terms for Contracted O\&M ............................. 137 


\section{List of Figures}

Figure 1. Two strings of batteries are recommended in design to allow O\&M service of one string while the other string serves the purpose. Photo by Andy Walker, NREL

Figure 2. Maintenance of wire management systems depend on plastic wire ties and grommets, which can break or pinch wires (left); exposure to sunlight; wind and weight of ice (center); and access by chewing rodents (right). Photos by Andy Walker, NREL.....

Figure 3. A best practice is to run a slip sheet continuously under rack members to avoid direct contact with the roof membrane. In this photo, direct contact of the rack is cutting into the roof surface. Photo by Norm Crouse, Lightbox Energy........................................................... 18

Figure 4. Sheep, but not goats or cattle, can be employed for vegetation control. Photo by Eliza Hotchkiss,

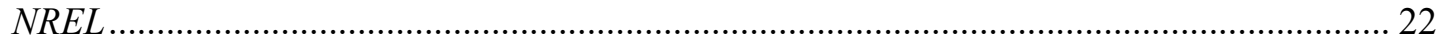

Figure 5. Drainage and storm-water run-off are difficult to improve after the PV array is installed, requiring diligence in design and construction of storm-water management systems. Photo by Andy Walker, NREL

Figure 6. Although improving annual energy delivery, especially in summer, tracking mechanisms and controls require regular maintenance to be effective. Photo by Andy Walker, NREL............ 25

Figure 7. Module soiling can often be traced to a source, such as construction-site dust, resulting in about $5 \%$ loss. Photo by Andy Walker, NREL 28

Figure 8. Bird populations are a source of soiling, as well as nests that need to be removed and seeds that can sprout on arrays. Photo by Andy Walker, NREL ......................................................... 29

Figure 9. Snow is an environmental condition that both reduces performance and complicates provision of O\&M services, but removal of snow off arrays is not recommended due to the potential for damage. Photo by Andy Walker, NREL

Figure 10. It might be the responsibility of the O\&M provider to respond and ensure that storm damage is rendered safe both in terms of electrical hazards and loose components following an extreme weather event such as this damage in St. Croix in 2017. Photo by Andy Walker, NREL ...... 31

Figure 11. Different definitions of Performance Ratio (as per IEC 61724) result if different values compared here for a sample of 2,200 PV systems. PR-1 is actual production divided by STC rating and normalized for insolation; PR-2 is actual production divided by PTC rating and normalized for insolation; and PR-3 is actual production divided by PTC rating normalized for insolation, ambient temperature, age of system, and balance of system efficiency. A value of PR-3 $=100 \%$ means the system is performing as expected. Figure by Andy Walker, NREL using data from oSPARC 2018.

Figure 12. Short-term test of PV Arrays on Carport of Degatau Federal Building and Courthouse, Puerto Rico, showing performance commensurate with calculated expected value, including that power is limited to $100 \mathrm{~kW}$ by the capacity of the inverter on this $125 \mathrm{~kW} \mathrm{DC}$ system. This test was conducted over a 1-hour period that included sunny periods (points to the right) and passing clouds (points to the left side of the graph). Figure and photo by Andy Walker, NREL

Figure 13. The National Park Service budgets, ideally, $\$ 100,000$ per year for O\&M of this PV energy storage system (308 kW PV; 1,920 kWh battery) on Alcatraz Island. Photo by Andy Walker, NREL

Figure 14. Failure in materials and workmanship, such as encapsulant of this module, are often covered by product manufacturer's warranty. Photo by Andy Walker, NREL .................................. 56

Figure 15. Snail trails in encapsulant are attributed to cracks in cells caused by flexure of the panel at the factory, shipping, or installation. The module would be covered by the performance warranty only if the cracks isolate fragments of the cell and reduce the output over time. Photo by Andy Walker, NREL 
Figure 16. Failure to follow product box handling and storage requirements can cause damage when moved and void a warranty. The umbrella symbol on this box indicates it should be kept dry and the box might fail when picked up with a forklift. Photo by Andy Walker, NREL

Figure 17. Premature failure of a lead-acid battery caused by low state-of-charge for an extended period of time can be avoided only by periodic fully saturated charge of the battery. A battery can recover from amorphous sulfation; but, given time to crystalize, the degradation in capacity and efficiency is permanent and can cause swelling and breakage of the battery jar. Photo by Andy Walker, NREL

Figure 18. Cracked or peeling backsheet leads to water infiltration and ribbon corrosion. Photo by Andy Walker, NREL

Figure 19. Manual inspection and testing requires opening NEMA-rated enclosures. The integrity of any enclosure seal must be restored after opening to avoid moisture damage as in this module junction box. Photo by Andy Walker, NREL

Figure 20. High-resolution infrared aerial imaging can identify failed strings, modules, and cells within modules, as shown on this image. Image by Rob Andrews, Heliolytics Inc.

Figure 21. Infrared imaging exposes an imbalance of current through three parallel strings of batteries (the string on top is cooler) and exposes the cause of the problem, which is a battery terminal connection that is badly corroded. Photo by Owen Roberts, NREL.

Figure 22. Probability that the reserve account amount will be sufficient to cover costs in a given year as a function of the fraction of the total number of a type of component and the probability of failure of the type of component in that given year. Figure by Andy Walker, NREL

Figure 23. Results of PV O\&M cost model for 10-MW ground-mount PV system with tracking, central inverters, and pollen as an environmental condition. Figure by Andy Walker, NREL ........... 96

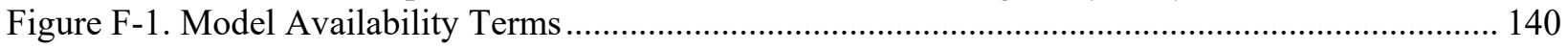




\section{List of Tables}

Table 1. Cost of String, DC-Optimized, Central, and Micro-Inverter Replacement (Feldman et. al, 201813

Table 2. Service Costs for Different Types of Roofs ${ }^{\mathrm{a}}$ (HomeAdvisor 2016; HomeAdvisor 2008) ............ 16

Table 3. Representative PV Module Degradation Rates (Jordan and Kurtz 2012).................................6 60

Table 4. Codes and Standards Related to Energy Storage System Maintenance (PNNL and Sandia 2016)

Table A-1. Example of Annual Degradation included in tabulation of Availability and Performance Ratio

Table B-1. Service Descriptions for Preventive Maintenance Selections Available in the PV O\&M Cost Model Tool...

Table C-1. Service Descriptions for Corrective Maintenance Selections Available in the PV O\&M Cost Model..... 116

Table D-1. Qualifications and Loaded Labor Rates for PV O\&M Service Providers ${ }^{\mathrm{a}}$ 121 


\section{Introduction}

The goal of this guide is to reduce the cost and improve the effectiveness of operations and maintenance (O\&M) for photovoltaic (PV) systems and combined PV and energy storage systems. Reported O\&M costs vary widely based on the requirements of the system and the nature of the O\&M contract, but a more standardized approach to planning and delivering O\&M has the potential to both decrease costs and make those costs more predictable over time. However, the bigger payoff for improved O\&M is increased performance. Actuarial data indicate that comprehensive PV-only system O\&M could improve the average performance ratio (PR, adjusted for age and temperature) of systems from 91.7 to at least $95 \%$, which is a substantial increase in revenue and environmental benefits of a PV system (oSPARC 2018). Drivers to improve O\&M include the following: increase efficiency and energy delivery $(\mathrm{kWh} / \mathrm{kW})$, decrease downtime (hours/year), extend system lifetime (e.g., from 25 to 40 years for PV modules), reduce cost of O\&M ( $\$ \mathrm{~kW} / \mathrm{year})$, ensure safety and reduce risk, enhance appearance, and meet requirements of financing and warranties.

\subsection{Purpose}

This guide encourages adoption of best practices to reduce the cost of O\&M and improve the performance of fielded systems, but it also enhances financing of new projects by making cost more predictable and mitigating performance risk. This guide also includes technical improvement opportunities in the design of systems and in specification of equipment because high-quality system deployment improves lifetime project performance and energy production while reducing, or at least optimizing, costs to deliver an O\&M program. This guide provides recommendations that increase the effectiveness of O\&M services; reduce O\&M costs, improve solar asset transparency for investors and rating agencies; provide an industry framework for quality management; and reduce transaction costs.

Most of the content of this guide relates to utility-scale or larger distributed generation PV systems, and also to portfolios or fleets of systems, but some sections are equally applicable to smaller distributed-generation or residential systems. The reader is referred to the Table of Contents to help find content applicable to system by size, type, and market sector.

\subsection{Background-The PV O\&M Working Group}

This is the $3^{\text {rd }}$ edition of this guide. The $2^{\text {nd }}$ edition is available at https://www.nrel.gov/docs/fy17osti/67553.pdf, which was a successful publication with an audience of almost 12,000 readers. The $1^{\text {st }}$ edition was an "interim" version issued in 2015, which is available at http://www.nrel.gov/docs/fy15osti/63235.pdf. These guides were developed by facilitated working groups, the membership of which is listed in the front matter. The Solar Access to Public Capital (SAPC) Working Group was convened in 2014 to open capital market investment in the solar asset class and consisted of solar developers, financiers and capital managers, law firms, rating agencies, accounting and engineering firms, and other stakeholders engaged in solar asset deployment. In 2016, a subset of the SAPC Working Group was merged with Sandia National Laboratories’ Technical O\&M Working Group to unify efforts by the U.S. Department of Energy (DOE) to improve O\&M practices, data standards, and costs. This combined body - the PV O\&M Working Group - is administrated by the National Renewable 
Energy Laboratory (NREL), Sandia National Laboratories, SunSpec Alliance, and Roger Hill, and it is supported by the DOE SunShot Initiative (SuNLaMP program).

Other products of the PV O\&M Working Group that support and inform this guide include two actuarial databases (the Open System Performance and Reliability Clearinghouse (oSPARC, 2018) performance database and the PV Reliability Operation and Maintenance database of failure and reliability data) and the PV O\&M Cost Model (initially a spreadsheet model; now an online tool to estimate annual O\&M costs called Asset Performance Suite at http://APsuite.SunSpec.org).

\subsubsection{Updates to the $3^{\text {rd }}$ Edition}

This edition includes the integration of O\&M considerations for systems that combine PV and energy storage. The storage-related additions to the $3^{\text {rd }}$ edition are integrated throughout the document. The scope of the types of battery technologies and the battery use cases considered are detailed in Section 3; system dependencies specific to storage are listed in Section 5; O\&M and end-of-performance period issues are addressed in Section 6; safety in Section 7; controls and monitoring considerations in Section 9; and cost estimate guidance is presented in Section 11 .

Other updates to the guide include the following:

- Expanded and created new section on health and safety considerations

- Developed the discussion on selecting and implementing software solutions in the context of the full life cycle of PV-only and PV plus storage systems

- Presented model PV system availability terms for contracted O\&M

- Described a scorecard methodology to evaluate an O\&M program

- Added O\&M actions to prepare for and recover from extreme weather events, such as hurricanes. 


\section{O\&M and the Financing of PV Assets}

An effective O\&M program enhances the likelihood that a system will perform at or above its projected production rate and cost over time. Therefore, it reinforces confidence in the long-term performance and revenue capacity of an asset. Historically, O\&M practices and approaches have not been standardized, and instead, they were implemented in various proprietary methods. This approach can increase the cost to projects and portfolios, as well as raise the perception of risk from investors. Specific recommendations from the PV O\&M Working Group to reduce variations in O\&M practices include:

- Define performance metrics uniformly. A system characterized by a "Guarantee" to deliver 1,000 MWh/year would be difficult to compare and bundle with another that has a "Key Performance Indicator" to be operational $90 \%$ of the time. Investors need performance metrics and evaluation methods to be the same across a bundle of assets.

- Refer to specified standards. Practices and delivery of O\&M services differ, and investors need to know that an existing system has been maintained according to standard definitions and criteria.

- Make cost estimates uniform and predictable. Differences in types of systems as well as geographic location and climate conditions can confound securitization. Investors want to know how much it will cost to perform required O\&M and secure the performance of the investment. Cost estimates must be uniform and predictable so that they can be bundled, yet they should reflect the factors that cause O\&M costs to vary from site to site.

Many investors are more interested in reducing risk than maximizing internal rate of return (IRR). Investors would prefer $100 \%$ certainty of achieving a 5\% IRR over a $50 \%$ certainty of achieving a $10 \%$ IRR, even though the two are of statistically equivalent value. Investors will first make an investment decision based on mitigating performance risk with effective O\&M; and then the financing rates are finally determined mainly through competition from other financiers (e.g., competing banks). Standardization of O\&M practices will facilitate investor analyses of risk factors and can reduce the time and cost to perform due diligence. Risk reduced by effective O\&M will enable more banks to qualify more projects, and that will eventually increase competition and reduce borrowing costs.

Although PV systems may have different origins, they can be pooled together in portfolios - and thus, be financed more efficiently - if they adhere to clear, industry-accepted business and technical guidelines regarding O\&M. Industry groups important to this effort include the Institute for Building Technology and Safety (IBTS), SunSpec Alliance, and North American Board of Certified Energy Practitioners (NABCEP). National and international standardsdeveloping organizations (SDOs) important to this effort include the American National Standards Institute (ANSI), Institute of Electrical and Electronics Engineers (IEEE), International Electrotechnical Commission (IEC), and ASTM International (formerly known as the American Society for Testing and Materials [ASTM]).

Two SDOs - the ASTM and IEC - are coordinating directly with NREL and Sandia National Laboratories to develop O\&M standards, with drafts being made available to working group members. These standards are primarily technical in nature and focus on life cycle management, design for O\&M guidelines, and detailed maintenance processes and procedures. Representatives from ASTM and IEC were involved in developing these best practices. This document is offered 
as what is referred to in the standards-making process as "research" to be considered as the IEC and ASTM committees develop the language of the standards. The IECRE, which is the Renewable Energy IEC system for certification to standards, will receive this guide for consideration of recommendations. It will serve as input to PV industry certification and compliance approaches and practices.

Combining PV with storage brings additional financial considerations. Battery energy storage can resolve technical barriers to grid integration of $\mathrm{PV}$ and increase total penetration and market for PV. Storage can add to the value propositions that PV projects can access and improve the value of PV but also can increase overall costs and add complexity to weigh against the benefits. Benefits of integration of storage include: shift when PV generation is used, which has an array of potential benefits such as savings on time-of-use and demand charge reductions; avoid net metering where not allowed by technical constraints or utility policy; increasing the resilience of facilities by keeping systems energized during grid outages; and potentially monetizing other grid benefits such as power factor correction, frequency regulation and voltage support. Monetizing and combining all the different value propositions of combining solar and storage is an ongoing area of research and business model innovation, and will increase the market for PV and the need for financing. The more interactive nature of battery dispatch (charge/discharge) increases the "operations" part of O\&M considerably. 


\section{Scope and Prerequisites for a Successful O\&M Program}

\subsection{Scope of O\&M Guide}

The services covered in this guide include asset management, monitoring, operations, preventive maintenance, corrective or condition-based maintenance (repair), and end of performance period (disposition).

This guide addresses dependencies due to system type, such as micro-, string-, or central inverter; ground versus roof-mounted PV; attached versus ballasted mount; and tracking versus fixed mount. The guide also addresses dependencies based on site conditions including sources of soiling, bird populations, snow, pollen, and high temperatures. Energy storage systems are discussed in the context of dependencies, including relevant technologies, system topologies, and approaches to energy storage management systems.

This guide provides information on the delivery of O\&M services, including qualifications of service providers, contractual relations, and performance guarantees related to O\&M.

\subsubsection{PV Scope}

This document covers a wide scope of PV size classes: residential rooftop (typically less than 10 $\mathrm{kW}$ ); commercial and industrial rooftops and shade structures such as carport (10 kW to 1,000 $\mathrm{kW}$ ); and utility-scale ground-mounted systems (often greater than 1,000 kW).

\subsubsection{Energy Storage Scope}

This guide focuses on electrochemical batteries and does not cover other energy storage technologies such as pumped hydro or compressed air energy storage. Within batteries, the focus will be on lead-acid and lithium-ion chemistries, with some limited discussion of flow batteries. This selection is based on current market penetration and forecasted future market growth for batteries in combination with PV systems.

\subsection{Prerequisites for a Successful O\&M Program}

Borrowing from classroom grades, where " $\mathrm{A}$ " is best, it is possible to bring a PV system earning a "D" grade up to a "C" or " $B$ " with effective O\&M. However, it is not possible to earn an " $A$ " unless O\&M was a consideration in the design of a system. Also, O\&M might not be able to save a failing system if the problems are intrinsic to the design or products used. O\&M issues should be considered in design, engineering, and construction in order to:

- Select low- or no-maintenance alternatives when available (for example plastic wire ties would require replacement whereas coated metal ones may not);

- Track the performance of fielded equipment and identify and specify the ones that have low failure rates, and which have the best OEM warranty service; standardize on preferred products to avoid mis-match of parts and expertise in a fleet;

- Make use of network-connected inverters for remote testing, software configurations and/or updates, and remote resets

- Provide required access to and clearance around equipment for maintenance (EPRI 2010) 
- Provide elevated pads to prevent flooding of ground-mounted equipment and provide permanent storm-water management system that is integrated with surrounding properties.

- Enable third-party inspection and commissioning of original EPC installations to spot operation problems before acceptance (EPRI 2010)

- Conform to the evaluation and quality-assurance protocol detailed in the SAPC PV System Installation Best Practices Guide (applicable to residential systems only) (Keating, Walker, and Ardani 2015).

- Build PV and storage systems to relevant standards, such as IEEE 937: Recommended Practice for Installation and Maintenance of Lead-Acid Batteries for Photovoltaic (PV) Systems (IEEE 2007).

- Apply IEC 62446: Grid Connected Photovoltaic Systems-Minimum Requirements for System Documentation, Commissioning Tests, and Inspections (IEC 2009), which requires documentation of the system, array testing, and whole-system performance test ${ }^{1}$ (applicable to commercial, industrial, and utility-scale systems). Commissioning is the link between the engineering, procurement, and construction (EPC) contractor and the operator. In addition to the above-mentioned safeguards, commissioning is now recommended to be a two-part process: The first part is done when the system starts operation, and the second is performed after one year of operation. Full acceptance of the system comes after the second step. Third-party verification of a plant can help ensure that best practices are applied throughout the life cycle of a plant. Such verification could include concept, site selection, design, equipment selections, installation, commissioning, final commissioning, PV system performance reporting, annual certification, certification for transfer of ownership or for refinancing, O\&M practices, and/or end-of-performance period.

Based on inspections of PV systems damaged in hurricanes, the following are prerequisites to address in the design and installation of a system in the areas vulnerable to hurricanes prior to O\&M tenure:

- Through-bolting is preferred to self-tapping screws. Self-tapping screws are more likely to pull out, and due to the hardened threads and lack of galvanized coating on the threads, they get weaker over time due to corrosion.

- Through-bolting is preferred to clamps in rack hardware. Clamps may have the specified strength in the proper orientation when forces are applied in the proper direction, but relative movement, rotation, or vibration of rack parts in a storm can cause them to release. An entire row of modules can fail if one module is lost, and they are held by Tshaped clamps that hold two modules at one point.

- Stainless-steel boxes with thick rubber gaskets and multiple closure attachments stay intact and exclude moisture more effectively than those with only handle-actuated attachments (specify NEMA 6 rating).

- Mastheads can break off or leak in a storm and must be sealed with foam packing provided for that purpose to avoid water infiltration and keep insects out.

- Drainage from boxes and conduit runs must be provided in the case of water infiltration.

${ }^{1}$ Other commissioning guides are also available. 
For battery storage systems, two parallel strings of batteries are recommended so that one may be taken out of service for maintenance while the other string provides at least some storage for continued operations. Design of a battery facility should consider easy access to each cell for service and also for replacement of individual units without disassembling the whole battery plant. The design should also include features to support battery O\&M such as safety systems and on-site storage of battery materials and supplies that is compliant with all safety and code requirements.

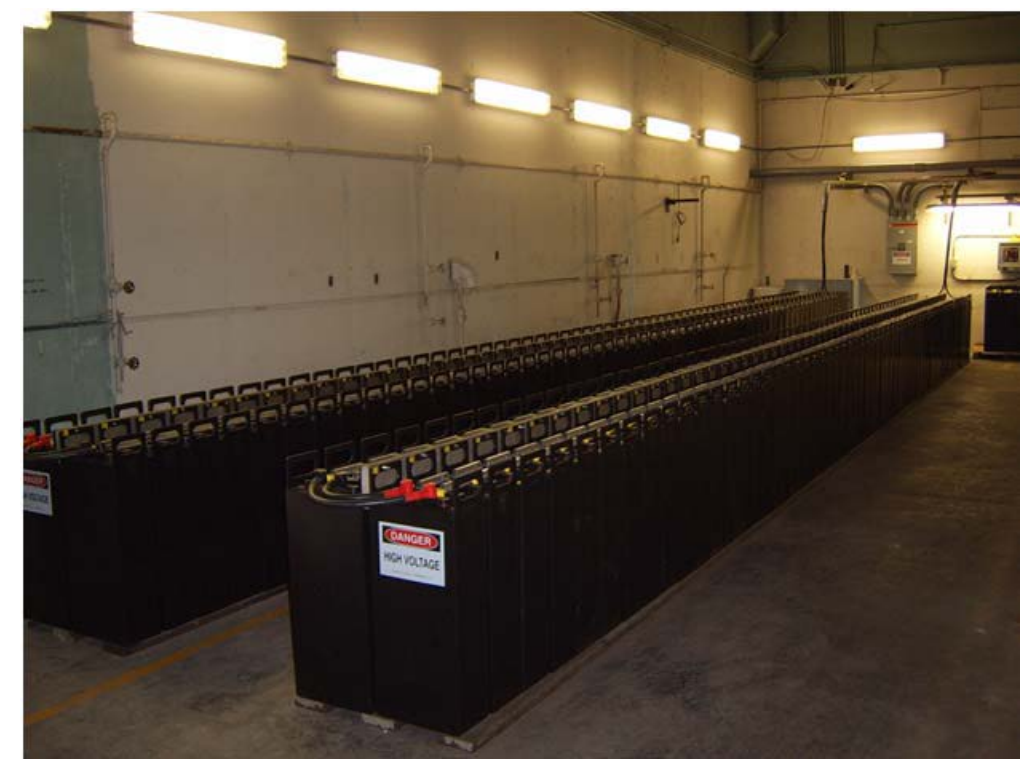

Figure 1. Two strings of batteries are recommended in design to allow O\&M service of one string while the other string serves the purpose. Photo by Andy Walker, NREL 


\section{Definitions}

For the purposes of this document, key terms are defined below.

Asset management is a systematic process of planning, operating, maintaining, upgrading, and replacing or disposing of assets effectively with minimum risk and at the expected levels of service over the assets' life cycles. It therefore contains all of the services that would fall under O\&M but also includes business services operations, such as billings and collections from power purchase agreements (PPAs) and lease-based systems (DOT 1999). Asset management involves planning and budgeting for O\&M, administration, billing, accounting, tax preparation and filing, hiring subcontractors, enforcement of warranties, management of budget and reserves, insurance policies, renewable energy certificate (REC) certification and trading, performance reporting, plant supervision, quality control, as-built plant documentation, ongoing environmental compliance, and compliance with any other regulatory or utility requirements.

Asset owner holds title to the PV system or portfolio of systems and may be an individual, a corporation, or, most commonly, a special-purpose corporation, such as a limited liability corporation (LLC), formed just to implement and operate the PV project.

PV operations includes the following five areas:

1. Administration of operations: Ensures effective implementation and control of O\&M services including curation of as-built drawings, equipment inventories, owners and operating manuals, and warranties. Curation involves not only keeping an archive but also selecting what to keep, pursuing missing documents, preserving documents, keeping them up to date, and, finally, archiving documents. Administration includes keeping records of performance and O\&M measures, preparing scopes of work and selection criteria for service providers, contracting with suppliers and service providers, paying invoices, preparing budget, and securing funding and contingency plans for O\&M services. Administration also includes compliance with regulations by the government or authorities having jurisdiction and mandatory guidelines issued by utilities.

2. Conducting operations: Ensures efficient, safe, and reliable process operations including making decisions about maintenance actions based on cost/benefit analysis. This includes serving as a point of contact for personnel regarding operation of the PV system; coordinating with others regarding system operation; preparing power and energy forecasts; scheduling maintenance operations; listing spare parts inventory (either instock onsite or in suppliers' consignment stocks); and inspecting work and approving invoices. Meanwhile, operations include any day-to-day operation of the system to maximize power delivery, assess performance and trends, operate the grid interface, manage curtailments, or adjust settings such as power factor or other ancillary services. Operations activities related to utility interaction or distribution-system integration/control are of increasing importance as individual plants get larger and the penetration of PV systems get more concentrated.

3. Directions for the performance of work: Specifies the rules and provisions to ensure that maintenance is performed safely and efficiently, including the formalization and enforcement of safety policy [including training for direct current (DC) and alternating 
current (AC)] safety, rooftop safety, minimum staffing requirements, arc flash, and lockout/tag-out); work hours; site access, laydown areas and parking; and any other stipulations under which work is performed. This includes confirming and enforcing qualifications of service providers, as well as compliance with any environmental or facility-level policies regarding the handling of controlled materials (e.g., solvents, weed killer, insecticide).

4. Monitoring: Maintains monitoring system and analysis of resulting data to remain informed on system status, metering for revenue, alarms, diagnostics, and security monitoring. Includes comparing results of system monitoring to benchmark expectation and providing reports to facility stakeholders. This includes periodically preparing reports as required by O\&M contract or as required by the system owner, including reports of plant performance, key performance indicators, problems and alarms, and maintenance services performed. Site security is performed both locally and with remote monitoring (e.g., cameras, intruder alarms) to protect against theft and vandalism.

5. Operator knowledge, protocols, documentation: Ensures that operator knowledge, training, and performance will support safe and reliable plant operation. Information such as electrical drawings, part specifications, manuals, performance information, and records must be deliberately maintained and properly filed/catalogued.

PV maintenance includes the following four types of maintenance procedures:

1. Administration of maintenance: This overlaps with "administration of operations" and ensures effective implementation, control, and documentation of maintenance services and results. Administration includes establishing budgets and securing funds for preventive maintenance; establishing reserves or lines of credit for corrective maintenance; planning services to avoid conflict with system operation or operations at the customer site; correspondence with customers; selection and contracting with service suppliers and equipment manufacturers; record keeping; enforcement of warranties; providing feedback to designers of new systems; and reporting on system performance and the efficacy of the O\&M program.

2. Preventive maintenance: Scheduling and frequency of preventive maintenance is set by the operations function and is influenced by a number of factors, such as equipment type, environmental conditions at the site (e.g., marine, snow, pollen, humidity, dust, wildlife), and warranty terms. Scheduled maintenance is often carried out at intervals to conform to the manufacturers' recommendations, as required by the equipment warranties.

3. Corrective maintenance: Required to repair damage or replace failed components. It is possible to perform some corrective maintenance such as inverter resets or communications resets remotely. Also, less urgent corrective maintenance tasks can be combined with scheduled, preventive maintenance tasks.

4. Condition-based maintenance: Condition-based maintenance is the practice of using real-time information from data loggers to schedule preventive measures such as cleaning or to head off corrective maintenance problems by anticipating failures or catching them early. Because the measures triggered by condition are the same as preventive and corrective measures, they are not listed separately. Rather, condition-based maintenance 
affects when these measures occur, with the promise of lowering the frequency of preventive measures and reducing the impacts and costs of corrective measures.

End-of-performance period disposition: Specifying the options for the parties in an offtake contract (such as a PPA) at the end of the performance period or at the end of the projected life of a host-owned system, the alternatives are the following: to continue the performance contract for an extended term, including continued O\&M; purchase of the system by the site or others (often at "fair market value") involving a new O\&M provider; or removal of the system and restoration of the site. 


\section{Dependencies on PV System Type, Site, and Environmental Condition}

It is useful to consider how O\&M requirements and attendant costs depend on the type of system and components, some details of the site, and climate and other environmental conditions such as agricultural area versus urban setting.

\subsection{Electrical System}

If micro-inverters are not used, the PV system will have both AC and DC components. The DC system determines system power capacity and energy production, whereas the inverter and the $\mathrm{AC}$ system has the greatest impact on system reliability. There can be several single points of failure in the AC system - for example, the central inverter, or the generator step-up (GSU) transformer. Central-inverter considerations are discussed in the next section.

O\&M measures and cost depend on the wire management system employed. Preventive maintenance entails making sure wires are secure and protected. Corrective maintenance entails finding and repairing ground faults, such as wire scaping against a module frame; and arc-faults that may be caused by a broken wire or loose connection. Wire management may be classified in three categories: open air; direct bury; or conduit/cable tray.

- Module-to-module and module-to-combiner wires are often in open air. These are most subject to damage, but it is easy to locate their problems and repair them.

- Direct bury of conductors is a lower first cost than installing conduit and pulling conductors. Failure risk of direct-bury conductors is usually low, and failures are typically caused by rodents chewing on them. Proper compaction of the soil is a best practice for reducing this problem. However, if the direct-bury conductor fails, it may be difficult to locate the fault, and the conductor must be dug up to find and fix the problem. This can be very expensive. Not only does the conductor need to be dug up, but there are likely other buried infrastructure in the vicinity, making the dig-up process very slow. Direct bury is chosen in many cases, driven by capital-cost considerations.

- O\&M will be minimal for conductors in conduit or lay-in trays, which are designed as an integral part of the rack and wiring system.

Maintenance must be provided to ensure that the wire management system continues to protect the wires from physical damage. O\&M problems will be exacerbated if:

- Wires, plastic wire ties, or grommets/bushings are exposed to sunlight. Even products listed for direct ultraviolet (UV) exposure will show degradation over the long life of a PV system and require eventual replacement.

- Movement or rubbing against modules, rack parts, or other wires due to wind or thermal expansion/contraction are allowed. This will require more frequent inspection, testing, and replacement. Movement of ballasted rack systems on a roof can cause damage to conduit or wires, and even ground -mounted parts can experience movement over a long period of time. A design that accommodates such movement and thermal expansion/contraction will require less corrective maintenance.

- Wire ties pinch wires too tightly. This will eventually deform the insulation. Faults may occur anywhere that wires are held tightly between metal parts. 
- Wires are pulled too tight or do not have strain relief. This will require more frequent maintenance. Wires exposed where there is weight from accumulated ice, or where module leads do not come in the right length for the installation, will require frequent testing and repair.

- Exposure to animals, such as squirrels, requires measures to deny the animals access to the wiring and to repair any sections where the insulation has been chewed.

- Large bundles of wires do not allow wires at the center of the bundle to cool as they would in open air, leading to early degradation of the insulation and potential fault.
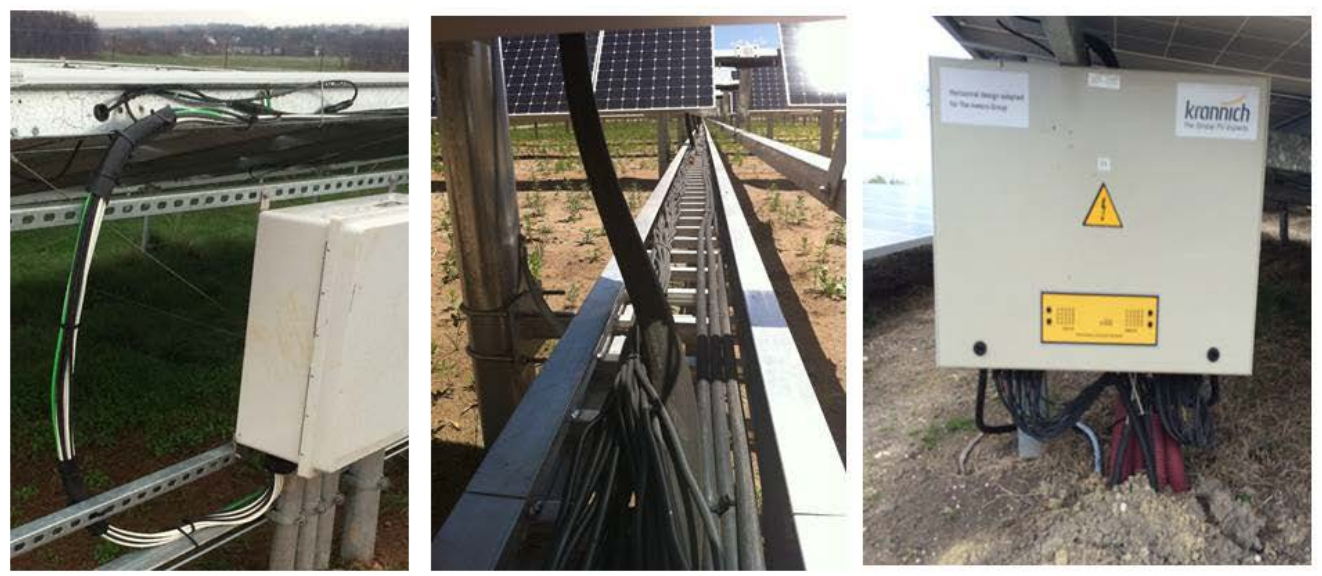

Figure 2. Maintenance of wire management systems depend on plastic wire ties and grommets, which can break or pinch wires (left); exposure to sunlight; wind and weight of ice (center); and access by chewing rodents (right). Photos by Andy Walker, NREL

GSU transformers are common in utility-scale PV plants, and the failure risk has been low historically. In the past, transformers were overbuilt and have a reputation for being very reliable. However, as design engineers now have access to computer-aided design (CAD) tools, they are able to meet requirements without overdesigning. If the GSU fails, it can idle the plant for months. GSUs are very expensive and have a very long lead time. Also, they are large and heavy, and the logistics associated with delivery are complicated. Delivery of GSUs may include a crane and require special permits for transport on roads and interstates. ${ }^{2}$

The risk of GSU transformer failure may be mitigated during the design phase by dividing the plant into multiple arrays, each with its own GSU transformer. It is critical to follow the manufacturer's recommendations for a preventive maintenance program. It may also be possible to work with local utilities to pool resources for better access to replacement units. At the minimum, the responsible party should have a fully formed reaction plan in place. Some operators keep a spare GSU on-site to reduce down-time associated with this critical component.

\subsection{Central, String, DC-Optimized, or Micro-Inverter Configuration}

O\&M depends on the topology of the inverter system: micro-inverters on each module, string inverters on series strings of modules, DC-optimized inverters that combine elements of both topologies, or larger central inverters. The cost per watt of capacity is much higher for a micro-

\footnotetext{
${ }^{2}$ Accessed August 2016. http://community.energycentral.com/community/t-d/managing-risk-transformer-failures
} 
inverter and string inverter than it is for a central inverter. The different types of inverters have different failure and replacement profiles and different effects on production.

Table 1. Cost of String, DC-Optimized, Central, and Micro-Inverter Replacement (Feldman et al. 2018

\begin{tabular}{|l|l|}
\hline Inverter Types & $\mathbf{2 0 - Y e a r ~ R e p l a c e m e n t ~ C o s t ~} \mathbf{( \$ \mathbf { W } )}$ \\
\hline String Inverter & $\$ 0.25$ (estimated as 2x factory price) \\
\hline DC Optimizer/Inverter & $\$ 25$ \\
\hline Central Inverter & $\$ 0.14(2 x$ factory price) \\
\hline Micro-Inverter & $\$ 0.40$ \\
\hline
\end{tabular}

Inverter reliability continues to increase for all types of inverters, with 10-year warranties now commonly available and 20-year extended warranties/service plans also gaining prevalence. However, a sound O\&M plan should account for inverter failure because it is one of the most frequent causes of PV system performance loss (EPRI 2010). The best preventive maintenance for the inverters would be to perform the manufacturer's required maintenance - to include, but not limit to, re-torqueing current-carrying conductor fasteners (screw lugs on terminal blocks) and thermal imaging of electrical connections and components. Inverter air filters will take in grass and dust during mowing, high winds, or dusty conditions, and the O\&M plan should establish a timeframe when the grass-cutting is done and schedule a preventive filter swap/cleaning to follow such dusty conditions. A technician will be dispatched faster to service a central inverter (see Appendix $\mathrm{C}$ for corrective maintenance choices for both string and central inverters), whereas failures of micro-inverters, and to a lesser extent string inverters, can be delayed until a scheduled visit because their impact on the performance of a large plant is incremental.

Additional O\&M measures related to inverters include the following:

- The decision to replace or repair an inverter is based on inverter size, type, manufacturer's ability and availability for timely repairs, and associated costs. Replacement is preferred over repair when it becomes difficult to source repair parts and desired new features trigger an upgrade. However, upgrading may lead to other concerns such as not being able to get the correct replacement size, footprint, and electrical conduit and wiring configuration. Include in any upgrade remote monitoring to confirm the inverter status, reset the inverter, and remotely diagnose problems.

- In remote locations, stock component replacements onsite, especially for equipment commonly in need of repair, such as driver boards, if the manufacturer support or warranty is not available. Store replacement micro-inverters and power optimizers onsite.

\subsubsection{Central Inverter}

Central inverters involve much more DC wiring to deliver the PV energy from a very large distributed array to the location of the central inverters. Electricians working on energized DC circuits (combiner box and array) must have the training and personal protective equipment as required per National Fire Protection Agency (NFPA) 70E (NFPA 2012) and Occupational Safety and Health Administration (OSHA) standards (including but not limited to arc-rated 
clothing, insulation gloves, face shield, and other personal protective equipment [PPE] as required for the level of voltage and arc-flash potential being worked on). The gloves with liners and leather protectors are sometimes unwieldy, so complex tasks are difficult, and tasks take longer to perform. The cost of a technician that has training and PPE to work on live DC circuits in one case (a campus in Denver CO with several PV systems totaling $8 \mathrm{MW}$ ) is $\$ 128 /$ hour versus $\$ 70 /$ hour for a journeyman electrician who could maintain ordinary AC circuits. Other items, such as disconnects, are also more expensive in a DC version than AC version. An arc fault is more persistent in DC wiring than in AC wiring. The additional DC wiring of a centralinverter configuration might require more repair than the corresponding $\mathrm{AC}$ wiring of a microinverter or string-inverter configuration. Large central inverters become a single point of failure - if the inverter is down, either intentionally for maintenance or unintentionally, the entire associated electrical production is lost, not just a portion. Monitoring using only a few central inverters is less complicated than multiple micro- and string inverters, and it involves less energy consumption by the monitoring system itself. Advanced features such as non-unity power factor (sourcing kVAR), curtailment of output power, low-voltage ride-through, and low-frequency ride-through are easier to implement in central inverters, and such controls will add more to the "per-watt" cost of micro- and string inverters. For central inverters, numerous subsystem repairs to the inverter are supported (control cards, driver cards, components such as an insulated-gate bipolar transistor [IGBT] matrix and capacitors), assuming that each is repaired independently, in contrast to micro- and string inverters, which require replacement of the entire unit.

\subsubsection{String Inverters, Micro-Inverters, and DC-Optimized Inverters}

Micro-inverters and string inverters shut down automatically as required by IEEE 1547 upon loss of AC connection, and only the strings of modules connected to the string inverter remain energized. The wiring from the string inverters to the central AC switchgear becomes deenergized, which is the important advantage of string inverters with an impact on O\&M costs because it is simpler and less expensive to work on de-energized, conventional, AC wiring than it is to work on energized DC wiring. Micro- and string inverters avoid the need for an additional control circuit and hardware required for rapid shutdown (NEC 690.12) and avoid the need for arc-flash protection when working on the connecting AC wiring. Power optimizers work similar to micro-inverters but shut down the DC power coming from the power optimizers to the inverters. Each power optimizer will output only $1 \mathrm{~V}$, meaning that the string connecting the modules to the inverter is also de-energized. Regarding corrective maintenance, manufacturers of string inverters vary but can take up to about one month to send in new warranty inverters for replacement. The customer should go to the site and take a photo of the dead string inverter and then call the company to ship the replacement materials authorization, which is a long process when compared to replacing failed components of a central inverter with spares on hand. However, replacement of string inverters is quicker and easier than repair of central inverters and can be accomplished by an electrician rather than an inverter specialist. Annual production can be improved over that of a central inverter by keeping string inverters in stock for replacement and to rotate this stock as inverters fail - an approach that is not feasible for central inverters. With string inverters, fewer arrays are impacted with one inverter failure. Even though it is unlikely that all the string inverters will be down at the same time, there is a corresponding probability that, at any given time, at least some string inverters will be down and in need of service or replacement (called "whack-a-mole" by service providers). Micro-inverter manufacturers have developed a sophisticated data platform that maps location and can monitor 
performance and also pushes out software upgrades on a module-by-module level-much more detailed information than data from a central inverter. Power optimizers also offer the ability to see module-level data through mapping module locations and, in many cases, can remotely offer the same troubleshooting capabilities of onsite current-voltage (I-V) sweeps. The selection of string inverters assumes replacement or swap as the most common corrective action, rather than replacing failed parts as in a central inverter.

\subsection{Roof Maintenance Related to PV System}

O\&M measures related to the roof for rooftop systems include finding and fixing roof leaks and any maintenance related to the rack attachments or effects of ballast on the roof. Rather than only the roof membrane, a "roof system" includes membrane, cover-board, insulation, air and vapor barriers, and the roof deck. O\&M considerations provide preventative maintenance for the roof and avoid damage to any of these roof-system components as the PV system is being serviced. Roofs under warranty require annual preventive roof maintenance to maintain the roof warranty. It is a best practice for the PV O\&M provider to meet with the roof maintenance provider to make sure both teams understand their roles and responsibilities and respect the needs of the other. Failure to provide maintenance of a roof system may result in roof-system failure, thereby necessitating PV system removal for roof repair/replacement, which is bad for the prospects of the PV system. By meeting, the roof maintenance provider can share particular areas of concern with the PV O\&M team and vice versa. This kind of collaboration can minimize contentious finger pointing when problems arise. Scope and cost of maintenance for rooftop systems are affected by several factors, as discussed below.

Complexity: It costs more to perform repairs on a roof with a complex layout, such as multiple sections or multiple ridges in different orientations.

Slope or pitch: It is more difficult, requires more safety equipment and training, and costs more to perform repairs on a steep roof than a low-slope roof. Slopes greater than 3-4:12 pitch (vertical to horizontal, about 18 degrees; some companies use 14 degrees as the low-slope/steep slope criterion) require a higher standard for fall protection (29 CFR 1926.500) - warning lines alone are not allowed, guardrails must have toeboards, etc.- and contractors charge more for pitches above 7:12 because of the difficulty and special equipment required and because the company pays higher insurance costs. See OSHA 1926.501(b)(10) for low-slope roof requirements and 1926.501(b)(11) for steep roofs. A ballasted, rather than attached, system may be used on flat and low-slope roofs but not sloped roofs.

Condition: If the roof and decking are damaged, any repairs or replacement costs will be additional scope and cost. This could occur if a water leak has damaged the underlying roof deck. Often, water damage is not noticed until after the roofer has removed shingles and looked at the deck.

Scale: The size of the roof-and more specifically, the areas under the PV system requiring maintenance associated with the solar energy system - affects the per-unit cost. With a high cost of mobilizing equipment and labor to the site, leaks in small roof areas (e.g., residential) will be very expensive to fix on a per-square-foot basis. Roofers talk in units of "squares," and one square equals 100 square feet (sf). 
Type of roof: The costs per square foot for the different roof types in Table 2 are based on a scale of 1,200 sf repair/replacement, typical of commercial-scale rooftop PV. Membrane flatroof applications include a fully adhered thermoplastic polyolefin (TPO) membrane roof, ethylene propylene diene monomer (EPDM), or polyvinyl chloride (PVC). For ballasted systems, there is a sacrificial slip sheet between the bottom of the ballast pan and the roof membrane. Cost to repair or replace a membrane roof is about $\$ 70 / \mathrm{m}^{2}$ (\$7/sf: $\$ 2 / \mathrm{sf}$ roofing material, supplies, and equipment; $\$ 5 /$ sf labor). Built-up asphalt roofs and other modified-bituminous roofs may cost on the order of $\$ 100 / \mathrm{m}^{2}$ ( $\$ 10 / \mathrm{sf}$ to repair). Asphalt shingles are perhaps the least expensive roofing, and, thus, also less expensive to maintain. Maintenance costs are on the order of $\$ 60 / \mathrm{m}^{2}(\$ 6 / \mathrm{sf}$, of which $\$ 1.50 / \mathrm{sf}$ is for materials) of affected roofing area plus mobilization costs. Composite shingles use better materials and may cost on the order of $\$ 70 / \mathrm{m}^{2}$ ( $\$ 7 / \mathrm{sf}$ to repair damaged areas; $\$ 2.50 /$ sf for materials). Wood shingles may cost $\$ 200 / \mathrm{m}^{2}(\$ 19 / \mathrm{sf})$ for repair or replacement. Slate roofing repair may cost on the order of $\$ 130 / \mathrm{m}^{2}$ ( $\$ 120 / \mathrm{sf}$; materials $\$ 10 / \mathrm{sf}$ ). A metal roof can accommodate solar very easily, and it would be difficult to attribute any O\&M cost with the attachments to the metal seams, except for inspections. However, if problems occur with metal roofing, they may cost on the order of $\$ 430 / \mathrm{m}^{2}$ ( $\$ 40 / \mathrm{sf}$ to repair; $\$ 15 / \mathrm{sf}$ for materials). Concrete tile is common on Spanish colonial-style homes and may cost on the order of $\$ 650 / \mathrm{m}^{2}(\$ 60 / \mathrm{sf})$ on area requiring repair or replacement ( $\$ 5 / \mathrm{sf}$ for materials) (HomeAdvisor 2016; HomeAdvisor 2018).

Table 2. Service Costs for Different Types of Roofs ${ }^{a}$ (HomeAdvisor 2016; HomeAdvisor 2008)

\begin{tabular}{|l|l|l|}
\hline Roofing Type & $\begin{array}{l}\text { Repair Materials } \\
\left(\mathbf{\$} / \mathbf{m}^{2}\right)\end{array}$ & Repair Labor $\mathbf{( h / \mathbf { m } ^ { 2 } )}$ \\
\hline Thermoplastic Polyolefin (TPO) & $\$ 20.00$ & 1.0 \\
\hline $\begin{array}{l}\text { Ethylene Propylene Diene Monomer } \\
(\text { EPDM) }\end{array}$ & $\$ 20.00$ & 1.0 \\
\hline PolyVinyl Chloride (PVC) & $\$ 20.00$ & 1.0 \\
\hline Built-up, Bituminous & $\$ 15.00$ & 1.5 \\
\hline Styrene-Butadiene-Styrene (SBS) & $\$ 20.00$ & 1.0 \\
\hline Asphalt Shingle & $\$ 15.00$ & 1.0 \\
\hline Composite Shingle & $\$ 25.00$ & 1.0 \\
\hline Wood Shingle & $\$ 40.00$ & 2.0 \\
\hline Slate & $\$ 50.00$ & 1.0 \\
\hline Metal Roof & $\$ 50.00$ & 0.5 \\
\hline Tile & $\$ 50.00$ & 1.0 \\
\hline
\end{tabular}

${ }^{a}$ Large variations can exist based on size, site access, location, and labor markets.

The use of manufacturer-specific materials is required for the flashing to PVC, TPO, and other membrane-type roofs. The flashing must bond chemically with the field membrane, and all materials and adhesives must be compatible. Bituminous and modified bitumen roofs use coneshaped metal flashings, and the skirt of the flashing is sealed with a torch-down bitumen 
capsheet, with an EPDM collar sealing the flashing to the post. The cost of repairing flashing can be on the order of $\$ 100$ per flashing of a roof stanchion or conduit penetration and as much as $\$ 500$ for larger objects such as the pedestal supporting a roof-mounted inverter, combiner box, or switchgear.

Overburden waiver: An overburden waiver, often required to maintain a roof warranty, includes an agreement to remove the PV system should the roofing company need access to do any roof work. If required, the cost of removing and re-installing a PV array is high and also entails lost production.

Roof warranty issues: Roofing contractors often guarantee the work they do, which is frequently between 5 and 10 years for their workmanship. This will typically cover leakage or total failure but not wear-and-tear or damage associated with the PV system. Some roofing manufacturers offer 25-year warranties, but those typically apply to commercial projects and require certain installation procedures. PV systems can be installed on many different types of roofs. However, installation of a PV system can increase a roof's potential for leaks and damage due to increased rooftop foot traffic and additional attachments to and through the roof membrane. Thus, measures need to be taken to continue a warranty and ensure long-term performance of the roof under the PV system. The following scope of work is recommended for the roofing company that has the warranty or service contract on the roof, or failing that, then another roofing company certified by the roof manufacturer:

- Roofing company should specify the procedures to follow and provide information required and forms to fill out to officially notify roofing company and manufacturer of roof problems related to a PV system and plan for repairs.

- Review the repair plan to ensure that it is appropriate for the existing type of roof, compatibility of materials, stresses, expansion/contraction, membrane puncture, insulation compression, and recommended repair/replace practices. Identify the conditions required to maintain the roof warranty or recommendations for the quality of the installation, such as thickness and material properties of slip sheets, as well as including the selection of cleaning agents and any other future O\&M impacts.

- Inspect the condition of the roof prior to repair work. Provide details of any repairs or reinforcements required.

- Inspect the final condition of the roof upon completion and acceptance of the repairs. To reduce the potential for leaks and to provide a more durable platform under all types of PV systems, the roof manufacturer will specify requirements and recommendations. For ballasted rack PV systems, this would include a sacrificial layer (membrane) of minimum thickness under the feet of the ballasted rack system (Figure 3); walkway system comprising a walkway pad or pavers around the blocks of the PV arrays; requirements to remove PV components to investigate a leak or make a repair; requirements that the system be rendered safe (de-energized) for roof work; and other requirements considered necessary by the roofing company or roof materials manufacturer. New flashings or other alterations to the roof must follow all technical standards and details provided by the manufacturer. 


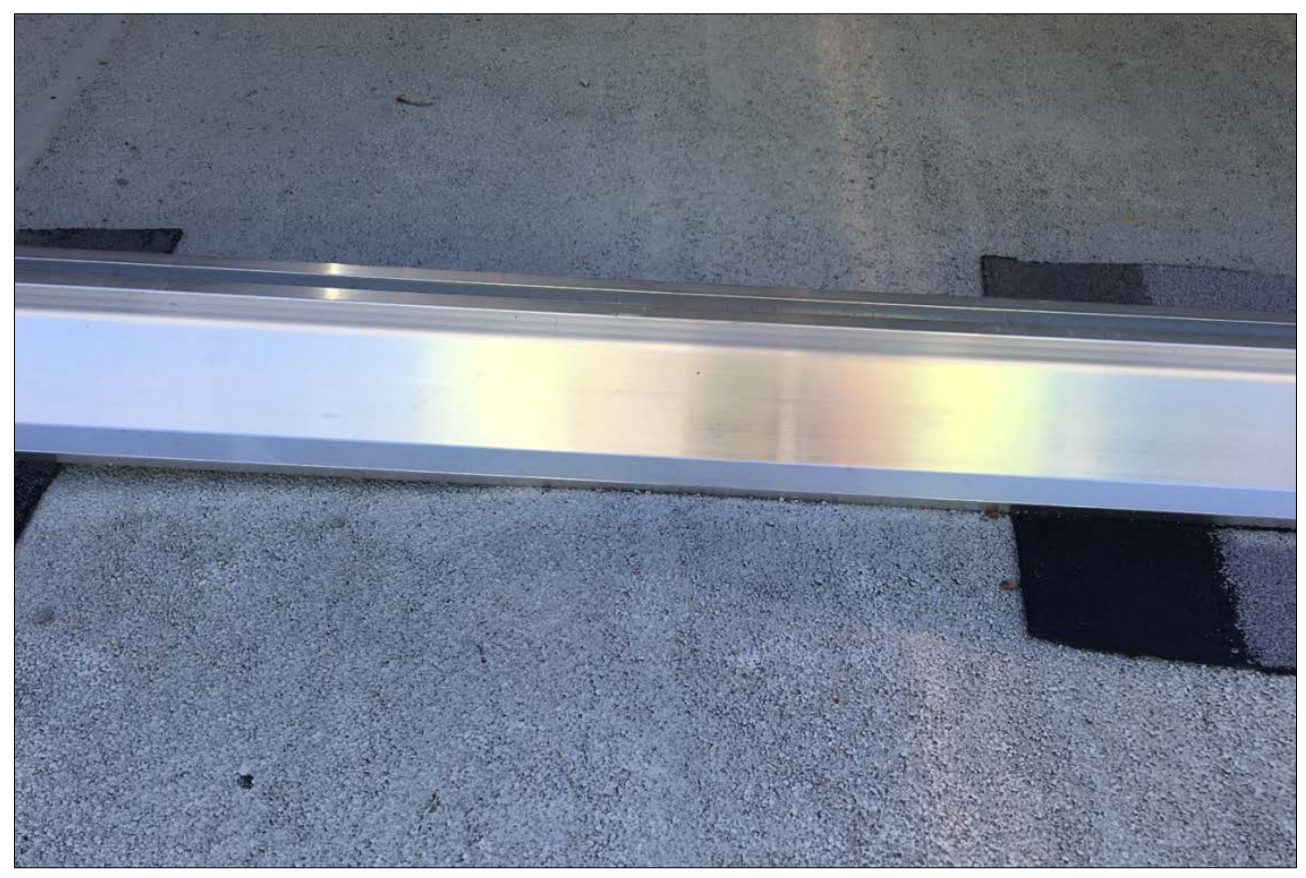

Figure 3. A best practice is to run a slip sheet continuously under rack members to avoid direct contact with the roof membrane. In this photo, direct contact of the rack is cutting into the roof surface. Photo by Norm Crouse, Lightbox Energy

Snow and ice removal: Snow is rarely removed from PV systems because it is not cost effective and damage may occur to the PV modules and wiring. Snow may slide off of arrays tilted more than approximately 30 degrees but will remain on lower tilts until it melts. The electrical configuration of the array can also affect losses due to snow, with horizontal strings of modules or micro-inverters suffering less loss in a partially covered array. If snow is not removed, annual production is reduced by about $3 \%$ on average and up to $15 \%$ in very snowy climates (e.g., Truckee, California). However, it is sometimes necessary to remove snow to avoid limits on roof weight loading. For light snow, a turbofan or brushes and squeegees may do less damage than shovels and rakes, but extreme care is required to avoid damage. Snow is sometimes removed from the roof or ground in front of the array to provide clearance for snow to slide off of the PV array. Cost for snow removal is about $\$ 50$ to $\$ 75$ per hour for labor, or about $\$ 0.50 /$ sf of array area.

Removal of ice dams: Ice dams should be removed to allow the roof to drain properly. Snow over the ice dam can be removed with a rake or shovel, and the ice dam can be removed using chemical ice melters or a de-icing cable. The cost is $\$ 70$ for labor per ice-dam location, and materials include a $\$ 50$ rake and ice-melting supplies. Extreme care must be taken not to damage the roof membrane, the PV modules, or connecting wiring.

Removal of debris: Debris that has collected such as leaves should be removed to allow water drainage and to prevent material for vegetation growth and nesting on the roof. Cost for removal of debris is often included in the estimated cleaning cost but is a cost in addition to cleaning the surface of the PV modules themselves. 


\subsection{Ballasted or Attached Rack}

PV arrays may be attached to the roof deck or structure or they may be ballasted, which means held in place by added weight. Ballasted systems can only be used with flat or low-slope roofs (as specified by supplier but not more than 5 degrees; 1:12 pitch). To reduce wind loads, ballasted systems can only be used if solar collectors are at a low tilt angle - usually a 10-degree tilt and limited to no more than 20 degrees (one dual-orientation ballasted system has a southfacing panel tilt angle of 25 degrees and north-facing of 15 degrees). Such a low tilt angle is a minor penalty on annual energy delivery depending on latitude but allows more kilowatts per square foot of roof area and delivers more in summer when utility rates are higher.

Roofing material: Maintenance of a ballasted PV system is affected by the type of roofing material. Coal tar pitch, styrene-butadiene-styrene (SBS) modified bitumen, or other soft materials may be damaged by the pressure of a ballasted system, although suppliers of those roofs have introduced products and methods to accommodate ballasted PV. Fully adhered TPO membrane roof, EPDM, or PVC-type roofs are protected by a slip sheet of material between the ballast foot and the roof membrane.

Compressible insulation: Maintenance issues may arise on roofs that have compressible insulation, and some measure may be needed to avoid membrane damage and ponding of water. Ponding of water in depressions under the added weight of a ballasted PV system can deform and stretch the membrane, accumulate dirt, and increase abrasion - in turn, requiring more maintenance to avoid leaks in the membrane. To avoid this, in design, the insulation should be polyisocyanurate (polyiso) board stock as base layer, with a more rigid backer-board to serve as an underlayment for the membrane, such as $15.8-\mathrm{mm}(5 / 8$-in.) gypsum cover board; otherwise, special protective layers may be required to avoid compression of insulation and membrane damage.

Wear on roof membrane: The manufacturer will specify requirements including the thickness of slip sheets between the ballast feet and the roof membrane. Even with this sacrificial layer, or where the layer is not present, movement causes wear of the membrane, and maintenance will be required to maintain the integrity of the membrane. Two best practices are recommended: (1) a continuous slip-sheet roll running underneath the entire racking rail (as compared to slip sheets placed individually under contact points; and (2) during O\&M, make sure these slip sheets are still in place under racking contact points. The slip sheets can sometimes work themselves loose over time.

Roof deflection: Typically, an attached system will add less than 3 pounds per square foot of solar collector area, whereas a ballasted system will add 3 to 8 pounds per square foot depending on the tilt angle and wind loading. The weight of ballast materials varies from the edges to the middle of the racking system, depending on the load to be resisted; thus, ballast weight is not necessarily distributed uniformly across the array. Edges of structures have greater wind loads than the center of the roof; thus, it has more ballast weight. The added weight of a ballasted system can cause deck deflection, resulting in increased ponding of water. In that case, there may be measures to improve drainage.

Wind damage: To use a ballasted rack solution, advanced wind-loading evaluations have to be performed above the general requirements of ASCE-07. Wind loading is usually the determining 
consideration on whether a ballasted system is feasible (i.e., in areas susceptible to high wind, the ballast weight required could be excessive and so an anchored system would be better). Product-specific design can aid in the placement of a ballasted array to avoid strong wind areas.

Extreme snow loads and ballasted racks: Snow loads are a variable load consideration common to both attached and ballasted systems. Extremely heavy snow loads may exceed the rating (often $240 \mathrm{~kg} / \mathrm{m}^{2}$ or $50 \mathrm{lbs} / \mathrm{ft}^{2}$ ) for low-slope ballasted rack hardware and may cause damage to the rack and modules.

Maintenance of proper roof drainage: The position of the PV rack and ballast materials must be arranged so that they do not disrupt drainage or result in accumulation of small debris. Ballasted racks have many obstructions (numerous ballast feet laid on the roof) unlike attached systems, which sit up taller on stanchions. Thus, ballasted racks take more effort to keep the roof clear of debris and ensure that these obstructions do not impede drainage.

Migration of connections on roof: Unattached, ballasted components can move over time. The design should accommodate this movement in the conduit to the stationary interconnection. But eventually, cumulative movement will require a revision to the conduit to avoid stresses. For large commercial rooftop PV systems, this cost may be on the order of $\$ 1,000$ (\$400 materials) and occur every 5 years.

\subsection{Ground Mount}

Ground mount avoids the roof maintenance issues listed above but introduces ground maintenance issues, including:

- Vegetation management (e.g., mowing, trimming, tree removal, herbicides), which is often estimated as a cost per acre of site area.

- Snow removal, which can involve removal from the array itself, clearing access roads and alleys, and removal where snow accumulates as it slides off an array. If snow is removed from the array, care should be taken to ensure that the modules are not mechanically damaged by the removal techniques. In the case of single-axis trackers, significant damage can occur if snow is not cleared from between tracker rows because the modules can come into contact with snow banks when the tracking mechanism is at its extreme east or west positions.

- Cleaning requirements, which increase for ground-mounted arrays because they are closer to the source of airborne dirt and pollen.

Just as equipment O\&M issues should be considered in the design phase, the long-term maintenance of the ground cover and drainage should be considered in the design, civil engineering, and construction phases of ground-mounted systems to reduce O\&M risks and costs. In climates with high rainfall, for example, grass cutting and vegetation control costs can equal or exceed equipment O\&M costs (Brehaut 2015; Huff 2013).

\subsubsection{Design}

Initial design considerations that can significantly impact O\&M costs for ground-mounted systems include ensuring that panels are mounted with sufficient and relatively uniform clearance from the ground, racking is spaced widely enough to allow access for efficiently sized 
mowing, and equipment is cleaned to protect panels from damage from such equipment (EPRI 2010; Brehaut 2015). During site selection, it is important to consider vegetation growing on adjacent properties - consider how tall the trees will be in 20 years and if this will cause shading of the system.

In an informal survey and series of interviews conducted by NREL with more than 30 members of the PV industry, several respondents cited significant problems with panels mounted too close to the ground to allow access under the panels by an arm of a mower, causing significant costs for more labor-intensive vegetation management approaches.

Initial design considerations also include establishing proper drainage to avoid or accommodate flooding and to control erosion, which can undermine equipment pads and racking. Several NREL survey respondents cited increasingly unpredictable and extreme weather conditions that impacted operations and pointed to the need to design for more extreme climatic conditions.

\subsubsection{Ground Cover}

Upfront investment in developing ground-cover solutions tailored to each site's climate and soil conditions and establishing such solutions in the initial year or two of operation can ensure longer-term viability and lower the risks of shading, erosion, and excessive weed and vegetation abatement costs during the operations phase (Hernandez et al. 2014).

Applying gravel as a ground cover was widely identified by NREL survey respondents as expensive and problematic because it creates uneven work surfaces, changes runoff coefficients, and does not provide a long-term weed abatement solution. Gravel applications were described as requiring either regular application of herbicides, which can be restricted by local regulations, or mechanical weed control, which can kick up rocks and damage modules.

In general, NREL survey respondents saw low-growth, vegetative ground cover as ideal for ongoing maintenance, although many cited challenges in re-establishing vegetation following construction. Successful solutions included:

- Replanting with low-growth species selected by a horticulturalist or other expert based on site soil and climate conditions, including bent grass, white clover, and buffalo grass combined with blue grama (ESCO Associates Inc., forthcoming)

- Replanting with pollinator-friendly or other habitat-supporting ground cover in coordination with local agricultural extension services or other partners

- Preserving existing, sometimes native, vegetation through minimizing grading, which can reduce weed infestations.

Some survey respondents, as well as an NREL study of revegetation applications at a utilityscale PV site in Colorado, report greater success with broadcasting seeds and raking them into the soil, or drill seeding, than with hydro-seeding to re-establish vegetative cover in more arid areas (ESCO Associates Inc., forthcoming).

\subsubsection{Vegetation Management}

Chemical vegetation abatement may be more efficient and at times less costly, particularly in arid areas. However, several NREL industry survey respondents cited problems with soil 
stabilization after herbicides eliminated vegetation; the added risk to, and safety requirements of, those handling the chemicals; and, most often, local or state regulations that restrict herbicide use. In addition, chemical vegetation abatement can conflict with public expectations of environmental stewardship from the solar industry.

In arid areas, mowing may be unnecessary with proper soil stabilization. For areas where mowing is required, there is the added risk of projectiles damaging modules.

Some companies in Germany and a growing number of utility-scale PV systems in North Carolina and Hawaii are working with local ranchers and farmers to use sheep grazing for vegetation management (Figure 4). Goats are not a good option because they jump up onto the array, and cattle are large powerful animals that damage the array by scratching against it. Those with experience in this area report greater success when forage needs are taken into consideration in the design phase and determining the re-seeding mix. Grazing considerations can include slightly higher ground clearance and conduit to protect wiring (Huff 2013).

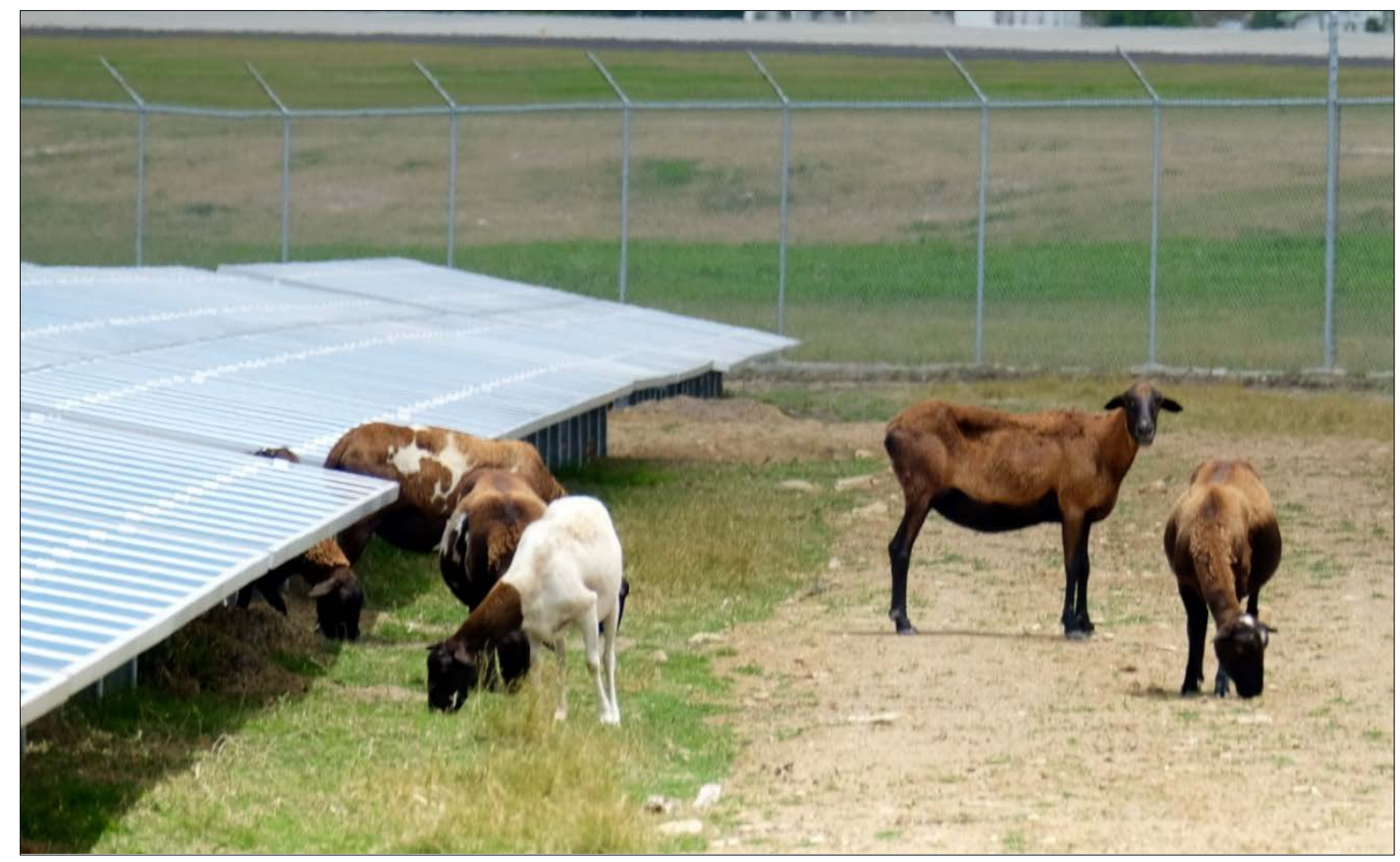

Figure 4. Sheep, but not goats or cattle, can be employed for vegetation control. Photo by Eliza Hotchkiss, NREL

\subsubsection{Erosion Control}

Grading prior to PV system construction exposes soil that is extremely susceptible to runoff and erosion due to rainfall. Civil engineers may design for "sheet flow" of storm water. But, in fact, once a small rill starts to form, it collects more water and grows into a large gully. The rill and gully erosion that occurs under such conditions can endanger the stability of the PV rack foundations and fences, expose buried conductors, and damage access roads and inverter pads. Thus, a best practice is to design specific pathways for storm-water runoff that include checkdams throughout the site that feed into channels lined with rock (rip rap) and that have the 
channels terminate in splash pads and integrated into the site storm-water management system, such as a retaining basin. Runoff and erosion can be reduced by stabilizing the aggregates at the soil surface with soil conditioners. Such soil conditioners are polymers that are sprayed on the dry soil surface before the rainy season. There are several types of polymer soil conditioners, but they all have a high molecular weight and complicated molecular shapes that bond with soil and act as a cementing material that stabilizes the soil against the force of raindrops, as well as preventing pores in the soil from clogging with clay. The type and amount of polymer applied depends on the soil type and conditions at the site. Reapplication is required if treated soil is disturbed or the appearance of rills shows the need for reapplication. Once the long-term ground cover (described above) is established, reapplication of the polymer should not be necessary.

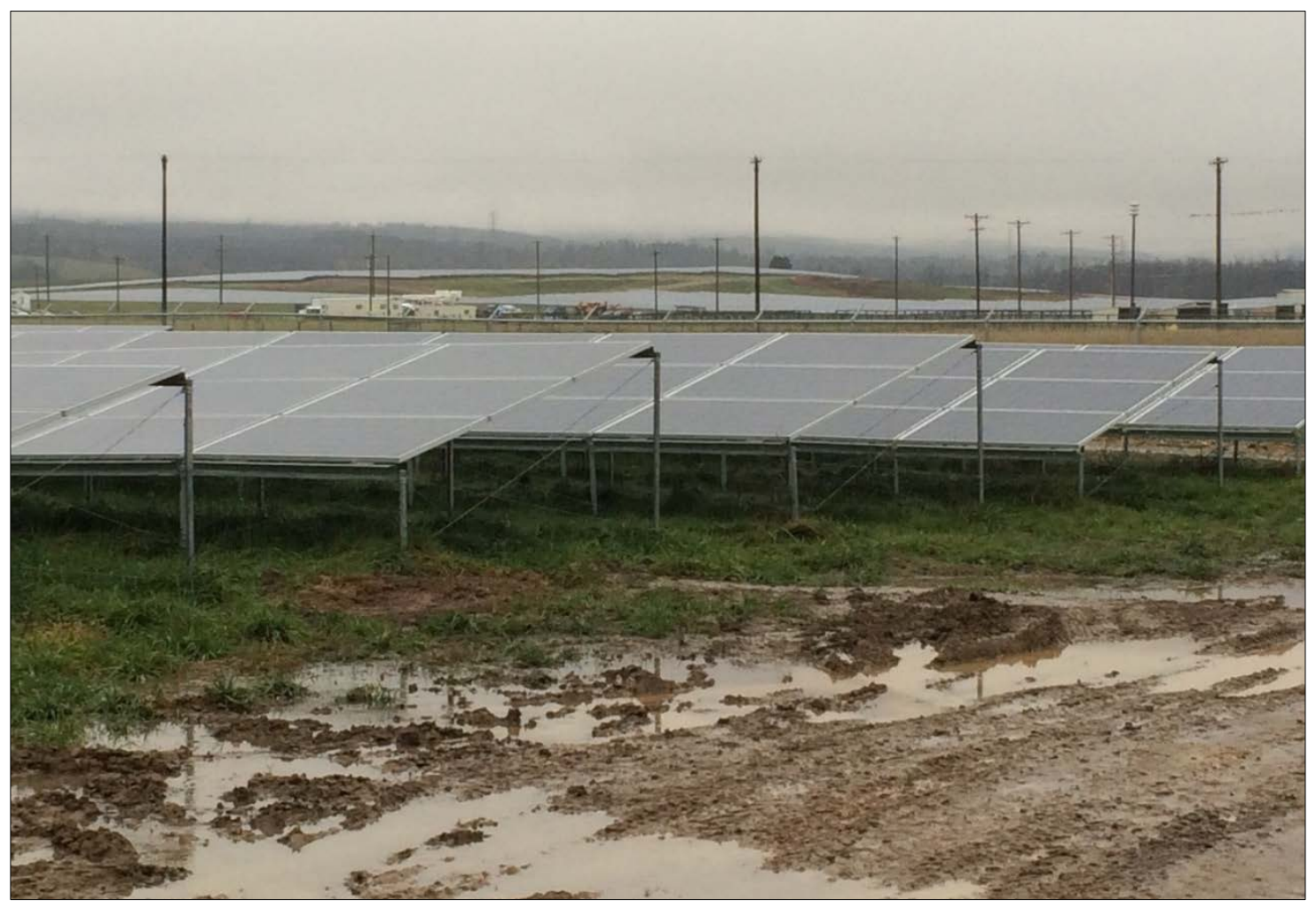

Figure 5. Drainage and storm-water run-off are difficult to improve after the PV array is installed, requiring diligence in design and construction of storm-water management systems. Photo by Andy Walker, NREL

\subsection{Tracking Mounts}

The complexity of tracking systems requires more maintenance - not only on the load-bearing moving parts of the array but also for the associated system for actuators and controls. The additional costs of the tracking system are weighed against the performance gains it is expected to provide. Depending on system design and location, there are settings where tracking mounts may be able to make O\&M less expensive per unit of energy as a result of the increased production.

Types of trackers include: 
- Single-axis, dual-axis: Single-axis trackers can rotate on a single axis while dual-axis trackers can move across dual axes of rotation. Both tracker types have several different sub-categories for their chosen axis of rotation, a mechanism for their rotation, and specific tracking capabilities. Each sub-category of tracking approach results in differing performance expectations and associated O\&M costs.

- Centralized, decentralized: The decision between centralized and decentralized tracking has important bearing on array layout and O\&M costs, particularly as a result of O\&M personnel access issues that can arise from centralized configurations. Decentralized designs can also facilitate more efficient land use.

Additional considerations for tracking systems include:

- Electrical: Check electrical connections and enclosure for tracking motor/controller; check grounding braids for wear

- Controls: Inspect and calibrate anemometer; replace cup-wheel; inspect inclinometer; inspect limit switch; replace tracking-controller power-supply fan filter; inspect/test tracking controller

- Rack and actuator: Check drive-shaft torque and visually inspect gearbox lubrication; inspect module table; grease screw jack; inspect screw jack; lubricate slew-gear; check slew-gear torque and inspect wear; grease universal joint (zerk fitting); inspect universal joint; lubricate tracker-mounting bearings/gimbals; repair/replace tracker drive shaft; replace hydraulic cylinder; replace tracker drive bearing; replace tracker motor controller; replace tracker mount bearing; replace/upgrade tracker control software

- Monitoring: Adjust availability calculations for tracking issues — original equipment manufacturers (OEMs) may have remote tracking platforms that support optimizing preventive maintenance scheduling

- Battery replacement: Replace during the life of the trackers even if only used as a backup, depending on technology type and function. 


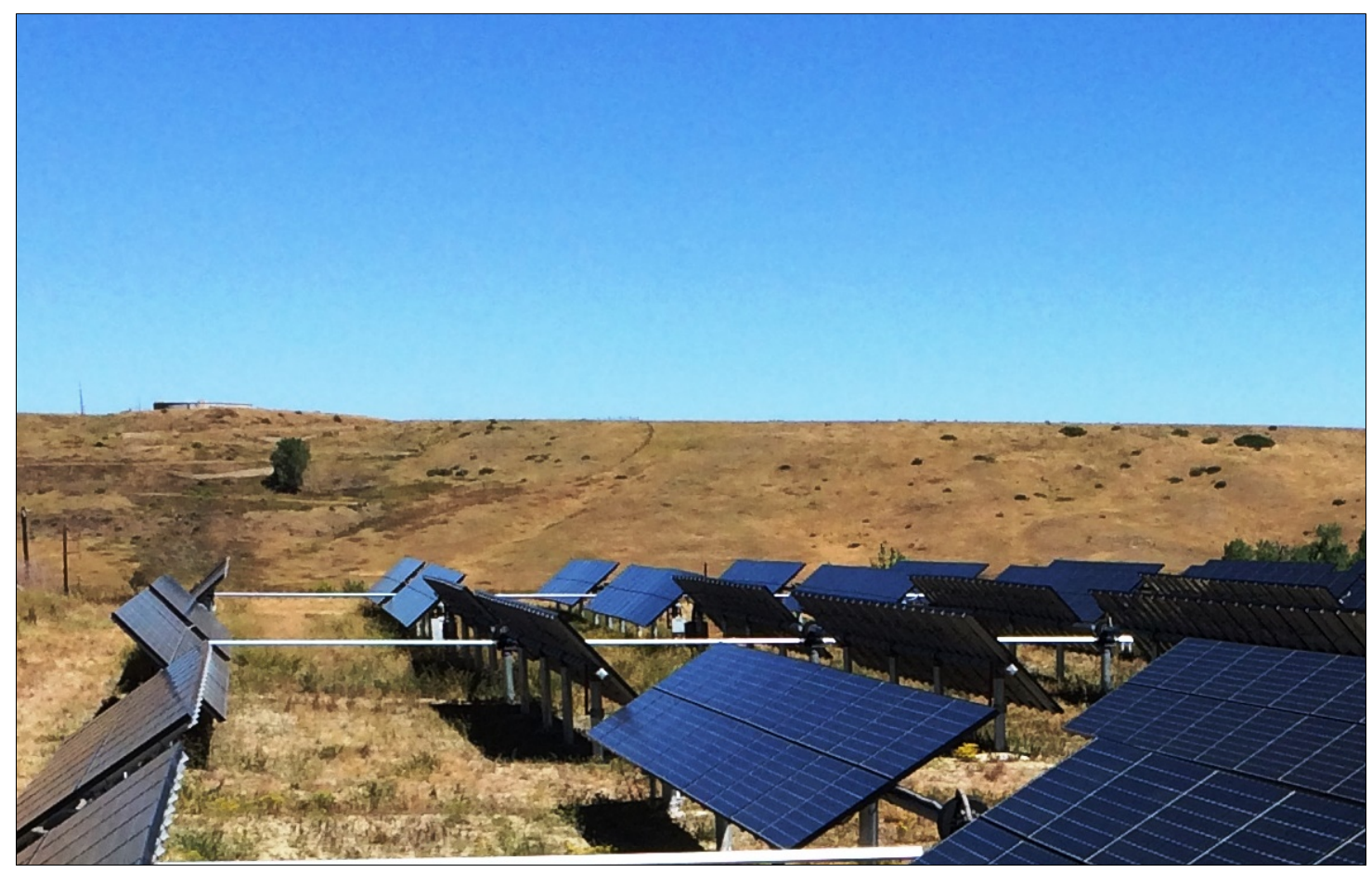

Figure 6. Although improving annual energy delivery, especially in summer, tracking mechanisms and controls require regular maintenance to be effective. Photo by Andy Walker, NREL

\subsection{Environmental Conditions}

Many environmental conditions can affect O\&M, and many are outside human control. Soiling can be addressed by the O\&M contractor through cleaning and possibly during the site-selection process. That is to say, if two potential sites are being evaluated, and the only difference is that one has a source of soiling and the other does not, choose the site with no soiling problem. Other environmental conditions can affect O\&M but are outside human control. Examples include:

- Humidity (this may be addressed by installing dehumidifiers in shelters that contain sensitive equipment)

- Hot climate, extreme temperatures

- High wind, possibility of hurricane or tornado

- Hail (PV module breakage)

- Salt air, marine environment (corrosion, soiling)

- High insolation (high temperatures and UV degradation)

- Heavy snowfall (damage to array, lost production)

- Flooding (high rainfall; water intrusion into enclosures).

\subsubsection{Cleaning}

Soiling reduces the energy output of the PV array and can lead to localized hot-spot failures if the soiling is uneven. Efforts should be taken to reduce uneven soiling, for example, from bird droppings. Care must be taken with array cleaning to avoid damaging the components. Follow the PV module manufacturer's recommendations with any array cleaning. Clean PV modules with plain demineralized water and mild detergent recommended by the manufacturer. An 
economical method is with a bucket of water, strip cleaner, and squeegee (often on opposite sides of the same tool), using overlapping vertical strokes in the same way window glass is cleaned on commercial buildings. Do not use high-pressure water, brushes, or any types of solvents, abrasives, or harsh detergents. Robotic cleaning systems are available for large systems, and many of these require that the design of the system accommodate the movement of the robotic cleaning system.

Cleaning may be on a defined interval or "condition based," and the impact of soiling can be measured by instruments to trigger a cleaning (e.g., a sensor with and without a shutter of soiled glass). In either case, the benefits of cleaning may be hard to calculate. For example, an instrument may indicate that the array is dirty, which would trigger a cleaning, but there may be a heavy rain the next day that would clean the array for free. In the case of uniform soiling, a local, site-specific cost-benefit analysis should be performed to determine whether routine cleaning of the array is warranted. The frequency determined may be seasonal, depending on local rainfall and dust characteristics. The optimal cleaning interval is affected by several parameters:

- Cost of cleaning: usually a fixed fee to mobilize a cleaning crew and then a per-unit-area cost for labor and materials $\left(\$ / \mathrm{m}^{2}\right)$

- The rate at which soil accumulates on the array, expressed as a power loss in \%/day, $\% /$ month, or $\% /$ year

- Capacity factor for the location: the better the solar resource is, the higher the reward for cleaning

- Value of the delivered power $(\$ / \mathrm{kWh})$ : the higher the value of the power, the higher the reward for cleaning

- PV module efficiency: the lower the efficiency, the more area $\left(\mathrm{m}^{2}\right)$ of array needs to be cleaned for the same benefit.

It is tempting to combine these parameters to calculate a cleaning interval that justifies the cleaning expense. However, because dirt begins to accumulate again as soon as a system is cleaned and because of rain, a simulation is required to account for time-series effects. Using such a simulation, Naeem (2014) found that for a system in Mesa, Arizona, with an annual soiling loss of $1.91 \%$, a single annual cleaning would reduce the loss to $1.52 \% /$ year $(-20 \%)$, two annual cleanings to $1.32 \%$ year (-31\%), and three annual cleanings to $1.20 \%$ /year $(-37 \%)$. Including the effects of soil accumulation and rain in an hourly simulation can also account for the effects of soiling changes throughout the day, with losses due to soiling in the morning and evening being about twice that in the middle of the day because of high incident angle (the shadow cast by each dirt particle grows longer with increasing incident angle).

Most rely on rain to keep the array clean; no cleaning regimen is employed. Heavy rains result in a nearly complete cleaning effect, whereas light rains clean much less effectively and can even increase soiling if dust then sticks to sparse water droplets. Naeem (2014) did a comprehensive study based on empirical data for both soiling rates and cleaning costs and concluded that cleaning is not cost-effective for residential, commercial, nor utility-scale plants. He found that cleaning costs varied from $\$ 0.25 / \mathrm{m}^{2}$ for large systems to $\$ 1 / \mathrm{m}^{2}$ for single residential systems, and water consumption was around 1 liter $/ \mathrm{m}^{2}$ of system area. 
However, where special conditions (listed below) occur, cleaning will be required on a schedule that depends on the source and nature of the soiling. Annual soiling losses are reported in a range from $4.3 \%$ to $7.5 \%$, with many studies confirming losses around $6 \% /$ year. However, annual values are confounded by the rain cycle, and it is more helpful to look at how soil accumulates daily, in between heavy rains. Studies report about $0.05 \%$ reduction in output per day due to soiling. Naeem (2014) provides a good analysis of cleaning and survey of the literature and reports daily soiling rates of $0.061 \% /$ day and a range from $0.057 \%$ to $-0.085 \%$ /day from his own experiments. He recounts a study of 186 systems reporting $0.051 \%$ /day and another reporting a range of $0.04 \%$ to $0.07 \%$ /day. In an area with heavy agricultural activity, $0.36 \% /$ day is reported and contrasted to a rate of $0.01 \% /$ day in a desert area void of agricultural, construction, or industrial activity. Large bird populations may result in losses accumulating as high as $0.5 \% /$ day, and dust storms in places such as India have reported losses accumulating around 1.5\%/day.

Soiling and resulting cleaning regimen depend on local sources of dirt. A sample swabbed from the PV module surface can be taken to an analytical laboratory to ascertain its origin. Some sources of soiling may be eliminated or reduced at the source (e.g., birds, factories, construction sites), whereas others will be corrected only by cleaning. Sources of soiling that may indicate the need for prevention or a cleaning regimen include:

- Agricultural dust: Cleaning can be scheduled following plowing. In parts of the world without active soil conservation, persistent dust can require frequent cleaning.

- Construction dust: Cleaning can be scheduled after completion of nearby construction. Encourage the construction manager to implement dust suppression.

- Pollen: Schedule cleaning after the end of pollen season.

- Bird populations: Reduce open cracks between panels where birds can build nests; use plastic bird slides to change flat surfaces to steep-sloped surfaces; use bird netting to seal areas under the panels down to the roof completely around the array; install bird spikes along the top edge of the array to prevent roosting; use plastic owl or falcon with swivel head to scare off birds; schedule rooftop services and removal of nests according to nesting season timing. Live birds (falcons) have also been used to scare away other birds. Birds are creatures of habit, and their behaviors can be changed over time to avoid your roof.

- Diesel soot: Present in cities and concentrations such as at bus depots and may require frequent cleaning.

- Industrial sources: Processes such as cooking or manufacturing can be sources of array soiling. This can be identified by testing samples of the dirt. As an example, a filter added to a fryer can reduce oil in kitchen exhaust air. 


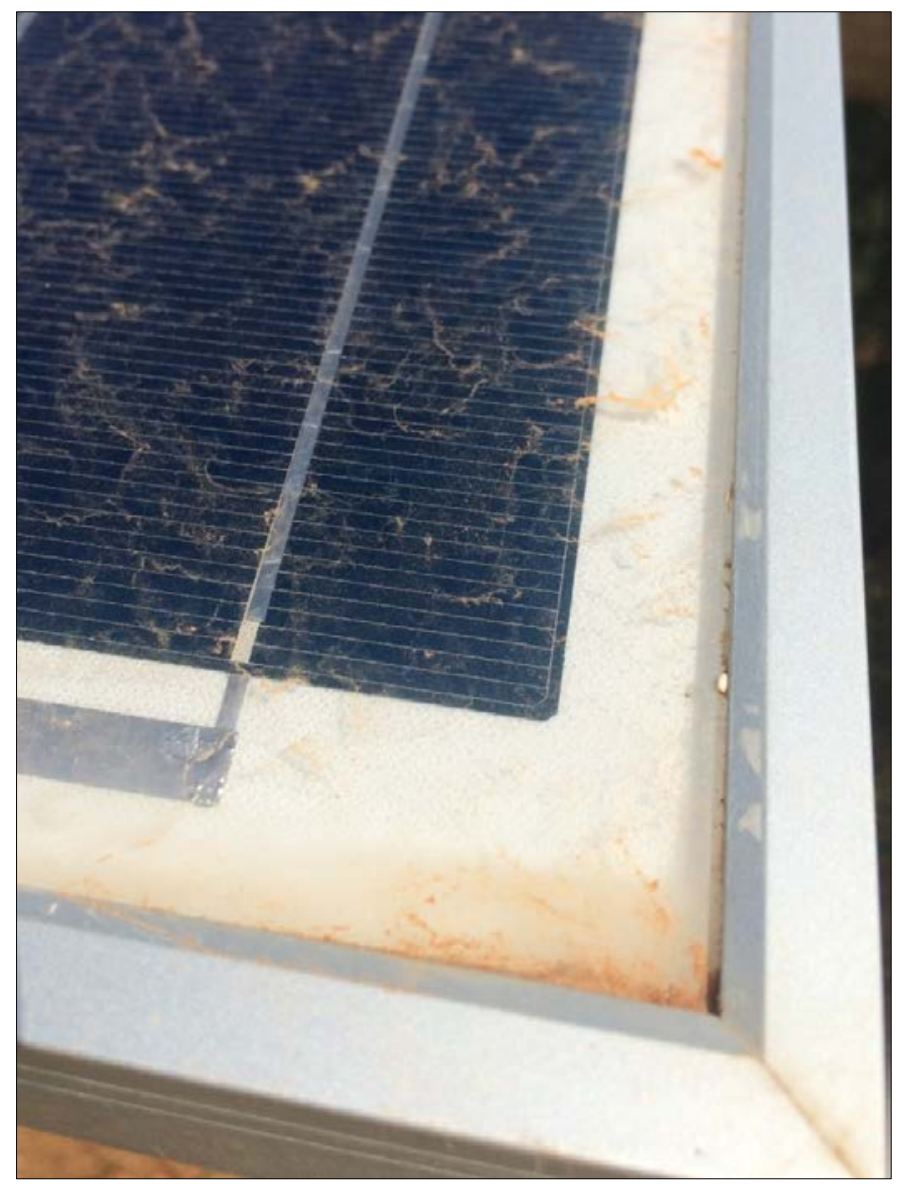

Figure 7. Module soiling can often be traced to a source, such as construction-site dust, resulting in about $5 \%$ loss. Photo by Andy Walker, NREL 


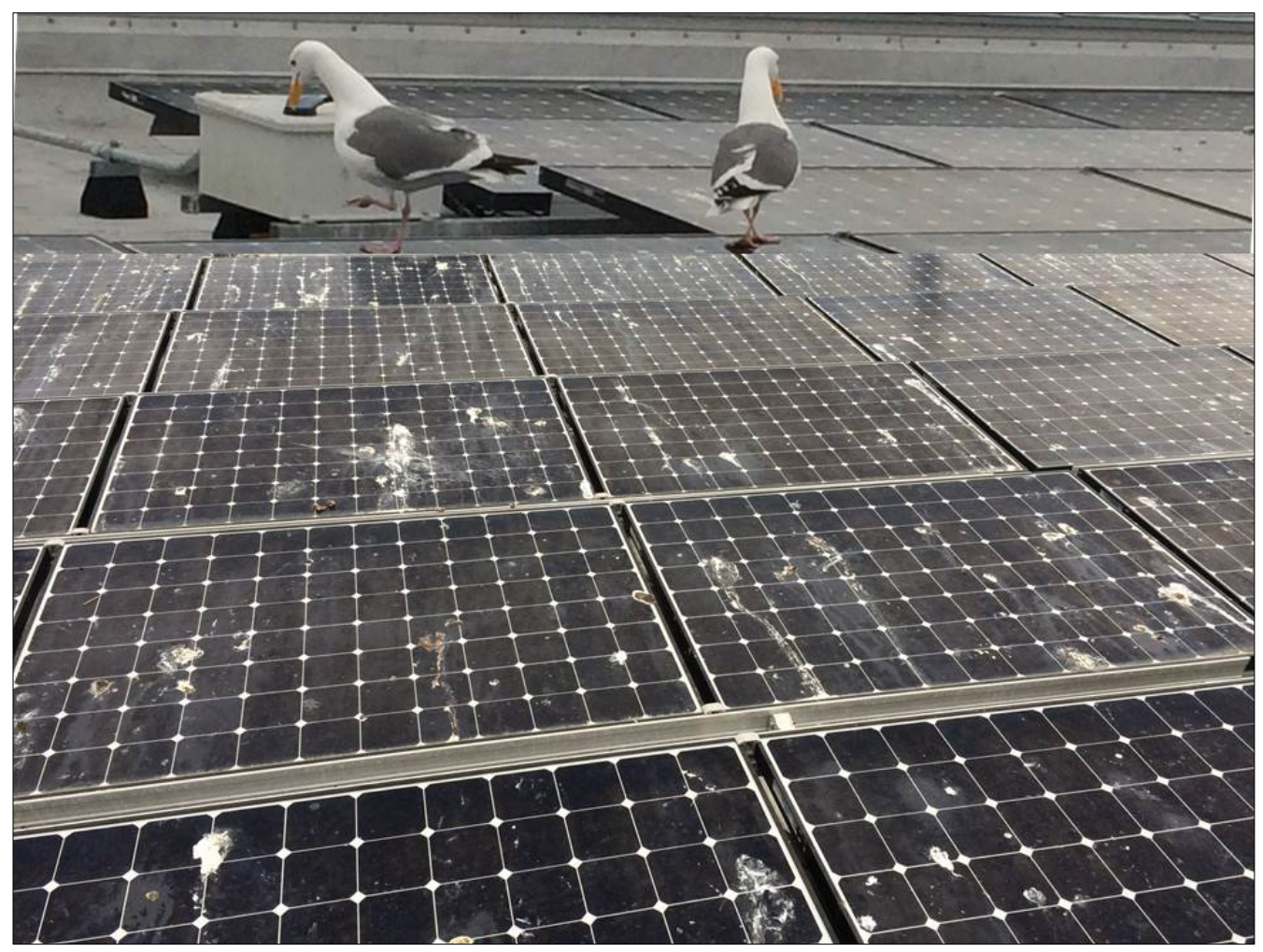

Figure 8. Bird populations are a source of soiling, as well as nests that need to be removed and seeds that can sprout on arrays. Photo by Andy Walker, NREL

\subsubsection{Snow Removal}

Snow accumulation on a PV array can reduce annual average performance by $0 \%-2 \%$ in southern states, $2 \%-4 \%$ in arid states such as Colorado, and $10 \%-16 \%$ in places with heavy snowfall such as Michigan, Wisconsin, and Maine (Ryberg and Freeman 2017). Design of array can increase or decrease snow accumulation (Figure 9). During design of the system, the necessary clearance between the bottom of the array and the ground or roof is determined to avoid wind-driven drifts and allow snow to slide off. Snow generally slides off steep arrays (e.g., 30 -degree tilt) but does not slide off low-sloped arrays ( $<20$-degree tilt). Snow removal is generally not recommended because it may damage the modules, but it is sometimes required to reduce snow weight on a roof or to remove ice dams. The weight of snow has been known to completely crush PV modules and racks in rare instances. Snow removal is by powerful turbofan, not shovel or other mechanical means. Snow removal to provide access (i.e., roads, walkways) is generally required. 


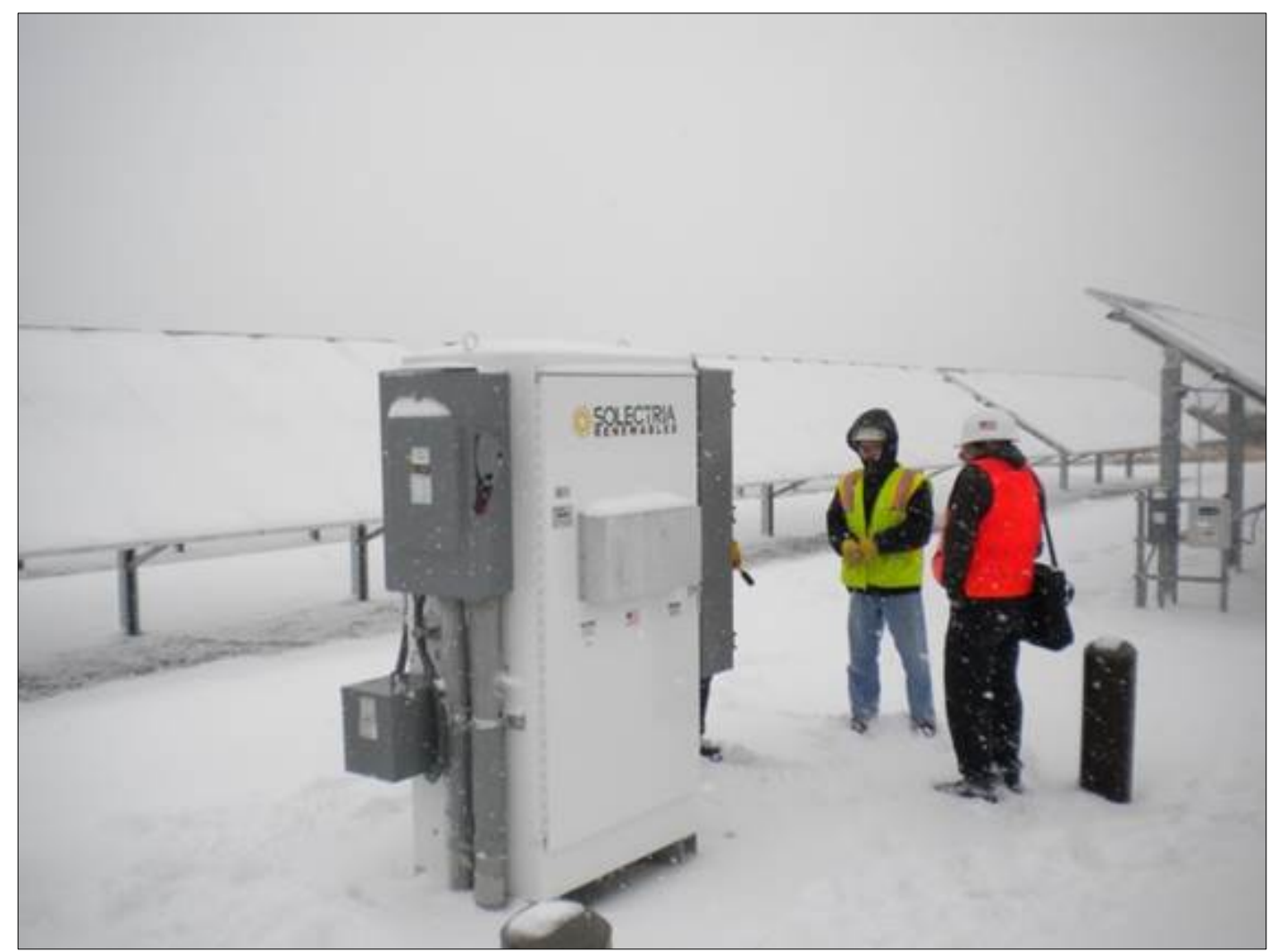

Figure 9. Snow is an environmental condition that both reduces performance and complicates provision of O\&M services, but removal of snow off arrays is not recommended due to the potential for damage. Photo by Andy Walker, NREL

\subsubsection{Extreme Weather Conditions: Hurricanes and Tornadoes}

$\mathrm{PV}$ is installed in locations where extreme weather conditions may occur, such as hurricanes in the Caribbean, storms along the eastern U.S. coast, and tornadoes in Texas and Oklahoma. PV systems should be designed and installed with such possibilities in mind, and measures should have been incorporated such as two-column racks (rather than post-strut), thick or non-glass covers, rigid backsheets, and through-bolted clamps. The designer should specify PV modules with high ratings for both uplift and down-force pressure. Some of these installation measures could be retrofit as part of making a system more resilient to extreme weather. Some practical O\&M considerations include:

- Carefully inspect and re-torque all fasteners. Many systems have fasteners that are loose or missing, but the structure has not been tested by high winds - in preparation for a storm, carefully inspect and torque every fastener in the system. Sophisticated fastener systems are available with anti-vibration locking features.

- Re-install any weak or broken wire ties. Add additional wire ties.

- Supplement or replace clamp-type connections with through-bolt solutions that can withstand a lot of vibration.

- Remove any objects that could become airborne and damage the array (foreign objects). Remove any broken tree branches, abandoned antenna stands, or such objects that serve no purpose and could be liberated in a storm. 
- Make sure cabinets and electrical boxes are properly latched with gasket intact and in place. Consider strapping doors closed on cabinets with less than NEMA 6 rating [see https://www.nema.org/Products/Documents/nema-enclosure-types.pdf].

- Leave the instrumentation in place to record the increasing storm conditions; however, anemometry and data backhaul antennas do not generally survive the worst storms, so consider taking these items down before a storm if you cannot afford to replace them after the storm.

Following a catastrophic weather event, personnel with the required training, certification, and protective equipment would:

- Render the system in a safe condition by disconnecting circuits that have sustained damage. Ground faults and arc faults might occur in damaged sections of the array, so disconnect damaged arrays at the module level.

- Perform inspection for both structure and electrical condition. Document any damage, prepare scopes of work and budgets for repairs, execute repairs quickly to ensure safe conditions and restore performance.

- Consider reinforcing or replacing components that failed with a stronger, properly engineered version. Replace any bent components.

- Secure PV modules and other items that have been liberated from the rack. Ensure that remaining rack sections are secure; if not, disassemble and secure.

- After making required rack and electrical repairs, re-commission the entire system before bringing it into service.

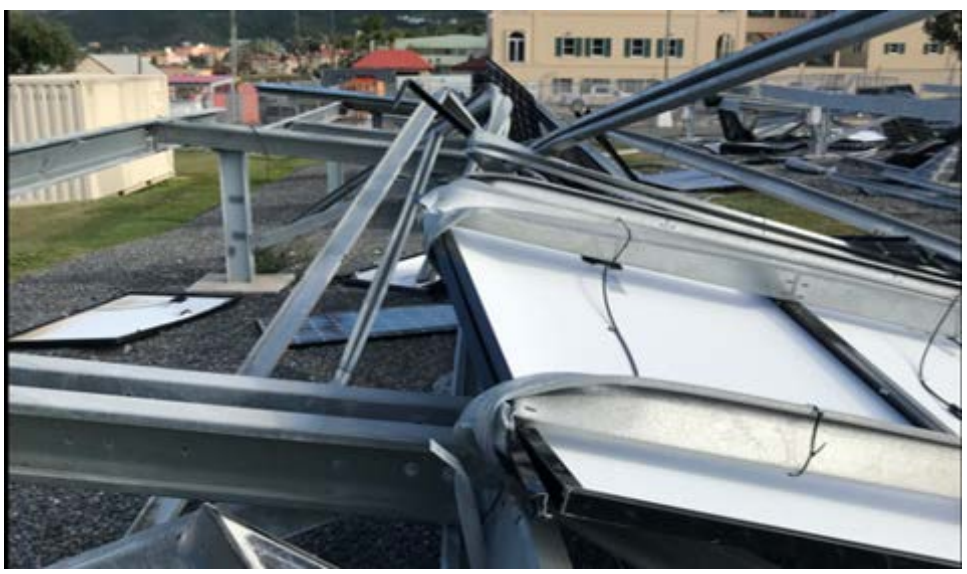

Figure 10. It might be the responsibility of the O\&M provider to respond and ensure that storm damage is rendered safe both in terms of electrical hazards and loose components following an extreme weather event such as this damage in St. Croix in 2017. Photo by Andy Walker, NREL

\subsection{Site Access}

Utility-scale sites frequently have access roads through the array. These are installed during civil construction to facilitate array construction services. Because these sites can be several acres, driving access is needed. Roads must also accommodate emergency vehicles such as fire trucks. The roads may be built to accommodate cranes, and crane access may be needed during O\&M services. Roads are placed in natural breaks, such as the end of several strings or the end of an 
array-tracking mechanism. To ensure an accessible site, these roads must be maintained periodically (EUCI 2016).

Site security is another issue to consider. If the site is in a rural area, perhaps a fence and locks on the enclosures and shelters is all that is needed. In a more populated area, cameras or occasional visits by a security guard may be warranted.

\subsection{Dependencies for PV Plus Storage Systems}

This section details additional system dependencies to consider when integrating PV and energy storage systems. After discussion of commonly used topologies for PV plus storage system designs, the subsections follow the same progression as those in the preceding PV-only section. As with PV-only systems, there is detail on operations in Section 6 and health and safety considerations in Section 7. O\&M considerations for energy storage depend on battery type, use case, and other parameters.

\subsubsection{Battery Type}

There are several types of batteries, each with their own characteristics, including:

- Lead acid

○ Vented lead acid (VLA)

- Valve regulated lead acid (VRLA)

- Lithium-ion

- Lithium iron phosphate (LFP)

- Lithium nickel manganese cobalt oxide (NMC)

- Lithium nickel cobalt aluminum oxide (NCA)

- Lithium manganese oxide (LMO)

- Lithium titanate (LTO)

- Lithium carbon (LC)

- Nickel cadmium.

In order to discuss applications of batteries to different use cases, it is important to clarify key terms that describe their performance and capacity. A battery can provide a maximum amount of power $(\mathrm{kW})$, and it can store a certain amount of energy $(\mathrm{kWh})$. Batteries are generally rated in units of amp-hours, which, when multiplied by cell voltage (V), is energy storage capacity in units of kilowatt-hours. Energy storage systems are also rated by power delivery capacity in units of kilowatts. The power rating is important to determine the rate at which power can be delivered and will vary according to the application and relevant load profiles. The energy rating is also important to determine how long the battery can be discharged and how to program the energy management system. For example, a $10 \mathrm{~kW} / 100 \mathrm{kWh}$ battery can provide power at a rate of $10 \mathrm{~kW}$ and stores $100 \mathrm{kWh}$, so one could discharge the battery at $10 \mathrm{~kW}$ (the maximum power) for 10 hours. 
Battery replacement intervals also present a special challenge when planning O\&M expenditures because how long a battery may last in service depends on how the battery is treated.

Replacement interval is no longer than "shelf life" or "float life" but is significantly less depending on how long the battery has spent at low states of charge, the magnitude of the charge/discharge rates applied, how effective service such as equalization of charge and maintenance of electrolyte has been (for lead acid), and the average and extreme temperatures that the battery has been exposed to. Batteries start to lose capacity (effective kilowatt-hours of storage) as soon as the battery is installed, so, to determine a battery replacement interval, we have to specify how much storage is required at a minimum. For example, a telecommunications application might specify that a battery be replaced when a test reveals that it has $70 \%$ of its initial capacity.

\subsubsection{Battery Use Cases}

The use cases for batteries in the guide include PV systems. Some of these use cases are more typically applied to standalone battery systems, such as utility-scale frequency regulation or substation- or feeder-level solutions that are implemented by the utilities themselves (Lazard 2016), or commercial or industrial grid-connected batteries that do not have complementary PV systems.

Frequency regulation: Electricity storage has the capability to very quickly source or absorb energy to provide primary frequency regulation services. The value of frequency regulation depends on the needs of the electric utility.

Time of use (arbitrage): Storage applications that seek to shift usage of PV-generated electricity from times of PV generation to later times, especially peak usage times when power demand $(\mathrm{kW})$ is at a premium price.

Ramp-rate controls: Ramp-rate controls using batteries are a good thing in grid-connected applications and a necessity for small grids such as an island or village power system. A growing number of jurisdictions are issuing regulations to stage ramp-up of solar power in the morning, ramp-down in the evening, and manage PV fluctuation throughout the day. Such controlled rates of change allow that ramping up conventional generators in a small grid (10-25 min) will be needed as the PV share of generation increases in general.

Peak shaving: Includes demand charge reduction in the commercial and industrial sector and, more generally, applications that manage peak loads.

Resiliency: Defined as applications that seek to provide extended energy services during system outages. An example is a home system that is outfitted with a separate critical loads panel that allows the combination of rooftop PV and storage to power critical loads for a period of time.

Micro-grid (islanded and grid-connected): Refers to bundles of loads that are electrically connected to distributed energy resources, such as PV generation and storage. These combined generation and storage systems can be "islanded" in remote or isolated areas or grid-tied with the ability to operate both with interaction with the grid or disconnect from the grid to maintain operations separately as needed (e.g., in the event of a grid outage). 


\subsubsection{PV Plus Storage System Topologies}

Topologies for PV plus storage systems are typically determined by a combination of regulatory constraints and technical inputs paired with anticipated system behavior and associated system efficiency and cost. For example, in some settings, investment tax credit considerations may encourage designs that prioritize charging batteries with solar-PV-generated electricity. On the customer usage side, whether the power use is coincident with PV generation will be a key consideration.

\subsubsection{Important O\&M Considerations in System Design}

There are a number of important considerations that go into system design and influence O\&M, both in terms of ongoing costs and system performance, and that influences topline power production (translating into revenue or avoided costs, depending on context).

Designing systems to minimize losses is central to performance and costs relating to optimizing system size for a given set of power needs. The first step in minimizing efficiency losses through effective system topology design and equipment selection is to evaluate expected typical system behavior. This analysis would include activities such as assessing the relevant load profile(s), comparing that to the solar resource for the location, and considering the rate and duration of power needs. A system that is well designed for its application will optimize the usage of the battery, potentially decreasing frequency of corrective actions, such as needing to replace batteries that are failing prematurely due to overuse and ideally extending battery life.

It is important to note that components have different efficiencies at different levels of utilization. Equipment efficiency changes as a function of environmental conditions such as temperature. Sizing considerations that flow from this analysis have an important bearing on O\&M planning and execution. For example, a system that requires batteries to discharge deeply often may require more maintenance and will shorten the usable life of the batteries and alter the associated costs that must be set aside in reserve accounts.

\subsubsection{AC-Coupled System}

AC-coupled systems link the battery and the PV array on the AC bus. As a result, PV-generated electricity can typically serve loads directly with a single conversion, but for PV to charge the batteries, it needs to flow back through a bi-directional inverter to be converted to DC (resulting in an efficiency loss). For example, AC coupling is common in residential markets, and when batteries are retrofitted to existing systems, they are typically coupled on the AC side to avoid wiring replacements and potential violations of terms of ownership agreements (Ardani et al. 2017).

\subsubsection{DC-Coupled System}

DC-coupled systems link the PV and the battery on the DC side of an inverter (typically still bidirectional to charge from the grid where permissible). A charge controller is needed to manage the voltage of the DC electricity coming from the PV that is used for battery charging. The charge controller is generally an efficient conversion, but nonetheless it represents an additional component that affects overall system efficiency. This configuration is sometimes classified as "AC/DC-coupled" when the battery can be charged from the grid in addition to the PV array. 
Additional information about bi-directional inverters to complement the inverter discussion above follows this review of topologies.

\subsubsection{Additional Topology Configurations and Settings}

Diesel generator: In certain settings, particularly isolated micro-grids, a diesel generator can be paired with PV and energy storage systems. Typically, this design decision is made to provide energy when weather conditions are unfavorable to renewable generation, reduce the capital cost of the project (e.g., decreasing PV and or storage component sizing to shift costs toward ongoing fuel costs), or both.

DC loads: Some systems are designed to serve a DC load directly as the only load (e.g., an electric motor) or in addition to AC loads. This can be done by serving the DC loads by way of the charge controller, drawing on PV-generated electricity or the battery.

Resiliency/backup power: Backup power applications are typically in DC-coupled topologies with an automatic transfer switch and a critical loads panel.

\subsubsection{Other Electrical System Information Related to Energy Storage}

Charge controllers: DC-coupled systems will generally require a charge controller to protect the battery from overcharging. Any DC loads included in the system can also be served directly through the charge controller.

Air conditioning: Batteries may require active cooling depending on operating characteristics, enclosure design, and ambient temperature. If so, there will be auxiliary power usage for the air conditioning that can detract from the total energy delivered from the system to serve loads. There are options for modeling this electricity demand from air conditioning systems to identify the optimal level of conditioning. For example, containerized batteries can leverage envelope and insulation modeling tools to narrow expectations of temperature variation and air conditioning needs to help guide O\&M staff or provider system monitoring. See below for additional information about environmental conditions.

Maintaining battery temperature within a given range is often a requirement for battery warranties, so maintaining battery temperatures through appropriate conditioning can become an important ongoing operational concern. For example, lead-acid batteries tend to have warranties that cap temperature tolerance at roughly $25-35^{\circ} \mathrm{C}$, so conditioning solutions need to be selected and monitored on an ongoing basis. In addition to satisfying equipment warranty requirements, if batteries are kept at elevated temperatures, the rate of capacity degradation can increase meaningfully. The balance between warranties, conditioning costs, and capacity degradation needs to be identified at the system design stage and then monitored carefully and re-calibrated over time.

DC wiring: Best practices for handling DC wires are discussed earlier in this section. It is important to note that a DC-coupled PV and battery system can involve a larger DC-wired network than a standalone PV application. 


\subsubsection{Inverter Considerations for Energy Storage Systems}

This section supplements the inverter discussion above by discussing relevant considerations for bi-directional inverters. Bi-directional inverters allow the battery to charge and discharge, converting battery or PV-generated DC electricity to serve an AC load or converting grid power or onsite generator power back into DC to charge the battery.

Combined PV and storage system topologies will generally require a bi-directional inverter, either as the primary inverter solution (DC-coupled) or in addition to the unidirectional PV inverters (AC-coupled). Bi-directional inverters are also integrating a growing number of different capabilities, particularly in grid-tied utility-scale settings and grid stability support services (use cases outside the scope of this document).

The cost considerations of replacing inverters and maintaining reserve accounts are similar to central inverters discussed above. The calculus for the reserve account can be adapted based on an estimation of the costs associated with not having the battery available, which depends on a given use case. For example, in settings where the battery serves a key role in demand charge reduction, downtime at an inopportune time could be exceedingly expensive. In other words, inverter selection should consider how system component failures can affect system operation as a whole and result in lost revenue.

\subsubsection{Environmental Conditions for Energy Storage Systems}

Though batteries will typically be in an enclosure, the containers or enclosures can still be influenced by environmental conditions in ways that can influence O\&M decisions and costs. For example, many batteries will have recommended temperature ranges for optimal performance. Operating batteries outside those set ranges can result in capacity degradation, shorter battery usable life, and possibly void product warranties, so ambient temperatures will generally influence O\&M practices and costs even in conditioned enclosures. Battery manufacturers recommend the temperature and humidity levels which should be maintained in the battery enclosure. Additionally, as with inverters and their air intake, it is also important to keep battery vents clear. The vents will be important for cooling batteries and venting gases for certain battery types (i.e., hydrogen off gassing in certain lead-acid battery technologies). Batteries can also have specific requirements and stipulations such as being de-rated above a certain altitude (or voiding product warranties above a certain altitude) and safety mechanisms associated with seismic ratings.

\subsubsection{Site Access for Energy Storage Systems}

Ease of access considerations included in the PV-only section above apply to batteries as well. In addition, batteries will have their own siting and signage requirements that reflect the hazards associated with energy storage, such as ANSI Z535. Depending on battery type and usage, there may also be a need to keep the surrounding area clear to allow proper ventilation if outdoors. Ventilation and other health and safety concerns are covered in detail by a number of codes and standards that are listed in Section 7. 


\subsection{System and Site Considerations Checklist}

Site and system considerations include the following.

\begin{tabular}{|l|l|}
\hline $\begin{array}{l}\text { Was O\&M a consideration in system design? Are the interests of EPC and O\&M provider } \\
\text { aligned? }\end{array}$ \\
\hline $\begin{array}{l}\text { Are conductors buried or placed in conduit? If direct-bury, is ground compacted to deter } \\
\text { chewing rodents? }\end{array}$ \\
\hline $\begin{array}{l}\text { Is the preventative maintenance schedule for inverters followed? } \\
\text { inverters have remote monitoring and control? }\end{array}$ \\
\hline $\begin{array}{l}\text { Is the system compliant with the roof warranty? Is there an overburden waiver defining } \\
\text { responsibilities for each party? Is a system in place for notifying the roofing company if roof }\end{array}$ \\
\hline $\begin{array}{l}\text { Does conduit design account for movement in rooftop ballasted systems? } \\
\text { Are climate, extreme weather events, ecological conditions, and environmental regulations } \\
\text { accounted for and budgeted into the O\&M plan? }\end{array}$ \\
\hline $\begin{array}{l}\text { Does civil engineering design adequately provide for road access, drainage, and security? } \\
\text { Does panel spacing allow for vehicle access between rows? }\end{array}$ \\
\hline $\begin{array}{l}\text { Do panel cleaning methods follow manufacturer recommendations and cleaning schedule } \\
\text { account for local conditions? Has a cost-benefit analysis been run to determine if regular } \\
\text { cleaning is cost-justified? }\end{array}$ \\
\hline $\begin{array}{l}\text { Is the plant required to meet North American Electricity Reliability Corporation (NERC) } \\
\text { compliance for utility-scale plants? }\end{array}$ \\
\hline
\end{tabular}




\section{System Performance and O\&M Plans}

The PV O\&M plan should be considered within the context of the performance period required for a residential or commercial PV system to generate a sufficient return on investment (ROI).

The PV O\&M life cycle begins with planning and system design. The life cycle ends with provision for decommissioning or disposal of the system. The asset life (about 25 years) is considered the performance period even though ownership may change multiple times during that period.

The cost of the monitoring program can range from minimal (e.g., checking the total electricity generated as reported by the inverter once per year) to exceeding $\$ 100,000 / \mathrm{yr}$ in high-accuracy monitoring equipment that is watched daily for signs of problems or needed cleaning. As discussed below and in the appendices, the monitoring program is chosen to align with the expected increased revenue because it would depend on the size of the system and the logistical details.

A system owner is likely to seek a performance contract where a specified performance indicator, such as $\mathrm{MWh} / \mathrm{year}$ energy delivery, is guaranteed. Indicators that account for changes in weather, force majeure, and anticipated degradation are recommended, such as the PR, as described in Appendix A. Appendix F includes guidance on how to address general downtime outages that affect performance.

The scope of work for the performance contract is called a Performance Work Statement, with "performance" being quantified by indicators such as energy delivery or availability. Appendix E includes an example Performance Work Statement based on the key performance indicator of $80 \%$ of system nameplate rating and corrected for balance-of-system efficiency and conditions.

\subsection{Planning for System Performance}

Many performance indicators have been proposed: select a type of key performance indicator (KPI) that minimizes cost but ensures optimal system performance under varying conditions. Consideration of KPIs includes how they should be used, when they are or are not accurate, benefits of each, and pitfalls of using them for the wrong application. PV system performance is based on how much time is lost when a system is not available and on the performance of the system when it is available. A system may have an availability of $95 \%$, but a performance ratio (weather adjusted) of $100 \%$. The stakeholders will have a much better assessment of the system if they measure performance based on both metrics - downtime and energy delivery. KPIs are also important in the monitoring and guarantee sections of this guide.

\subsubsection{PV Performance Indicators}

People have much different needs and expectations regarding performance indicators depending on their perspective. Financiers and asset managers are interested in production and revenue regardless of the cause, so are satisfied with high level aggregated metrics. O\&M service providers, on the other hand, want metrics that separate issues they can control from those they can't control and that identify which issues are having the biggest impact on performance and return to service, and thus they need a more detailed "scorecard" with subsets of DC system health, inverter health, and grid interactions. Examples of KPIs include the following: 
1. "Availability" (or "uptime") refers to the percentage of time that a condition is metusually that a component or system is operating. In contrast, IEC 61724 states that "energy availability" is a metric of energy throughput capability that quantifies the expected energy when the system is operating relative to the total expected energy, rather than the percent of time that a plant is available, which is the more traditional use of the term "availability" (IEC 1998). When defining availability as a contract term (see Appendix F), it is important to distinguish events that are "outside management control" (OMC). Operators should not be penalized for events that are OMC. Availability standards under development strive to remove from the calculation the lost energy production during the time of an $\mathrm{OMC}$ event.

However, there are many modified forms of defined availability, the details of which can be segmented, and which should be explicitly documented.

A. Is the availability affected by the grid interaction (grid down, power reduction, or planned shutdowns to avoid grid instabilities) or by the plant itself (shutdowns for planned O\&M downtime due to malfunction)? IECRE's implementation of IEC 61724-3 suggests also reporting the energy availability with external causes identified and OMC events excluded (IEC 1998).

B. The energy availability may be reported for the complete system or for "blocks" within systems. For example, a 2-MW plant may consist of four 500-kW "blocks," and one may be down while the other three continue to operate. The energy availability may be reported either for the subsystems or for the entire system. Block availability is more appropriate than whole-system availability whenever the unaffected parts of a system can continue to operate unimpeded.

C. Availability can also be specific to the components or subsystems within a system. For example, there may be a KPI for one service provider to maintain a given availability for the tracking system and a separate KPI for another provider regarding uptime of the inverter. See Klise and Balfour (2015) for more detail. When availability is applied at the component level, it may make more sense to use the time-based availability, reporting, for example, the fraction of days per year that the component was available rather than attempting to identify the energy availability associated with that specific component.

D. An availability specification is currently being drafted by IEC (IEC 63019, 2018) that further breaks down unavailability into various categories. Appendix F summarizes the key points. Some categories may be planned categories such as maintenance; others may be unplanned such as equipment failure, or unplanned but force majeure, such as weather or grid outage.

2. "Energy availability": Because the availability of a PV system during times of darkness is not of much relevance to functionality, it is useful to define "energy availability," which effectively provides an energy-weighted version of the time-derived availability metric. For a PV system, IEC 61724-3 states that energy availability is a metric of energy throughput capability that quantifies the expected energy when the system is operating relative to the total expected energy (IEC 1998). The energy availability may be expressed as a percentage or a fraction. The system is viewed to be operating when the inverter(s) is peak-power tracking and feeding energy into the grid. If a system has 
multiple inverters and only a fraction of the inverters are functioning, then the calculation of the "operating" expected energy is calculated only for the inverters that are operating. If a system has string-level monitoring, then the "operating" expected energy may be calculated to reflect only the operating strings. Measurement of the energy availability requires knowledge of the weather data in addition to knowledge of when the inverters are operating; it is described in more detail in IEC 61724 (IEC 1998).

3. "Energy performance index": The performance index is defined by IEC 61724-3 and may be used to complement the energy availability metric (IEC 1998). The performance index compares the energy that was produced by the plant with the energy that was expected for the plant based on the measured weather and irradiance, and a performance model agreed to by the stakeholder. The performance index may be defined to stand alone or to complement the energy availability metric by using the options:
A. "All-in energy performance index," which is the ratio of the total electricity produced divided by the electricity that was expected including all hours and seasons of the year.
B. "In-service energy performance index," which is the same ratio but excludes the electrical energy that was expected when the system was not operating. The in- service performance index is useful toward quantifying how well the plant functions when it is functioning and is best used to complement the energy availability metric.

4. "Energy delivery" refers to the measured MWh/year energy delivery; adjusted energy guarantee is discussed in IEC 61724 (IEC 1998) and NREL report Analysis of Photovoltaic System Energy Performance Evaluation Method (Kurtz et al. 2013).

5. "Specific performance" refers to energy delivery divided by plant rated capacity, in units of $\mathrm{kWh} / \mathrm{kW} /$ year. This is also referred to as "array output energy" in IEC 61724 (IEC 1998).

6. "Performance ratio" is described in IEC 61724-1 (IEC 1998) or ASTM E2848 - 13 Standard Test Method for Reporting Photovoltaic Non-Concentrator System Performance (ASTM 2013). The latest version of IEC 61724-1 defines several ways to calculate various types of PRs. Variable definitions of PR can prevent direct comparisons in some cases. The "standard" definition of PR does not include a temperature correction. Recommendations are provided in the NREL report Weather-Corrected Performance

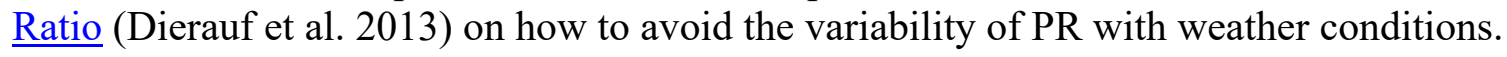
Appendix A presents an example of such a description of how PR is applied. Figure 11 shows a comparison of different definitions of PR for 2,200 systems in California as measured over a period of 6 years, or less for the newer systems in the sample (oSPARC 2018).

7. "Power performance index": Measurement of the power performance index is described in IEC 61724-2 and is similar to the energy performance index except that it reflects the power output rather than the energy output (IEC 1998). A PR is not as relevant as a performance index. A PR of 0.8 may be fine for some locations but not for others. PR will usually be higher in the winter and lower in the summer. In contrast, a more consistent metric is the performance index, which compares the measured power or 
energy to the expected power or energy - where expected power or energy is based on measured weather and irradiance and a performance model agreed to by the stakeholders. Ideally, both the power performance index and the energy performance index are close to unity. Thus, the performance indices are more likely to deliver consistent metrics across times of the year, geographic locations, and times of weather anomalies.

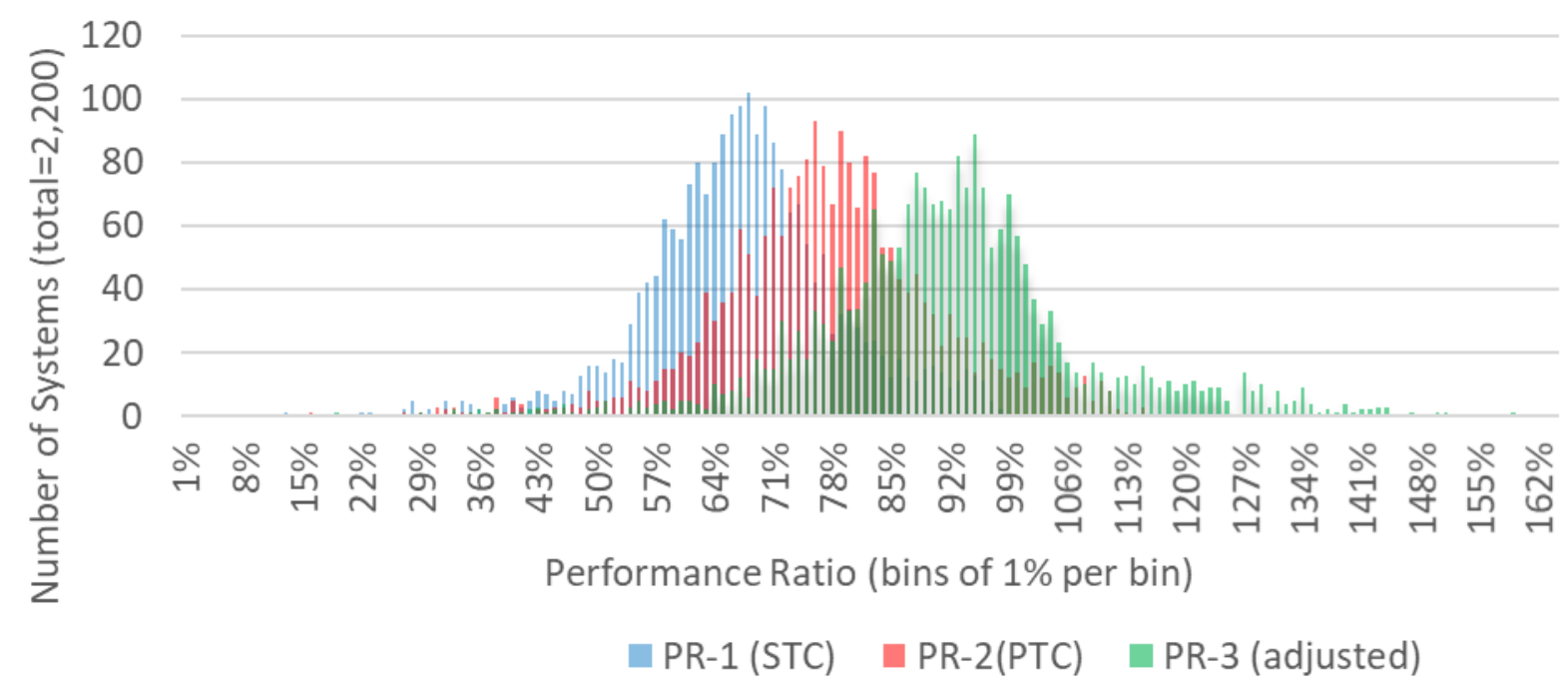

Figure 11. Different definitions of Performance Ratio (as per IEC 61724) result if different values compared here for a sample of 2,200 PV systems. PR-1 is actual production divided by STC rating and normalized for insolation; PR-2 is actual production divided by PTC rating and normalized for insolation; and PR-3 is actual production divided by PTC rating normalized for insolation, ambient temperature, age of system, and balance of system efficiency. A value of PR-3 $=100 \%$ means the system is performing as expected. Figure by Andy Walker, NREL using data from oSPARC 2018

8. Capacity test, or "short-term performance test": The power delivered by the inverter $(\mathrm{kW})$ is compared to the power of the PV system as calculated as a function of environmental conditions by the following equation:

$$
P_{\text {solar }}=P_{S T C}\left\{\frac{\left(\eta_{\text {BOS }} * \text { degr }\right)}{\left(\frac{1000 W}{m^{2}}\right)} I_{C}\left(1-\delta\left(\left(T_{\text {ambient }}+\frac{(N O C T-20 C)}{\left(\frac{800 W}{m^{2}}\right)} I_{C}\right)-25 C\right)\right)\right\}
$$

where:

$\mathrm{P}_{\text {solar }}=$ predicted average power output in kilowatts of the solar system, averaged over the duration of the test

PsTC $=$ rated size in kilowatts, nameplate capacity; STC refers to standard test conditions $\eta_{\text {BOS }}=$ balance-of-system efficiency; typically 0.77 to 0.84 (NREL 2011) but stipulated based on published inverter efficiency and other system details

degr $=$ an age degradation factor that is 1.0 initially but degrades at $0.5 \%$ per year 
$\mathrm{I}_{\mathrm{c}}=$ measured solar insolation in plane of array $\left(\mathrm{W} / \mathrm{m}^{2}\right)$, averaged over the duration of the test

$\delta=$ temperature coefficient of power $\left(1 /{ }^{\circ} \mathrm{C}\right)$, which is usually on the order of $0.0041 /{ }^{\circ} \mathrm{C}$ for silicon PV modules and may be less for other technologies

$\mathrm{T}_{\text {ambient }}=$ ambient temperature $\left({ }^{\circ} \mathrm{C}\right)$, averaged over the duration of the test

NOCT $=$ nominal operating cell temperature, which is a number found in the manufacturer's literature and is often around $47^{\circ} \mathrm{C}$

The ratio of measured average power to predicted average power is the performance index based on the short-term performance test. Notice that this is a "spot check" on instantaneous power performance and does not include availability (or downtime) in the metric. Figure 12 shows an example of such as short-term test performed as part of a system inspection.
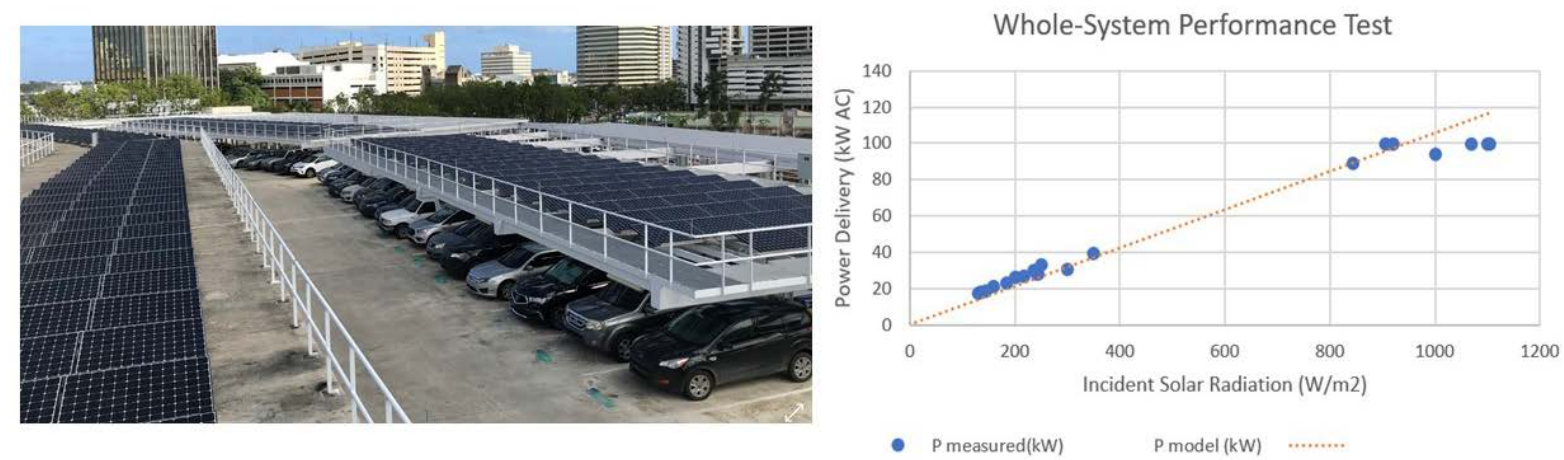

Figure 12. Short-term test of PV Arrays on Carport of Degatau Federal Building and Courthouse, Puerto Rico, showing performance commensurate with calculated expected value, including that power is limited to $100 \mathrm{~kW}$ by the capacity of the inverter on this $125 \mathrm{~kW}$ DC system. This test was conducted over a 1-hour period that included sunny periods (points to the right) and passing clouds (points to the left side of the graph). Figure and photo by Andy Walker, NREL

O\&M managers should consider how to allocate risk associated with inaccuracy of the calculation of PR or error in the implementation of the evaluation method. For example, dirt on a pyranometer will exaggerate PR. Thus, exclusions such as clipping (high AC/DC ratio), force majeure, specific representations made by the O\&M provider, and underlying solar resource considerations should be specified in calculations and the evaluation method. The exclusions are also organized into an information model in IEC 63019 as categories of operation as a way to manage unavailability data for system assessment and availability calculations in Appendix F. Note that a dirty irradiance sensor may be a maintenance issue, but clipping may be a model issue, and it is useful to distinguish between the two issues. The maintenance of instrumentation is very important. Current PV system performance standards development suggests that a model should be used in the calculation, and such a model may include simulation of issues such as clipping. An example of such a performance model is the System Advisor Model (SAM) program by NREL (https://sam.nrel.gov/), although there are many acceptable models available. 


\subsubsection{Energy Storage Performance Indicators}

Combined PV and energy storage systems draw on the performance indicators included above and add a set of additional battery and system-wide indicators. As in the preceding PV performance indicators section, this section lists a number of key performance indicators to consider tracking. The final set of indicators will depend on system design, user needs, metering, and data analysis capacity.

\subsubsection{Uptime/Availability}

Uptime or availability measures the percentage of time the storage system is functioning or available. There are several different ways to measure this indicator, including:

- Scheduled and unscheduled downtime: Scheduled or unscheduled downtime is a simple first approximation of whether uptime is meeting expectations. Scheduled and unscheduled downtime can be aggregated for customer reporting (e.g., for a system owner, both scheduled and unscheduled downtime will result in lost revenue, degraded savings, and extended payback) or the scheduled maintenance can be excluded to focus the indicator on operations issues. This indicator can be framed in an absolute number of days, as a percentage of days of the year, or as a comparative measure such as year over year or facility vs. facility.

- Downtime relative to expectations: A ratio of observed downtime to expected downtime is an additional layer of analysis to consider. The expected downtime can be derived from existing data from a given site, derived from existing data from a comparable site, or modeled. Modeling expected downtime could include integrating information from the OEM for the battery, expected or actual data on battery performance [such as depth of discharge (DOD) covered below], and sources of failure mode distribution data.

Regardless of which availability metric is used for reporting or ongoing operations, it may also be useful to disaggregate downtime to support system optimization.

\subsubsection{Cycling and Depth of Discharge}

Battery longevity for lead-acid and lithium-ion batteries is a function primarily of DOD, number of cycles, time spent at each level of state charge, and operating temperature. Warranties will often have stipulations for usage to remain eligible for coverage.

Depth of discharge: DOD refers to the percentage of capacity that is used when a battery is discharged. A battery that is used once a day to shift PV-generated electricity that is discharged down to $65 \%$ of capacity has a DOD of $35 \%$. DOD can be measured as an average percentage over time with a separate indicator for the variability in the reading and the deepest discharges the battery typically sees. The relationship between DOD and battery life is non-linear, so depending on the specifications for the battery and typical usage, there may be more or less value in increasing granularity of DOD data. Batteries will also have a minimum state of charge that the battery can sustain without damage, so monitoring systems and set points should be configured to avoid violating that constraint.

Cycles: A cycle is typically defined as each instance the battery is discharged and then recharged. There are several more complex approaches to counting cycles that can provide more 
granular data on cycling behavior, and the ideal methodology for cycle counting will depend on the analytical needs for battery performance evaluation. Cycle depth and frequency will vary based on usage of the battery. For many time-of-use shifting applications, batteries will often cycle one time per day or less as they charge from PV and discharge at peak periods. In other use cases, such as frequency regulation, the number of cycles can be much greater and more variable, wherein the minimum number of cycles per year can vary from 250 to 10,000 (Akhil et al. 2013).

Cycling indicators can be tracked as a total number, as a percentage as modeled, or as OEMadvised useful life for batteries. It may also be useful to note when the battery is only partially recharged during a cycle. Certain lead-acid technologies will also require a periodic equalization charge to ensure proper longevity.

Total longevity: To estimate how long a battery will last, it may be valuable to build a model of the system or develop expectations based on input from similar systems or battery OEMs. If battery life is modeled, inputs to the model would include load profile, irradiance data, system sizing, efficiency characteristics, and assumptions for degradation rates. Ideally, these inputs would be drawn from actual system measurements, but modeled assumptions for inputs can be developed as well. OEMs may also to be able to provide input on what expectations should be for battery longevity under different use-case scenarios that can be used as a basis for modeling or as a means of validating outputs. The expected total longevity of a battery system can be continually revised throughout the battery's life based on DOD, number of cycles, and battery age. Honing estimates of time until replacement has benefits for reserve account management and predictive maintenance scheduling.

\subsubsection{Energy Availability/Capacity Degradation}

Another key performance metric is capacity degradation of the batteries. It is important to monitor root causes of capacity degradation and carefully diagnose and respond to issues. There are a number of codes and standards that can guide this data collection and analysis.

There are several different approaches to assessing battery health, and they depend in large part on the type of battery and how they are used. For example, for lead-acid batteries, tracking voltage during charging and discharging cycles may be a valuable approach to comparing the relative health of strings within a battery bank. Comparing resistance across cells and between cells can also show signs of uneven degradation. For lithium-ion batteries, increases in battery resistance can point to reductions in battery capacity that stem from several types of electrochemical degradation within the battery (Neubauer 2014).

The ultimate goal of assessing battery health is to determine if the battery is degrading prematurely and, if so, whether the issues are being caused by charging or discharging approaches, temperature deviations from acceptable operating ranges, or typical loss from approaching the end of usable life (IEEE 1661) so adjustments can be made and reserve accounts can be adjusted based on revised useable life assumptions.

Temperature is an important input for understanding battery health and performance. Temperature readings can be valuable data points, and some battery instrumentation will track temperature deviations. Tools such as the Battery Lifetime Analysis and Simulation Tool (BLAST) or SAM can also be used to assess temperature behavior of batteries and estimate the 
impact on degradation. It is important to contextualize readings with temperature at testing time. For VRLA lead-acid battery testing, IEEE Standard 1188-2005 provides adjustments for testing being done outside ideal temperature conditions.

\subsubsection{Energy Delivery}

As with PV-only systems, energy delivery can also be included as a performance indicator for batteries. Throughput based on cycling and DOD is an important indicator for battery health and longevity, but energy delivery in $\mathrm{kWh} /$ year or $\mathrm{MWh} /$ year can also be tracked for financial and operational reporting.

\subsection{The PV O\&M Plan}

An O\&M Plan is recommended for all system sizes and types, but the plan for small residential systems might be very simple instructions on how to monitor system status and who to call if things go wrong. For larger utility or commercial scale systems a detailed PV O\&M plan prepared by the owner, EPC firm, and/or the developer and accepted by the asset manager is the only long-term operations plan for a PV system. The motivations of the EPC and the long-term operator may be different and they may clash - the EPC is more concerned with getting through the installation workmanship warranty period, but the operator is more interested in protecting the value of the system and his or her contractual agreements for many years. The O\&M manager retains in the plan archive all the initial planning, warranty, design, and other system specification documents and also revises the plan as the system is constructed, maintained, and modified over time. The O\&M plan provides the specific measures to achieve the level of performance specified by the KPIs in the Performance Work Statement.

An O\&M plan can accommodate different system configurations by including all the descriptions and measures for systems and adding the terms "if applicable"-for example, "lubricate tracking ring gear, if applicable." However, the scope of work and cost estimate for suppliers should itemize the measures to be performed based on system details affecting maintenance, such as the number and types of different inverters, fixed rack vs. tracker, rooftop vs. ground mount, and transformer vs. transformer-less system.

\subsubsection{PV and Energy Storage O\&M Plan Checklist}

A documented PV O\&M plan for a system or fleet of systems should include the following (depending on system size, complexity, and investment).

\begin{tabular}{|l|l|}
\hline $\begin{array}{l}\text { List of responsible-party contact information including site owner and offtaker of power, } \\
\text { utility, local jurisdiction, local landowner, and emergency numbers. }\end{array}$ \\
\hline $\begin{array}{l}\text { System documentation including as-built drawings, specifications, site plans, photo records, } \\
\text { special safety considerations, electrical single-line diagrams, schematics, drawings, installed } \\
\text { components' "cut sheets" and warranties (including warranties from system installer), } \\
\text { performance estimates, insolation/shade studies (including a description of nominal } \\
\text { conditions to make it easier to see malfunctions or deviations), operation manuals } \\
\text { associated with any of the equipment (including emergency shutdown and normal operating } \\
\text { procedures), and contracts for preventive maintenance, service, and other operations } \\
\text { documents, including contacts for each, and specified response times and availability. }\end{array}$ \\
\hline
\end{tabular}




\begin{tabular}{|c|}
\hline $\begin{array}{l}\text { Uphold manufacturers' preventative-maintenance measures to preserve warranties and to } \\
\text { optimize system energy delivery and the schedule for each. Include details such as cost and } \\
\text { current supplier of each preventive-maintenance measure and special instructions such as } \\
\text { hours that work is to be performed, access to site, and locations where vehicles may be } \\
\text { parked and equipment staged. }\end{array}$ \\
\hline $\begin{array}{l}\text { Include descriptions of operational indicators, meters, and error messages; descriptions of } \\
\text { any physical monitoring setup and procedures by which performance data are to be } \\
\text { archived and reported; and procedures by which data are regularly examined for system } \\
\text { diagnostics and analytics. }\end{array}$ \\
\hline $\begin{array}{l}\text { Keep an inventory of spare parts onsite or easily accessed by maintenance crew and } \\
\text { implement a process for determining when other spare parts need to be ordered based on } \\
\text { component failure history. }\end{array}$ \\
\hline $\begin{array}{l}\text { Clearly define availability and performance metrics and events outside of management } \\
\text { control. }\end{array}$ \\
\hline $\begin{array}{l}\text { Implement focused training program for all O\&M staff on processes relevant to each worker } \\
\text { and the equipment they may be working on. }\end{array}$ \\
\hline $\begin{array}{l}\text { Implement chronological O\&M log: work order and task tracking to include initial commission } \\
\text { report, inspection reports, and ongoing O\&M history. }\end{array}$ \\
\hline $\begin{array}{l}\text { Establish procedure for responding to alerts from monitoring diagnostics, error messages, or } \\
\text { complaints from the building owner. Compile a troubleshooting guide for common problems. }\end{array}$ \\
\hline $\begin{array}{l}\text { List all equipment with make, model, and serial numbers and map of placement in system } \\
\text { (to spot trends in manufacturing defects); for each piece, list a supplier of replacement part } \\
\text { (vendor). }\end{array}$ \\
\hline $\begin{array}{l}\text { Determine criteria to decide whether to repair or replace a component; criteria to decide } \\
\text { whether to "cannibalize" a string of modules to source replacement modules or to order new } \\
\text { parts; and criteria to decide if an energy storage system with declining energy storage } \\
\text { capacity should be replaced. }\end{array}$ \\
\hline Establish procedures for re-acceptance testing following a repair. \\
\hline $\begin{array}{l}\text { Budget for O\&M program including costs for monitoring and diagnostics, preventive } \\
\text { maintenance, corrective maintenance, and minimum exposure (line of credit) if replacement } \\
\text { of inverter or more expensive corrective maintenance is needed. }\end{array}$ \\
\hline $\begin{array}{l}\text { Plan for degradation in performance of and periodic replacement of Energy Storage System } \\
\text { but be prepared to revise the plan based on test results and actual battery system } \\
\text { performance. }\end{array}$ \\
\hline
\end{tabular}

\subsection{Use of O\&M Plan}

Following construction and commissioning, the O\&M plan is the only surviving operational plan that contains the complete history of the plant in its archive. Therefore, it is critical to ensure that the O\&M plan is well documented and safely archived. 
- Ensure, by establishing a well-organized directory, that a well-documented and maintained O\&M plan is available for each system in the fleet, along with a preventive maintenance schedule

- Maintain a tracking log for customer-driven alerts for corrective maintenance and any measures taken on a system; include up-to-date document service histories for each installation

- Maintain the O\&M plan in an online mobile work-order management system (there are dozens); use a ticketing system to record work

- Include decommissioning in the PV O\&M plan and/or asset management.

\subsubsection{O\&M Plan for Residential/Small Commercial PV Systems}

The residential and small commercial O\&M focus is on fleet performance goals rather than individual systems; meeting performance warranties of individual systems to meet customer satisfaction goals should be balanced against cost and cash-flow optimization. These PV systems are typically simple, small, and geographically spread out over different metropolitan areas and states. The aim of the operations team is to minimize "truck rolls" and efficiently schedule any needed work.

\subsubsection{O\&M Plan Considerations for Residential and Small Commercial}

\begin{tabular}{|l|l|}
\hline & $\begin{array}{l}\text { System should be installed according to SAPC PV System Installation Best Practices Guide } \\
\text { (http://www.nrel.gov/docs/fy15osti/63234.pdf). }\end{array}$ \\
\hline $\begin{array}{l}\text { Small commercial and residential onsite inspections are the responsibility of the contract } \\
\text { offtaker (small commercial) or homeowner (residential). Often the small size precludes the } \\
\text { use of automated monitoring (although developments, such as micro-inverter or power } \\
\text { optimizer communications, are making automated and remote monitoring more feasible). }\end{array}$ \\
\hline $\begin{array}{l}\text { Any inspection of fleets of small systems is usually on a representative sample rather than } \\
\text { every system. }\end{array}$ \\
\hline $\begin{array}{l}\text { Performance guarantees should consider typical amounts of malfunction (e.g., one string } \\
\text { fuse) and soiling to ensure insignificant corrections can be deferred and module cleaning } \\
\text { and snow removal (by turbofan) is not provided. Treat extreme soiling situations as } \\
\text { corrective maintenance. }\end{array}$ \\
\hline $\begin{array}{l}\text { A manual should be provided to the homeowner with contact information and description of } \\
\text { operational indicators and procedures he/she can do, including clear documentation that } \\
\text { states the customer is responsible for maintaining original insolation/shade study results by } \\
\text { completing routine bush and shrub trimming. }\end{array}$ \\
\hline
\end{tabular}

\subsubsection{O\&M Plan for Larger Commercial and Industrial PV Systems}

O\&M focus for commercial and industrial PV is more on the performance of individual systems rather than fleets and meeting performance warranties. The investment and revenue of large systems justifies more detailed monitoring for anomalies in performance and increased communications and sensors to trigger condition-based or corrective maintenance services and alerts. Module cleaning, snow removal (i.e., for access to and in front of modules, only from modules themselves in unusual circumstances where required, such as excessive weight of 
snow), and tree trimming, for example, should be included in the O\&M plan and schedule of services and based on the plant environment (e.g., dusty) and financial and performance goals. The PV O\&M cost tool supports modeling of different regimes (see Appendix B). One of two reference modules could be cleaned to compare and evaluate the effect of cleaning; this information could be used to trigger a cleaning based on cost.

\subsubsection{O\&M Plan Considerations for Commercial and Industrial}

Key considerations for an O\&M plan for systems larger than $500 \mathrm{~kW}$ include the following.

\begin{tabular}{|l|l|}
\hline & Automated monitoring with diagnostics to push error alerts triggering corrective maintenance \\
\hline $\begin{array}{l}\text { Continually analyzing performance information to optimize condition-based O\&M, such as } \\
\text { cleaning, and long-term issues, such as reliability trends }\end{array}$ \\
\hline $\begin{array}{l}\text { Providing offtaker with manuals containing contact information and descriptions of their } \\
\text { participation and responsibilities, self-inspection of the system, and what conditions } \\
\text { necessitate the O\&M provider to be notified of problems }\end{array}$ \\
\hline Providing offtaker with a shelter onsite for workers to meet and look at plans if size warrants \\
\hline
\end{tabular}

\subsubsection{O\&M Plan Considerations for Energy Storage Systems}

Key considerations for an O\&M plan for systems that involve energy storage include the following.

\begin{tabular}{|l|l|}
\hline $\begin{array}{l}\text { Plan for a steady decline in capacity of the energy storage system, consider the storage } \\
\text { requirements at the end of the battery life, and set criteria for when the capacity is } \\
\text { insufficient and the battery will be replaced; plan for contingency that the battery will not last } \\
\text { as long as the manufacturer claims-in field applications, batteries may only last half as long } \\
\text { as manufacturer literature suggests. }\end{array}$ \\
\hline $\begin{array}{l}\text { Consider non-invasive monitoring of battery health; maintain good records so that decline in } \\
\text { energy storage system capacity and efficiency are charted relative to as-new performance. }\end{array}$ \\
\hline $\begin{array}{l}\text { Ensure that charge control is specific to the type and configuration of battery installed and } \\
\text { that charge rates are corrected for temperature and within the specified limits of the battery. }\end{array}$ \\
\hline $\begin{array}{l}\text { Provide for demand control (load control) to ensure that specified limits are observed for } \\
\text { battery discharge rates and DOD-this may require that the load be curtailed to prevent low } \\
\text { DOD (e.g., low voltage disconnect). }\end{array}$ \\
\hline $\begin{array}{l}\text { Provide for heating and cooling of battery enclosure to keep batteries within specified } \\
\text { temperature limits and ensure that air flow is effective at removing heat from batteries. }\end{array}$ \\
\hline $\begin{array}{l}\text { Do not mix old cells of high impedance with new cells of low impedance in the same string, } \\
\text { which would result in higher voltage and sulfation in the high impedance cells. Sulfation } \\
\text { further increases internal resistance, exacerbating the problem. Replacing failed cells with } \\
\text { new batteries kills the remaining old batteries more quickly. Consider cannibalizing a string } \\
\text { of cells with similar impedance and then installing new cells in a new string under separate } \\
\text { charge control. }\end{array}$ \\
\hline
\end{tabular}


Have a fund (i.e., reserve account, line of credit, sinking fund) to supply an eventual battery replacement. Battery maintenance costs increase as a battery plant ages, so have a strategy of when to replace batteries and how to do so in a phased way so that some service to the load can continue.

\subsection{Document Management and Record Keeping}

Documentation is essential to O\&M services, and important records include the physical condition of a PV plant, current contracts for services, insurance policies, tax records, proof of ownership, compliance with regulations, warranties and the terms to keep warranties in effect, records of past changes to the system, and records of past corrective maintenance services and the results of each. Before undertaking any maintenance service, the service provider must know what equipment was installed initially and any changes that have been made since. If not available, such records should be created (complete set of as-built drawings) at the cost of the asset owner. Some problems are difficult to diagnose and solve, so records of what has been attempted previously are often essential for eventually correcting the problem. Good record keeping of work orders and trouble tickets is required to ensure that each issue is ultimately resolved.

A document management system provides proper storage, access control, change control, and backup of essential data. A log should be kept of who has accessed the documents, who has taken them out, and what modifications were made, if any. Version control should be implemented so that people can see what document is currently in effect and can look at the history of the document.

\subsubsection{Document Management Checklist}

Considerations for managing documents in a structured document management system include the following.

\begin{tabular}{|l|l|}
\hline $\begin{array}{l}\text { Maintain list of responsible party contact information including site owner and offtaker of } \\
\text { power, utility, local jurisdiction, local landowner, and emergency numbers. }\end{array}$ \\
\hline $\begin{array}{l}\text { Maintain list of all equipment with make, model, and serial numbers and map of placement } \\
\text { in system. }\end{array}$ \\
\hline $\begin{array}{l}\text { Maintain all documents produced by the EPC, including as-built drawings (e.g., plant } \\
\text { location, property boundaries, plant layout, electrical diagram), specifications, product data } \\
\text { sheets, and wiring diagrams. }\end{array}$ \\
\hline Maintain operating manuals for inverters and other equipment. \\
\hline Maintain documentation of health and safety issues and rules. \\
\hline Maintain records and reports from commissioning, re-commissioning, and inspections. \\
\hline $\begin{array}{l}\text { Maintain past and current contracts with all service providers and suppliers' names, start } \\
\text { and end dates, scope of work, contract value and pricing, performance indicators and } \\
\text { guarantees, and contract clauses. }\end{array}$ \\
\hline
\end{tabular}




\begin{tabular}{|l|l|}
\hline $\begin{array}{l}\text { Maintain preventative maintenance and inspection records (proof that preventive } \\
\text { maintenance required to keep warranties in effect has been completed), as well as } \\
\text { corrective maintenance event logs [alarms (with date); status (problem flagged, cause } \\
\text { identified; pending, action taken, confirmed that problem is solved); corrective action taken } \\
\text { and date; who did the work with contact information]. }\end{array}$ \\
\hline $\begin{array}{l}\text { Maintain an inventory of spare parts: stock count and location, names and part numbers, } \\
\text { date purchased. }\end{array}$ \\
\hline $\begin{array}{l}\text { Maintain all warranty documentation: warranty documents and claims made (affected } \\
\text { equipment, claim description, occurrence date, correspondence with manufacturer/supplier). }\end{array}$ \\
\hline $\begin{array}{l}\text { Document environmental (weather) conditions: meteorological data (insolation in plane of } \\
\text { array, temperature, other such as wind speed). }\end{array}$ \\
\hline $\begin{array}{l}\text { Document production data: AC active and reactive power at point of interconnection, power } \\
\text { consumption of auxiliary systems and "house power," power at other subsystems such as } \\
\text { DC power into inverter, and other measurements as available. }\end{array}$ \\
\hline
\end{tabular}

\subsection{PV Plant Operations}

PV systems are often thought of as passive systems without much "operation" as a conventional fossil-fuel engine. However, operations programs that consisted largely of delivering solar power whenever it was available are becoming obsolete. PV system operations is a growing field because increasing PV penetration into the larger utility system and an emerging market for ancillary services (e.g., dispatch of storage, sourcing reactive power, curtailment of output) require more system interaction on an ongoing basis. Plant operations include forecasting output, scheduling maintenance operations, creating a spare parts inventory (either in stock onsite or in supplier's consignment stock), and inspecting work and approving invoices. Meanwhile, operations include any day-to-day operation of the system to maximize power delivery, assess performance and trends, operate grid interface, manage curtailments, or adjust settings such as power factor.

\subsubsection{Forecasting PV Plant Output}

Plant operations include forecasts of power and energy delivery hours and days in advance. Suppliers of PV monitoring systems often also supply production forecasts based on proprietary or publicly available weather forecasts, satellite data, and statistical methods. In addition to these weather-based forecasts, the operator should impose any scheduled outages or maintenance services that affect the forecasted plant energy delivery. Forecasts are important for two applications:

- Allow PV systems to participate in markets that require advance (e.g., "day-ahead") contracts to provide power. Such contracts come with an associated level of reliability and financial penalty for non-performance, so an accurate forecast is essential to participate in such day-ahead markets.

- Allow for unit commitment and dispatch of conventional resources (e.g., diesel generator), which is essential in a micro-grid application or for a remote system (such as on an island out in the sea) and is desirable in mainland grid-integration efforts. 
Metrics associated with forecasting systems include:

- Forecast horizon: How far in advance the system predicts PV plant energy delivery. Some provide a 2 -week forecast, but the second week appears to be the astronomical (sun position) forecast, and only the first week appears to incorporate site-specific weather forecast.

- Time resolution: When using conventional weather forecasting techniques, hourly is considered state of the art. To get higher time resolution may require onsite sky observations. Image processing instruments to project cloud movement have been invented and demonstrated but are not yet in commercial use. Likewise, models to predict cloud formation based on thermodynamics and transport phenomenon in the atmosphere are in their infancy.

- Update frequency: How often is the forecast updated? For example, one vendor updates its forecast every 4 hours.

- Accuracy: Accuracy of the forecast can be proven over time by taking the root mean square error (RMSE) of the production forecast compared to actual plant output and considering other factors such as if parts of the plant are dirty or out of service for maintenance.

\subsubsection{Energy Management Control Approaches for PV Plus Storage Systems}

Energy management (control) systems become a critical element of system economics when a battery is paired with solar PV. There are a number of different energy management approaches that are applied to PV plus storage systems. The selection for a given context will depend on constraints based on system design and topology, markets, and costs. In a residential setting for a system that is AC-coupled, the interconnection requirements and relevant regulations may preclude storing grid energy, and the algorithm may be as straightforward as pushing excess solar energy into the battery and then using the battery until it reaches minimum charge levels whenever the solar PV is not generating electricity. On the other hand, a micro-grid that has solar $\mathrm{PV}$, a battery, and a diesel generator can have a much more complicated control algorithm and requirements on control solutions. If demand management is introduced as another option, the possibilities to optimize system performance and cost savings expand but so does the complexity of the supporting energy management and control systems.

\subsubsection{Control Approaches}

This subsection discusses some of the issues to consider in settings where there is flexibility in control approaches, such as the PV, battery, and diesel generator use case mentioned above.

In residential grid-connected settings, the control algorithm decisions tend to be more narrowly bounded than in other use cases. The systems are fairly small, the customizations are limited, and the economics at play are more straightforward. As discussed above, the most common approach is to take advantage of the battery to maximize usage of the power that is being generated by the PV to minimize curtailment during the day. A modification of this approach, which is contingent on rate structures that include meaningful price changes during peak periods, is time-of-use shifting using the battery. This would again call for limiting curtailment during the day but then also discharging the battery to meet household loads during peak charge times. 
In commercial or industrial settings, the control choices will be driven in large part by the rate structure and load profile. For example, demand charge management through a PV plus storage system dictates the strategy for when to discharge the battery and when to charge it. In these situations, the control algorithm will be more complicated and likely call for some degree of forecasting and monitoring PV power, load profiles, and demand charges. The approach that comes from that modeling exercise will be custom to each individual commercial or industrial customer.

In utility settings of avoiding curtailment, model predictive control algorithms may be applied to take forecasts and wholesale market pricing into account. There are also settings where the battery can serve a ramp-rate control function in addition to the time-of-use shifting application, which has operational and control algorithm ramifications.

\subsubsection{Inventory of Spare Parts}

The O\&M service provider is usually responsible for stocking spare parts, but the asset owner may also participate in spare-parts ownership and storage. Parties should agree on "bailment," which is liability if the parts are stolen or damaged in storage, and the party providing storage should have insurance to mitigate such risk. Storage should provide for security (e.g., theft, vandalism), storage conditions (e.g., temperature, humidity, moisture), and organization (e.g., first in-first out, do not mix new and returned parts).

As part of the O\&M manual and system documentation, the EPC contractor should have provided a spare-parts list with makes and model numbers, as well as recommended sources of such parts. Frequently used parts are called "consumables" and should always be stocked (e.g., fuses, filters, nuts, and bolts). The number of other spare parts in inventory depends on several factors: the reaction time required by the O\&M contract, the allowable downtime, contractual commitments, and potential for liquidated damages. The higher the desired (or contractually required) availability for a plant, the more spare parts will have to be kept in inventory.

As discussed in more detail below regarding a cost estimate for a reserve account, the number of replacement parts to keep in inventory, $n$, depends on the total number of parts (of that component) in the system, $\mathrm{N}$; the probability that a part will fail in a given year, $\mathrm{P}$; and the desired reliability, $\mathrm{R}$, according to the relationship $\mathrm{n}=\mathrm{N} * \mathrm{R}^{\wedge} \mathrm{P} /(1-\mathrm{P})$. The cost of maintaining this amount of inventory must be weighed against the time delay in obtaining parts not in the inventory and the consequences of down time. Experience with this equation indicates that it is prohibitively expensive to stock parts to maintain a desired reliability of greater than approximately 0.95 . Experience in operating the plant (i.e., which parts fail, which failures result in lost production) will help fine-tune the inventory of spare parts.

Strategies to reduce the cost of maintaining an inventory of spare parts include:

- Maintaining regional clusters of systems surrounding a warehouse to share stock and reduce travel time; sharing spares for long-lead-time items such as inverters and transformers among multiple projects in a portfolio

- Standardizing certain makes and models to reduce diversity in stock

- Making arrangements with suppliers to guarantee availability or consignment stock with the manufacturer. 


\subsubsection{Compliance with Regulatory Requirements}

Large PV power plants (i.e., greater than $20 \mathrm{MW}$ at the utility interconnection) that provide power into the bulk power system must comply with standards related to reliability and adequacy promulgated by authorities such as NERC and the Federal Energy Regulatory Commission (FERC). This requires that an operator trains and certifies personnel and demonstrates compliance with multiple requirements specified in standards. NERC and FERC regulations require that the operator establish and maintain a listing on the NERC compliance registry as a generator owner (GO) and generator operator (GOP) and provide and document such things as cybersecurity and critical infrastructure protection, emergency preparedness plans, reactive power and voltage control, services during and after disturbances, active power control, harmonics, facility interconnection studies, and communications (voice and data link) between plants and grid operators. PV plant operations increase quite a bit and impose additional maintenance requirements if the plant operator is registered by NERC as a GOP. Most of the services and associated costs are associated with the systems and security that come regarding the documentation process. There is also a risk of incurring costs associated with not meeting the FERC/NERC requirements.

\subsubsection{Operations Checklist}

Operations considerations include the following.

\begin{tabular}{|l|l|}
\hline $\begin{array}{l}\text { Is system performance monitored and recorded? Are trends in performance examined } \\
\text { continuously or regularly? }\end{array}$ \\
\hline $\begin{array}{l}\text { Does the monitoring supplier provide forecasting? At what horizon, time resolution, update } \\
\text { frequency, and accuracy? }\end{array}$ \\
\hline Are corrective maintenance response times specified in the contract? \\
\hline Is module degradation rate specified? \\
\hline Are all service contracts and insurance policies kept up to date? \\
\hline Are all required operating permits, compliance documents, and licenses kept up to date? \\
\hline
\end{tabular}

\subsection{Preventive/Scheduled Maintenance}

Preventive maintenance maximizes system output, prevents more expensive failures from occurring, and maximizes the life of a PV and energy storage system. Preventive maintenance must be balanced by financial cost to the project. Therefore, the goal is to manage the optimum balance between cost of scheduled maintenance, yield, and cash flow through the life of the system. Preventive maintenance protocols depend on system size, design, complexity, and environment. A comprehensive list of these protocols is supported by the PV O\&M cost model included in Appendix B.

The requirements for periodic maintenance for energy storage products should be identified by the OEM (IEEE 2010). In settings where predictive analytics maintenance is economical, 
guidance should also be available from the manufacturer that identifies methodologies for assessing when a product may be approaching a failure mode.

As discussed briefly in Section 5, design aspects of storage systems will inform scheduled maintenance cost and benefit analysis. For example, in some systems, it is preferable to build the battery bank in multiple separate strings so that maintenance can be made on a single string without shutting down the full battery and all the storage-tied components. Data granularity also has a bearing on what preventive maintenance is deemed economical. For example, real-time cell-level data have the potential to identify and justify preventive maintenance that may not be visible at the battery string or battery bank level.

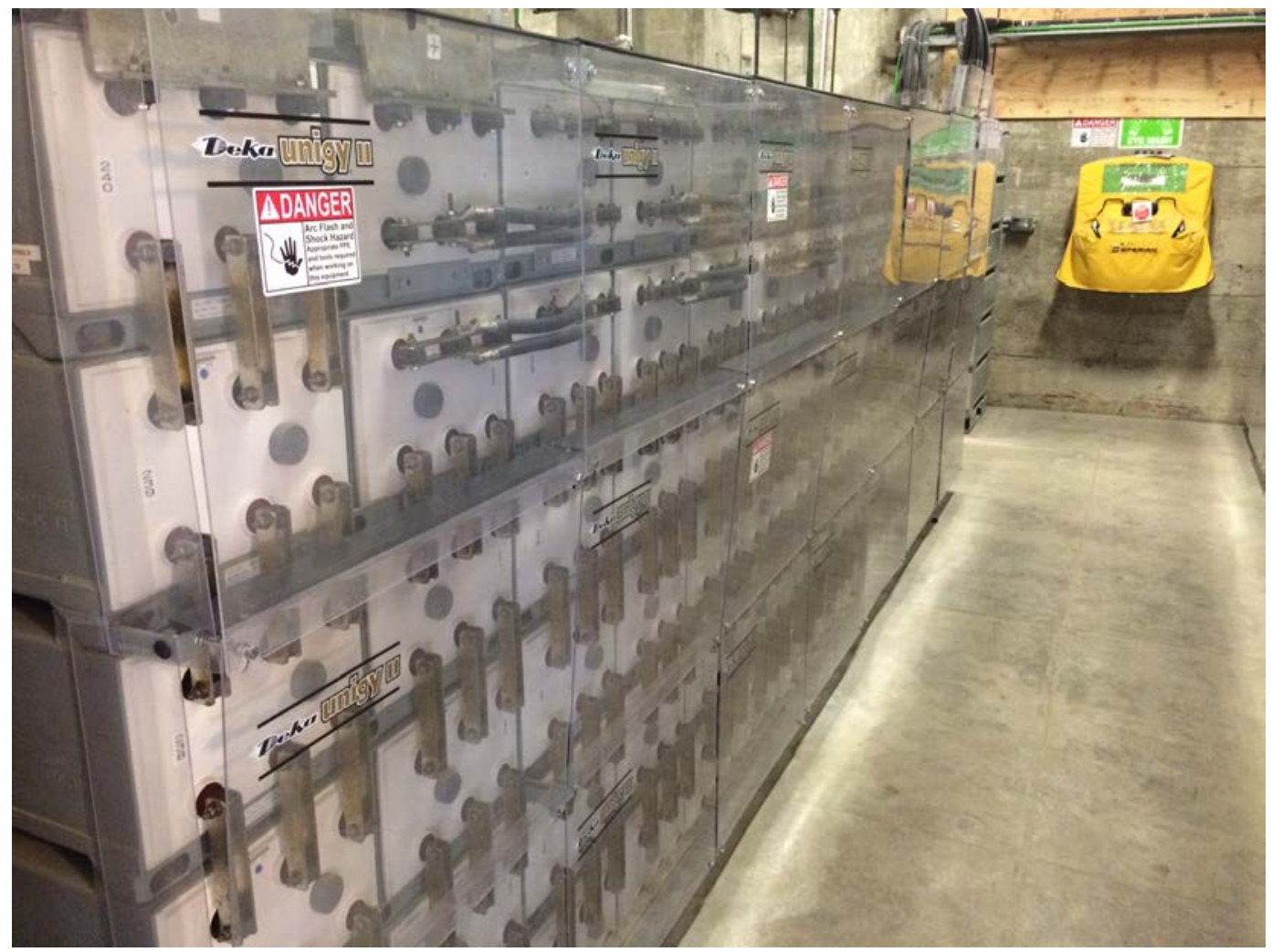

Figure 13. The National Park Service budgets, ideally, $\$ 100,000$ per year for O\&M of this PV energy storage system (308 kW PV; 1,920 kWh battery) on Alcatraz Island. Photo by Andy Walker, NREL

Figure 13 shows the PV energy storage system on Alcatraz Island. The National Park Service budgets ideally $\$ 90,000-\$ 100,000$ /year for maintenance of this $1,920-\mathrm{kWh}$ battery storage plant, including a monitoring contract for $\$ 30,000$ /year; battery testing for $\$ 5,000$ three times/year; and $\mathrm{PV}$ array cleaning and maintenance for $\$ 15,000$ twice per year. There are 480 cells in two strings of 240 cells each, and O\&M staff feel that more parallel strings would ease maintenance scheduling. Battery replacement is planned on an 8-year cycle. Battery replacement provides an opportunity to revisit battery type, size, and voltage. Inverter replacement is planned on a 10year cycle and battery management system on a 7-year cycle (information from Jeff Obirek, National Park Service, provided for a tour March 2016). 


\subsection{Corrective Maintenance}

Lost revenue accrues while a system is down or when output is reduced. Repairs should be delayed only if there is an opportunity to do the repair more efficiently in the near future.

Response time for alerts or corrective action for the O\&M function should be specified as part of the contract but typically will be 10 days or less for non-safety-related corrective maintenance service. For small residential systems, a fleet operator may make repairs only when enough work has accumulated to justify a truck roll to the area or at the next regularly scheduled preventive/inspection of a site. Appendix $\mathrm{C}$ contains service descriptions for corrective maintenance selections available in the PV O\&M cost model. This cost model (described in Section 11) provides an estimated prediction of the corrective maintenance costs from year to year, but it is impossible to accurately predict when and where failures will specifically occur. The model has the ability to use fault and failure probabilities of specific components, if known.

Additional considerations include the following:

- The O\&M plan should include how to perform corrective maintenance quickly in response to field failures, including how funds may be used from a reserve or line of credit.

- Response time and urgency of repair specified in the O\&M plan should balance the cost of a "truck roll" with lost revenue. Consider system size, geographic location, spare-parts inventory, other scheduled maintenance, fleet performance requirements, and cost of response.

- Faults or conditions that introduce a safety problem should be addressed as soon as possible, even if the recovered revenue is small.

The O\&M plan should include procedures for replacing batteries, including relevant safety requirements for handling and transporting batteries. Strategies for replacing batteries vary based on system topology and battery technology. For example, with VRLA lead-acid batteries, replacing individual cells in a string may not be optimal if the system has been running for a period of time. The imbalance in the resistance between the new and older cells (even if functional relative to degradation expectations) can cause the new cells to degrade faster than scheduled.

\subsubsection{Enforcement of Warranties}

There is a distinction between "product warranties" and "performance warranties." Product warranties cover materials and workmanship and protect a purchaser against failures due to manufacturing defects (Figures 14 and 15). Most solar panel manufacturers provide product warranties of 10-12 years, although some are as short as 5 years and one extends for 25 years. The performance warranty guarantees a certain power output that declines over time because the manufacturer knows that there will be some natural degradation in the performance, usually ending up at $80 \%$ of the initial rating after 25 years. PV modules are unique in that they carry very long-term performance warranties of 20 or 25 years (very few types of electrical equipment have such long warranties). The schedule of the decline in anticipated power output has an impact on the value of the warranty, with manufacturers offering a linear decline in the guaranteed output, claiming that they provide a benefit over those that reduce the guaranteed performance in a stair-step fashion. In the past, inverter warranties were only for a 1-year term, but starting initially with European manufacturers, a 10-year warranty is now more the norm, 
with some offering the longer term only along with a 10-year service contract. The EPC contractor may offer a shorter-term warranty (e.g., 1-year, 2-year) on the entire plant including civil works such as storm-water management.

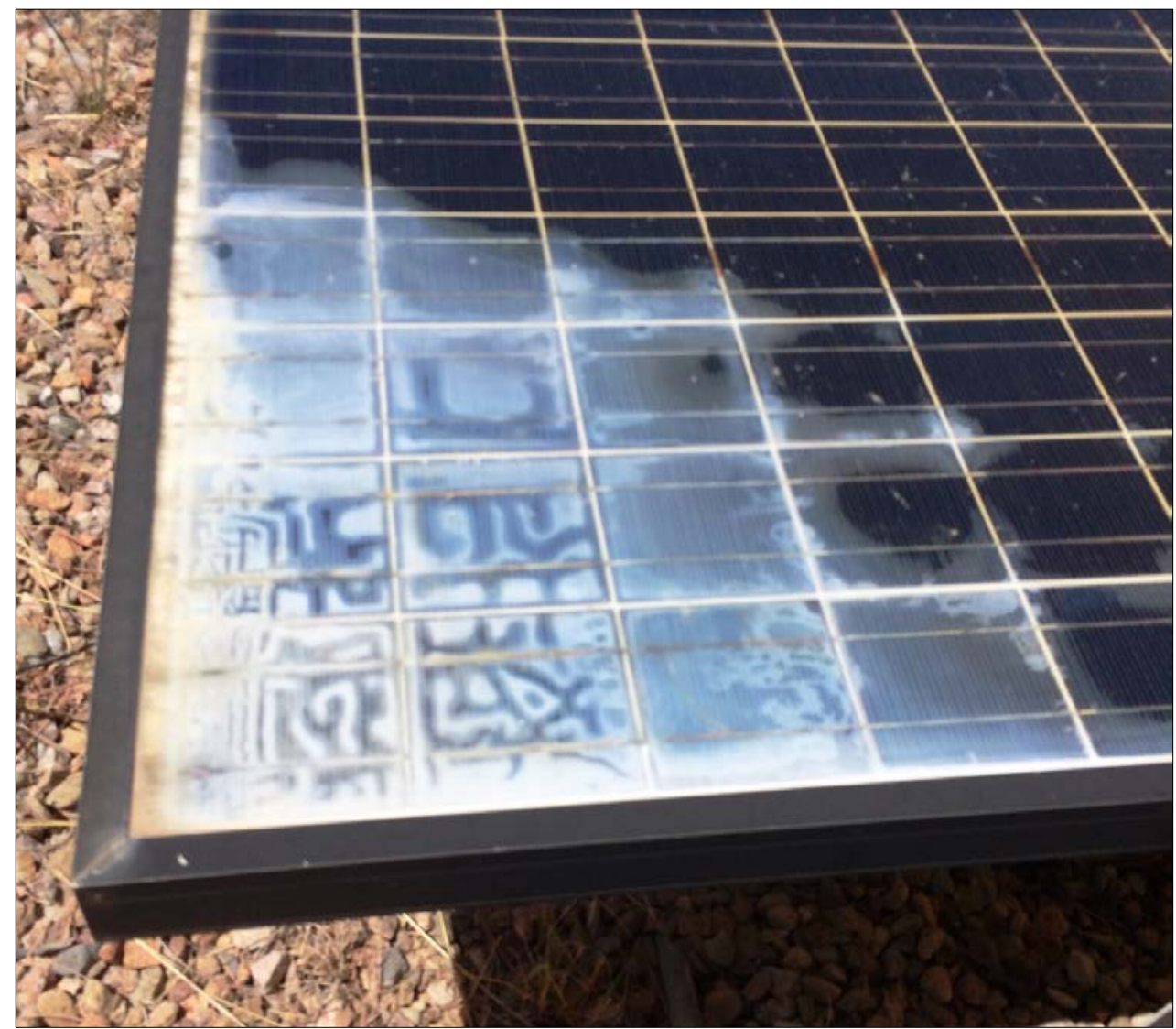

Figure 14. Failure in materials and workmanship, such as encapsulant of this module, are often covered by product manufacturer's warranty. Photo by Andy Walker, NREL 


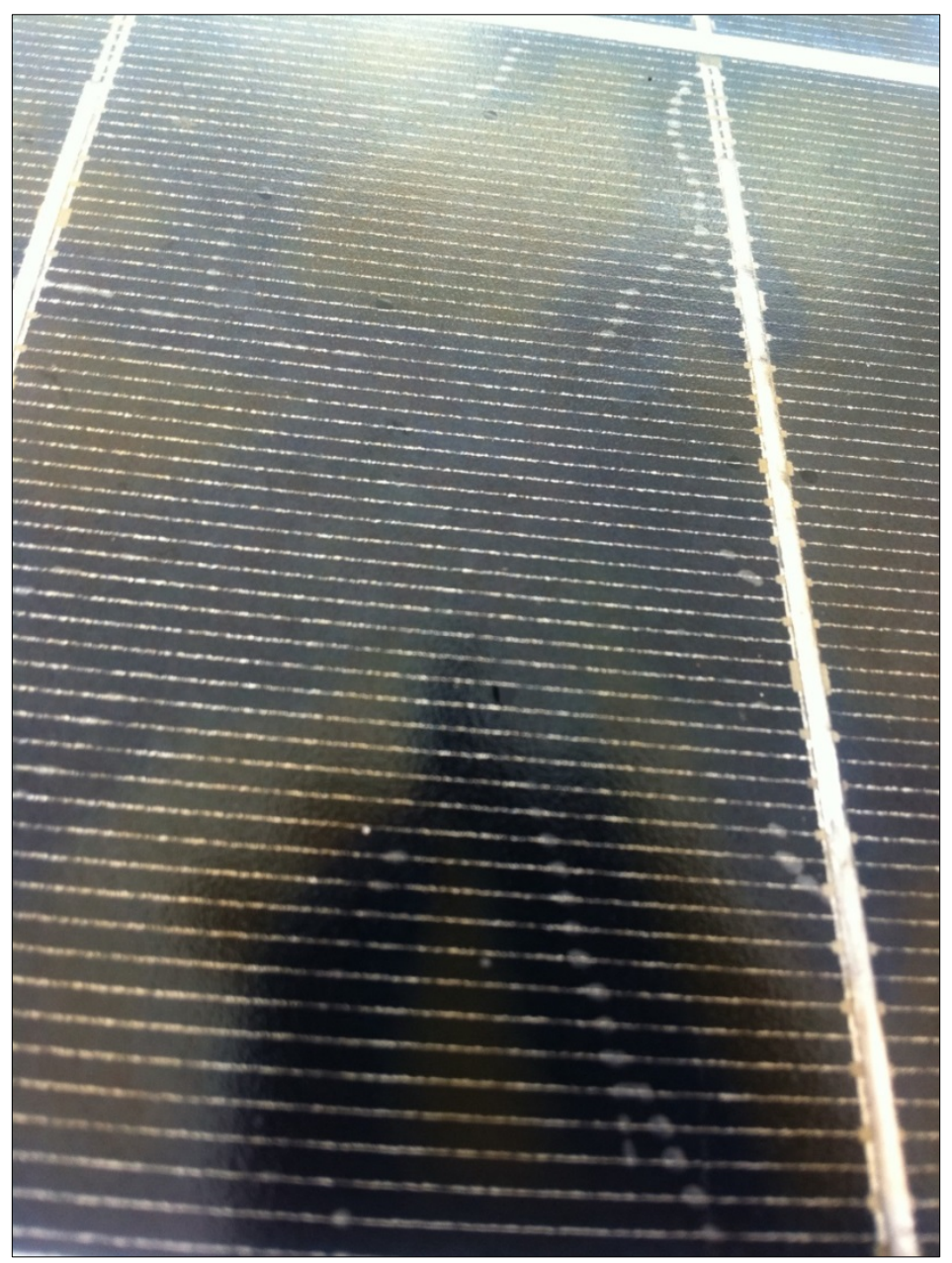

Figure 15. Snail trails in encapsulant are attributed to cracks in cells caused by flexure of the panel at the factory, shipping, or installation. The module would be covered by the performance warranty only if the cracks isolate fragments of the cell and reduce the output over time. Photo by Andy Walker, NREL

Many financiers do not have faith in manufacturer's warranties for the following reasons:

- A warranty may be voided by mishandling or not observing instructions or conditions of the warranty. For example, storing modules improperly onsite, such that the packaging is destroyed by rain, may void a warranty (Figure 16). Failure to provide adequate ventilation may void an inverter warranty.

- Even reputable PV manufacturers with quality products have gone out of business.

- It is difficult to prove that a module is underperforming, and it might require an expensive standardized test of each module.

- The manufacturer's warranty might cover replacement but not labor to remove, ship, and re-install an underperforming module. In marketing literature and proposals, the dealer may offer to cover these labor costs, but such language rarely makes it into the final contract because small local dealers are not in the position to incur such costs.

- The warranty often gives the manufacturer the option to "repair, replace, or supplement," with "supplement" meaning to provide modules to make up the difference in lost power. For example, if a system has 100 modules that are underperforming by $5 \%$, the guarantor 
could satisfy that by providing five additional modules to make up for the lost power, rather than replacing the 100 modules. However, increasing the plant size by five modules to restore guaranteed power might not be possible due to lack of rack space or electrical infrastructure. Also, expanding the system "nameplate" capacity would generally trigger a new interconnect agreement and permitting, even though it would generate no more than the initial amount of power.

- Manufacturers often have the option of paying a cash-value equivalent to the lost capacity of underperforming modules, but as the price of modules declines, this might be less than originally paid for the modules. Given the complications described above, this option is often preferred by system owners unless there is a required level of performance that must be maintained. 


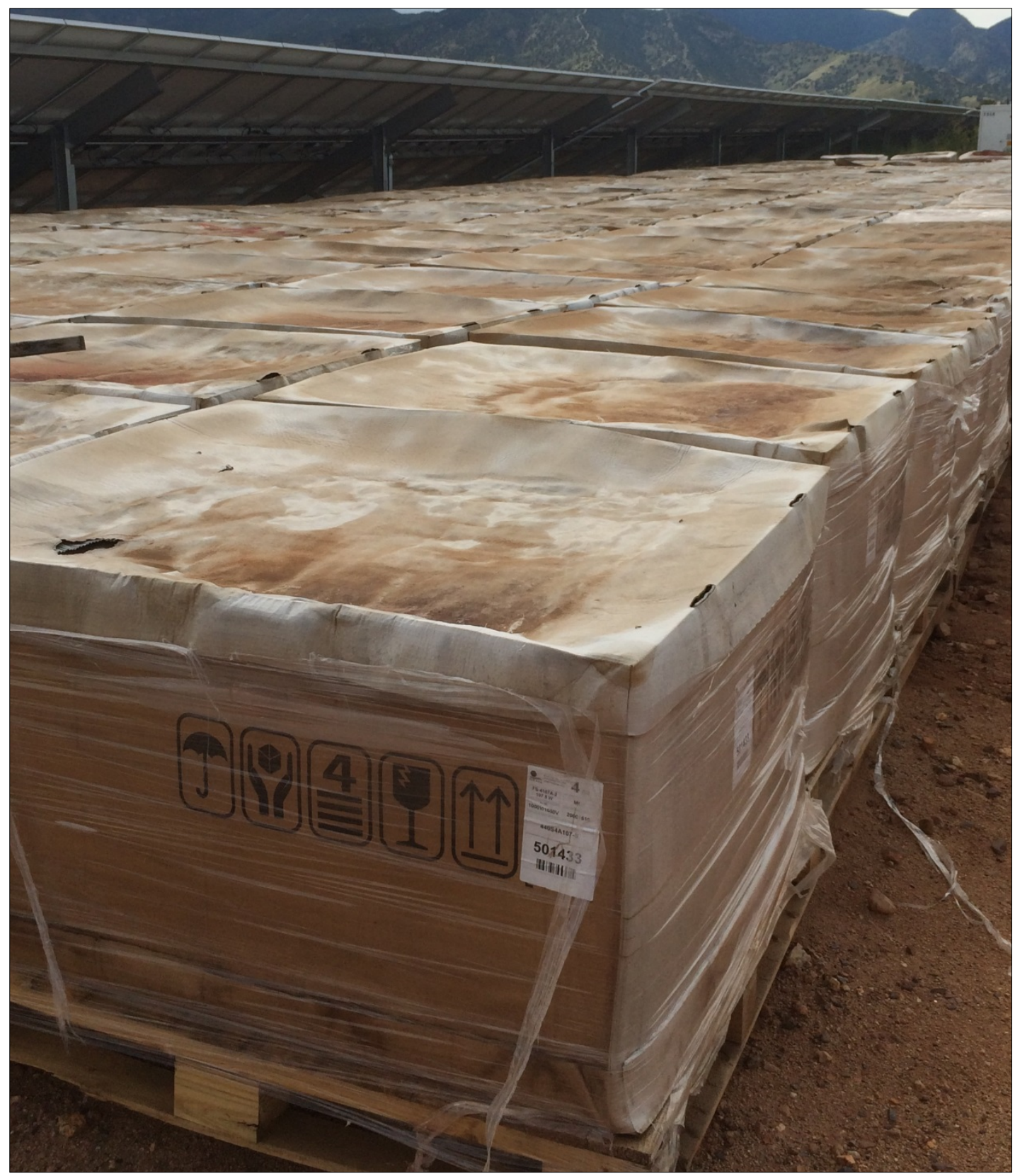

Figure 16. Failure to follow product box handling and storage requirements can cause damage when moved and void a warranty. The umbrella symbol on this box indicates it should be kept dry and the box might fail when picked up with a forklift. Photo by Andy Walker, NREL

Financiers take warranties into account in their financial prospectus only when offered by larger, more reputable, or more diversified companies with a sound credit rating. To hedge risk, warranty insurance is available from insurance companies, but adding the cost of such insurance to a project reduces the ROI or may make a competitive bid too high to get the contract. The cost of such insurance is lower for portfolios than for individual projects because risk is mitigated by a diverse collection of manufacturers - if one manufacturer goes out of business, it would affect only part of the portfolio (Ben Cook, NextPower Capital; Michael Bishop, ONGRID Solar; and Mike Borger, RECSolar, telephone conversation, September 23, 2016.). 


\subsection{PV Module Degradation Rate; Degradation in Energy Storage Capacity}

When comparing measured performance to predicted performance, it is important to consider the expected degradation in PV module output over time in the prediction. Prior to 2000, degradation rates exhibited considerable variability; currently, these rates are more uniform among types and manufactures and are often on the order of $0.5 \%$ per year (Jordan and Kurtz 2012). However, module degradation rates are only part of the story. As modules degrade, they do so at varying rates. This causes an induced circuit-level mismatch loss that should also be modeled. Some module-level power electronics (MLPE) solutions have the advantage of minimizing this added mismatch loss.

This is not to be confused with the failure rate of modules. PV module failures are rare, with a reported failure rate of $0.025 \%$ year to $0.1 \%$ /year (Dhere 2005), depending on the source.

Measured and predicted performance can be compared using a module degradation value given by the manufacturer. If no value is available, one can assume a default value of $0.5 \%$ per year for new crystalline silicon products.

Degradation is calculated based on the age of the system at the time of evaluation. But for life cycle cost analysis, a degradation factor of 0.94 provides an estimate of the degradation levelized over a 25-year lifetime with a 5\% discount rate.

Module type does not have a large effect on raw O\&M cost (\$/year), but it has a tremendous effect on cost of O\&M per kilowatt-hour delivered - especially late in the performance period when production is markedly decreased, failure rates are higher in the aged equipment, and inflation has increased the per-unit O\&M costs. The impact of O\&M costs on levelized cost of energy (LCOE) is much less with PV modules that have lower degradation rates.

Table 3. Representative PV Module Degradation Rates (Jordan and Kurtz 2012)

\begin{tabular}{|l|c|}
\hline \multicolumn{1}{|c|}{ PV Module Type } & $\begin{array}{c}\text { Degradation Rate per Year } \\
\text { (\%/year) }\end{array}$ \\
\hline Amorphous silicon (a-Si) & 0.87 \\
\hline Monocrystalline silicon (sc-Si) & 0.36 \\
\hline Multicrystalline silicon (mc-Si) & 0.64 \\
\hline Cadmium telluride (CdTe) & 0.40 \\
\hline Copper indium gallium diselenide (CIGS) & 0.96 \\
\hline Concentrator & 1.00 \\
\hline
\end{tabular}

Degradation rates in batteries depend heavily on usage, temperature, and shelf life. OEMs will typically provide a chart that pairs anticipated cycling with DOD, which can be used to model 
use-case-specific degradation rate expectations. That approach will produce an estimate that should be cross-referenced with actual data from the battery over time. Battery lifetime in field applications is often about half of that in manufacturers' literature, most likely due to overheating and, for many PV applications, long periods at low state of charge. Energy storage systems used in PV applications are usually discharging their capacity and then waiting for the solar resource to recharge, in contrast to energy storage applications that can keep the batteries under optimal float voltage and maintain long battery life.

\subsection{Example Work Statements}

A contract to implement an O\&M plan or part of an O\&M plan should include a complete list of obligations under the contract. Examples of commercial-system work statements are detailed in Appendix E; the statements contain a maintenance "Schedule of Services" typically found as an addendum to an O\&M contract comprising a fixed contract fee, with provision for an added time-and-materials cost adder for non-warranty corrective maintenance. Schedules are included for commercial rooftop and ground-mount systems. Appendix F outlines the foundation for developing language that can be utilized in model equipment availability terms typically included in an O\&M services agreement for a PV system and between a plant owner, operator, and O\&M services provider.

\subsection{End-of-Performance Period}

The economic prospectus for a PV project contemplates an initial investment followed by a long performance period. Life cycle cost standards specify a maximum of 25 years for electrical equipment (10 CFR 436), but there is evidence that PV systems could last longer and some industry guidance suggests a 40-year analysis period (EISA 2007). Asset owners and managers will have several options at the end of the performance period depending on the contractual commitments to the landowner and regulatory requirements of the authority having jurisdiction. These options include:

- Refurbishing the system and extending its life (e.g., 25 years to 40 years)

- Extending the term of the performance contract or PPA

- Selling the system at fair market value

- Removing the system and restoring the site to an earlier condition or other use.

The rate at which PV systems are being installed today will be equal to the rate of system disposition in 25 years or so. Relevant U.S. law here is codified under the U.S. Resource Conservation and Recovery Act (RCRA) governing non-hazardous waste (Subtitle D) and hazardous waste (Subtitle C). These laws assign responsibility to the generator of waste, although some PV manufacturers also practice extended producer responsibility (e.g., http://www.firstsolar.com/Modules/Recycling). Today's manufacturer may in 25 years become a recycler, or rather, a re-processor of PV modules and other components. Components should be designed for recyclability and to control toxic materials. Current best practices are to minimize hazardous materials and/or design for recyclability and control of such materials (IRENA 2016).

Such foresight in recyclability and management of substances may affect the eventual cost and benefits of end-of-life PV waste management. During project permitting, decommissioning plans may include site-restoration requirements and financial mechanisms to deal with recycling or 
proper disposal of waste. Such planning would likely consider the value of recovered copper, aluminum, and steel, which can be substantial.

Demonstration projects at SolarWorld and commercial-scale recycling operations at First Solar have shown that $84 \%$ to $90 \%$ by weight of a PV module can be recycled (Larsen 2009).

If a system transfers ownership, it is important to consider how warranties are handled. Often, manufacturers or EPCs will not honor the warranty if the original purchaser no longer owns the equipment. However, many manufacturers have a process for transferring the warranty to the new owner. Such a process typically consists of paperwork, a small fee, and a finalization period (usually 30 days) after the equipment sale. This service must be planned along with the rest of the ownership transfer process.

\subsubsection{Battery Failure Patterns}

As discussed above, batteries lose capacity and efficiency over time and with "throughput" or energy in and out of the battery. Manufacturing literature might cite a "cycle life" and often as a function of DOD. For lead-acid batteries, time spent at a low state of charge leads to irreversibility in the reaction and damage to the battery. This is cited as an advantage of battery material systems other than lead acid that can accommodate a deep discharge for long time periods.

Lifetimes of 1,000 or 2,000 cycles for lead-acid batteries are typical, with 10,000 cycles being the goal for research in new materials systems such as Lithium-ion. There is a gradual reduction in capacity over time beginning before the battery is even installed and increasing with use. So "lifetime" implies some criteria as to when the battery needs to be replaced. For applications where reliability is important, a cell whose capacity had fallen to $80 \%$ after 1,000 cycles would probably be slated for replacement, but in many applications, the battery could continue working until perhaps 2,000 cycles when its effective capacity will have fallen to $60 \%$ of its initial capacity or longer, as long as the user can live with the reduced capacity and as long as variability in the status of individual cells does not lead to physical or catastrophic failure. Figure 17 shows now not only the electrical performance but also the physical condition of the battery can affect the need for replacement. Actual capacity of a battery can be measured by a charge/discharge test, but this requires that operation of the battery be interrupted for the duration of the test. An alternative measure of cycle life is based on the internal resistance/impedance of the cell. In this case, the cycle life is defined as the number of cycles that the battery can perform before its internal resistance increases by a specified amount, such as 1.3 times the initial value. When battery systems are specified, it is usual to specify the required capacity at the end of life rather than its capacity when new. 


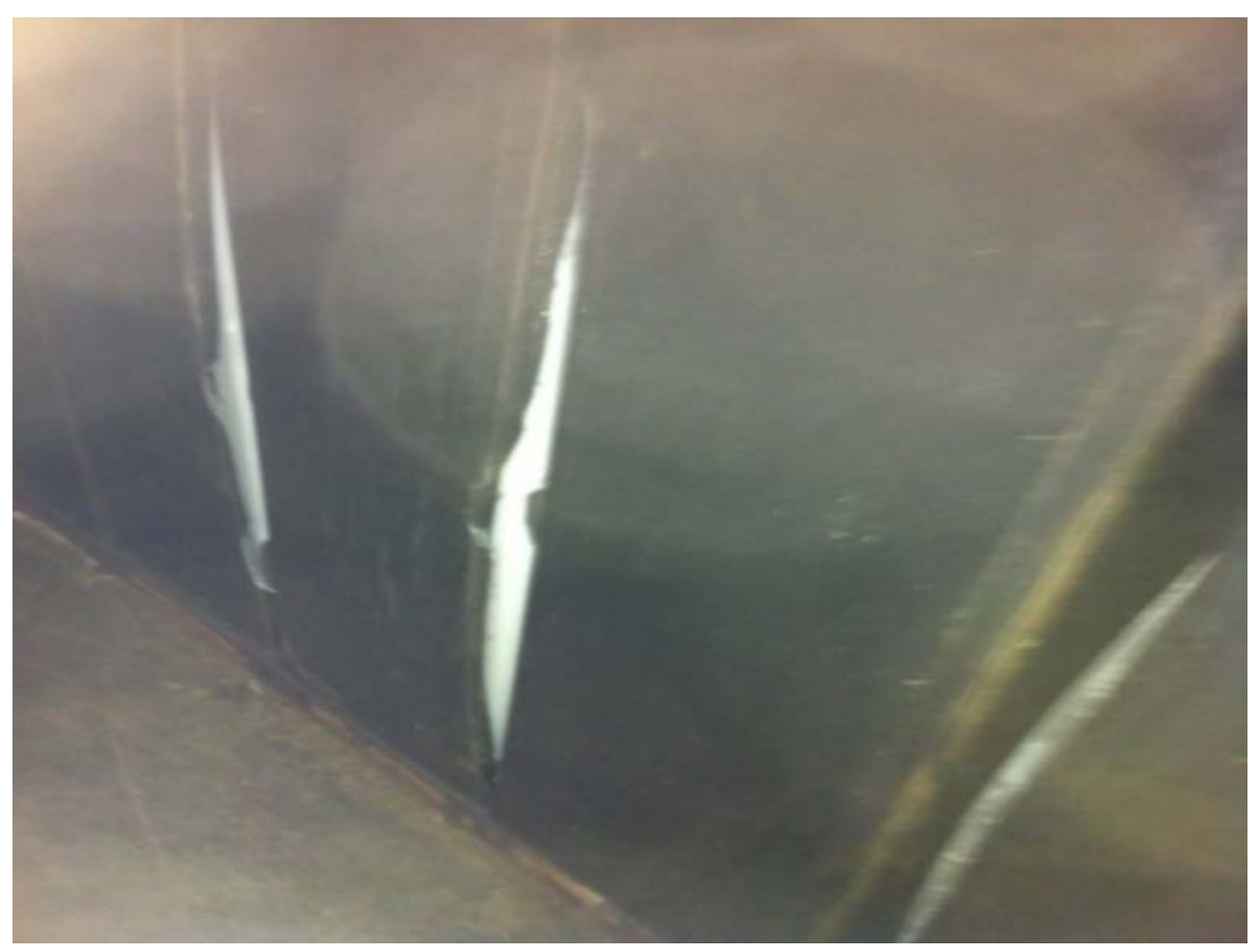

Figure 17. Premature failure of a lead-acid battery caused by low state-of-charge for an extended period of time can be avoided only by periodic fully saturated charge of the battery. A battery can recover from amorphous sulfation; but, given time to crystalize, the degradation in capacity and efficiency is permanent and can cause swelling and breakage of the battery jar. Photo by Andy Walker, NREL

\subsubsection{Battery Recycling and Reuse}

In combined PV and storage systems, the above end-of-life considerations apply, but batteries also bring their own end-of-life issues. It can be expected that batteries will be replaced two or more times during the typical life of the PV system they are anchored to. End-of-life disposition activities and options for batteries depend on the technology employed. In all cases the supplier or a community-based waste management solution takes the battery back for recycling. Consult with the supplier regarding disposal before purchasing a battery and for large battery purchases require a guarantee or bond that the spent batteries will be recycled. This subsection provides a brief background on lithium-ion and lead-acid end-of-life issues and associated recycling industries.

\subsubsection{Lead Acid}

Recycling lead-acid batteries in combined PV and storage settings benefit from widespread usage of lead-acid batteries in other industries, such as automobiles, and regulations on their disposition in many settings because lead is toxic. The regulation and the battery market size led to the development of a healthy recycling industry. Lead-acid batteries are also composed of roughly $65 \%$ heavy metals that support the economic case. Recovered lead can cost less than mined lead as a result (Gies 2015). 


\subsubsection{Lithium Ion}

Lithium-ion batteries are less regulated for end-of-life issues, and the batteries themselves are more complicated to recycle than lead-acid batteries. While lead-acid car batteries have more natural touch points for recycling markets, lithium-ion batteries are dispersed into a number of different products in different shapes and sizes, further complicating market development (Gies 2015).

As the market for lithium-ion grows, in particular through electric vehicle market growth, there may be more of a push to ensure products are recycled and reused (Gaines and Nelson 2010). It is also possible that economics will drive greater recycling (e.g., increased costs of new materials for battery manufacturing).

\subsection{Evaluation of O\&M Plans}

Evaluation of an existing/ongoing O\&M plan involves:

- Assembling a qualified team to conduct the assessment; scheduling and organizing team meetings and at least one site visit. The team designates a team lead and functional O\&M leads for each area such as site, operations, and maintenance.

- Planning the steps to go through, logistical issues, and selection of an "assessment database," a web tool, spreadsheets, or databases to manage the information.

Conducting the assessment includes:

- Reviewing documents and procedures prior to a site visit

- Visiting the site to collect information and observe site conditions

- Interviewing personnel at in-person meetings, on the phone, or in a webinar-most assessors deem closed in-person meetings as most effective for candid review

- Entering data into the assessment tool (web tool, spreadsheets, or database). The operations lead will collect and enter information regarding each area. An example of what each topic lead will be looking at includes:

- Operations lead collects information regarding shift turnover procedures, security and clearances for staff to site and computer systems, frequency and content of shift meetings, control room procedures and performance, operator rounds, condition and performance of operations equipment such as monitoring and control systems, effectiveness of record keeping.

- Maintenance topic lead will enter information regarding work management; inspections; frequency and content of crew briefings; confirmation of training requirements, certifications, and personal-protective equipment (PPE) for such things and arc-flash protection, lock-out/tag-out, and general safety; maintenance support; presence and condition of labels and signage; orderly site and housekeeping issues; and condition of tools and equipment.

- Comprehensively analyzing performance of the attribute ratings and comments, including data review and identification of strengths and improvement items

- Briefing client, site management and O\&M team, first-line supervisors, and others as deemed necessary about the strengths and improvement items with supporting 
information. Plant staff are present to ask questions and clarify any of the information. The briefing should conclude with a discussion to confirm that plant staff understand all of the recommendations resulting from the assessment.

- Delivering written report after the briefing and incorporating any clarifying information derived from the briefing. The report should include information about the assessment team and the overall scope of the assessment, an overall summary of the plant's assessed performance, strengths, and recommendations for improvement including a means to confirm that the improvement has been implemented. The report should also include references where site staff can find relevant guidance. As an appendix, the final report may also include the database of ratings and observations.

The Electric Power Research Institute (EPRI) promulgates guidelines and a web-based tool for conducting comprehensive O\&M assessments of power plant performance, which can be adapted for use with PV systems (Buck 2018). Use of such a standardized approach provides a means whereby the policy, process, and execution of O\&M plans and execution are assessed in a uniform way and more independent of individual reviewer's opinions. 


\section{Health and Safety}

The asset owner is ultimately responsible for safety related to a PV system and must meet that responsibility through the specific requirements of O\&M service contracts and mitigate risk through accident and liability insurance. O\&M of battery systems involves important considerations related to environmental and safety requirements. Batteries often involve materials, such as the acid and lead found in lead-acid batteries that present not only immediate hazards to personnel but also careful custody over the life of the battery, concluding in full recycling of a worn-out battery.

In the United States, OSHA (www.osha.gov) promulgates regulations related to workplace safety. PV health and safety issues include affect those involved in construction or electrical maintenance work, vegetation control, and PV systems. Roof fall protection, electrocution, arcflash protection, lock-out/tag-out, and dehydration and heat stress are of special importance to workers providing maintenance of PV systems. It is important to recognize that health and safety issues are relevant to all personnel and work locations, even office workers (e.g., ergonomics, safe work environment). All workers must have at least basic training in safety and at least an orientation to hazards specific to each system.

O\&M services are usually done by small teams of workers, and it is cost-prohibitive to have a dedicated health and safety professional with each team for each site visit. As a result, the O\&M contractor depends on a strong safety culture, along with well-trained workers. Health and safety is usually considered an indirect cost, and it falls into the overhead cost category. It consists mainly of training, inspection, and auditing functions, with typical services that may include:

- Periodic inspection of personal protective equipment

- "Ride-alongs" to watch workers perform their jobs, capitalizing on teachable moments

- Site inspections to ensure that measures such as dead fronts on electrical panels and other guards are in place.

Because PV systems only produce power from sunrise to sunset, O\&M teams have a plant shutdown every night. Many O\&M contractors do their work at night, only working on deenergized systems. Although nighttime work introduces its own risks, these are lower than risks present when equipment is energized. Working at night assumes that problems have been identified with certainty and that the work being done is likely to solve the problem (EUCI 2016).

PPE is required for all jobs depending on the hazards. It is important to understand that providing the equipment is not enough - the user of the equipment has to be trained and, in most cases, certified in its use, and the condition of the equipment has to be continuously assessed and the equipment replaced if need be. PPE often encountered in PV system maintenance includes the following (which is not all-inclusive and depends on particular circumstances):

- General: Most sites will require at all times a helmet, safety glasses, safety vest, and work boots (steel-toed preferred).

- Lock-out/tag-out: Locks and tags are shaped to fit onto the types of switches and breakers in the system and the procedure of locking out circuits so that someone unaware does not energize a circuit that someone else is working on. 
- Fall protection: Working at elevated heights requires fall protection, which may include personal fall arrest systems and guardrails around openings and edges of roofs.

- Arc-flash protection: Face shield, helmet, gloves, and apron suited for the amount of arcflash energy that is calculated based on details of the circuit being worked on.

Storage systems in PV plus storage settings call for many overlapping safety standards and precautions, particularly those that apply to working on DC wiring, and bring a set of technology-specific new considerations. Many storage systems will be built to various standards for safety, but there is an ongoing O\&M role in keeping facilities to standard.

\subsection{Energy Storage Safety Considerations}

General battery safety rules include: remove any jewelry before handling batteries; wear protective clothing, especially safety glasses, apron, and gloves; use proper insulated tools; disconnect batteries from power source while working around batteries; wash hands after handling batteries; provide warning label areas where batteries are charging; ensure proper venting of battery enclosure; keep open flames and sparks away from batteries; no smoking near batteries; have baking soda or neutralizing agent accessible to neutralize acid spills; do not water batteries before equalizing; and do not measure current (amps) across terminals, voltage only.

Follow any additional manufacturer's safety instructions. There are many codes and standards relating to safety of stationary energy storage at the local, national, and international levels by UL, NFPA (NEC, 70E), ANSI, CSA, and IEC, among others. Standards involve markings and ratings, use and safety instructions, casing, physical strength, vibration/impact/drop, flammability/explosion, temperature, venting, pressurization, leakage, short circuit, overcharge, over-discharge, voltage reversal, and environmental limits such as temperature, altitude, and humidity (http://www.mpoweruk.com/testing.htm).

Table 5 provides a non-exhaustive list of codes, standards, and regulations that support health and safety at energy storage installations. Lithium-ion standards lag those for the more established lead-acid technologies, though standards for several different settings are under development, such as IEC 62897 (Rosewater 2015). In addition to the above, the U.S. Department of Transportation, Federal Aviation Authority, International Air Transport Association (IATA), International Maritime Organization, or United Nations (UN) regulations may need to be referenced when battery systems are being replaced (IEEE 2010).

Table 5 is drawn from the Energy Storage System Guide for Compliance with Safety Codes (PNNL and Sandia 2006) and highlights many of the relevant codes and standards. 
Table 4. Codes and Standards Related to Energy Storage System Maintenance (PNNL and Sandia 2016)

\begin{tabular}{|c|c|}
\hline $\begin{array}{l}\text { Fire and smoke detection, fire suppression, fire and smoke } \\
\text { containment }\end{array}$ & $\begin{array}{l}\text { NFPA } 1, \text { NFPA } 13, \\
\text { NFPA } 15 \text {, NFPA } 101, \\
\text { NFPA } 850, \text { NFPA } 851, \text { IBC, } \\
\text { and IFC }\end{array}$ \\
\hline $\begin{array}{l}\text { Ventilation, exhaust, thermal management, and mitigation of the } \\
\text { generation of hydrogen or other hazardous or combustible gases } \\
\text { or fluids }\end{array}$ & $\begin{array}{l}\text { NFPA 1, IEEE 1635/ASHRAE 21, } \\
\text { IFC, IMC, NFPA } 70\end{array}$ \\
\hline $\begin{array}{l}\text { Egress and access (normal operations and emergency), } \\
\text { physical security and illumination }\end{array}$ & $\begin{array}{l}\text { NFPA 1, NFPA 101, IBC, } \\
\text { IFC and local zoning codes }\end{array}$ \\
\hline $\begin{array}{l}\text { Electrical safety, emergency shutoff, working space, } \\
\text { electrical connections/installation for installations on the } \\
\text { customer side of the meter }\end{array}$ & NFPA 70 and $70 \mathrm{E}$ \\
\hline $\begin{array}{l}\text { Electrical safety, emergency shutoff, working space, } \\
\text { electrical connections/installation for installations } \\
\text { on the utility side of the meter }\end{array}$ & IEEE C2 \\
\hline $\begin{array}{l}\text { Anchoring and protection from natural disasters } \\
\text { (seismic, flood, etc.) and the elements (rain, snow, } \\
\text { wind, etc.) }\end{array}$ & $\begin{array}{l}\text { IEC } 60529 \text {, IEEE } 1375, \text { UL 96A, } \\
\text { IBC, IFC and NFPA } \\
70\end{array}$ \\
\hline Signage & $\begin{array}{l}\text { ANSI S535, NFPA } 1, \text { NFPA } \\
70, \text { NFPA 70E, NFPA 101, } \\
\text { IBC and IFC }\end{array}$ \\
\hline Spill containment, neutralizing and disposal & $\begin{array}{l}\text { NFPA 1, IPC, IFC, and IEEE } \\
1578\end{array}$ \\
\hline Communications networks and management systems & IEC 61850 \\
\hline
\end{tabular}

A more exhaustive list of relevant codes and standards is available in Inventory of Safety-Related Codes and Standards for Energy Storage Systems (PNNL 2014). Some individual states will make available listings of relevant national, state, and local codes, standards, and regulations, such as California's Safety Best Practices for the Installation of Energy Storage.

The Energy Storage System Safety Working Group is led by Sandia National Laboratories, and Pacific Northwest National Laboratory seeks to "foster confidence in the safety and reliability of energy storage systems" and is a valuable repository of the latest developments in codes and standards. ${ }^{3}$

Diligent documentation of battery system information that is pertinent to safety is critical. One format is proposed in "Suggested Template for Energy Storage System Review and Approval" in Section 5.1 of Energy Storage System Guide for Compliance with Safety Codes and Standards and includes site details, battery technology information, equipment and interconnection details, ventilation and thermal management, and fire protection (PNNL and Sandia 2016).

\footnotetext{
${ }^{3}$ More information available at http://www.sandia.gov/ess/publications/EnergyStorage safetyroadmap_2017.pdf.
} 


\subsubsection{Health and Safety Checklist}

Considerations for health and safety include the following.

\begin{tabular}{|c|}
\hline $\begin{array}{l}\text { Meet with "first responders" such as fire marshal, local fire department, first-aid providers, } \\
\text { and police to familiarize them with access and shutoffs and make them aware of the plant } \\
\text { purpose and location. }\end{array}$ \\
\hline Control access to site and brief visitors and workers on safety procedures. \\
\hline $\begin{array}{l}\text { Identify hazards unique to the site and system and plan work to reduce risks associated with } \\
\text { these and all hazards. }\end{array}$ \\
\hline $\begin{array}{l}\text { Use a company health and safety manual, which establishes appropriate rules and } \\
\text { procedures concerning reporting of health and safety problems, injuries, unsafe conditions, } \\
\text { risk assessment, and first aid and emergency response. Verify that this satisfies all laws and } \\
\text { regulations regarding workplace safety; the manual should provide a complete list of } \\
\text { personnel training requirements and certifications. }\end{array}$ \\
\hline Designate a health and safety coordinator or point of contact for questions or complaints. \\
\hline $\begin{array}{l}\text { Have an entity with the authority to periodically inspect and stop work to verify that safety } \\
\text { measures are in place and observed. }\end{array}$ \\
\hline $\begin{array}{l}\text { Ensure that all site personnel are equipped with complete PPE for the task, including fall } \\
\text { protection from roofs and arc-flash protection for working on live circuits. Ensure that all } \\
\text { personnel have met the training and certification requirements of NFPA 70E for being a } \\
\text { qualified worker. }\end{array}$ \\
\hline $\begin{array}{l}\text { Verify that areas with hazards have clear and evident signage identifying the hazard to } \\
\text { authorized or unauthorized visitors and that visitors are kept away from hazards by } \\
\text { enclosures and barriers. }\end{array}$ \\
\hline $\begin{array}{l}\text { Ensure that site supervisor (if applicable) has a minimum of an OSHA } 30 \text { certification and all } \\
\text { site personnel have an OSHA } 10 \text { certification. }\end{array}$ \\
\hline $\begin{array}{l}\text { Maintain an OSHA total case incident rate of } 5.00 \text { or less or similar rate based on a } \\
\text { substantially equivalent, accepted measure used to report workplace injuries. }\end{array}$ \\
\hline
\end{tabular}




\section{O\&M Provider Qualifications and Responsibilities}

PV O\&M personnel, service category, scope of work, salary, and qualifications for the following roles are detailed in Appendix D: administrator/management, designer, cleaner, tree trimmer, pest control, roofer, structural engineer, mechanic, master electrician, journeyman electrician, network/information technology (IT) specialist, inspector, inverter specialist, PV module/array specialist, and utilities locator. These roles are defined in the PV O\&M cost model for work calculations but can be customized by the user for different pay rates, roles, and local work conditions and context.

\subsection{Qualifications of Plant Operators}

Solar plant operators require monitored data to analyze and identify the root cause of performance issues observed by the operator. It is critical to identify the root cause of failure to reduce maintenance costs when dispatching service providers.

There are two ways to identify root causes of failures and performance problems:

- Qualified personnel who understand the specific plant design, with the necessary experience to identify anomalies (i.e., NERC-certified operators, experienced in power plant operations/generation, remote monitoring, remote data analysis)

- A software and/or asset management system infrastructure that is able to define the specific plant hierarchy that can then automatically identify anomalies, conduct rootcause analysis, and suggest remedies long before the need to dispatch a service provider.

\subsection{Qualifications of Service Providers}

Every service provider-from the person that mows the grass to the master electrician-requires some sort of qualifications. Examples are listed in Appendix D for most types of service providers. Most electricians work on AC building systems, and most electricians are unfamiliar and untrained to deal with DC-based PV systems.

These electrical qualifications are essential, but each O\&M service category has required qualifications. For example, certifications to apply herbicides and insecticides may be required for those removing weeds and infestations, as listed in Appendix D for each job category.

\subsubsection{Service Provider Qualification Checklist}

Considerations for service provider qualifications include the following.

\begin{tabular}{|l|l|}
\hline & Licensed electrical contractor \\
\hline & NABCEP PV installer certified and/or UL PV system installation certified \\
\hline & Experience with and on power generation systems \\
\hline & Experience with medium-voltage DC electrical systems \\
\hline & Experience and working knowledge of NFPA 70E \\
\hline & Familiarity with sections of the National Electric Code specific to PV (section 690/691) \\
\hline $\begin{array}{l}\text { ASNT certified for planning and conducting thermal imaging (American Society for Non- } \\
\text { destructive Testing) }\end{array}$ \\
\hline
\end{tabular}




\begin{tabular}{|l|l|}
\hline & Met NERC compliance for utility-scale systems \\
\hline & Audited financial statements available \\
\hline $\begin{array}{l}\text { Bank and/or supplier references and access to letters of credit, surety bonds, etc. and credit } \\
\text { rating }\end{array}$ \\
\hline Track record of performance \\
\hline
\end{tabular}

\subsection{Financial Solvency}

Contractors should provide documentation that communicates the financial solvency of the O\&M service provider. The purpose of references is to determine if the contractor is in financial distress. Financial distress of the installation contractor or O\&M service provider could have a negative impact on the level of system quality and the timeliness and quality of delivered O\&M services.

These references should be made available to financing sources upon request. Sample documentation includes:

- Audited financial statements

- Bank references [Data Universal Number System (DUNS)]

- Supplier references

- Bond ability/bank letter of credit

- Credit rating matrix

- Track record.

\subsection{Insurance}

A good O\&M contract and good insurance coverage are the two keys to mitigate any financial risk. O\&M program best practices can have a positive impact on reducing insurance losses, thus reducing premiums paid for insurance. An insurance engineer and underwriter should be engaged to evaluate a facility (or the design for a yet-built system), including the O\&M program, to quantify loss potential and estimate insurance coverage and costs. This review also provides a better understanding of risks that might impact the performance of a PV plant. Insurance products that may be of interest to the owner (which are different than coverages that an O\&M provider should have at a minimum) are outlined by EPRI (2015).

The three categories of insurance are "Property," "Liability," and "Business Interruption" insurance. Property Insurance protects against loss damage to land, buildings and equipment and is often combined with Casualty Insurance that protects businesses from injuries and crimes. These policies are often the expanded to offer coverages for equipment not on the premises; liability for the cost of harm caused to others; and perhaps for major equipment failure. What is included and excluded from policy offerings should be carefully evaluated.

A relatively new offering is Energy Production Insurance, also known as a "Solar Revenue Put," which pays the difference if a solar power plant fails to reach an agreed-upon output, perhaps $80 \%$ to $95 \%$ of expected output. Such insurance allows projects to get $10 \%$ or $15 \%$ more debt financing (lower debt coverage ratio, less equity financing) and at lower interest rates because it reduces risk and guarantees the project cash flow necessary to meet the requirements of lenders. A performance assessment is conducted to set expected output and put a price on the risk to 
establish the insurance premium to be paid, but the cost of the premium is often exceeded by the savings in financing cost and the ability to get financing for more projects.

"Weather Transfer Risk" is a financial instrument that pays according to a "collar" on production. For example, if the production is less than $50 \%$ of the expected production range (P50 meaning that $50 \%$ of the years have more production), then the insurance company pays a proportional amount and if the production is greater than P60 the customer pays a premium to the company. As the name implies this instrument might refer to irradiance only, not equipment performance.

An insurance company might offer a "O\&M Cost Cap" where a customer pays a premium, say every 6 months, and the policy pays out if O\&M cost exceed the specified dollar amount during the covered time period.

Liability and risks should be mitigated through contracts that clearly articulate the insurance requirements to O\&M service providers. Concepts related to insurance include:

- Normal loss expected (NLE), which determines the dollar amount of the deductible for an item that can be expected to occur, such as inverter replacement, without an insurance claim.

- Probable maximum loss (PML), which determines the premium paid on a portfolio over time. As far as insurance premiums are concerned, a rate of $\$ 0.001$ (total insurable value, the reported value of physical assets + annual business income, is offered as a cost benchmark (from David Walter, The Hartford Steam Boiler Inspection and Insurance Company, by working group correspondence June 7, 2016).

- Maximum foreseeable loss (MFS), which sets dollar limits on coverage and represents the worst-case loss scenario.

Confirm that the contracting company maintains current and appropriate business insurances.

\subsubsection{Insurance Checklist}

For small commercial or residential PV systems the home-owners insurance extends property and liability coverage to the PV array. Regardless of system size utilities may require specified levels of insurance coverage. For stand-alone utility or distributed-generation PV systems insurance considerations include the following.

\begin{tabular}{|l|l|}
\hline $\begin{array}{l}\text { Property insurance: coverage commensurate with value of buildings, equipment, or } \\
\text { improvements to a property; might also cover against other risks if included or unless } \\
\text { excluded. }\end{array}$ \\
\hline $\begin{array}{l}\text { Commercial general liability insurance: in a form covering all actions by owner or contractors, } \\
\text { written on an occurrence basis, including coverage for products and completed operations, } \\
\text { independent contractors, premises and operations, personal injury, broad form property } \\
\text { damage, and blanket contractual liability: Large utility scale systems may have coverage limits } \\
\text { of } \$ 30 \text { million, to cover against liability of a wildfire, for example. Smaller rooftops ground } \\
\text { mount systems may carry } \$ 1,000,000 \text { per occurrence, } \$ 2,000,000 \text { aggregate; covers } \\
\text { negligence claims, settlements, and legal costs }\end{array}$ \\
\hline
\end{tabular}




\begin{tabular}{|l|l|}
\hline $\begin{array}{l}\text { Inland insurance or marine insurance: insures against loss of equipment not on the property } \\
\text { premises. Inland insurance is often covered under property insurance policy. }\end{array}$ \\
\hline $\begin{array}{l}\text { Workmen's compensation: } \$ 1,000,000 \text { each accident, each employee, policy limit } \\
\text { Professional liability insurance: insures against errors and omissions often required by board of } \\
\text { directors }\end{array}$ \\
$\begin{array}{l}\text { Commercial vehicle insurance: insurance for owned and rented vehicles or personal vehicles } \\
\text { used on company business }\end{array}$ \\
\hline $\begin{array}{l}\text { Warranty insurance: equipment warranty issued by manufacturer but backed up by an } \\
\text { insurance company in the event that the manufacturer company goes out of business. Many } \\
\text { insurance companies do not offer warranty insurance but rather cover such risk under property } \\
\text { insurance. }\end{array}$ \\
$\begin{array}{l}\text { Business interruption insurance covers lost revenue due to downtime caused by covered } \\
\text { event- this can be important in PPAs where revenue is essential for debt service and O\&M } \\
\text { expenditures }\end{array}$ \\
\hline $\begin{array}{l}\text { "Energy production insurance" or "solar revenue put" insures against production less than } \\
\text { specified, which can improve access to debt financing and reduce debt interest rate }\end{array}$ \\
\hline $\begin{array}{l}\text { Insurance claims: made by the asset owner or a representative of the owner such as asset } \\
\text { manager or O\&M service provider. The procedure for making claims described in the } \\
\text { insurance policy should be followed to the letter, keeping copies of all submittals and } \\
\text { correspondence with the insurance company. The insurance company (claims adjuster) will } \\
\text { need to be provided access to the site to assess damage and to collect information needed to } \\
\text { process the claim. }\end{array}$ \\
\hline
\end{tabular}

\subsection{Redundancy in Service Providers}

Investor confidence is increased if a "hot backup" service provider is available. This second service provider would be paid a fee to be available and to have the capability (products and training) to perform O\&M on the system if a current O\&M service provider fails to perform. This second company could be hired to perform capacity and energy tests and provide a check on the decisions of the current O\&M service provider. 


\section{System Monitoring, Software Solutions, and Data Management}

The three main areas of best practices for system monitoring are the following: data presentation, quality of monitoring equipment, and transparency of measurement protocols and procedures. The approach to monitoring and associated cost depends on the revenue associated with the performance of the asset. IEC 61724 classifies monitoring systems (A, B, C); the O\&M related to monitoring depends on the system class (IEC 1998).

Data are valuable, and it should be established who owns the monitoring data and who will have access to the data and for what purpose. Data analysis is a powerful tool for understanding PV system performance, but it is fundamentally limited by the quality of sensors and models being used, in addition to the condition of the array.

The objective of monitoring is to provide enough information to accomplish an "energy balance" accounting for the amount of solar resource available and the losses in each energy conversion process up to delivery at the point of interconnection. Advanced operation of a PV plant such as modulating output or power factor can confound the drawing of conclusions from monitored data. A monitoring system should account for clipping of output due to high DC-to-AC ratio, interconnect limits, and called-for curtailment or any other reason.

\subsection{Array Inspection}

Because of the inherent inaccuracies of data monitoring alone, it is common to implement a secondary check of the DC array to detect string- and module-level faults through periodic inspection and testing. The two main methodologies used for these inspections are manual electrical testing and aerial thermal-imaging inspections.

\subsubsection{Manual Electrical Testing}

Manual electrical testing such as open-circuit voltage, operating current, or field I-V curve tracing is used as a method to detect faults in the DC system that the monitoring system is not able to detect. The accuracy of testing equipment is limited by the combined accuracy of irradiance, temperature, and electrical sensors, and in the case of $\mathrm{I}-\mathrm{V}$ tracing, it is limited to around $5 \%$ for standard field units. This testing reveals only defects that are currently causing significant module failure, and it will not detect hot-spot defects that are not currently causing significant electrical degradation of the module. However, these signatures can be important for understanding underlying module-quality issues, in addition to allowing early detection of possible fire risks. Figure 18 shows a module that shows physical damage and compromised electrical insulation even though the module continues to perform electrically. 


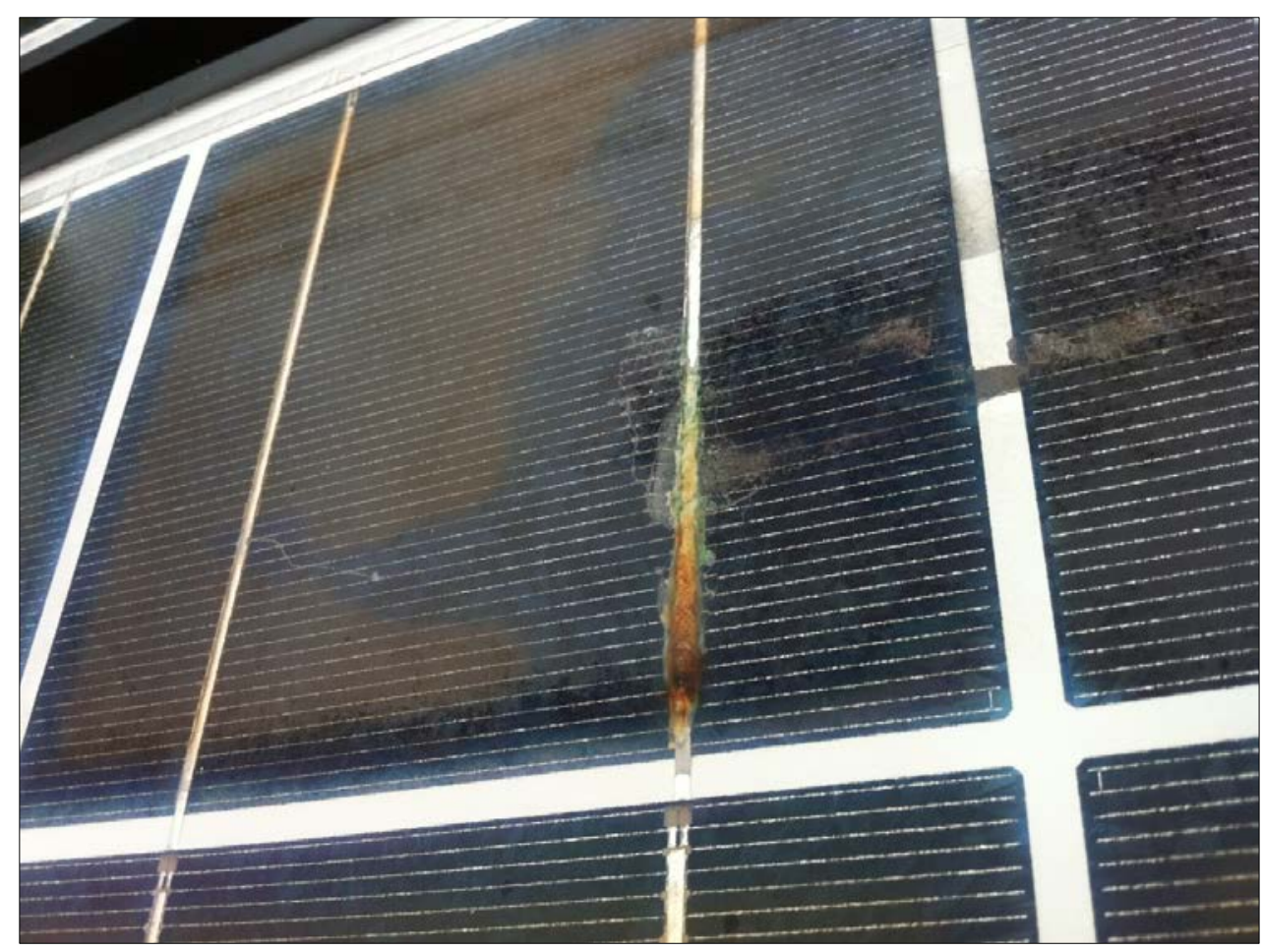

Figure 18. Cracked or peeling backsheet leads to water infiltration and ribbon corrosion. Photo by Andy Walker, NREL

Manual testing is performed over several days or weeks to test a large array, and the meteorological conditions will vary over this time, making it difficult to spot relative differences in the array and requiring significant documentation to ensure that measurements are comparable. Because this testing must be performed inside the isolated combiner while the system is operational, arc-flash PPE is required for all testing - which can limit the speed of effective inspections and can pose a potential safety risk to operators. It should be noted that for some combiner topologies, the arc-flash hazard may be too high according to NFPA 70E, and electrical testing on live circuits in the combiner box may not be possible or may require portions of the array to be de-energized prior to measurement (NFPA 2012). Manual inspection and testing requires that inverter wiring enclosures, re-combiner boxes, combiner boxes, and eventually module junction boxes be opened to access the circuits; it is important to note that these must be properly re-sealed (gasket, screw-torque) to maintain the original NEMA rating for the type of enclosure (Figure 19). 


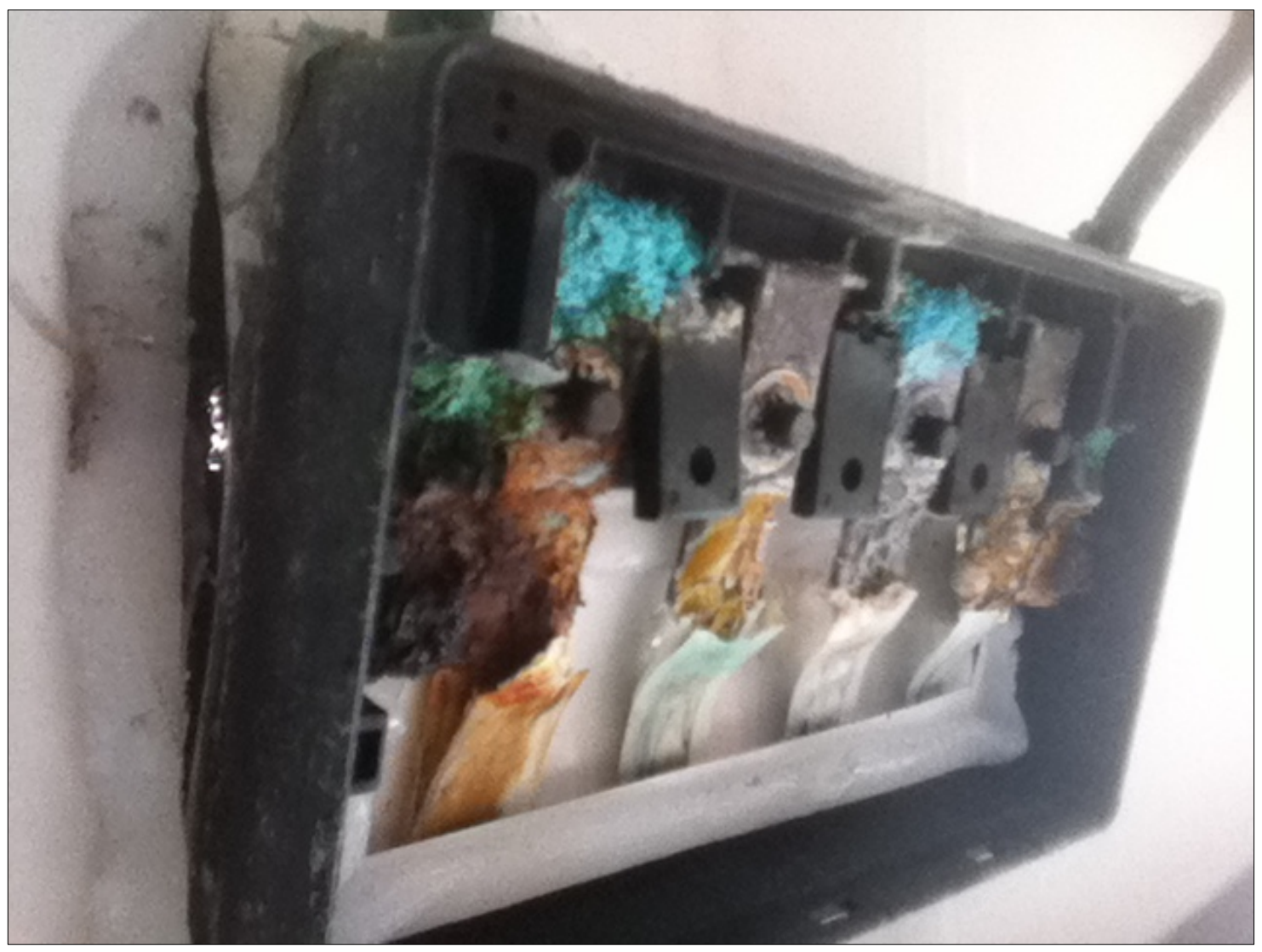

Figure 19. Manual inspection and testing requires opening NEMA-rated enclosures. The integrity of any enclosure seal must be restored after opening to avoid moisture damage as in this module junction box. Photo by Andy Walker, NREL

\subsubsection{Aerial Thermal Imaging}

Aerial thermal imaging inspections refer to the collection and processing of image data collected by aerial sensors with the goal of detecting string, module, and sub-module faults in the array. By detecting thermal variations between modules, any critical defect that is causing a reduction in module efficiency can be detected, in addition to the proactive detection of hot spots and potential fire risks (Figure 20). These inspections can be performed instead of manual electrical testing as part of annual preventative maintenance and can also be used for system commissioning, end-of-warranty inspections, and infrared inspection of AC substation.

Aerial thermal imaging can be performed using manned survey aircraft or unmanned aerial vehicles (UAVs). The quality of the assessment depends largely on the imaging and postprocessing systems that are used. These systems should have the following characteristics (according to Rob Andrews of Heliolytics Inc. in a 2016 communique called "DC Assessment Proposed Best Practice" provided in a review of this Best Practices document.)

- Thermal detector sensitivity of $<0.02^{\circ} \mathrm{C}$ and frame integration time of $<2 \mathrm{~ms}$

- Thermal wavelength imager ground resolution of $19 \mathrm{~cm} /$ pixel or better; visible wavelength imager ground resolution of $3 \mathrm{~cm} /$ pixel or better 
- Irradiance at a minimum of $600 \mathrm{~W} / \mathrm{m}^{2}$ with an irradiance deviation of $<100 \mathrm{~W} / \mathrm{m}^{2}$ and a temperature deviation of $<5^{\circ} \mathrm{C}$ during inspections

The resulting imagery should be processed by a validated processing routine to correctly identify module defects and their specific location in the field. These defects should be identified to the module level, and labelling should be provided to allow field technicians to quickly identify and remediate module-level issues. When properly applied, remote imaging inspections can proactively detect the following classes of array faults:

- Module faults: Hot spots, diode failures, full module failures, junction-box heating, cracked modules, ethylene vinyl acetate (EVA) fogging, yellowing, antireflective coating degradation, acute soiling (bird droppings, debris, vegetation), and other module-level defects

- String and system faults: Fuse failures, inverter failures, module-connector failures, reverse-polarity wiring, major maximum power-point tracking (MPPT) faults

- Racking and balance of system: Major racking shifts, systemic shading, major erosion.

The use of proper post-processing tools is critical to accurately detect and classify module faults. Post-processing tools should be validated against ground data, allowing a properly validated tool to identify the exact location and probable cause of all thermal faults in an array.

For inspections without validated post-processing routines, it is important to note that many of the problems described above cannot be diagnosed with aerial inspections. The inspection simply points out symptoms and the rough location of the problem. Further troubleshooting on the ground is required (EUCI 2016).

Alternatively, if the system is metered at the string level, and robust data analytics or data review is in place, then module faults that are affecting string output can be identified with a robust remote monitoring system. However, cell-level hot spots generally will not significantly affect module performance and cannot be detected by data analytics alone. 


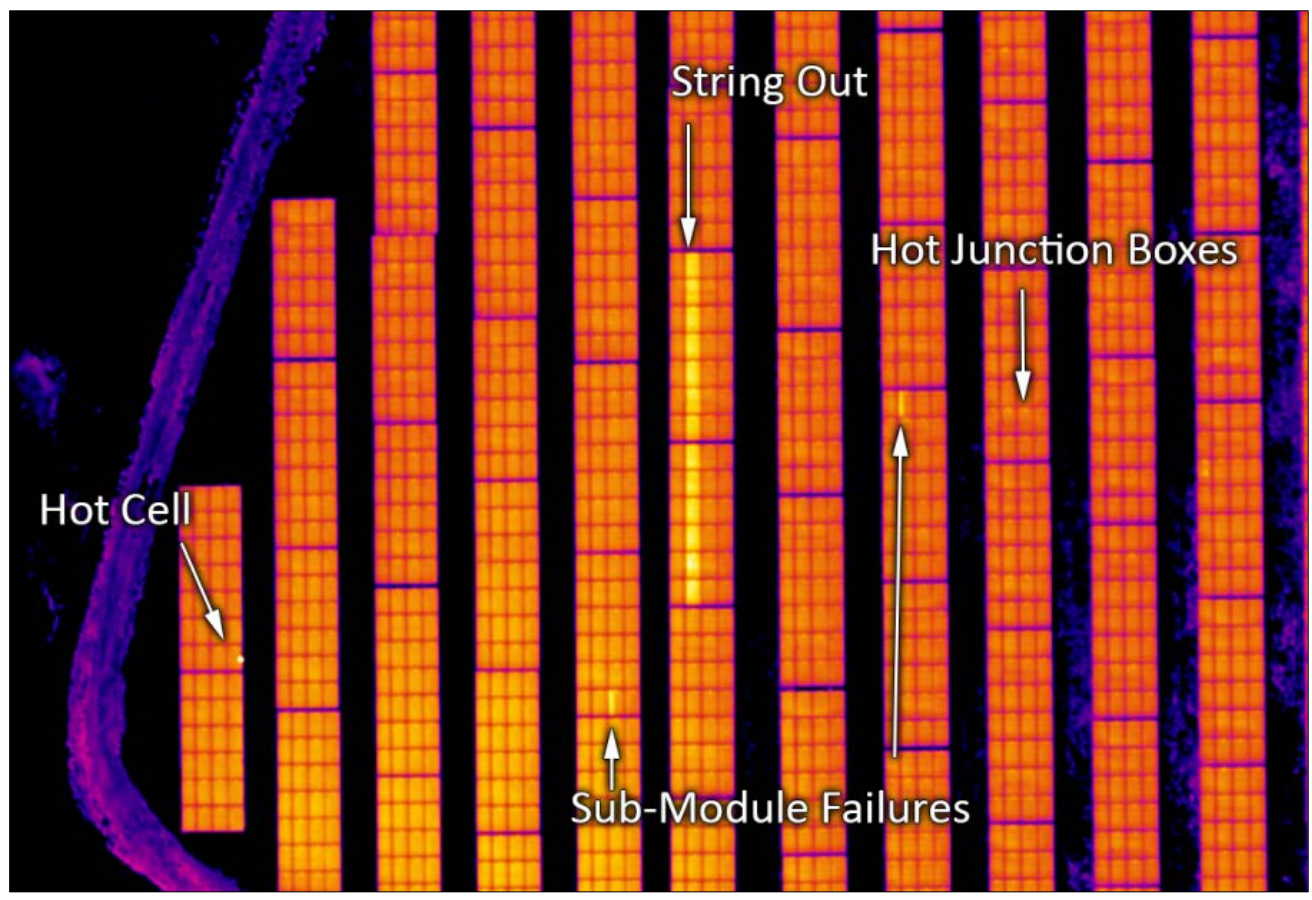

Figure 20. High-resolution infrared aerial imaging can identify failed strings, modules, and cells within modules, as shown on this image. Image by Rob Andrews, Heliolytics Inc.

\subsection{Energy Storage System Inspection and Testing}

Before a battery plant is installed, qualification testing can ensure that the specified battery can perform in the application and environmental conditions, and the O\&M provider will have to adapt procedures to that particular battery type and configuration. After installation, state-ofhealth testing is required to ascertain what the actual, and declining, capacity is over time and to diagnose problems that require corrective maintenance or replacement of cells or complete battery systems.

\subsubsection{Battery Qualification Tests}

The O\&M required of a battery, including expected replacement, depends a lot on the application. For those purchasing many battery systems, it makes sense to do qualification testing to make sure the battery will work in the application. Qualification testing includes:

- Physical tests: Dimensional accuracy, static and dynamic mechanical stresses, and puncture resistance.

- Environmental tests: Extreme environmental conditions are likely to be encountered by the battery over its lifetime, most notably temperature. The manufacturers' published temperature limits on batteries are often exceeded by climate conditions in actual applications.

- Cycle life: Number of charge/discharge cycles a battery completes before its capacity falls below $80 \%$ of its initial rated capacity. These tests are expensive because they take a long time to run, ruin the battery under test, and require a statistically significant number of cells be tested. Thus, the only test data most practitioners have access to are performed by the manufacturers and published in the product literature. Temperature, 
charge/discharge rates (amps), and the DOD each have a major influence on the cycle life of the cells. Independent tests specific to the application are recommended for those purchasing many batteries in order to create realistic reliability and lifetime expectations. Warranty claims may be reduced or voided by temperatures or operating conditions beyond battery specifications (http://www.mpoweruk.com/testing.htm).

\subsubsection{State-of-Health Testing}

A complete rendering of the state of health of a battery would require tests of capacity, internal resistance, self-discharge, charge acceptance, discharge capabilities, the mobility of electrolyte, and cycle counting. Such testing is beyond the capability of most battery system operators and internal resistance/impedance is often used as a proxy indicator of internal conditions affecting battery capacity, heat generated during charge/discharge, and build-up of sulfates in lead-acid batteries.

\subsubsection{Test Conditions}

Test conditions must be specified so that estimates of capacity $(\mathrm{kWh})$ and cycle life are repeatable and can be compared to the manufacturers' specifications or to other batteries. Conditions to specify include:

- Definition of cycle life and range of test (e.g., to $80 \%$ of initial rated capacity)

- DOD (e.g., to $40 \%$ of capacity with each cycle)

- Rate of discharge: current in amps or percent of capacity per hour; rates are sometimes expressed as capacity divided by a number of hours; a discharge rate of $\mathrm{C} / 10$ for a 1,000 amp-hour battery would be (1,000 amp-hours/10 hours $)=100 \mathrm{amps}$

- Rate of charging: current in amps or percent of capacity per hour

- Temperature: battery performance is heavily dependent upon temperature; even small deviations from reference conditions $\left(77^{\circ} \mathrm{F}\right)$ have significant effects on capacity, efficiency, and lifetime.

\subsubsection{Non-Invasive Testing}

State-of-charge testing required discharging the battery. Other tests might require that a battery be disconnected from its circuit. Some parameters of interest such as state-of-charge do not have any direct way of measuring (to cite an aging example: density of electrolyte is a proxy for stateof-charge in flooded lead-acid batteries). For these reasons, such tests are often not conducted and non-invasive approaches to ascertain battery status and health are needed, such as impedance and voltage.

\subsubsection{Internal Resistance/Impedance}

Comparing measured value of cell resistance to initial value provides an indication of any deterioration in battery performance. Impedance is calculated by measuring the current that results from a small AC voltage of known frequency applied across the terminals of the cell and can be carried out while the battery is under load to continuously monitor battery performance. Cell impedance is the applied voltage divided by the resulting current. This test detects other cell defects in the internal circuitry such as short or open circuits. 


\subsubsection{Voltage Measurements}

Voltage measurements are available without interrupting battery operation, but in order to be meaningful, voltage measurements must be mathematically adjusted for voltage level, temperature, discharge rate, and the age of the cell.

Both impedance and voltage measurements depend not only on measurement conditions but also on the history of the batteries. Still, for an arrangement of batteries all at the same condition, differences in voltage over time or over position within the arrangement are important indicators of battery performance and the need for maintenance or replacement. Good record keeping is needed to track trends over time.

\subsubsection{Infrared Imaging of Battery Systems}

Similar to the use of infrared imaging in spotting problems in PV arrays, combiner boxes, and switchgear, infrared imaging can expose the location and effects of problems in battery systems. Individual battery cells with high internal resistance appear hotter than neighboring cells, battery post connections that are loose or corroded appear hotter, and imbalance of current between strings can be seen by a temperature difference. Batteries not passing current at all would appear cooler (see Figure 21).
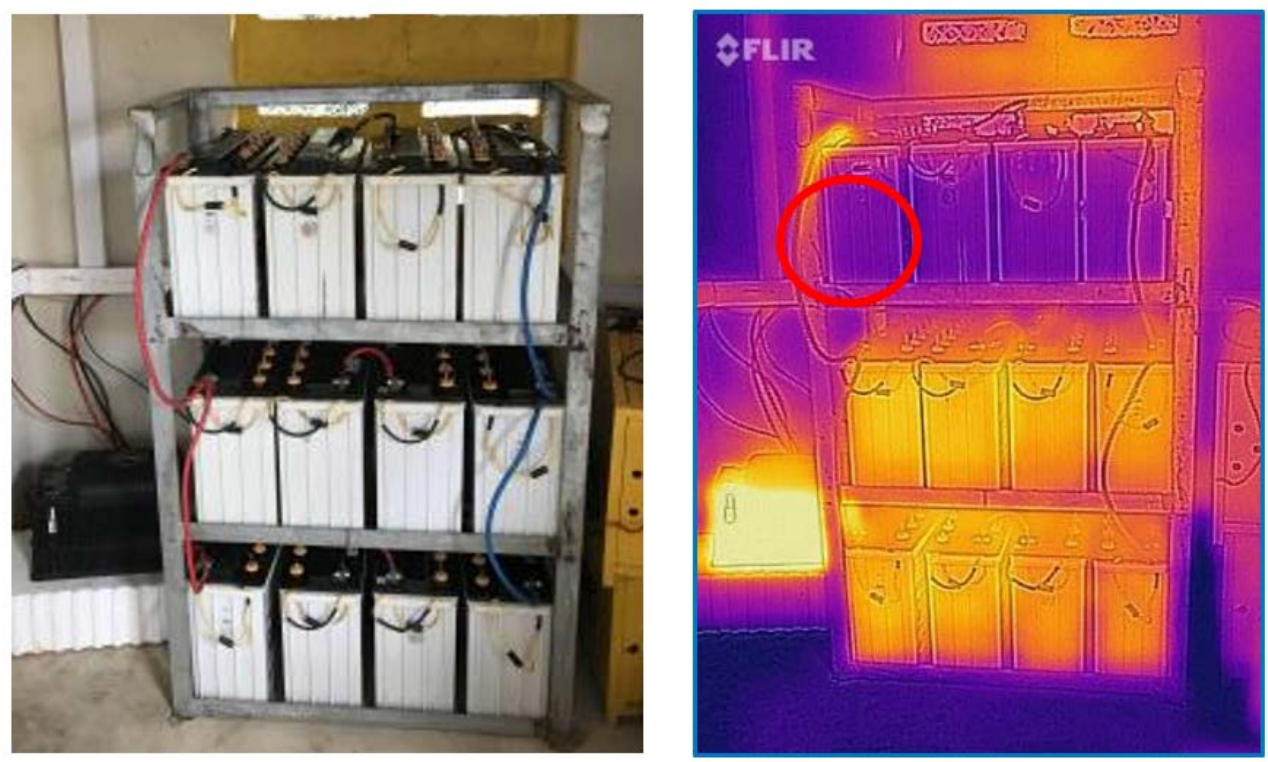

Figure 21. Infrared imaging exposes an imbalance of current through three parallel strings of batteries (the string on top is cooler) and exposes the cause of the problem, which is a battery terminal connection that is badly corroded. Photo by Owen Roberts, NREL 


\subsubsection{Energy Storage System Testing Checklist}

Considerations for energy storage system testing include the following.

\begin{tabular}{|l|l|}
\hline & If cost-justified by a large purchase, consider qualification testing of battery systems. \\
\hline & Include test conditions in specifications for battery O\&M diagnostics and testing. \\
\hline $\begin{array}{l}\text { Consider non-invasive test techniques, such as impedance and voltage testing, to continuously } \\
\text { or frequently monitor battery performance. }\end{array}$ \\
\hline $\begin{array}{l}\text { Keep records of initial and subsequent test results to see how parameters, such as internal } \\
\text { resistance, change over time. }\end{array}$ \\
\hline
\end{tabular}

\subsection{Instrumentation}

Requirements vary depending on the performance measurement model used, the required accuracy, and other considerations - and not just whether the system size is above or below a certain system size. For instance, a fleet of 5,000 residential systems may rely on satellite and local weather data. A fleet of $50-$ to $100-\mathrm{kW}$ commercial systems may have requirements to accurately measure irradiance, module temperature, and weather at each site. We describe recommended guidelines, but the requirements should actually be based on an accuracy level required by the subject system or fleet of systems.

It is important to understand that for any system there exists an underlying uncertainty in the calculation of system performance from measured data. Some studies have shown that the combined effects of system measurement and modeling errors can range from 5\%-10\% (Thevenard 2010; Cameron, Boyson, and Riley 2008; Freeman et al. 2014).

Some examples of the sources of these errors are as follows:

- Meteorological data measurement

Onsite environmental sensors that measure irradiance and temperature for systems $>100 \mathrm{~kW}$. For large plants, adding an extra irradiance sensor for each $\sim 2 \mathrm{MW}$ would help discern irregularities caused by cloud movement over the array. Radio communicationbased weather sensor (such as a Deno Watts weather station) would help to avoid the wiring for the weather stations.

- Irradiance - plane of array (POA)

IEC 61724 Class A pyranometer uncertainty: $\pm 3 \%$ (IEC 1998)

POA model uncertainty if using Global Horizontal Insolation (GHI): $2 \%-5 \%$

If there is more than one orientation of the PV array (e.g., part fixed and part tracking), then a separate pyranometer would be required for each orientation (in the POA), and each pyranometer must be properly assigned to that portion of the system for calculation of PR. 
The pyranometer must be kept clean to provide an actual measurement of the solar resource. Condition of the onsite pyranometer and data acquisition system (DAS) must be checked frequently (daily) to ensure proper operation and to avoid loss of data.

Irradiance measurements should be recorded at a minimum interval of 1 hour, and 15minute or 1-minute data are often specified.

- Satellite-based irradiance measurement

Services are available that take data from satellites and process them with models to create an estimate of ground-level irradiance at a site. Although less accurate than a wellmaintained and calibrated onsite pyranometer, satellite measurements can be more accurate than an onsite pyranometer that is dirty, out of calibration, or installed incorrectly.

- Temperature-module back sheet

A back-of-module temperature sensor with an uncertainty of $\pm 1{ }^{\circ} \mathrm{C}$ and an ambient temperature sensor with an uncertainty of $\pm 1^{\circ} \mathrm{C}$ (IEC 1998).

Intra-array temperature variation: $2-5^{\circ} \mathrm{C}$ (variations greater than this can obscure the cause of images based on temperature).

Firmly affix the temperature sensor with thermal conduction adhesive in the middle of a cell, in the middle of the module, and in the middle of the array. Arrays with sections of different orientation or mounting conditions would require multiple temperature measurements.

- Measurement of system electrical performance

Combiner-level data generally come from current transformers (CTs) measuring current from combiner-box home runs measured at the inverter. Monitoring at the string level is also available (instrumented combiner box).

IEC 61869 Class 1 CT uncertainty is $1 \%$.

Inverter-direct monitoring (no external AC meter) with an uncertainty of $\pm 5 \%$ for systems $<100 \mathrm{~kW}$. For modular plants, adding an external AC meter for each inverter $500 \mathrm{~kW}$ and greater would help to give visibility to the production of each inverter (necessary if the inverter does not include direct monitoring and providing an independent check and redundancy if it does).

Measurements at the inverter also include instantaneous power (AC), cumulative energy delivery (kWh), inverter alarms, inverter control settings, input (DC) current and voltage, and any other information available from the inverter data interface such as inverter temperature. If the inverter does not report temperature, then it is recommended to add a temperature sensor to the inverter enclosure to identify overheating. 
Energy meter: There is often a separate high-accuracy "revenue-grade" AC meter for energy-revenue invoicing or independent measurement of performance for a performance guarantee or other purpose. Specified accuracy is sometimes required for plants where third-party financing is involved or where solar RECs generate revenue. This should be a high-accuracy, high-reliability meter with accuracy within $\pm 0.5 \%$ and with communications that are compatible with both the online monitoring system and a separate automatic meter reading (AMR) service or advanced metering infrastructure (AMI) at the site. The meter should report at a minimum cumulative energy delivery, but may also include advanced "smart-meter" functions such as power-outage notification and power-quality monitoring.

- Model errors

Measured performance is meaningful only when compared to a model of expected performance. The accuracy of the model is affected by:

- Wire length affecting losses between combiner and measurement CTs

- Actual power rating of modules

- Actual module mismatch

○ Shading

○ Soiling

- Degradation.

The following can act to increase the uncertainty in system measurement and modeling:

- Failure to re-calibrate instruments per manufacturer instructions. Most pyranometers must be re-calibrated every 2 years.

- Failure to clean pyranometers on a regular basis. Pyranometers should be mounted in such a way as to allow regular access by service personnel.

- Detachment or poor adhesion of module temperature sensors to modules. The adhesive should allow good thermal conductivity between the module backsheet and temperature sensor.

- Poor temperature sensor placement. The module temperature sensor should be placed away from inverter exhaust, disconnected modules (those used for soiling measurement only), and the edges of roads that will be more acutely affected by wind. Temperature variation from a module at the edge of a road to a module in the center of an array can be as high as $5^{\circ} \mathrm{C}$ due to wind effects.

- Poor documentation of system as-builts. It is important to understand the power capacity connected to any monitored section of the array.

- Unreliable Data Backhaul. A dedicated or shared network connection such as a cellular, satellite, or dedicated broadband backhaul is required to retrieve the data from a monitoring system. In remote areas where utility-scale projects may be located, a satellite data connection may be necessary. It is often not reliable to use the offtaker's network to backhaul monitored data, and in many cases, that is not possible due to security reasons. It is important to perform automated or manual quality checks frequently on the data to detect failed or dirty sensors. All raw data should be archived and backed up automatically and regularly. Onsite data storage helps to prevent loss of data when the communication link is down. 


\subsection{Data Presentation}

Good reporting is essential to obtain value from monitoring data. In the field of PV plant operations, operations quality is determined by (1) the ratio of the amount of energy harvested to the potential amount of energy available for a particular plant and (2) plant equipment availability over time. Given this definition, keeping the plant up and running at its peak operating point requires accurate performance measurements, the ability to easily pinpoint issues, and prompt cost-effective repair of defects. Active plant monitoring is essential, and the quality of the monitoring system itself is fundamental to the overall quality of the plant.

Reports should include the following information:

- Site name, location, size of PV plant, other reference information

- Insolation (onsite or satellite data, plane of array, $\mathrm{kWh} / \mathrm{m}^{2}$ ), temperature (ambient, module)

- Real power and energy delivery $(\mathrm{kW}, \mathrm{kWh})$

- Peak power delivery $(\mathrm{kW})$

- Other advanced meter data such as reactive power (kVAR)

- Estimate of power that should have been produced and PR

- Time-based availability; energy-based availability

- Inverter efficiency, balance-of-system efficiency

- Measurement of soiling, if any.

Additional considerations:

- An internet-accessible portal should be available at any time with:

○ Downloadable raw data

- Charts and tables to interpret data (dashboard or user interface configured to specific user).

- Daily feeds of previous day, month-to-date, and year-to-date production values should be developed and stored.

- Data should include insolation in the POA; energy delivery $(\mathrm{kWh}) ; \mathrm{PR}(\mathrm{kWh}$ delivered/kWh expected); and specific yield $(\mathrm{kWh} / \mathrm{kW})$, as well as any alarms or other performance indicators. Alarms should convey all the information in the alarm format of the manufacturer so that operators can act on the error message.

- Data format should be compatible with standards ("open platform," IEC 61724, and SunSpec Alliance) for aggregation into larger data platforms. Data format should be clearly documented.

- O\&M plans should be built to notify actionable personnel on critical production or safety issues as soon as possible and within 5 days for issues that affect production but not safety, depending on what the anomaly is and considering lost revenue and safety issues. Fire alarms and intrusion detection alarms should be pushed out immediately to on-call personnel.

- Complete loss of production and non-communication should be reported on a daily basis (immediate reporting of such issues is a source of false alarms- communications might be quickly restored). 
- Systems producing lower-than-forecasted energy correlated to local weather/insolation conditions should be reported on a weekly or monthly basis. Using intervals smaller than a week increases the possibility of false positives and usually does not provide business value.

- Reliable data backup and storage should be provided. A best practice is for data loggers to store 6 months of data and to backup data to cloud storage. A reliable method to "backhaul" the data is required. Most connect to the internet via DSL, but be aware that many site owners will not allow the solar monitoring system to use the site network. This may require a separate internet connection and often requires cellular or satellite backhaul of the data to an operations center or user website.

\subsection{Quality of Monitoring Equipment}

Use open standards for information and data communication throughout the plant, fleet, and enterprise. Ensure that the monitoring system addresses the following:

- Transparency of measurement protocols and procedures

- Ability to audit measurement protocols and procedures

- Ability to maintain hardware and software by a variety of service providers, including calibration and servicing requirements

- Ability of systems to share information with stakeholders

- Ability to ensure "operational continuity" (backup and restore)

- Support of third-party access for custom application development

- Security of software and applications

- Ability to have entire monitoring system on an uninterruptible power supply.

In this document, we do not pick a standard to be used to calculate and report system performance. However, there should be an effort to at least collect and maintain data that can be used to report PV system performance as specified in the most common standards for the industry, regardless of how it is reported by any operator or for any plant. This procedure will allow system performance to be reported according to any of these standards if the need arises.

\subsection{Transparency of Measurement Protocols and Procedures}

The benefits of adopting open standards for information and communication are wellestablished. As it relates to the quality of the solar monitoring system, open standards are applied at four levels:

1. Device communication and plant sensor readings

2. Data collection and storage at the plant

3. Information transmission from the plant to the information data store

4. Information access to the data store from applications.

High-quality monitoring systems can be built with proprietary methods that encourage lock-in to a single vendor. But a standard information model used across all four levels ensures high fidelity and eliminates poor or inconsistent mappings from one model to another. A standard information model allows systems to be compared to one another, independent of the monitoring 
vendor. The SunSpec Alliance standard information models - combined with standard transport protocols such as Modbus, Ethernet, and $\mathrm{WiFi}$ - are recommended, with support information models, as defined in IEC 61850 (IEC 2003) and/or Smart Energy Profile 2.0. SunSpec standards are harmonized with both of these technologies. Sandia National Laboratories has developed an open-source data-filtering and analysis platform, "Pecos" (https://github.com/sandialabs/pecos), that can be used to provide insight into PV system data quality and roll up raw data into energy tests, such as those outlined by IEC 61724 (IEC 1998).

Data quality is an issue that should be addressed. Recent work in standards recognizes that data collection anomalies do occur, such as missing data or highly inaccurate instrument readings for a period of time. Quality checks should be established to quickly screen data so that they do not skew reported results and so that repairs can be made in a short time. Sandia National Laboratories, perhaps among others, is working on a set of data-handling techniques that will be open to the industry once released. It is also worth noting that some requirements may include third-party certification of data collection, calculation, and reporting. Proper application and maintenance of instrumentation should also be mentioned because it can be vital to accurate readings.

\subsection{Software Solutions}

Software solutions can both decrease costs and improve revenue optimization, depending on the setting and organizational priorities. Software solutions can also reduce risk and uncertainty (e.g., automating compliance processes to avoid missing dates and receiving fines). While the full life cycle of PV or PV plus storage systems is touched upon throughout this guide, it is particularly important to consider when selecting and implementing software solutions that are influenced by upstream activities, such as generating leads for prospective clients, and in turn also influence downstream processes, such as financing ownership changes and end-of-life deposition.

The suite of software tools is changing rapidly, and business models and processes vary greatly across fleets. Each asset or O\&M manager will have a custom solution reflecting the business model and level of vertical integration, markets it is active in, stage of development, and technical capacity to bring solutions in-house, among others. On the software side, there is a spectrum from service providers with narrow expertise to vertically integrated companies that offer integrated products for multiple parts of the business and a blend of companies offering software as a service and software packages to implement through licensing arrangements. This section lays out emerging practices for selecting and integrating software solutions into O\&M.

The ultimate goal that this section drives toward is identifying and implementing an appropriate solution for asset management or O\&M plans, which would include functions such as:

- Document archive for complete plant documentation upkeep and reference

- Performance monitoring dashboard with actual performance compared to expected performance for the day, month, year

- Customer/plant interaction tracking logs

- System/portfolio analysis

- Budget tracking 
- Trouble ticket or incident tracking

- Mobile work-order flow management and documentation systems.

Though many of those activities are executed entirely within the O\&M function, the underlying inputs and outputs touch other aspects of the business. The following sections seek to take that broader organizational perspective in approaching appropriate software solutions. The four subsections below cover assessing the need, selecting appropriate solutions, integrating new software, and using decision support software. This discussion is relevant for vertically integrated operations with O\&M in-house and for identifying third-party service providers.

\subsubsection{Assessing Need}

It is important to identify functional requirements of the software before evaluating specific options and trade-offs between different approaches. It is analogous to needing to establish criteria for hiring a new employee before interviews to ensure that the candidate fits the need rather than molding the need to the individual who stands out most in the process. In understanding the needs specific to a project or set of projects, it is perhaps equally important to understand the future trajectory of the firm or portfolio as the current state that the software solutions will benefit right away.

Current state: Below are several of the different data points that can be helpful in the process:

- Stakeholder assessment: Understanding who has an interest in the business challenge at hand and who will be most influential in its successful adoption and implementation. A stakeholder matrix is an approach to cataloguing stakeholders during a change process, such as implementing a software solution, but there are many other frameworks that can serve that purpose.

- Prospective users: Assessing who the users are going to be and what their capabilities and technical skill sets are.

- Data availability: What are available data streams that will feed into new software solutions and how standardized are those inputs.

Future trajectory: Several large asset management firms have reported using Excel spreadsheets to serve critical business support and analysis functions even after scaling, which is a testament to the value of looking ahead to future activities when a need arises for a tool. Areas of analysis to consider about future trajectory include:

- Portfolio growth - size: For example, some firms may be seeking growth while others decide to focus on maximizing profits or market share in a niche. For companies in the growth category, it may make sense to invest in an oversized solution that the firm can grow into over time.

- Portfolio growth - geography: Geographical spread that is anticipated in a growing portfolio has a bearing on solutions that are employed for issues such as training staff and interacting with support staff from software providers or partners.

- Human capital: Assessing how growth in the usage of software might influence human capital needs can play a role in deciding between licensing software packages that are implemented in-house or software as a service, for example. Some firms decide that as they grow, they will not prioritize building core competency in software packages that are 
central to their business but not a strong suit from a human capital and recruiting perspective.

\subsubsection{Selection Criteria}

Selection criteria for software solutions will depend on specific needs and how they compare to what is available internally or on the market, so this section covers some high-level, interconnected considerations that can go into the due diligence process.

Scope: It is often preferred to have a software solution that is an all-in-one product or service. However, this may be hard to find depending on the degree of interconnection between O\&M activities and other aspects of the business. There may not be a platform that spans the different uses that were established in the needs assessment stage, or the all-in-one platform may force a trade-off in quality for particular features or services. There are benefits from integrated solutions, such as alleviating the number of different log-ins and passwords needed to navigate different systems, which is often cited as a challenge, to be weighed against those costs. On the other hand, with good in-house abilities to integrate solutions, it may be optimal to interlink the best fit for different services together.

Human capital requirements: An important determinant of scope decisions is the human capital needs associated with the solutions. At the highest level, human capital needs have bearing on pursuing software-as-service options where limited technical staff are needed, but higher ongoing costs may be incurred or deploying software packages on a licensing basis and leveraging internal talent to interlink them with existing systems.

Outputs: Users of the ever-growing suite of advanced analytics that are available for PV-only and PV plus storage systems sometimes note that data overload can be an issue. Rather than prioritizing solutions with a broad swath of approaches to analyze and output data, it may be more effective to focus on key performance indicators specific to a given context or company and in-house capabilities to parse and understand output data and analytics.

Execution: There are a few practical elements of execution that are valuable to consider upfront in the due diligence process, including the amount of time to make changes in the future and the speed to train new people. There will always be user turnover and training times may differ substantially between different product options.

Track record: As noted elsewhere in this guide, firm track record and financial solvency for providers is important to evaluate before committing to a long-term software solution that will be hard to change later.

\subsubsection{Integration}

Best practices for integrating a new software product depend heavily on the nature of the product and its features. This subsection covers high-level issues to consider. Building on the stakeholder evaluation done in the assessment stage, it can be valuable to reach outside the direct users of the product to raise awareness with other stakeholders. For example, sometimes system owners can benefit from understanding the nature and capabilities of a new tool, even if they will never use it directly. There may also be data standards that can be incorporated in roll-out that would be beneficial to other segments of the business, such as financial reporting functions. 
A key theme throughout this guide is the importance of clear documentation. This is just as important with software solutions as elsewhere in this guide. It is important to develop institutional knowledge and resiliency to staffing changes at software providers and within O\&M staff or service providers.

\subsubsection{Workflow and Decision Support Software}

For plants where onsite environmental sensing equipment is not practical (i.e., most residential plants), measurements of irradiance and ambient temperature should be supplied by a nearby weather station or estimated from satellite data. These proxies for actual irradiance measurements may only be accurate to $< \pm 7 \%$ for global horizontal radiation and $\pm 12 \%$ for direct normal radiation (http://solargis.com/support/knowledge-base/accuracy/overview/) and temperature measurements to $\pm 5^{\circ} \mathrm{C}$ - which increases uncertainty but is currently acceptable in the residential setting as opposed to onsite measurements for such small systems. In fact, this accuracy of satellite data can be more accurate than a poorly maintained or dirty sensor onsite.

A dedicated network connection such as a cellular, satellite, or dedicated broadband backhaul is required for plants that are greater than $100 \mathrm{~kW}$. For smaller plants, where it is not practical to implement a dedicated network connection, a shared network connection may be used, but this raises the service risk profile considerably. In fact, shared Internet Protocol (IP) network outages have been reported by industry-leading vendors as the number-one source of service calls. Where possible, a dedicated network connection is highly recommended.

Onsite data storage is required to prevent data loss during communication network outages. The amount of storage needed depends on the expected mean time to repair should an outage occur. An amount of storage that is equal to two times the highest-recorded communications outage is recommended. If you don't know what the highest recorded communications outage is, six months of data storage is recommended.

Standard data-encryption techniques should be employed to protect the confidentiality and integrity of the data in transit over wide-area networks. For example, the SunSpec Alliance Logger Upload protocol specifies the use of Transport Layer Security standards (e.g., https, SSL) for data transmission over the IP-based networks.

Trouble-report code definitions, corrective actions taken, and results should be standardized at the fleet or large-system level. This allows more definitive tracking of cause-and-effect, repetitive problems, corrective action deficiencies, and more. This also leads to better operating efficiencies, better preventive techniques, identification of large-scale equipment problems, and more.

\subsubsection{Enterprise Asset Management platforms}

Fleet management and aggregation requires developing or adopting software systems termed enterprise asset management (EAM); these are specialized workflow platforms similar to enterprise resource planning (ERP) software.

EAM/O\&M software platforms and services are available from several companies including Meteocontrol, Alectris, Draker Labs, and MaxGen Energy Services (formerly True South), whereas several large-fleet operators such as SolarCity and First Solar have developed their own 
custom platform. Deployment of these software platforms, which are now a requirement for large-fleet operators, enables tight resource control to optimize O\&M cost, especially administration and document cost. 


\section{O\&M Implementation Strategies}

The asset owner or asset manager should allocate sufficient internal resources and secure any required external resources to implement the O\&M plan.

Operating and maintaining a fleet of PV systems requires active resource management and data acquisition and analysis by the asset and operation manager(s).

The choices for resourcing O\&M are:

- Use the EPC company or the installer who built and warrants the system (who has a dedicated plant O\&M department to provide the necessary care)

- Bring the O\&M service in-house

- Outsource the service to a specialized third-party O\&M provider.

Often a mix of these three strategies is chosen, depending on the age of the PV system, provider's business model, system composition (either commercial or residential), fleet geographic density/distribution, and strengths of the available resources in-house.

For commercial systems, the EPC/installer O\&M model is common because most early failures will be warranted, and the provider can perform routine maintenance at the same time. One disadvantage of this model is that the EPC/installer may lack dedicated O\&M resources; thus, O\&M services will compete with higher-margin installation and construction businesses. As warranties expire, the dedicated third-party O\&M model gets more attractive because fleets can be combined or allocated to specialists who may have many systems in geographic concentrations to gain cost advantages.

For residential systems, "vertically integrated" developers/installers are using more in-house services because they can gain an advantage in providing uniform quality across the whole PV system life cycle. Meanwhile, developers using the "partner" residential model - in which the finance and development company partner with an installer-rely on the installer for O\&M services and/or a dedicated third-party O\&M provider as needed.

\subsection{0\&M Contract and Performance Guarantee}

Detailed contract terms are beyond the scope of this document. However, it is important to define the parameters for the O\&M of a PV project during its life. As stated earlier, these conditions must, as a minimum, cover the maintenance requirements to ensure compliance with the individual component warranties and EPCs or the installer's contract guarantee.

Most contracts will specify a fixed cost for plant operations, standard preventive maintenance, and agreed-upon response time, with additional fees for corrective maintenance and non-covered services.

So-called "performance contracts" cite KPIs, which are agreed-to measures of whether the contracted-for level of performance is achieved or not. It is sometimes required for third-partyowned systems to provide a guarantee for the energy yield output and/or the availability of the PV system when plant operations are included in the contract or an O\&M provider is not well known or does not have significant financial backing. It is also possible for the system warranty 
to include targets for the energy yield, PR, or availability (Klise and Balfour 2015). In fact, these warranties are also available from third parties, O\&M contractors, and insurance companies. How each indicator is calculated must be specified in detail, and standards are under development (IEC TC82) to provide standard definitions that distinguish, for example, availability as a fraction of time or as a fraction of energy. The agreed limits are often based on the independently verified energy yield report, produced at the time of commissioning. For an example of the calculation method, see Appendix A. As time goes on, comparison to the initial yield report, from before a system starts operation, becomes less accurate. A multi-year yield report uses average historical weather and irradiance to predict output. Actual output will vary year to year based on actual weather and irradiance. It is more important for the stakeholders to have a yield report based on an acceptable model and then use that same model to measure performance each year based on measured weather and irradiance, as well as operations that may affect the yield such as curtailment of output.

To summarize, important items to observe regarding warranty coverage and performance guarantees include:

- Define what is involved in plant operations - who is watching the system, identifying the issue, and dispatching the required personnel to fix the issue in a timely manner

- Examine the parameters for the PV project preventive maintenance requirements documented during its life, which are required to keep the warranty in effect and identify issues that may void the warranty

- Examine the warranty in terms of KPIs (plant availability, specific energy delivery, and PR) to ensure that each is defined in enough detail such that all parties calculate the same value

- Ensure at the conclusion of an installer warranty, which may be only 1-5 years, that any equipment warranties (which may be as long as 25 years for PV modules) transfer or are designated to the responsible O\&M provider

- Ensure the current status of KPIs is available to all parties in the performance contractboth present values and trends over time. 


\section{Estimating PV O\&M Costs}

Research of the PV O\&M Working Group has concentrated on three estimates related to the cost of delivering a PV O\&M program: annual cash flow, net present value, and reserve account.

1. Annual cash flow: Costs for administrative or preventive maintenance that are scheduled on regular intervals are escalated according to an inflation rate to the year in which they occur. Costs for corrective maintenance are the replacement cost of the component multiplied by the probability that a failure will occur in that year. The probability that a component will fail in any given year is calculated by a Weibull, log-normal, or other distribution that is informed (ideally) by actuarial data. Warranties affect whether a failure will result in hardware costs, labor costs, or both if the year is within the warranty period. This provides a cash flow (\$/year) for each year of an analysis period.

2. Net present value: Each of the future years' cash flows calculated are then discounted to their present value according to a discount rate. The discount rate is the owner's corporate bond rate or "minimum attractive rate of return." Net present value is useful for evaluating an overall financial prospectus and calculating the impact of O\&M on LCOE.

3. Reserve account: The Weibull distribution of failure gives us a good estimate of life cycle cost, but the method spreads the costs over the years and shows a rather uniform average cost per year - when, in fact, expensive repairs can occur all at once (Figure 22).

Financiers and operators want to know "maximum exposure." In other words, what dollar amount of a "reserve account" or "line of credit" would a bank offer to sell to a project? Reserve account is calculated for each year of the analysis period.

Consider a simple example regarding reserve account: A PV system with two inverters, each with a replacement cost of $\$ 10,000$ in year 1 and each with a Weibull failure distribution of mean interval 20 years and shape factor 5.0. In year 20, this failure distribution would predict a probability of failure of $\mathrm{Q}=0.092$, and thus, a probability of non-failure of $\mathrm{P}=0.908$. If we have enough in reserve or in stock to replace NEITHER of the two inverters, then $\mathrm{P} 1 \mathrm{P} 2=\mathrm{P}^{\wedge} \mathrm{N}=$ $(0.908)^{\wedge} 2=0.824$ (you get this level of probability that the reserve account would be sufficient even with no funds in the reserve account). If we have enough in reserve to replace EITHER ONE of the two inverters, the reserve account would be $=\$ 10,000$ (inflated to year 20), and the resulting probability that the reserve amount would be sufficient is P1P2 + P1Q2 + P2Q1 = $0.824+(0.908 * 0.092) * 2=0.991$. If we have enough in reserve to replace BOTH of the inverters, the reserve account $=\$ 20,000$, and the probability that the reserve account is sufficient is P1P2 + $\mathrm{P} 1 \mathrm{Q} 2+\mathrm{P} 2 \mathrm{Q} 1+\mathrm{Q} 1 \mathrm{Q} 2=0.666+0.300+(0.092)^{\wedge} 2=1.00$. So, in this simple example, if the desired availability is 0.824 , then we would need $\$ 0$ in reserve; if the desired availability is 0.991 , then we would need $\$ 10,000$ in reserve; and if the desired reliability is 1.0 , then we would need $\$ 20,000$ in reserve.

We generalize this approach to a very large number of components, $\mathrm{N}$, where $\mathrm{n} / \mathrm{N}$ is the fraction of the total number of components funded in the reserve account; $\mathrm{R}$ is the desired probability that the reserve account will be sufficient; and Q is the probability of failure in each year of the analysis period according to the failure distribution. This is done for each measure (PV module replacement, inverter replacement, every other type of component) and added up to calculate the total amount in the reserve account for each year of the analysis period. 


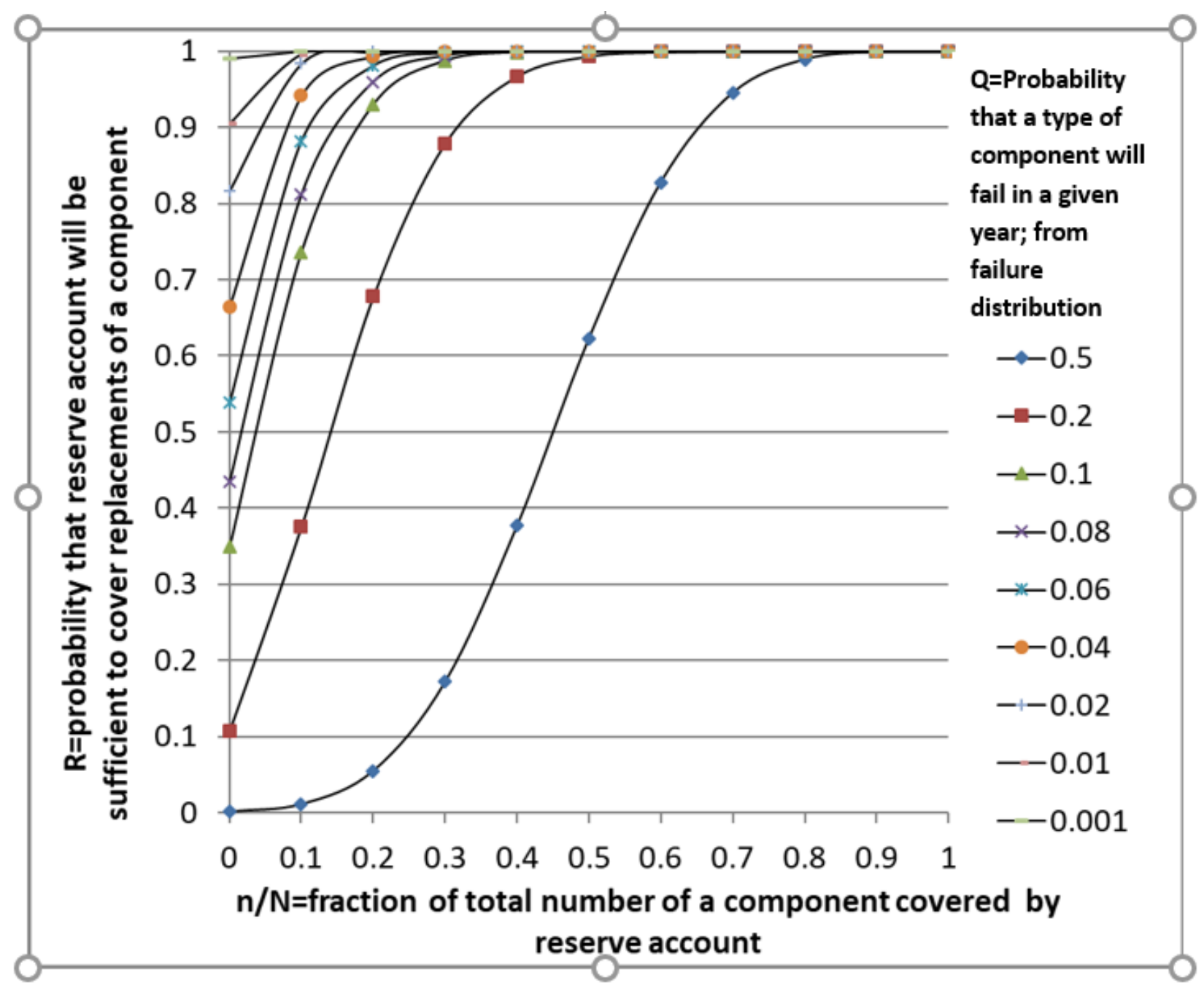

Figure 22. Probability that the reserve account amount will be sufficient to cover costs in a given year as a function of the fraction of the total number of a type of component and the probability of failure of the type of component in that given year. Figure by Andy Walker, NREL

Figure 22 shows a graph of the fraction of components to be covered by the reserve account, depending on the probability of failure in a given year and desired confidence that the reserve account will be sufficient. For example, if we had 10 inverters and the probability of each inverter failing in a given year was $Q=0.1$, and if we desired a probability of $99 \%$ that our reserve account would be sufficient, then we would need to have enough in the reserve account to cover 3.25 times the cost of a single inverter replacement. In reality, low values of Q and high values of $\mathrm{R}$ are of interest, but this chart shows the behavior of the relationship over the whole range.

The PV O\&M Working Group has developed a PV O\&M cost model (version 1.0) with a long list of O\&M measures (Figure 23). Each measure has estimated materials, equipment, and labor costs, many of which are on a per-unit basis (per kilowatt or per square meter). Each measure is applicable based on system type (commercial rooftop, residential, or ground mount); inverter type (micro-, string, DC-optimized, or central-inverter); mounting type (fixed tilt or tracking, attached or ballasted rack); and environmental conditions (snow, pollen, bird populations, 
sand/dust, humidity, heat, high wind, hail, salty air, diesel soot, industrial emissions, nearby construction site, and high insolation). Cost depends on warranty/service plan modeling switches. The PV O\&M cost model is available from NREL and SunSpec.org as a standalone Excel spreadsheet tool for O\&M cost modeling and planning, and an online version is currently being developed at SunSpec Alliance.

The cost model contains selections of scheduled and corrective maintenance tasks that are detailed in Appendices B and C. A list of job roles, requirements, and sample costs are included in Appendix D. As noted above, the model allows customization of all these variables to suit system configuration, job time estimates, failure rates, and local costs.

Administrative and preventive-maintenance measures are on defined schedule intervals (e.g., once per year), whereas corrective-maintenance measures are scheduled according to a failure distribution curve (Weibull distribution) for each measure. Selection by the user of the environmental conditions (e.g., bird populations, pollen, snow) trigger measures such as additional cleanings or snow-removal costs.

This cost model based on failure distribution (Weibull distribution) is an accepted way to estimate net present value of the O\&M program, which is useful in a life cycle cost analysis (for a feasibility study) or to estimate metrics such as cents $/ \mathrm{kWh}$ delivered or average $\$ / \mathrm{kW} /$ year. However, financiers and system operators also need to know the maximum exposure. This is the amount that should be secured in a line of credit or reserve fund to cover worst-case scenarios of O\&M costs. The need for this is exemplified by a 924-kW carport system that was down for 2 years because the owner did not have funds immediately available to replace a failed inverter. Accurately estimating this maximum exposure based on statistics has proven to be prohibitively complex if the number of components exceeds approximately 10, which is the case even for a small PV system. Thus, the PV O\&M cost model takes a simpler approach of identifying (with a "1" or a " 0 ") which of the long list of measures and costs should be included in the reserve account, and this would include major items such as complete inverter replacement. 


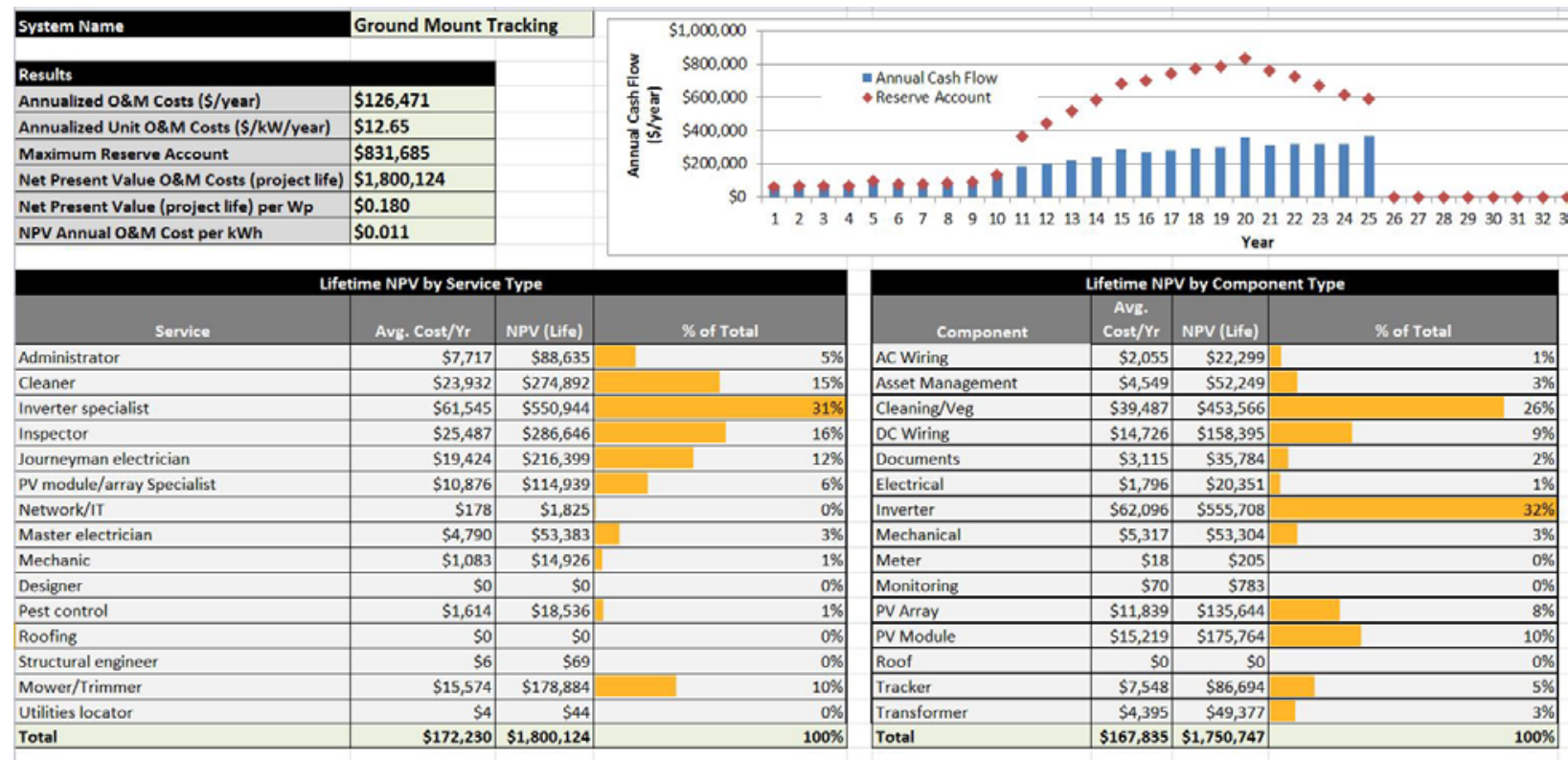

Figure 23. Results of PV O\&M cost model for 10-MW ground-mount PV system with tracking, central inverters, and pollen as an environmental condition. Figure by Andy Walker, NREL 


\section{PV O\&M Cost Survey Information and Trends}

In a 2018 report LBNL researchers report that average O\&M costs for a sample of 39 utilityscale PV projects have declined from about \$31/kWAC-year (or \$20/MWh) in 2011 to about \$16/kWAC-year (\$8.4/MWh) in 2017 (Bollinger and See 2018).

EPRI (2015) reported average O\&M budgets costs of $\$ 16 / \mathrm{kW} /$ year in 2016, down from over $\$ 20 / \mathrm{kW} /$ year reported in 2015 for utility-scale systems. Overall budget for O\&M varies from $\$ 10.00-45.00 / \mathrm{kW}-\mathrm{yr}$, and the report provides a breakdown of cost for General Site Maintenance \$0.20-\$3.00/kW-yr; Wiring/Electrical Inspection \$1.40-\$5.00/kW-yr; Cleaning \$0.80-\$1.30/kWyr; Vegetation Management \$0.50-1.80/kW-yr; Inverter Maintenance \$3.00-7.50/kW-yr; Inverter Replacement $\$ 6.00-10.00 / \mathrm{kW}$; and Spares $\$ 2.00-\$ 20.00 / \mathrm{kW}-\mathrm{yr})$. In 2010, EPRI reported costs of $\$ 6-\$ 27 / \mathrm{kW} /$ year $(<1 \%$ to $5 \%$ of installed cost per year) for systems less than $1 \mathrm{MW}$ and costs of $\$ 47-\$ 60 / \mathrm{kW} /$ year for larger utility-scale systems, depending on PV type and fixed or tracking mounts (EPRI 2010). An early study reports O\&M costs of $\$ 12 / \mathrm{kW} /$ year or $0.17 \%$ of capital cost without tracking and $0.35 \%$ of initial cost with tracking (Mortensen 2001).

The Federal Energy Management Program (FEMP) has tabulated O\&M costs for grid-tied distributed generation-scale systems varying from $\$ 21 \pm \$ 20 / \mathrm{kW} /$ year for systems $<10 \mathrm{~kW}$ to $\$ 19 \pm \$ 10 / \mathrm{kW} /$ year for large systems $>1$ MW (NREL 2013).

Another estimate approximates O\&M of PV systems at $\$ 40 / \mathrm{kW} /$ year (about $0.5 \%$ of initial cost per year for these early systems), about half of which is amortized inverter replacements (Wiser, Barbose, and Peterman 2009).

Data collected by Tucson Electric Power from 2002 to 2006 (Tucson Electric Power 2007) report annual preventive maintenance at $0.04 \%$ to $0.08 \%$ of initial cost per year and corrective/reactive unplanned maintenance at $0.01 \%$ to $0.22 \%$ of initial cost per year. The average combined cost for these utility-scale ground-mounted systems was $0.16 \% /$ year. Costs are not evenly distributed, with several years of low cost punctuated by a year of high cost when the inverter is replaced.

Arizona Public Service reports $0.35 \%$ of initial costs for O\&M exclusive of inverter replacements (Moore and Post 2008) for large grid-connected systems. For small off-grid systems with batteries, Arizona Public Service reports that the average annual O\&M cost is 5\%$6 \%$ of the initial capital cost (Canada et al. 2005) and that travel time and mileage account for $42 \%$ of the unscheduled maintenance cost of these remote systems.

Members of the working group have discussed these results and are currently recommending $0.5 \%$ for large systems and $1 \%$ of system initial cost per year for small systems as a reasonable expectation of PV system O\&M costs.

These heuristics inform an expectation of PV system O\&M costs. The PV O\&M cost model allows a customized, if not more accurate, estimate of system cost based on system type and components and on environmental conditions. Survey data on cost and backup service providers are being correlated with model test data to "calibrate" the cost model. The cost model can also lay out year-by-year fluctuations in O\&M costs based on scheduled intervals for preventive measures, failure distributions that increase with age, and inflation in the cost of O\&M services. 


\section{References}

Akhil, Abbas A., Georgianne Huff, Aileen B. Currier, Benjamin C. Kaun, Dan M. Rastler, Stella Bingqing Chen, Andrew L. Cotter, Dale T. Bradshaw, and William D. Gauntlett. 2013. DOE/EPRI 2013 Electricity Storage Handbook in Collaboration with NRECA. Albuquerque, NM: Sandia National Laboratories. http://www.sandia.gov/ess/publications/SAND20135131.pdf.

Anderson, Kate, Kari Burman, Travis Simpkins, Erica Helson, Lars Lisell, and Tria Case. 2016. New York Solar Smart DG Hub-Resilient Solar Project: Economic and Resiliency Impact of PV and Storage on New York Critical Infrastructure. NREL/TP-7A40-66617. Golden, CO: National Renewable Energy Laboratory. http://www.nrel.gov/docs/fy16osti/66617.pdf.

Ardani, Kristen, Eric O'Shaughnessy, Ran Fu, Chris McClurg, Joshua Huneycutt, Robert Margolis. 2017. Installed Cost Benchmarks and Deployment Barriers for Residential Solar Photovoltaics with Energy Storage: Q1 2016. NREL/TP-7A40-67474. Golden, CO: National Renewable Energy Laboratory. https://www.nrel.gov/docs/fy17osti/67474.pdf.

ASTM. 2013. ASTM E2848-13, Standard Test Method for Reporting Photovoltaic NonConcentrator System Performance. West Conshohocken, PA: ASTM International.

Bollinger and See, 2018. "Empirical Trends in Project Technology, Cost, Performance, and PPA Pricing in the United States - 2018 Edition." Mark Bolinger and Joachim Seel. Accessed September 17, 2018; https://www.researchgate.net/profile/Joachim_Seel/publication/327607147_UtilityScale_Solar_Empirical_Trends_in_Project_Technology_Cost_Performance_and_PPA_Pricing_i n the United_States_- 2018 Edition/links/5b99983b299bf14ad4d69024/Utility-Scale-SolarEmpirical-Trends-in-Project-Technology-Cost-Performance-and-PPA-Pricing-in-the-UnitedStates-2018-Edition.pdf?origin=publication detail.

Brehaut, C. 2015. Megawatt-Scale PV O\&M and Asset Management 2015-2020: Services, Markets and Competitors. Boston: GTM Research. http://splunk01.nrel.gov/store/GTM/GTM2015/Megawatt-Scale-PV-OM-Asset-Management2015-2020-Report.pdf.

Cameron, C.P., W.E. Boyson, and D.M. Riley. 2008. "Comparison of PV System PerformanceModel Predictions with Measured PV System Performance.” Photovoltaic Specialists Conference. PVSC'08. 33rd IEEE.

Canada, S., L. Moore, H. Post, and J. Strachan. 2005. “Operation and Maintenance Field Experience for Off-Grid Residential Photovoltaic Systems.” Progress in Photovoltaics: Research and Applications 13, no. 1: 67-74.

Dhere, N.G. 2005. "Reliability of PV Modules and Balance-of-System Components." Conference Record of the Thirty-First IEEE Photovoltaic Specialist Conference. IEEE Cat. No. 05CH37608, pp. 1570-6. 
Dierauf, T., A. Growitz, S. Kurtz, J.L. Becerra Cruz, E. Riley, and C. Hansen. 2013. WeatherCorrected Performance Ratio. NREL/TP-5200-57991. Golden, CO: NREL. www.nrel.gov/docs/fy13osti/57991.pdf.

Buck, Matt. 2018. "EPRI: New guideline and webtool help standardize O\&M assessments." Energy-Tech, 2018. https://www.energy-tech.com/plant_operations/article_662ee820-1c0211e8-8ffa-0b69a1 eceb9d.html.

Electric Power Research Institute (EPRI). 2010. Addressing Solar Photovoltaic Operations and Maintenance Challenges -A Survey of Current Knowledge and Practices. https://www.epri.com/\#/pages/product/000000000001021496/?lang=en.

EPRI. 2015. Budgeting for Solar PV Plant O\&M: Practices \& Pricing. https://www.epri.com/\#/pages/product/3002006218/?lang=en.

Electric Utility Consultants, Inc. (EUCI). 2016. "PV O\&M Best Practices." Workshop with presentations by Matt Brinkman, Burns \& McDonnell; Zach Kreifels, First Solar; Johnny Nicholson, First Solar. March 2016, Phoenix AZ.

ESCO Associates, Inc. Forthcoming. SunEdison 1 Megawatt PV Array Vegetation Test Plots Final Report. Golden, CO: NREL.

Feldman et al (2018) David Feldman, Jack Hoskins, Robert Margolis, "Q4 2017/Q1 2018 Solar Industry Update" May 2018 NREL/PR-6A20-71493 Freeman, Janine, Jonathan Whitmore, Nate Blair, and Aron P. Dobos. 2014. Validation of Multiple Tools for Flat Plate Photovoltaic Modeling Against Measured Data. Golden, CO: National Renewable Energy Laboratory. https://www.nrel.gov/docs/fy14osti/61497.pdf.

Gaines, Linda, and Paul Nelson. 2010. Lithium-Ion Batteries: Examining Material Demand and Recycling Issues. Lemont, IL: Argonne National Laboratory. https://anl.app.box.com/s/ywkdwjaqsc61vtqkakhmhg06tm3adfgl.

Gies, Erica. 2015. "Recycling: Lazarus Batteries.” Nature 526, S100-S101. doi:10.1038/526S100a.

Hernandez, R.R., S.B. Easter, M.L. Murphy-Mariscal, F.T. Maestre, M. Tavassoli, E.B. Allen, C.W. Barrows, J. Belnap, R. Ochoa-Hueso, S. Ravi, and M.F. Allen. 2014. "Environmental Impacts of Utility-Scale Solar Energy." Renewable and Sustainable Energy Reviews 29: 766-99. https://www.sciencedirect.com/science/article/pii/S1364032113005819.

HomeAdvisor. 2016. "Nail Down the Cost of Your Roofing Project." Accessed December 2016. http://welcome.homeadvisor.com/costguide roofing

HomeAdvisor. 2018. "How Much Does It Cost to Repair a Roof?” Accessed July 2018. https://www.homeadvisor.com/cost/roofing/repair-a-roof/. 
Huff, J. 2013. “Solar Farm Grounds Management Vegetation Control.” Blog. Chesterfield, VA: Abakus Solar. http://www.abakus-solar.us/blog/solar-farm-pv-power-plant-groundsmanagement-vegetation-control/.

IEC 61724. 1998. International Electrotechnical Commission (IEC). 1998. "IEC 61724 ed1.0." Geneva, Switzerland: IEC. Accessed November 2014. https://webstore.iec.ch/searchform\&q $=61724$.

IEC 61850. 2003. "IEC TR 61850-1:2013 Communication networks and systems for power utility automation - Part 1: Introduction and overview." Accessed September 17, 2018. https://webstore.iec.ch/publication/6007.

IEC 62446. 2017. "IEC TS 62446-3:2017 Photovoltaic (PV) systems - Requirements for testing, documentation and maintenance." Geneva, Switzerland: IEC. Accessed December 2014. https://webstore.iec.ch/publication/28628.

IEC 63019. 2018. "IEC TS 63019 ED1 Information model for availability of photovoltaic (PV) power systems.” Geneva, Switzerland: IEC. Accessed September 2018. http://www.iec.ch/dyn/www/f?p=103:38:0::::FSP ORG ID,FSP APEX PAGE,FSP PROJECT ID: $1276,23,22635$.

IEEE. 2010. "IEEE 1679: IEEE Recommended Practice for the Characterization and Evaluation of Emerging Energy Storage Technologies in Stationary Applications."

https://ieeexplore.ieee.org/document/5618903.

IEEE. 2007. "IEEE 937: Recommended Practice for Installation and Maintenance of Lead-Acid Batteries for Photovoltaic (PV) Systems.” https://ieeexplore.ieee.org/document/4238866.

International Renewable Energy Agency (IRENA). 2016. End-of-Life Management: Solar Photovoltaic Panels. Abu Dhabi: IRENA.

http://www.irena.org/DocumentDownloads/Publications/IRENA_IEAPVPS End-ofLife Solar_PV_Panels_2016.pdf.

Jordan, D., and S. Kurtz. 2012. Photovoltaic Degradation Rates-An Analytical Review. NREL/JA-5200-51664. Golden, CO: NREL. https:/www.nrel.gov/docs/fy12osti/51664.pdf.

Keating, T.J., A. Walker, and K. Ardani. 2015. SAPC Best Practices in PV Operations and Maintenance. NREL/SR-6A20-63235. Golden, CO: National Renewable Energy Laboratory. https://www.nrel.gov/docs/fy15osti/63235.pdf.

Klise, G., and J. Balfour. 2015. A Best Practice for Developing Availability Guarantee Language in Photovoltaic (PV) O\&M Agreements. SAND2015-10223. Albuquerque, NM: Sandia National Laboratories. https://doi.org/10.2172/1227340.

Kurtz, S., E. Riley, J. Newmiller, T. Dierauf, A. Kimber, J. McKee, R. Flottemesch, and P. Krishnani. 2013. Analysis of Photovoltaic System Energy Performance Evaluation Method. Golden, CO: National Renewable Energy Laboratory. https://www.nrel.gov/docs/fy14osti/60628.pdf. 
Larsen, K. 2009. "End-of-Life PV: Then What? - Recycling Solar PV Panels." Renewable Energy Focus. Accessed September 2016.

http://www.renewableenergyfocus.com/view/3005/end-of-life-pv-then-what-recycling-solar-pvpanels/.

Lazard. 2016. Lazard's Levelized Cost of Storage - Version 2.0. https://www.lazard.com/media/438042/lazard-levelized-cost-of-storage-v20.pdf.

Moore, L.M., and H.N. Post. 2008. "Five Years of Operating Experience at a Large, UtilityScale Photovoltaic Generating Plant." Progress in Photovoltaics: Research and Applications 16, no. 3: 249-59.

Naeem, Mohammad Hussain. 2014. "Soiling of Photovoltaic Modules: Modelling and Validation of Location-Specific Cleaning Frequency Optimization.” Master's thesis, Arizona State University.

Neubauer, J. 2014. Battery Lifetime Analysis and Simulation Tool (BLAST) Documentation. NREL/TP-5400-63246. Golden, CO: National Renewable Energy Laboratory. https://www.nrel.gov/docs/fy15osti/63246.pdf.

National Fire Protection Agency (NFPA). 2012. "70E: Standard for Electrical Safety in the Workplace.” Quincy, MA: National Fire Protection Agency.

oSPARC. 2018. open System Performance and Reliability Clearinghouse; SunSpec Alliance; Accessed September 14, 2018; https://sunspec.org/osparchelp/.

Pacific Northwest National Laboratory (PNNL). 2014. Inventory of Safety-Related Codes and Standards for Energy Storage Systems with some Experiences Related to Approval and Acceptance. http://www.sandia.gov/ess/docs/safety/ESS Inventory 9-15-14 PNNL 23618.pdf.

PNNL and Sandia National Laboratories (Sandia). 2016. Energy Storage System Guide for Compliance with Safety Codes and Standards. http://www.sandia.gov/ess/publications/SAND2016-5977R.pdf.

Rosewater, David. 2015. Energy Storage System Safety - Codes and Standards. Albuquerque, NM: Sandia National Laboratories.

http://www.sandia.gov/ema sp/assets/documents/EMA_2 5 SAND_ESS_Codes and Standar ds_1130_Rosewater_Day_2m.pdf.

Ryberg, David Severin, and Janine Freeman. 2017. Integration, Validation, and Application of a PV Snow Coverage Model in SAM. Golden, CO: National Renewable Energy Laboratory. https://www.nrel.gov/docs/fy17osti/68705.pdf.

Thevenard, D. 2010. Uncertainty in Long-Term Photovoltaic Yield Predictions. Natural Resources Canada. Report 2010-122 (RP-TEC) 411-IEARES. March 31, 2010, https://www.nrcan.gc.ca/sites/www.nrcan.gc.ca/files/canmetenergy/files/pubs/2010-122.pdf. 
U.S. Department of Transportation (DOT). 1999. Asset Management Primer, 1999. U.S.

Department of Transportation Federal Highway Administration Office of Asset Management. https://www.fhwa.dot.gov/asset/pubs.cfm, previously

https://www.fhwa.dot.gov/infrastructure/asstmgmt/amprimer.pdf. 


\section{Appendix A. System Performance Guarantee Example Calculation (Without Shade Correction)}

\section{Exhibit}

\section{Commercial System: System Performance Guarantee}

IEC 61724 describes a PR, a temperature-corrected PR, and PRs based on either STC data or performance test condition data (IEC 1998). PR is actual energy delivery divided by the energy delivery estimated based on environmental conditions and exclusions such as clipping (when DC output exceeds AC output). In other words, PR is the measured electrical yield divided by POA irradiance, divided by nameplate rating, and multiplied by the reference irradiation value (e.g., $1,000 \mathrm{~W} / \mathrm{m}^{2}$ ) corresponding to the nameplate rating, where the electrical yield and POA irradiance are integrated over the same time period. If conducted over a short time period, this example of PR will be inaccurate because this PR will vary substantially based on the time of year it is calculated and weather. This variation caused by weather could be improved using weather-adjusted energy performance index and availability. PR can vary, up or down, year to year, and this operator gets penalized for a year when it is down but does not get rewarded for a year when it is up. In addition to using different metrics for a guarantee, multi-year averaging or a penalty/reward type of system for calculating the guarantee can address this inequity.

The PR of the system is defined as follows:

$$
P R=\frac{Y_{f}}{Y_{r}}=\frac{E}{P_{n}} * \frac{I_{S T C}}{H_{m}}
$$

where:

$\mathbf{Y}_{\mathbf{f}}=$ number of production equivalent hours recorded at the STC.

$\mathbf{Y}_{\mathbf{r}}=$ number of irradiation equivalent hours at the STC.

$\mathbf{E}=$ actual energy output ( $\mathrm{kWh}$ ) plus that number of $\mathrm{kWh}$ based on the operator's goodfaith calculation lost during the contract year due to force majeure event(s) and/or by any action or inaction of the owner, utility, or host.

$\mathbf{P}_{\mathbf{n}}=$ nominal peak power of the PV plant $\left(\mathrm{kW}_{\mathrm{p}}\right)$ equal to XXXX.00 kWp.

$\mathbf{H}_{\mathrm{m}}=$ actual irradiance during the performance period recorded through a pyranometer $\left(\mathrm{kWh} / \mathrm{m}^{2}\right)$. The PR is usually defined relative to the POA irradiance. Global horizontal (historical reported weather) data are fed into a model to correct for PV module orientation.

$\mathbf{I}_{\mathbf{S T C}}=$ standard condition of the irradiation equal to $1 \mathrm{kWh} / \mathrm{m}^{2}$.

Within 20 business days of the end of each contract year, the operator shall provide to the owner a written report setting forth the following information: 
A. The actual energy output produced by the system in $\mathrm{kWh}$ as recorded by the DAS for the 12-month period of the contract year, plus that number of kWh based on the operator's good-faith calculation lost during the contract year due to force majeure event(s) and/or by any action or inaction of the owner, utility, or host and as reviewed by the owner's technical representative at the owner's sole discretion.

B. The actual annual insolation for the contract year calculated as the sum of the monthly insolation levels measured in the POA or measured in the global horizontal plane and corrected for orientation of the PV modules in units of $\mathrm{kWh} / \mathrm{m}^{2}$ for the system, as recorded by the DAS for the 12-month period of the contract year.

With respect to the data set forth in each annual report provided by the operator, the operator guarantees for each combined period $i$ of one contract year ("PR Performance Period") during the 20 contract years following the effective date that the actual relevant PR during the performance period exceeds or equals the expected PR of the system for the contract year

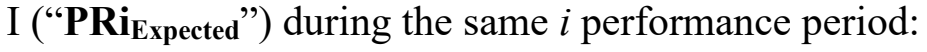

$$
\text { PRi } \geq \text { PRiExpected }
$$

where:

$\mathbf{P R} \boldsymbol{i}$ is the PR directly measured onsite, as described above, for the performance period "i".

$\mathbf{P R}_{\text {iExpected }}$ is the expected PR to be achieved by the operator under its obligations pursuant this agreement ("Expected Performance Ratio").

The operator shall achieve a PR contracted after availability for as listed below:

$$
\mathrm{PR}_{\text {iExpected }}=82.8 \times \mathrm{K} \times(1-\mathrm{Y} \text { iDegradation }) \times\left(\mathrm{Y}_{\text {Availability }}\right)
$$

where:

$\mathbf{Y}_{\text {iDegradation is }} 0.5 \%$ from the previous year.

$\mathbf{Y}_{\text {Availability is }} 98 \%$ (for the first year) and $99 \%$ (for the second and subsequent years).

$\mathbf{K}$ is the corrective factor equal to 1.3 for mono-axial tracker-based systems and 1 for fixed systems. 
Table A-1. Example of Annual Degradation included in tabulation of Availability and Performance Ratio

\begin{tabular}{|c|c|c|c|c|}
\hline Year & $\begin{array}{c}\text { Degradation \% } \\
\text { from Previous } \\
\text { Year } \\
\text { Y Degradation }\end{array}$ & $\begin{array}{c}\text { Cumulative } \\
\text { Degradation } \\
\text { of the } \\
\text { Modules } \\
Y_{\text {Degradation }} \\
\end{array}$ & $\begin{array}{l}\text { Availability } \\
Y_{\text {Availability }}\end{array}$ & $\begin{array}{l}\text { PRi Expected } \\
\text { (for each } \\
\text { year i) }\end{array}$ \\
\hline 0 & $0.50 \%$ & $0.00 \%$ & & \\
\hline 1 & $0.50 \%$ & $0.50 \%$ & $98 \%$ & $108.20 \%$ \\
\hline 2 & $0.50 \%$ & $1.00 \%$ & $99 \%$ & $107.66 \%$ \\
\hline 3 & $0.50 \%$ & $1.50 \%$ & $99 \%$ & $107.12 \%$ \\
\hline 4 & $0.50 \%$ & $2.00 \%$ & $99 \%$ & $106.59 \%$ \\
\hline 5 & $0.50 \%$ & $2.50 \%$ & $99 \%$ & $106.06 \%$ \\
\hline 6 & $0.50 \%$ & $3.00 \%$ & $99 \%$ & $105.52 \%$ \\
\hline 7 & $0.50 \%$ & $3.50 \%$ & $99 \%$ & $105.00 \%$ \\
\hline 8 & $0.50 \%$ & $4.00 \%$ & $99 \%$ & $104.47 \%$ \\
\hline 9 & $0.50 \%$ & $4.50 \%$ & $99 \%$ & $103.95 \%$ \\
\hline 10 & $0.50 \%$ & $5.00 \%$ & $99 \%$ & $103.43 \%$ \\
\hline 11 & $0.50 \%$ & $5.50 \%$ & $99 \%$ & $102.91 \%$ \\
\hline 12 & $0.50 \%$ & $6.00 \%$ & $99 \%$ & $102.40 \%$ \\
\hline 13 & $0.50 \%$ & $6.50 \%$ & $99 \%$ & $101.89 \%$ \\
\hline 14 & $0.50 \%$ & $7.00 \%$ & $99 \%$ & $101.38 \%$ \\
\hline 15 & $0.50 \%$ & $7.50 \%$ & $99 \%$ & $100.87 \%$ \\
\hline 16 & $0.50 \%$ & $8.00 \%$ & $99 \%$ & $100.37 \%$ \\
\hline 17 & $0.0 \%$ & $8.50 \%$ & $99 \%$ & $99.86 \%$ \\
\hline 18 & $0.50 \%$ & $9.00 \%$ & $99 \%$ & $99.36 \%$ \\
\hline 19 & $0.50 \%$ & $9.50 \%$ & $99 \%$ & $98.87 \%$ \\
\hline 20 & $0.50 \%$ & $10.00 \%$ & $99 \%$ & $98.37 \%$ \\
\hline
\end{tabular}

Non-availability due to willful act or willful negligence of the owner, force majeure, or interruptions requested by or agreed with the owner will imply an equivalent reduction in $\mathrm{H}_{\mathrm{m}}$. These outages may vary and should be defined and agreed to by the stakeholders when crafting the guarantee language. 
Should the PRi of the system for a performance period fall short of the PR $i_{\text {Expected }}$ of the system during the $i$ performance period, as described in Table A-1, the operator shall pay the owner an amount in U.S. dollars equal to:

$$
\mathrm{LDs}=\mathrm{H}_{\mathrm{m}} * \mathrm{P}_{\mathrm{p}} *\left(\mathrm{PR} \mathrm{i}_{\text {Expected }}-\mathrm{PR}_{\mathrm{i}}\right) * \mathrm{R}
$$

where:

LDs = amount of performance liquidated damages.

$\mathbf{H}_{\mathrm{m}}=$ reference horizontal plane irradiation during the PR performance period.

$\mathbf{P}_{\mathbf{p}}=$ installed nameplate capacity of the plant $\left(\mathrm{kW}_{\mathrm{p}}\right)$.

$\mathbf{P R}=\mathrm{PR}$ measured on the plant during the reference period.

PR $\mathbf{i}_{\text {Expected }}=$ the PR expected.

$\mathbf{R}=$ average post-time-of-day (TOD) PPA-contracted revenue per unit of electricity generated, equal to $\$ / \mathrm{kWh}$. 


\section{Appendix B. PV O\&M Cost Model Preventive Maintenance Service Descriptions}

\section{Table B-1. Service Descriptions for Preventive Maintenance Selections Available in the PV O\&M Cost Model Tool}

Consult equipment manuals for maintenance activities and intervals as required by the manufacturer.

\begin{tabular}{|c|c|c|c|c|c|c|c|}
\hline Service Name & Service Description & $\begin{array}{l}\text { Service } \\
\text { Category }\end{array}$ & $\begin{array}{l}\text { O\&M } \\
\text { Category }\end{array}$ & Interval & $\begin{array}{l}\text { Service } \\
\text { Provider }\end{array}$ & $\begin{array}{l}\text { Warranty } \\
\text { Type }\end{array}$ & $\begin{array}{l}\text { Applicable } \\
\text { Unit }\end{array}$ \\
\hline $\begin{array}{l}\text { General } \\
\text { cleaning }\end{array}$ & $\begin{array}{l}\text { General } \\
\text { cleaning/vegetation } \\
\text { mobilization }\end{array}$ & Cleaning & PV array & $\begin{array}{l}\text { Condition or } \\
\text { study } \\
\text { dependent }\end{array}$ & Mower/ trimmer & $\mathrm{N} / \mathrm{A}$ & Site \\
\hline Array cleaning & Array cleaning & Cleaning & PV array & $\begin{array}{l}\text { Condition or } \\
\text { study } \\
\text { dependent }\end{array}$ & Cleaner & $\mathrm{N} / \mathrm{A}$ & Acre \\
\hline Snow cleaning & Snow removal & Cleaning & PV module & $\begin{array}{l}\text { Condition or } \\
\text { study } \\
\text { dependent }\end{array}$ & Cleaner & N/A & Acre \\
\hline Dust cleaning & $\begin{array}{l}\text { Dust removal: } \\
\text { agricultural/industrial }\end{array}$ & Cleaning & PV module & $\begin{array}{l}\text { Condition or } \\
\text { study } \\
\text { dependent }\end{array}$ & Cleaner & $\mathrm{N} / \mathrm{A}$ & Acre \\
\hline Pollen cleaning & Pollen cleaning & Cleaning & PV module & $\begin{array}{l}\text { Condition or } \\
\text { study } \\
\text { dependent }\end{array}$ & Cleaner & N/A & Acre \\
\hline $\begin{array}{l}\text { Vegetation } \\
\text { management }\end{array}$ & $\begin{array}{l}\text { Determine if any new } \\
\text { objects, such as vegetation } \\
\text { growth, are causing } \\
\text { shading of the array and } \\
\text { move them if possible; } \\
\text { remove any debris from } \\
\text { behind collectors and from } \\
\text { gutters }\end{array}$ & Cleaning & PV array & As needed & Mower/ trimmer & $\mathrm{N} / \mathrm{A}$ & Acres \\
\hline Bird cleaning & Bird cleaning & Cleaning & PV array & Bi-annual & Cleaner & $\mathrm{N} / \mathrm{A}$ & Acres \\
\hline
\end{tabular}




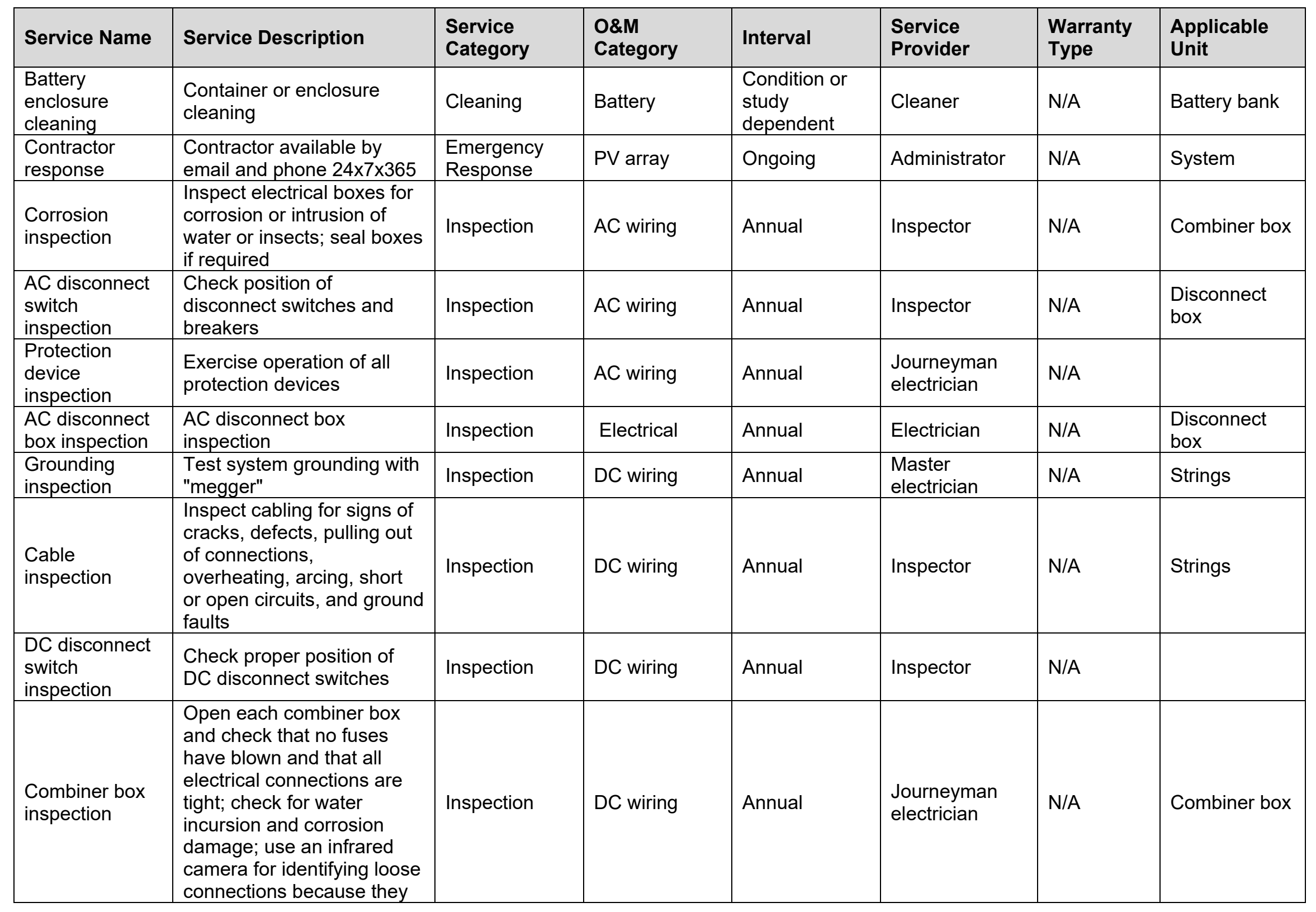




\begin{tabular}{|c|c|c|c|c|c|c|c|}
\hline Service Name & Service Description & $\begin{array}{l}\text { Service } \\
\text { Category }\end{array}$ & $\begin{array}{l}\text { O\&M } \\
\text { Category }\end{array}$ & Interval & $\begin{array}{l}\text { Service } \\
\text { Provider }\end{array}$ & $\begin{array}{l}\text { Warranty } \\
\text { Type }\end{array}$ & $\begin{array}{l}\text { Applicable } \\
\text { Unit }\end{array}$ \\
\hline & $\begin{array}{l}\text { are warmer than good } \\
\text { connections when passing } \\
\text { current }\end{array}$ & & & & & & \\
\hline $\begin{array}{l}\text { Electrical box } \\
\text { inspection }\end{array}$ & $\begin{array}{l}\text { Look for any signs of } \\
\text { intrusion by pests such as } \\
\text { insects and rodents; } \\
\text { remove any nests from } \\
\text { electrical boxes (junction } \\
\text { boxes, pull boxes, combiner } \\
\text { boxes) or around the array; } \\
\text { use safe sanitation } \\
\text { practices because pests } \\
\text { may carry disease }\end{array}$ & Inspection & DC wiring & Annual & Pest control & $\mathrm{N} / \mathrm{A}$ & \\
\hline $\begin{array}{l}\text { Inverter } \\
\text { inspection }\end{array}$ & $\begin{array}{l}\text { Observe instantaneous } \\
\text { operational indicators on } \\
\text { the faceplate of the inverter } \\
\text { to ensure that the amount } \\
\text { of power being generated is } \\
\text { typical of the conditions; } \\
\text { compare current readings } \\
\text { with diagnostic benchmark; } \\
\text { inspect inverter housing or } \\
\text { shelter for physical } \\
\text { maintenance required if } \\
\text { present. }\end{array}$ & Inspection & $\begin{array}{l}\text { Inverter } \\
\text { (electrical) }\end{array}$ & Annual & Inspector & $\mathrm{N} / \mathrm{A}$ & Inverter \\
\hline $\begin{array}{l}\text { Instrument } \\
\text { inspection }\end{array}$ & $\begin{array}{l}\text { Spot-check monitoring } \\
\text { instruments (e.g., } \\
\text { pyranometer) with hand- } \\
\text { held instruments to ensure } \\
\text { that they are operational } \\
\text { and within specifications }\end{array}$ & Inspection & Monitoring & Annual & Inspector & N/A & \\
\hline $\begin{array}{l}\text { String } \\
\text { inspection }\end{array}$ & $\begin{array}{l}\text { Test open-circuit voltage of } \\
\text { series strings of modules }\end{array}$ & Inspection & PV array & Annual & $\begin{array}{l}\text { PV module/ } \\
\text { array specialist }\end{array}$ & $N / A$ & Strings \\
\hline $\begin{array}{l}\text { Corrosion } \\
\text { inspection }\end{array}$ & $\begin{array}{l}\text { Check all hardware for } \\
\text { signs of corrosion and } \\
\text { remove rust and re-paint if } \\
\text { necessary }\end{array}$ & Inspection & $\begin{array}{l}\text { PV array } \\
\text { (mechanical) }\end{array}$ & Annual & Inspector & N/A & Connection \\
\hline
\end{tabular}




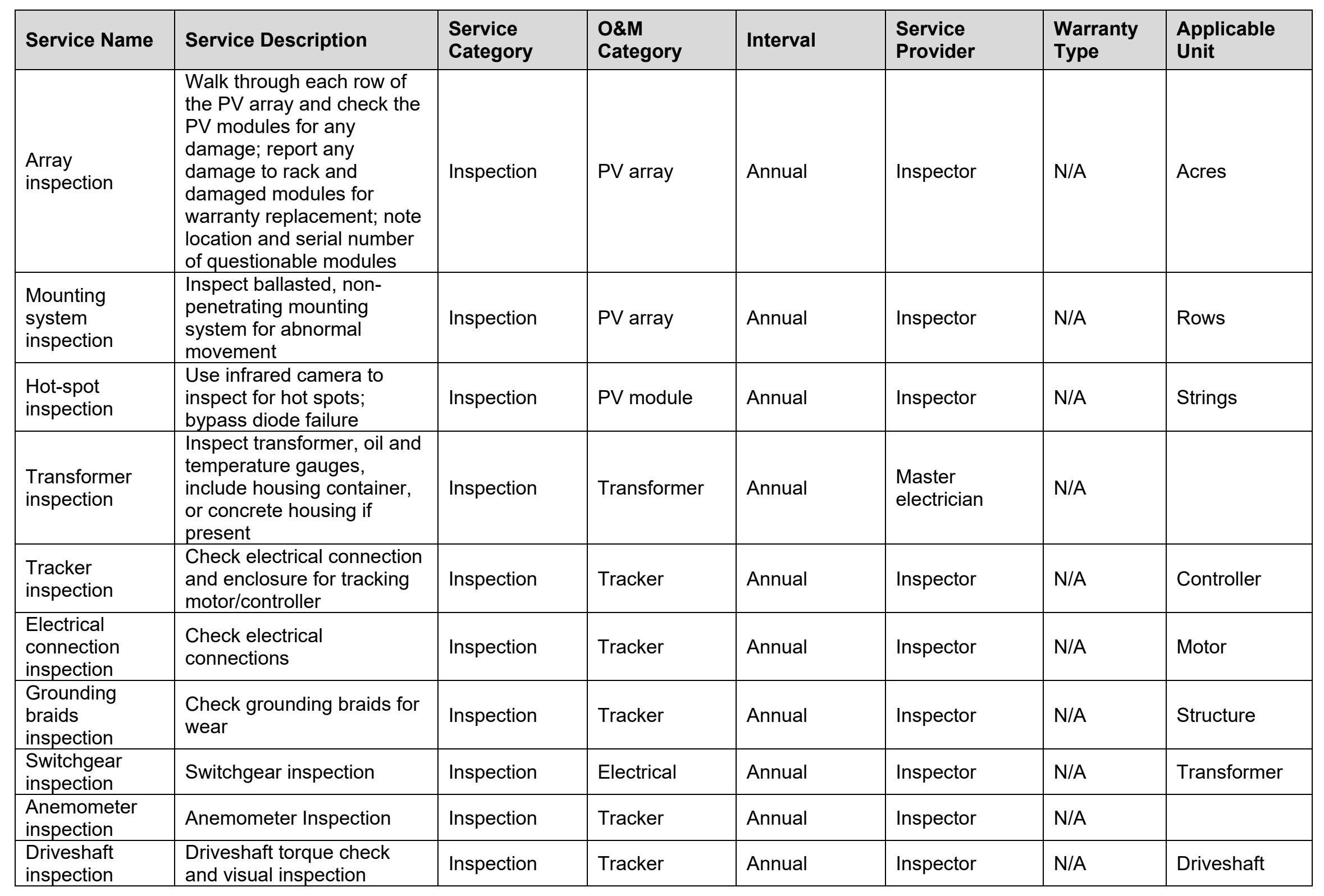




\begin{tabular}{|c|c|c|c|c|c|c|c|}
\hline Service Name & Service Description & $\begin{array}{l}\text { Service } \\
\text { Category }\end{array}$ & $\begin{array}{l}\text { O\&M } \\
\text { Category }\end{array}$ & Interval & $\begin{array}{l}\text { Service } \\
\text { Provider }\end{array}$ & $\begin{array}{l}\text { Warranty } \\
\text { Type }\end{array}$ & $\begin{array}{l}\text { Applicable } \\
\text { Unit }\end{array}$ \\
\hline $\begin{array}{l}\text { Inclinometer } \\
\text { inspection }\end{array}$ & Inclinometer inspection & Inspection & Tracker & Annual & Inspector & $\mathrm{N} / \mathrm{A}$ & \\
\hline $\begin{array}{l}\text { Module table } \\
\text { inspection }\end{array}$ & Module table inspection & Inspection & Tracker & Annual & Inspector & $\mathrm{N} / \mathrm{A}$ & Connection \\
\hline $\begin{array}{l}\text { Screw jack } \\
\text { inspection }\end{array}$ & Screw jack inspection & Inspection & Tracker & Bi-annual & Inspector & N/A & Block \\
\hline $\begin{array}{l}\text { Torque } \\
\text { inspection }\end{array}$ & Torque inspection & Inspection & Mechanical & Annual & Inspector & $\mathrm{N} / \mathrm{A}$ & Block \\
\hline $\begin{array}{l}\text { Tracking } \\
\text { controller } \\
\text { inspection }\end{array}$ & $\begin{array}{l}\text { Tracking controller } \\
\text { inspection }\end{array}$ & Inspection & Tracker & Annual & Inspector & $\mathrm{N} / \mathrm{A}$ & \\
\hline Gear inspection & $\begin{array}{l}\text { Universal joint inspection, } \\
\text { gears, gear boxes, and } \\
\text { bearings as required or } \\
\text { documented by } \\
\text { manufacturer }\end{array}$ & Inspection & Tracker & Annual & Inspector & $\mathrm{N} / \mathrm{A}$ & Driveshaft \\
\hline $\begin{array}{l}\text { Module torque } \\
\text { inspection }\end{array}$ & $\begin{array}{l}\text { PV module torque check } \\
\text { and visual inspection }\end{array}$ & Inspection & Mechanical & 5 years & $\begin{array}{l}\mathrm{PV} \\
\text { module/array } \\
\text { specialist }\end{array}$ & $\mathrm{N} / \mathrm{A}$ & Rail/fastener \\
\hline $\begin{array}{l}\text { Racking torque } \\
\text { inspection }\end{array}$ & $\begin{array}{l}\text { Racking torque check and } \\
\text { inspection }\end{array}$ & Inspection & Mechanical & 5 years & Inspector & $\mathrm{N} / \mathrm{A}$ & Structure \\
\hline $\begin{array}{l}\text { Galvanization } \\
\text { inspection }\end{array}$ & Galvanization inspection & Inspection & Mechanical & Annual & Inspector & $\mathrm{N} / \mathrm{A}$ & Connection \\
\hline $\begin{array}{l}\text { Corrosion } \\
\text { inspection }\end{array}$ & $\begin{array}{l}\text { Check all hardware for } \\
\text { signs of corrosion and } \\
\text { remove rust and re-paint if } \\
\text { necessary }\end{array}$ & Inspection & Battery & Annual & Inspector & $\mathrm{N} / \mathrm{A}$ & Battery bank \\
\hline $\begin{array}{l}\text { String } \\
\text { inspection }\end{array}$ & $\begin{array}{l}\text { Chemistry dependent, test } \\
\text { voltage, and resistance at } \\
\text { module, cell, and } \\
\text { connection level as } \\
\text { appropriate }\end{array}$ & Inspection & Battery & $\begin{array}{l}\text { Condition or } \\
\text { study } \\
\text { dependent }\end{array}$ & $\begin{array}{l}\text { Battery } \\
\text { specialist }\end{array}$ & $\mathrm{N} / \mathrm{A}$ & Battery bank \\
\hline
\end{tabular}




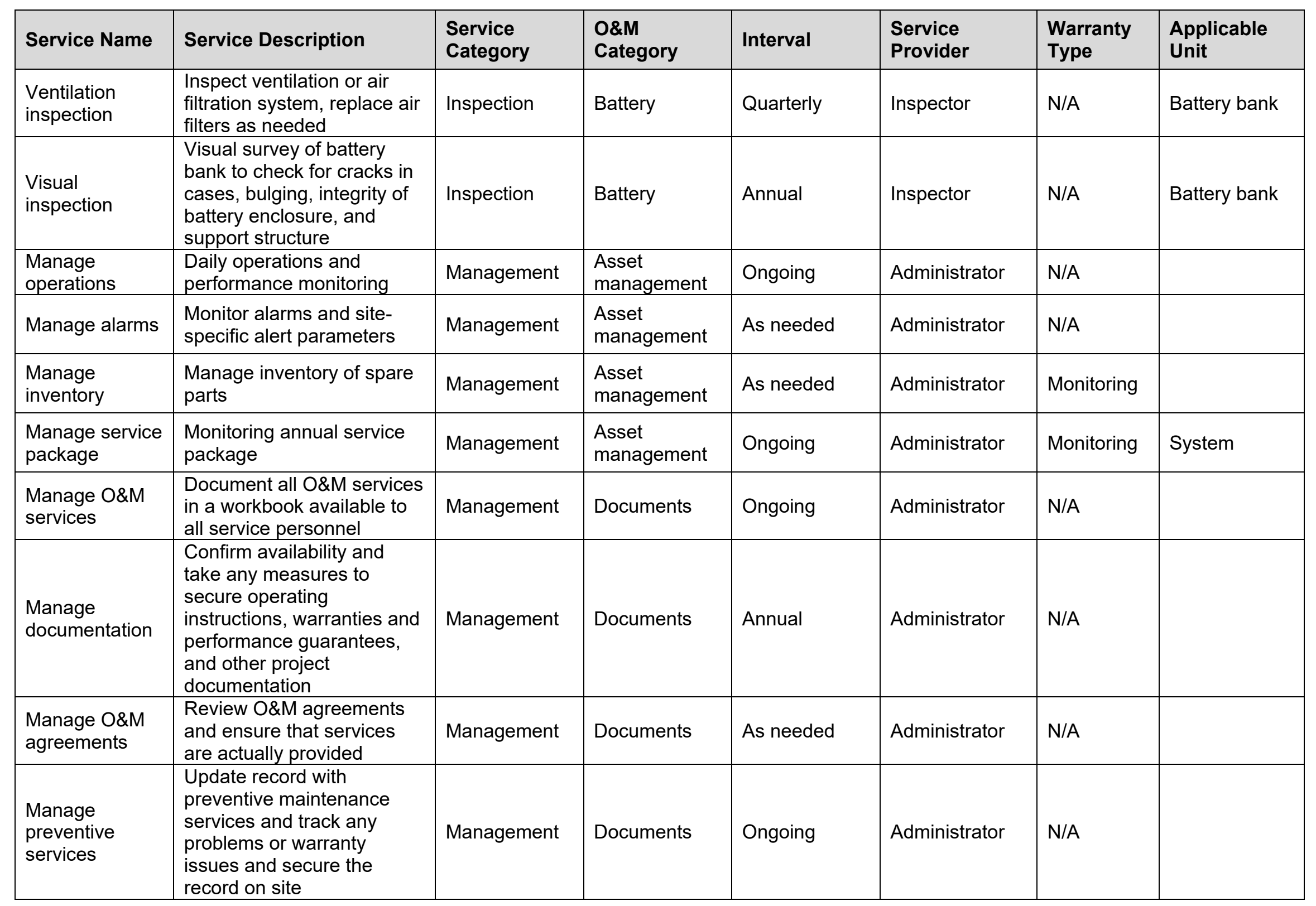




\begin{tabular}{|c|c|c|c|c|c|c|c|}
\hline Service Name & Service Description & $\begin{array}{l}\text { Service } \\
\text { Category }\end{array}$ & $\begin{array}{l}\text { O\&M } \\
\text { Category }\end{array}$ & Interval & $\begin{array}{l}\text { Service } \\
\text { Provider }\end{array}$ & $\begin{array}{l}\text { Warranty } \\
\text { Type }\end{array}$ & $\begin{array}{l}\text { Applicable } \\
\text { Unit }\end{array}$ \\
\hline $\begin{array}{l}\text { Meet with site } \\
\text { staff }\end{array}$ & $\begin{array}{l}\text { Meet with key site staff to } \\
\text { continue awareness, } \\
\text { question any issues, and } \\
\text { report on findings }\end{array}$ & Management & Documents & Annual & Administrator & $\mathrm{N} / \mathrm{A}$ & \\
\hline Maintain log & $\begin{array}{l}\text { Maintain a log of cumulative } \\
\text { power delivery (kWh to } \\
\text { date) and chart this value } \\
\text { against date; chart the } \\
\text { value even for uneven or } \\
\text { infrequent intervals; explain } \\
\text { variation by season or } \\
\text { weather }\end{array}$ & Management & Meter & Monthly & Administrator & N/A & \\
\hline $\begin{array}{l}\text { Mobilize } \\
\text { electrical labor }\end{array}$ & Electrical labor mobilization & Management & Electrical & Annual & $\begin{array}{l}\text { Master } \\
\text { electrician }\end{array}$ & EPC & Site \\
\hline $\begin{array}{l}\text { Mobilize } \\
\text { mechanical } \\
\text { labor }\end{array}$ & $\begin{array}{l}\text { Mechanical labor } \\
\text { mobilization }\end{array}$ & Management & Mechanical & Annual & Mechanic & EPC & Site \\
\hline $\begin{array}{l}\text { Re-torque AC } \\
\text { connection }\end{array}$ & $\begin{array}{l}\text { Re-torque all electrical } \\
\text { connections on AC side of } \\
\text { system }\end{array}$ & Service & AC wiring & Annual & $\begin{array}{l}\text { Journeyman } \\
\text { electrician }\end{array}$ & N/A & \\
\hline $\begin{array}{l}\text { Re-torque } \\
\text { combiner box } \\
\text { connections }\end{array}$ & $\begin{array}{l}\text { Re-torque all electrical } \\
\text { connections in combiner } \\
\text { box }\end{array}$ & Service & DC wiring & Annual & Electrician & $\mathrm{N} / \mathrm{A}$ & Combiner box \\
\hline $\begin{array}{l}\text { Replace } \\
\text { weather } \\
\text { sensors } \\
\end{array}$ & $\begin{array}{l}\text { Calibrate or replace } \\
\text { weather sensors and } \\
\text { meters }\end{array}$ & Service & Electrical & $\begin{array}{l}\text { As per } \\
\text { manufacturer }\end{array}$ & Network/ IT & N/A & $\begin{array}{l}\text { Weather } \\
\text { station }\end{array}$ \\
\hline $\begin{array}{l}\text { Replace } \\
\text { transient } \\
\text { voltage surge } \\
\text { suppression } \\
\text { device }\end{array}$ & $\begin{array}{l}\text { Replace transient voltage } \\
\text { surge suppression devices }\end{array}$ & Service & Inverter & $\begin{array}{l}\text { As per } \\
\text { manufacturer }\end{array}$ & $\begin{array}{l}\text { Master } \\
\text { electrician }\end{array}$ & Inverter & \\
\hline
\end{tabular}




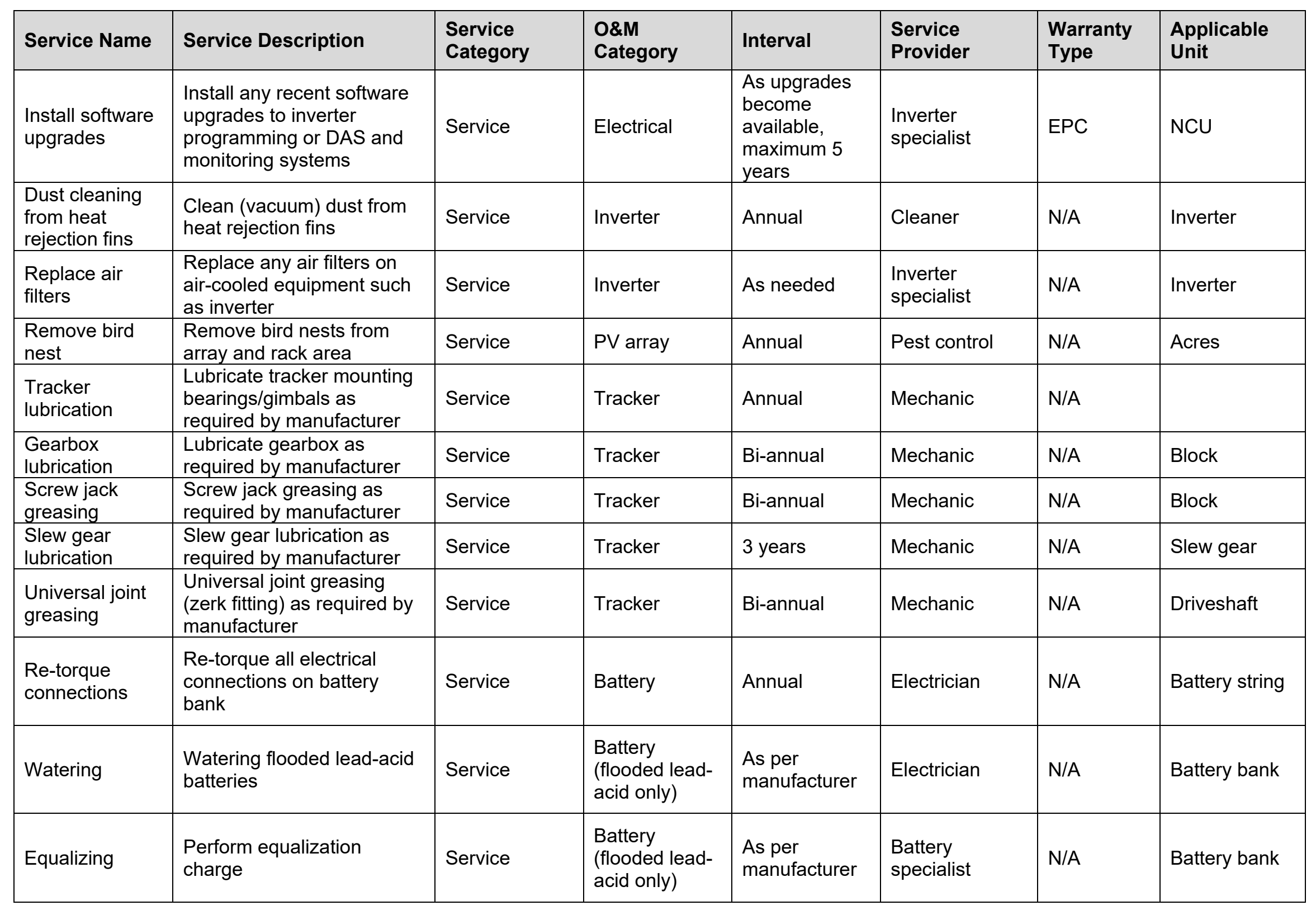




\begin{tabular}{|c|c|c|c|c|c|c|c|}
\hline Service Name & Service Description & $\begin{array}{l}\text { Service } \\
\text { Category }\end{array}$ & $\begin{array}{l}\text { O\&M } \\
\text { Category }\end{array}$ & Interval & $\begin{array}{l}\text { Service } \\
\text { Provider }\end{array}$ & $\begin{array}{l}\text { Warranty } \\
\text { Type }\end{array}$ & $\begin{array}{l}\text { Applicable } \\
\text { Unit }\end{array}$ \\
\hline $\begin{array}{l}\text { Performance } \\
\text { testing }\end{array}$ & $\begin{array}{l}\text { Perform performance test: } \\
\text { measure incident sunlight } \\
\text { and simultaneously observe } \\
\text { temperature and energy } \\
\text { output; calculate PV } \\
\text { module efficiency as a } \\
\text { function of temperature and } \\
\text { calculate the balance-of- } \\
\text { system efficiency; compare } \\
\text { readings with diagnostic } \\
\text { benchmark (original } \\
\text { efficiency of system) }\end{array}$ & Testing & Inverter & Annual & Inspector & $\mathrm{N} / \mathrm{A}$ & \\
\hline $\begin{array}{l}\text { Overvoltage } \\
\text { surge } \\
\text { suppressor } \\
\text { testing }\end{array}$ & $\begin{array}{l}\text { Test overvoltage surge } \\
\text { suppressors in inverter }\end{array}$ & Testing & Inverter & 5 Years & $\begin{array}{l}\text { Inverter } \\
\text { specialist }\end{array}$ & Inverter & Inverter \\
\hline Module testing & $\begin{array}{l}\text { Test modules showing } \\
\text { corrosion of ribbons to } \\
\text { junction box }\end{array}$ & Testing & PV module & 5 years & $\begin{array}{l}\text { Journeyman } \\
\text { electrician }\end{array}$ & $\mathrm{N} / \mathrm{A}$ & Modules \\
\hline $\begin{array}{l}\text { Combiner box } \\
\text { inspection }\end{array}$ & $\begin{array}{l}\text { DC circuit test and } \\
\text { combiner-box inspection }\end{array}$ & Testing & Electrical & Annual & $\begin{array}{l}\text { PV module/ } \\
\text { array specialist }\end{array}$ & N/A & Combiner box \\
\hline $\begin{array}{l}\text { Module } \\
\text { electrical } \\
\text { connection } \\
\text { testing }\end{array}$ & $\begin{array}{l}\text { PV module electrical } \\
\text { connection check }\end{array}$ & Testing & Electrical & 5 years & $\begin{array}{l}\text { PV module/ } \\
\text { array specialist }\end{array}$ & $\mathrm{N} / \mathrm{A}$ & PV module \\
\hline $\begin{array}{l}\text { Grounding } \\
\text { hardware } \\
\text { testing }\end{array}$ & Check grounding hardware & Testing & Electrical & Annual & $\begin{array}{l}\text { Master } \\
\text { electrician }\end{array}$ & N/A & Structure \\
\hline
\end{tabular}




\section{Appendix C. PV O\&M Cost Model Corrective Maintenance Service Descriptions}

The following is a list of corrective/reactive maintenance measures that would be performed to fix problems encountered in operation of a PV system over time.

Table C-1. Service Descriptions for Corrective Maintenance Selections Available in the PV O\&M Cost Model

\begin{tabular}{|c|c|c|c|c|c|c|c|}
\hline Service Name & Service Description & $\begin{array}{l}\text { Service } \\
\text { Category }\end{array}$ & $\begin{array}{l}\text { O\&M } \\
\text { Category }\end{array}$ & Interval & $\begin{array}{l}\text { Service } \\
\text { Provider }\end{array}$ & $\begin{array}{l}\text { Warranty } \\
\text { Type }\end{array}$ & $\begin{array}{l}\text { Applicable } \\
\text { Unit }\end{array}$ \\
\hline $\begin{array}{l}\text { Dispatch } \\
\text { contractor }\end{array}$ & $\begin{array}{l}\text { Dispatch contractor in } \\
\text { response to alarms, } \\
\text { alerts, or contact by } \\
\text { others }\end{array}$ & $\begin{array}{l}\text { Emergency } \\
\text { response }\end{array}$ & PV array & As needed & Administrator & Monitoring & \\
\hline $\begin{array}{l}\text { Replace inverter } \\
\text { AC fuse }\end{array}$ & $\begin{array}{l}\text { Replace inverter AC } \\
\text { fuse(s) }\end{array}$ & Repair & $A C$ wiring & As needed & $\begin{array}{l}\text { Journeyman } \\
\text { electrician }\end{array}$ & EPC & \\
\hline $\begin{array}{l}\text { Replace protective } \\
\text { devices }\end{array}$ & $\begin{array}{l}\text { Replace protective } \\
\text { devices (breakers) in } \\
\text { building panel }\end{array}$ & Repair & $A C$ wiring & As needed & $\begin{array}{l}\text { Master } \\
\text { electrician }\end{array}$ & $\mathrm{N} / \mathrm{A}$ & \\
\hline $\begin{array}{l}\text { Replace AC wiring } \\
\text { conduit }\end{array}$ & $\begin{array}{l}\text { Replace } \\
\text { broken/crushed AC } \\
\text { wiring conduit and } \\
\text { fittings }\end{array}$ & Repair & $A C$ wiring & As needed & $\begin{array}{l}\text { Journeyman } \\
\text { electrician }\end{array}$ & $\mathrm{N} / \mathrm{A}$ & Strings \\
\hline $\begin{array}{l}\text { Repair line-to-line } \\
\text { fault }\end{array}$ & $\begin{array}{l}\text { Repair line-to-line } \\
\text { fault }\end{array}$ & Repair & $A C$ wiring & As needed & $\begin{array}{l}\text { Master } \\
\text { electrician }\end{array}$ & $\mathrm{N} / \mathrm{A}$ & \\
\hline $\begin{array}{l}\text { Locate line-to-line } \\
\text { fault }\end{array}$ & $\begin{array}{l}\text { Locate line-to-line } \\
\text { fault }\end{array}$ & Repair & $A C$ wiring & As needed & $\begin{array}{l}\text { Master } \\
\text { electrician }\end{array}$ & EPC & \\
\hline $\begin{array}{l}\text { Replace combiner } \\
\text { box fuses }\end{array}$ & $\begin{array}{l}\text { Replace failed fuses } \\
\text { in combiner box }\end{array}$ & Repair & DC wiring & As needed & $\begin{array}{l}\text { Journeyman } \\
\text { electrician }\end{array}$ & N/A & Strings \\
\hline $\begin{array}{l}\text { Replace } \\
\text { connectors } \\
\text { between module }\end{array}$ & $\begin{array}{l}\text { Replace connectors } \\
\text { between modules }\end{array}$ & Repair & DC wiring & As needed & $\begin{array}{l}\text { PV module/ } \\
\text { array specialist }\end{array}$ & $\begin{array}{l}\text { Module } \\
\text { (product) }\end{array}$ & Modules \\
\hline $\begin{array}{l}\text { Replace MC } \\
\text { connector lead to } \\
\text { combiner box } \\
\end{array}$ & $\begin{array}{l}\text { Replace MC } \\
\text { connector lead to } \\
\text { combiner box }\end{array}$ & Repair & DC wiring & As needed & $\begin{array}{l}\text { PV module/ } \\
\text { array specialist }\end{array}$ & $\begin{array}{l}\text { Module } \\
\text { (product) }\end{array}$ & Modules \\
\hline Re-route conduit & Re-route conduit & Repair & DC wiring & As needed & $\begin{array}{l}\text { Journeyman } \\
\text { electrician }\end{array}$ & N/A & \\
\hline
\end{tabular}




\begin{tabular}{|c|c|c|c|c|c|c|c|}
\hline Service Name & Service Description & $\begin{array}{l}\text { Service } \\
\text { Category }\end{array}$ & $\begin{array}{l}\text { O\&M } \\
\text { Category }\end{array}$ & Interval & $\begin{array}{l}\text { Service } \\
\text { Provider }\end{array}$ & $\begin{array}{l}\text { Warranty } \\
\text { Type }\end{array}$ & $\begin{array}{l}\text { Applicable } \\
\text { Unit }\end{array}$ \\
\hline $\begin{array}{l}\text { Replace DC wiring } \\
\text { conduit }\end{array}$ & $\begin{array}{l}\text { Replace } \\
\text { broken/crushed DC } \\
\text { wiring conduit and } \\
\text { fittings }\end{array}$ & Repair & DC wiring & As needed & $\begin{array}{l}\text { Journeyman } \\
\text { electrician }\end{array}$ & $\mathrm{N} / \mathrm{A}$ & \\
\hline $\begin{array}{l}\text { Repair ground } \\
\text { fault }\end{array}$ & Repair ground fault & Repair & DC wiring & As needed & $\begin{array}{l}\text { Master } \\
\text { electrician }\end{array}$ & EPC & \\
\hline $\begin{array}{l}\text { Locate ground } \\
\text { fault }\end{array}$ & Locate ground fault & Repair & DC wiring & As needed & $\begin{array}{l}\text { Master } \\
\text { electrician }\end{array}$ & EPC & \\
\hline $\begin{array}{l}\text { Locate } \\
\text { underground DC } \\
\text { wiring }\end{array}$ & $\begin{array}{l}\text { Locate underground } \\
\text { DC wiring as part of } \\
\text { repairs to faults }\end{array}$ & Repair & DC wiring & As needed & Utilities locator & $\mathrm{N} / \mathrm{A}$ & \\
\hline $\begin{array}{l}\text { Repair DC direct- } \\
\text { bury wire }\end{array}$ & $\begin{array}{l}\text { Carefully dig to } \\
\text { expose fault and } \\
\text { repair wire }\end{array}$ & Repair & DC wiring & As needed & $\begin{array}{l}\text { Journeyman } \\
\text { electrician }\end{array}$ & EPC & \\
\hline $\begin{array}{l}\text { Replace fuse on } \\
\text { DC source circuits } \\
\text { to inverter }\end{array}$ & $\begin{array}{l}\text { Replace fuse(s) on } \\
\text { DC source circuits to } \\
\text { inverter }\end{array}$ & Repair & DC wiring & As needed & $\begin{array}{l}\text { Master } \\
\text { electrician }\end{array}$ & EPC & \\
\hline $\begin{array}{l}\text { Repair junction } \\
\text { box }\end{array}$ & $\begin{array}{l}\text { Seal leaking junction } \\
\text { box }\end{array}$ & Repair & DC wiring & As needed & $\begin{array}{l}\text { Journeyman } \\
\text { electrician }\end{array}$ & $\begin{array}{l}\text { Module } \\
\text { (product) }\end{array}$ & Modules \\
\hline Reboot inverter & $\begin{array}{l}\text { Start/stop inverter } \\
\text { (reboot to clear } \\
\text { unknown error) }\end{array}$ & Repair & Inverter & As needed & Inspector & EPC & Inverter \\
\hline $\begin{array}{l}\text { Replace inverter } \\
\text { fan motor }\end{array}$ & $\begin{array}{l}\text { Replace inverter fan } \\
\text { motor }\end{array}$ & Repair & Inverter & As needed & $\begin{array}{l}\text { Inverter } \\
\text { specialist }\end{array}$ & Inverter & Inverter \\
\hline $\begin{array}{l}\text { Replace inverter } \\
\text { data acquisition } \\
\text { card }\end{array}$ & $\begin{array}{l}\text { Replace inverter data } \\
\text { acquisition } \\
\text { card/board; diagnose } \\
\text { with fault code }\end{array}$ & Repair & Inverter & As needed & $\begin{array}{l}\text { Inverter } \\
\text { specialist }\end{array}$ & Inverter & Inverter \\
\hline $\begin{array}{l}\text { Replace inverter } \\
\text { control card }\end{array}$ & $\begin{array}{l}\text { Replace inverter } \\
\text { control card (signal, } \\
\text { voltage, phase, } \\
\text { frequency, } \\
\text { shutdown); diagnose } \\
\text { with fault code }\end{array}$ & Repair & Inverter & As needed & $\begin{array}{l}\text { Inverter } \\
\text { specialist }\end{array}$ & Inverter & Inverter \\
\hline $\begin{array}{l}\text { Replace IGBT } \\
\text { driver }\end{array}$ & $\begin{array}{l}\text { Replace IGBT driver } \\
\text { card/board; diagnose } \\
\text { with fault code }\end{array}$ & Repair & Inverter & As needed & $\begin{array}{l}\text { Inverter } \\
\text { specialist }\end{array}$ & Inverter & Inverter \\
\hline
\end{tabular}




\begin{tabular}{|c|c|c|c|c|c|c|c|}
\hline Service Name & Service Description & $\begin{array}{l}\text { Service } \\
\text { Category }\end{array}$ & $\begin{array}{l}\text { O\&M } \\
\text { Category }\end{array}$ & Interval & $\begin{array}{l}\text { Service } \\
\text { Provider }\end{array}$ & $\begin{array}{l}\text { Warranty } \\
\text { Type }\end{array}$ & $\begin{array}{l}\text { Applicable } \\
\text { Unit }\end{array}$ \\
\hline $\begin{array}{l}\text { Replace maximum } \\
\text { power-point } \\
\text { tracker }\end{array}$ & $\begin{array}{l}\text { Replace maximum } \\
\text { power-point tracker } \\
\text { card/board; diagnose } \\
\text { with fault code }\end{array}$ & Repair & Inverter & As needed & $\begin{array}{l}\text { Inverter } \\
\text { specialist }\end{array}$ & Inverter & Inverter \\
\hline $\begin{array}{l}\text { Replace AC } \\
\text { contactor in } \\
\text { inverter }\end{array}$ & $\begin{array}{l}\text { Replace AC } \\
\text { contactor in inverter }\end{array}$ & Repair & Inverter & As needed & $\begin{array}{l}\text { Inverter } \\
\text { specialist }\end{array}$ & Inverter & Inverter \\
\hline $\begin{array}{l}\text { Replace IGBT } \\
\text { matrix in inverter }\end{array}$ & $\begin{array}{l}\text { Replace IGBT matrix } \\
\text { in inverter }\end{array}$ & Repair & Inverter & As needed & $\begin{array}{l}\text { Inverter } \\
\text { specialist }\end{array}$ & Inverter & Inverter \\
\hline $\begin{array}{l}\text { Replace power } \\
\text { supply for inverter } \\
\text { controls }\end{array}$ & $\begin{array}{l}\text { Replace } 24 \text { VDC } \\
\text { power supply for } \\
\text { inverter controls }\end{array}$ & Repair & Inverter & As needed & $\begin{array}{l}\text { Inverter } \\
\text { specialist }\end{array}$ & EPC & Inverter \\
\hline $\begin{array}{l}\text { Replace DC } \\
\text { contactor in } \\
\text { inverter }\end{array}$ & $\begin{array}{l}\text { Replace DC } \\
\text { contactor in inverter }\end{array}$ & Repair & Inverter & As needed & $\begin{array}{l}\text { Inverter } \\
\text { specialist }\end{array}$ & Inverter & Inverter \\
\hline $\begin{array}{l}\text { Replace ground } \\
\text { fault interruption } \\
\text { (GFI) components }\end{array}$ & $\begin{array}{l}\text { Replace GFI } \\
\text { components in } \\
\text { inverter }\end{array}$ & Repair & Inverter & As needed & $\begin{array}{l}\text { Inverter } \\
\text { specialist }\end{array}$ & Inverter & Inverter \\
\hline $\begin{array}{l}\text { Replace } \\
\text { capacitors }\end{array}$ & $\begin{array}{l}\text { Replace capacitors in } \\
\text { inverter }\end{array}$ & Repair & Inverter & As needed & $\begin{array}{l}\text { Inverter } \\
\text { specialist }\end{array}$ & Inverter & Inverter \\
\hline Replace induction & $\begin{array}{l}\text { Replace inductors } \\
\text { (coils) in inverter }\end{array}$ & Repair & Inverter & As needed & $\begin{array}{l}\text { Inverter } \\
\text { specialist }\end{array}$ & Inverter & Inverter \\
\hline $\begin{array}{l}\text { Replace fuses } \\
\text { internal to inverter }\end{array}$ & $\begin{array}{l}\text { Replace fuses } \\
\text { internal to inverter }\end{array}$ & Repair & Inverter & As needed & $\begin{array}{l}\text { Inverter } \\
\text { specialist }\end{array}$ & Inverter & Inverter \\
\hline $\begin{array}{l}\text { Replace inverter } \\
\text { relay/switch }\end{array}$ & $\begin{array}{l}\text { Replace inverter } \\
\text { relay/switch }\end{array}$ & Repair & Inverter & As needed & $\begin{array}{l}\text { Inverter } \\
\text { specialist }\end{array}$ & Inverter & Inverter \\
\hline $\begin{array}{l}\text { Replace } \\
\text { overvoltage surge } \\
\text { suppressors }\end{array}$ & $\begin{array}{l}\text { Replace overvoltage } \\
\text { surge suppressors for } \\
\text { inverter }\end{array}$ & Repair & Inverter & As needed & $\begin{array}{l}\text { Inverter } \\
\text { specialist }\end{array}$ & Inverter & Inverter \\
\hline Re-install software & $\begin{array}{l}\text { Re-install inverter } \\
\text { control software }\end{array}$ & Repair & Inverter & As needed & $\begin{array}{l}\text { Inverter } \\
\text { specialist }\end{array}$ & EPC & Inverter \\
\hline Reset arc-fault trip & $\begin{array}{l}\text { Manual reset of arc- } \\
\text { fault trip (NEC } \\
690.11 \text { ) }\end{array}$ & Repair & Inverter & As needed & $\begin{array}{l}\text { Inverter } \\
\text { specialist }\end{array}$ & EPC & Inverter \\
\hline Restore internet & $\begin{array}{l}\text { Restore lost internet } \\
\text { connection }\end{array}$ & Repair & Monitoring & As needed & Network/ IT & $\mathrm{N} / \mathrm{A}$ & Site \\
\hline
\end{tabular}




\begin{tabular}{|c|c|c|c|c|c|c|c|}
\hline Service Name & Service Description & $\begin{array}{l}\text { Service } \\
\text { Category }\end{array}$ & $\begin{array}{l}\text { O\&M } \\
\text { Category }\end{array}$ & Interval & $\begin{array}{l}\text { Service } \\
\text { Provider }\end{array}$ & $\begin{array}{l}\text { Warranty } \\
\text { Type }\end{array}$ & $\begin{array}{l}\text { Applicable } \\
\text { Unit }\end{array}$ \\
\hline $\begin{array}{l}\text { Replace } \\
\text { foundation } \\
\text { element }\end{array}$ & $\begin{array}{l}\text { Excavate and replace } \\
\text { failed foundation } \\
\text { element }\end{array}$ & Repair & PV array & As needed & $\begin{array}{l}\text { Structural } \\
\text { engineer }\end{array}$ & $\mathrm{N} / \mathrm{A}$ & \\
\hline Replace rack parts & $\begin{array}{l}\text { Repair or replace } \\
\text { rack parts damaged } \\
\text { by corrosion or } \\
\text { physical damage }\end{array}$ & Repair & PV array & As needed & Mechanic & EPC & \\
\hline Replace modules & $\begin{array}{l}\text { Replace modules } \\
\text { failing performance } \\
\text { test and infrared scan } \\
\text { after showing cracks } \\
\text { in glazing, } \\
\text { discoloration of } \\
\text { metallic contacts, } \\
\text { delamination, or } \\
\text { signs of water }\end{array}$ & Repair & PV module & As needed & $\begin{array}{l}\text { Journeyman } \\
\text { electrician }\end{array}$ & $\begin{array}{l}\text { Module } \\
\text { (product) }\end{array}$ & Modules \\
\hline $\begin{array}{l}\text { Repair module } \\
\text { backsheet }\end{array}$ & $\begin{array}{l}\text { Repair cracking of PV } \\
\text { module backsheet }\end{array}$ & Repair & PV module & As needed & $\begin{array}{l}\text { Journeyman } \\
\text { electrician }\end{array}$ & $\begin{array}{l}\text { Module } \\
\text { (product) }\end{array}$ & Modules \\
\hline $\begin{array}{l}\text { Repair module } \\
\text { frame }\end{array}$ & $\begin{array}{l}\text { Repair or replace } \\
\text { damage to module } \\
\text { frame }\end{array}$ & Repair & PV module & As needed & Mechanic & $\begin{array}{l}\text { Module } \\
\text { (product) }\end{array}$ & Modules \\
\hline Repair roof leaks & $\begin{array}{l}\text { Repair roof leaks as } \\
\text { related to PV } \\
\text { structure penetration } \\
\text { problems }\end{array}$ & Repair & Roof & As needed & Roofer & $\mathrm{N} / \mathrm{A}$ & Acres \\
\hline Re-roof & $\begin{array}{l}\text { Re-roof (new roof) as } \\
\text { related to PV } \\
\text { structure penetration } \\
\text { problems }\end{array}$ & Repair & Roof & As needed & Roofer & $\mathrm{N} / \mathrm{A}$ & Acres \\
\hline $\begin{array}{l}\text { Repair tracker } \\
\text { drive shaft }\end{array}$ & $\begin{array}{l}\text { Repair/replace } \\
\text { tracker drive shaft }\end{array}$ & Repair & Tracker & As needed & Mechanic & $\mathrm{N} / \mathrm{A}$ & Row \\
\hline $\begin{array}{l}\text { Replace tracker } \\
\text { drive bearing }\end{array}$ & $\begin{array}{l}\text { Replace tracker drive } \\
\text { bearing }\end{array}$ & Repair & Tracker & As needed & Mechanic & $N / A$ & Row \\
\hline $\begin{array}{l}\text { Replace tracker } \\
\text { mount bearing }\end{array}$ & $\begin{array}{l}\text { Replace tracker } \\
\text { mount bearing }\end{array}$ & Repair & Tracker & As needed & Mechanic & $\mathrm{N} / \mathrm{A}$ & \\
\hline $\begin{array}{l}\text { Replace tracker } \\
\text { motor controller }\end{array}$ & $\begin{array}{l}\text { Replace tracker } \\
\text { motor controller }\end{array}$ & Repair & Tracker & As needed & $\begin{array}{l}\text { Journeyman } \\
\text { electrician }\end{array}$ & $\mathrm{N} / \mathrm{A}$ & \\
\hline
\end{tabular}




\begin{tabular}{|c|c|c|c|c|c|c|c|}
\hline Service Name & Service Description & $\begin{array}{l}\text { Service } \\
\text { Category }\end{array}$ & $\begin{array}{l}\text { O\&M } \\
\text { Category }\end{array}$ & Interval & $\begin{array}{l}\text { Service } \\
\text { Provider }\end{array}$ & $\begin{array}{l}\text { Warranty } \\
\text { Type }\end{array}$ & $\begin{array}{l}\text { Applicable } \\
\text { Unit }\end{array}$ \\
\hline $\begin{array}{l}\text { Upgrade tracker } \\
\text { software }\end{array}$ & $\begin{array}{l}\text { Replace/upgrade } \\
\text { tracker control } \\
\text { software }\end{array}$ & Repair & Tracker & As needed & Network/ IT & $\mathrm{N} / \mathrm{A}$ & \\
\hline $\begin{array}{l}\text { Replace tracker } \\
\text { power supply }\end{array}$ & $\begin{array}{l}\text { Replace tracking- } \\
\text { controller power } \\
\text { supply fan filter }\end{array}$ & Repair & Tracker & 2 years & Mechanic & EPC & Controller \\
\hline $\begin{array}{l}\text { Replace hydraulic } \\
\text { cylinder }\end{array}$ & $\begin{array}{l}\text { Replace hydraulic } \\
\text { cylinder }\end{array}$ & Repair & Tracker & As needed & Mechanic & $N / A$ & \\
\hline $\begin{array}{l}\text { Replace } \\
\text { transformer (e.g., } \\
\text { GSU) }\end{array}$ & Replace transformer & Repair & Transformer & As needed & $\begin{array}{l}\text { Master } \\
\text { electrician }\end{array}$ & $\mathrm{N} / \mathrm{A}$ & Transformer \\
\hline $\begin{array}{l}\text { Re-tap } \\
\text { transformer }\end{array}$ & Re-tap transformer & Repair & Transformer & As needed & $\begin{array}{l}\text { Master } \\
\text { electrician }\end{array}$ & $N / A$ & Transformer \\
\hline $\begin{array}{l}\text { Replace terminal } \\
\text { block }\end{array}$ & $\begin{array}{l}\text { Replace terminal } \\
\text { block }\end{array}$ & Repair & Inverter & As needed & $\begin{array}{l}\text { Journeyman } \\
\text { electrician }\end{array}$ & Inverter & $\begin{array}{l}\text { Combiner } \\
\text { box }\end{array}$ \\
\hline Replace inverter & Replace inverter & Repair & Inverter & As needed & $\begin{array}{l}\text { Inverter } \\
\text { specialist }\end{array}$ & Inverter & Inverter \\
\hline $\begin{array}{l}\text { Locate } \\
\text { underground } A C \\
\text { wiring }\end{array}$ & $\begin{array}{l}\text { Locate underground } \\
\text { AC wiring }\end{array}$ & Repair & AC wiring & As needed & Utilities locator & $\mathrm{N} / \mathrm{A}$ & \\
\hline $\begin{array}{l}\text { Replace battery } \\
\text { cell }\end{array}$ & Replace battery cell & Repair & Battery & As needed & $\begin{array}{l}\text { Battery } \\
\text { specialist }\end{array}$ & Battery & Battery cell \\
\hline $\begin{array}{l}\text { Replace battery } \\
\text { string }\end{array}$ & $\begin{array}{l}\text { Replace battery } \\
\text { string }\end{array}$ & Repair & Battery & As needed & $\begin{array}{l}\text { Battery } \\
\text { specialist }\end{array}$ & Battery & $\begin{array}{l}\text { Battery } \\
\text { string }\end{array}$ \\
\hline $\begin{array}{l}\text { Replace battery } \\
\text { bank }\end{array}$ & Replace battery bank & Repair & Battery & As needed & $\begin{array}{l}\text { Battery } \\
\text { specialist }\end{array}$ & Battery & Battery bank \\
\hline $\begin{array}{l}\text { Replace battery } \\
\text { bank air } \\
\text { conditioner }\end{array}$ & $\begin{array}{l}\text { Replace battery bank } \\
\text { air conditioner }\end{array}$ & Repair & Battery & As needed & $\begin{array}{l}\text { Battery } \\
\text { specialist }\end{array}$ & $\mathrm{N} / \mathrm{A}$ & Battery \\
\hline $\begin{array}{l}\text { Perform initial } \\
\text { testing on } \\
\text { replacement } \\
\text { battery }\end{array}$ & $\begin{array}{l}\text { Perform initial testing } \\
\text { on replacement } \\
\text { battery }\end{array}$ & Repair & Battery & As needed & $\begin{array}{l}\text { Battery } \\
\text { specialist }\end{array}$ & $\mathrm{N} / \mathrm{A}$ & Battery \\
\hline
\end{tabular}




\section{Appendix D. PV O\&M Scope of Work, Salary, and Qualifications}

These rates are defined in the PV O\&M Cost Model and can be customized by the user. They are from the U.S. Bureau of Labor Statistics, 2015, for each service provider, but most reviewers comment that these rates are too low. A "loading factor" is used to convert these values, which are more representative of employee take-home pay, with the cost to the employer, which includes the cost of benefits and fringe benefits. A typical "loading factor" is on the order of 1.7.

Table D-1. Qualifications and Loaded Labor Rates for PV O\&M Service Providers ${ }^{a}$

\begin{tabular}{|c|c|c|c|}
\hline $\begin{array}{l}\text { Service } \\
\text { Category }\end{array}$ & $\begin{array}{l}\text { Loaded } \\
\text { Rate } \\
\text { (\$/hour) }\end{array}$ & Scope of Work & Qualifications \\
\hline Administrator & 23.00 & $\begin{array}{l}\text { Record keeping, } \\
\text { service confirmation, } \\
\text { correspondence }\end{array}$ & $\begin{array}{l}\text { Excellent interpersonal and communication } \\
\text { skills (written and verbal); diligent record } \\
\text { keeping; } 2 \text { to } 5 \text { years of experience; excellent } \\
\text { MS Office and computer skills; management } \\
\text { of contractors and quality }\end{array}$ \\
\hline Cleaner & 14.74 & Cleaning PV arrays & $\begin{array}{l}\text { 10-hour OSHA card; required level of } \\
\text { bonding and insurance; driver's license and } \\
\text { reliable transportation; minimum } 18 \text { years old }\end{array}$ \\
\hline Designer & 58.33 & $\begin{array}{l}\text { Specifications, } \\
\text { drawings, modeling } \\
\text { and analysis, codes } \\
\text { and standards }\end{array}$ & $\begin{array}{l}\text { B.S. in electrical engineering (4-year degree); } \\
\text { registered PE licensed to practice } \\
\text { engineering in the jurisdiction; NABCEP PV } \\
\text { Installer certification; CAD (AutoCAD) and } \\
\text { graphics skills; knowledge of IEEE, NEC, } \\
\text { NESC, and other codes and standards for } \\
\text { PV systems; required level of errors and } \\
\text { omissions insurance }\end{array}$ \\
\hline Inspector & 33.12 & $\begin{array}{l}\text { Diagnostic analysis, } \\
\text { visual inspection, } \\
\text { specific testing }\end{array}$ & $\begin{array}{l}\text { Diagnostic analysis; NABCEP PV Installer } \\
\text { Certification; } 2 \text { to } 5 \text { years of experience }\end{array}$ \\
\hline $\begin{array}{l}\text { Inverter } \\
\text { specialist }\end{array}$ & 33.17 & $\begin{array}{l}\text { Inverter repair, } \\
\text { upgrades }\end{array}$ & $\begin{array}{l}\text { (estimated) skills to perform maintenance, } \\
\text { diagnostics, and repair for inverter: factory } \\
\text { trained and certified; } 5+\text { years of experience }\end{array}$ \\
\hline $\begin{array}{l}\text { Journeyman } \\
\text { electrician }\end{array}$ & 19.90 & $\begin{array}{l}\text { Module replacement, } \\
\text { inverter replacement, } \\
\text { fuse/breaker } \\
\text { replacement, conduit } \\
\text { routing, wiring, } \\
\text { ground-fault repair }\end{array}$ & $\begin{array}{l}\text { (estimated) } 50 \text { OSHA card; training in arc- } \\
\text { flash, lock-out/tag-out, and other special } \\
\text { protective equipment and procedures; } \\
\text { NABCEP PV Installer certification; } \\
\text { experience in the design of medium-voltage } \\
\text { electrical systems; } 5+\text { years of experience } \\
\text { with PV systems; color vision }\end{array}$ \\
\hline $\begin{array}{l}\text { Master } \\
\text { electrician }\end{array}$ & 32.01 & $\begin{array}{l}\text { Module replacement, } \\
\text { inverter replacement, } \\
\text { fuse/breaker } \\
\text { replacement, conduit } \\
\text { routing, wiring, } \\
\text { ground-fault repair }\end{array}$ & $\begin{array}{l}\text { Electrical contractor's license for the } \\
\text { jurisdictions; 50-hour OSHA card; NABCEP } \\
\text { PV Installer certification; experience in the } \\
\text { design of medium-voltage electrical systems; } \\
5+\text { years of experience with PV systems; } \\
\text { color vision; certification by NERC is }\end{array}$ \\
\hline
\end{tabular}




\begin{tabular}{|c|c|c|c|}
\hline $\begin{array}{l}\text { Service } \\
\text { Category }\end{array}$ & $\begin{array}{l}\text { Loaded } \\
\text { Rate } \\
\text { (\$/hour) }\end{array}$ & Scope of Work & Qualifications \\
\hline & & & $\begin{array}{l}\text { necessary for positions that affect the power } \\
\text { grid }\end{array}$ \\
\hline Mechanic & 29.30 & $\begin{array}{l}\text { Maintenance and } \\
\text { repair/replace of } \\
\text { tracking mount } \\
\text { components }\end{array}$ & $\begin{array}{l}50 \text {-hour OSHA card; } 2 \text { to } 5 \text { years of } \\
\text { experience; required level of bonding and } \\
\text { insurance }\end{array}$ \\
\hline Network/IT & 45.89 & $\begin{array}{l}\text { Internet/network } \\
\text { repair, monitoring } \\
\text { equipment repair }\end{array}$ & $\begin{array}{l}\text { Knowledge of specific monitoring devices } \\
\text { (training by system supplier) and how } \\
\text { monitoring system is connected through } \\
\text { network connections or wireless or cellular } \\
\text { modem; knowledge of Modbus, DNP3, and } \\
\text { other protocols and HMl operator interfaces; } \\
2 \text { to } 5 \text { years of experience; Locus, Enphase, } \\
\text { Itron, etc. monitoring device knowledge }\end{array}$ \\
\hline Pest control & 20.13 & $\begin{array}{l}\text { Nesting vermin } \\
\text { removal, nesting } \\
\text { vermin prevention }\end{array}$ & $\begin{array}{l}10 \text { OSHA card; safety training in handling } \\
\text { animals and detritus; required level of } \\
\text { bonding and insurance; driver's license and } \\
\text { reliable transportation; minimum } 18 \text { years } \\
\text { old; most states require license for pesticide }\end{array}$ \\
\hline $\begin{array}{l}\text { PV module/array } \\
\text { specialist }\end{array}$ & 33.17 & Module repair & $\begin{array}{l}\text { (estimated) skills to operate, troubleshoot, } \\
\text { maintain, and repair PV equipment: NABCEP } \\
\text { PV Installer certification; } 2 \text { to } 5 \text { years of } \\
\text { experience }\end{array}$ \\
\hline Roofing & 22.70 & $\begin{array}{l}\text { Roof leak repair, roof } \\
\text { tile repair, re-roof }\end{array}$ & $\begin{array}{l}\text { Roofing contractor's license for the } \\
\text { jurisdiction; } 10 \text { OSHA card; safety training in } \\
\text { fall-protection equipment and use (or } 50 \\
\text { OSHA card); required level of bonding and } \\
\text { insurance }\end{array}$ \\
\hline $\begin{array}{l}\text { Structural } \\
\text { engineer }\end{array}$ & 55.82 & $\begin{array}{l}\text { Foundations and rack } \\
\text { inspection/design }\end{array}$ & $\begin{array}{l}\text { B.S. Structural Engineering (4-year degree); } \\
\text { registered PE licensed to practice } \\
\text { engineering in the jurisdiction }\end{array}$ \\
\hline Mower/trimmer & 15.75 & Removal of vegetation & $\begin{array}{l}50 \text { OSHA card; driver's license and reliable } \\
\text { transportation; required level of insurance; } \\
\text { minimum } 18 \text { years old; any required training } \\
\text { or license for herbicide application }\end{array}$ \\
\hline Utilities locator & 25.55 & $\begin{array}{l}\text { Locate underground } \\
\text { utilities }\end{array}$ & 2 to 5 years of experience \\
\hline
\end{tabular}

${ }^{\mathrm{a}}$ Unloaded rates from National Bureau of Labor Statistics, 2014, loaded at 1.38 factor. 


\section{Appendix E. Examples of Scope of Work Documents}

Below is an example Scope of Work provided by working group member SolarCity (now Tesla) for inclusion here.

\section{EXHIBIT:}

\section{SCOPE OF SERVICES}

\section{Operation and Maintenance:}

- Provider will (i) keep all Covered Systems in good repair, good operating condition, appearance and working order in compliance with the manufacturer's recommendations, the Customer Agreements, all manufacturers' warranties and the Company's standard practices (but in no event less than Prudent Industry Practices), (ii) properly service all components of all Covered Systems following the manufacturer's written operating and servicing procedures and in accordance with the Customer Agreements, and (iii) replace any Part of a Covered Systems that becomes unfit or unavailable for use under the Customer Agreements from any cause (whether or not such replacement is covered by a maintenance agreement) with a replacement Part of a Covered System pursuant to paragraph 2 of this Exhibit A.

- Provider shall promptly furnish or cause to be furnished to the Company such information as may be required to enable the Company to file any reports required to be filed by the Company with any Governmental Authority because of the Company's ownership of any Covered System.

\section{Replacement of Parts:}

- In accordance with the Customer Agreements, Provider will promptly replace or cause to be replaced all Parts that may from time to time be incorporated or installed in or attached to a PV System and that may from time to time become worn out, lost, stolen, destroyed, seized, confiscated, damaged beyond repair or permanently rendered unfit for use under the Customer Agreements for any reason whatsoever, except as otherwise provided in paragraph 3 of this Exhibit A.

- Provider may, in accordance with the Customer Agreements, remove in the ordinary course of maintenance, service, repair, overhaul or testing, any Parts, whether or not worn out, lost, stolen, destroyed, seized, confiscated, damaged beyond repair or permanently rendered unfit for use; provided that Provider, except as otherwise provided in paragraph 3 of this Exhibit A, will replace such Parts as promptly as practicable. All replacement Parts will be free and clear of all Liens (except for Permitted Liens and except in the case of replacement property temporarily installed on an emergency basis) and will be in as good operating condition as, and will have a value and utility at least equal to, the Parts replaced assuming such replaced Parts were in the condition and repair required to be maintained by the terms hereof.

\section{Alterations, Modifications and Additions:}

- Provider will make such alterations and modifications in and additions to PV Systems as may be required from time to time to comply with Applicable Law and the terms of the applicable Customer Agreements; provided, however, that Provider may, in good faith, contest the validity or application of any such Applicable Law in any reasonable manner, 
but diligently and in good faith, and only if there is no material risk of the loss or forfeiture of a PV System or any interest therein or breach of the related Customer Agreement; and provided further, that Provider's failure to make (or cause to be made) any such alterations, modifications of additions will not constitute noncompliance with the requirements of this paragraph 3 or a breach of Provider's undertaking hereunder for so long a period as may be necessary to remedy such failure, if such failure can be remedied, so long as during such period Provider is using due diligence and best efforts to remedy such failure.

\section{Customary Information: Provider will furnish or cause to be furnished to the Company:}

- Promptly upon an officer of the Provider becoming aware of the existence thereof, a notice stating that a breach of, or a default under, any material contractual obligation of the Company in respect of any Covered System has occurred and specifying the nature and period of existence thereof and what action the Provider has taken or is taking or proposes to take with respect thereto; and

- From time to time such other information regarding the PV Systems or the Projects as the Company may reasonably request.

\section{Reports of Liability:}

- Provider shall give prompt written notice to the Company of each accident likely to result in material damages or claims for material damages against any Covered System or any such Person or likely to result in a material adverse change to the financial or business condition of the Company occurring in whole or in part (whenever asserted) during the Term, and on request shall furnish to the Company information as to the time, place and nature thereof, the names and addresses of the parties involved, any Persons injured, witnesses and owners of any property damaged, and such other information as may be known to it, and shall promptly upon request furnish the Company with copies of all material correspondence, papers, notices and documents whatsoever received by the Provider or the Company, as applicable, from third parties in connection therewith.

\section{Billing, Collecting and Enforcement of Customer Agreements:}

- Provider will, at its sole cost and expense, administer or cause to be administered all Customer Agreements. Provider's obligations under this paragraph 6 shall include, without limitation, delivering periodic bills to all Host Customers, collecting from all Host Customers all monies due under the Customer Agreements, and managing all communications with or among Host Customers.

- Provider will assist the Company in the enforcement of all Customer Agreements. Provider will, at the Company's direction and expense, diligently exercise any remedies that may become available under the Customer Agreements in respect of any defaults by Host Customers thereunder; provided that, in the event that the 
Company elects, in the exercise of any such remedies, to remove a PV System from the Host Customer's real property, (a) the cost of such removal shall be borne by Provider, and (b) Provider will use commercially reasonable efforts to redeploy such $P V$ System following any such removal (it being agreed that, in connection with any such redeployment, Provider shall not discriminate against such PV System as compared to similar equipment that is not subject to this Agreement and will not unreasonably favor new equipment over the redeployment of the PV Systems hereunder).

- In the event that a Host Customer sells its real property, changes locations or otherwise vacates the real property upon which the PV System is installed and proposes to transfer its Customer Agreement, to the extent the new owner or occupant does not meet the minimum credit standard applicable to the original Host Customer, Provider will (i) forward the transfer request to the Company for review and approval or (ii) require the Host Customer to relocate or purchase the PV System, or prepay its future obligations under the Customer Agreement as provided in the Customer Agreement, and Provider will be responsible for all administrative duties associated with the foregoing.

\section{Event of Loss with Respect to a PV System:}

- If any PV System is damaged or destroyed by fire, theft or other casualty, Provider will, at the Company's expense, repair, restore, replace or rebuild such PV System to substantially the same condition as existed immediately prior to the damage or destruction and substantially in accordance with the Customer Agreement related to such PV System.

- If a PV System is required to be replaced as described above, then Provider will cause the supplier of the replacement equipment to deliver to the Company a bill of sale for such equipment free and clear of all Liens (except for Permitted Liens) and such replacement equipment will become a PV System subject to this Agreement.

\section{Administration of Government Incentives:}

- Provider shall timely: (a) complete and submit, on behalf of the Company, all applications and other filings required to be submitted in connection with the procurement of all Government Incentives that are available in respect of each Covered System hereunder; (b) deliver to the Company for the Company's signature such certifications, agreements and other documents required to be delivered or submitted under Applicable Laws in connection with such Government Incentives; and (c) take such other action as may be reasonably necessary to effectuate the procurement and receipt by the Company of such Government Incentives in accordance with Applicable Laws. 


\section{Example Performance Work Statement}

This example Performance Work Statement was used in a site-wide operating contract for a military base that included maintenance for other systems such as lighting and mechanical systems, and thus is necessary very concise:

"This Performance Work Statement covers all labor, supplies and materials, replacement parts, equipment used to provide the services, transportation to the site, and any other goods and services required to provide preventive and corrective maintenance on this $P V$ system.

Performance is defined as maintaining the ability of the solar systems to provide power according to specifications and considering solar and temperature conditions as well as de-rated for expected inefficiencies such as dirt on the collector. The intent is to perform preventive maintenance and to replace failed components, and some small degradation of performance is expected over time. Solar system output shall be no less than $80 \%$ of the rated output of the PV system, corrected for solar and temperature conditions at the time of the test. System shall be tested annually. Key to the performance definition is that all components be capable of accomplishing their intended purpose within specifications. The definition of the PV system to be maintained shall include PV modules, the support structure, disconnects, inverter(s), monitoring equipment, and all other appurtenances to make the PV system complete, grid-connected, and operational."

\section{Example Description of Maintenance Services for Commercial Rooftop Installations}

A Performance Work Statement is a list of all the services that a service provider is expected to provide. The text below is offered as an example of such a description of work for a commercial rooftop installation. This example was provided for this Best Practices document by working group member SunSpec Alliance.

As of the Commencement Date, Owner and Contractor shall provide the Services marked below at the frequency indicated in accordance with the terms and conditions of this Agreement.

\begin{tabular}{|c|c|c|c|}
\hline \multicolumn{2}{|c|}{ Service Schedule } \\
\hline Item & $\begin{array}{c}\text { Services } \\
\text { included } \\
\text { (only if } \\
\text { checked) }\end{array}$ & \multicolumn{1}{|c|}{ Service Description } & $\begin{array}{c}\text { Frequency/ } \\
\text { Response } \\
\text { Time }\end{array}$ \\
\hline \multicolumn{3}{|c|}{ Preventive Maintenance } \\
\hline 1 & & $\begin{array}{l}\text { Visual inspection of Solar Facility's general site conditions, } \\
\text { PV arrays, electrical equipment, mounting structure, fence, } \\
\text { shading, trackers, vegetation, animal damage, erosion, } \\
\text { corrosion, and discolored panels. }\end{array}$ & 1x per year \\
\hline 2 & $\begin{array}{l}\text { Visual inspection and correction of Solar Facility for loose } \\
\text { electrical connections and ground connections. }\end{array}$ & 1x per year \\
\hline
\end{tabular}




\begin{tabular}{|c|c|c|c|}
\hline \multicolumn{4}{|c|}{ Service Schedule } \\
\hline Item & $\begin{array}{l}\text { Services } \\
\text { included } \\
\text { (only if } \\
\text { checked) }\end{array}$ & Service Description & $\begin{array}{l}\text { Frequency/ } \\
\text { Response } \\
\text { Time }\end{array}$ \\
\hline 3 & & $\begin{array}{l}\text { String-level open-circuit voltage, DC operating current } \\
\text { tests, and I-V curve traces on [ ]\% of [ ] strings. }\end{array}$ & $1 \mathrm{x}$ per year \\
\hline 4 & & $\begin{array}{l}\text { [ ] switches and disconnects test to ensure they are not } \\
\text { jammed. }\end{array}$ & $1 \mathrm{x}$ per year \\
\hline 5 & & $\begin{array}{l}\text { Infrared scans on all [ ] combiner and re-combiner boxes; } \\
\text { tighten connections to manufacturer's torque specification; } \\
\text { report broken terminal blocks. }\end{array}$ & $1 \mathrm{x}$ per year \\
\hline 6 & & $\begin{array}{l}\text { [ ] check calibration expiration on sensors and meters, } \\
\text { including pyranometers, and anemometers and perform } \\
\text { other service such as cleaning and replacement of any } \\
\text { desiccant. }\end{array}$ & $1 \mathrm{x}$ per year \\
\hline 7 & & $\begin{array}{l}\text { Turn off and on logging and communications to ensure } \\
\text { they are communicating and ensure battery backups are } \\
\text { working. }\end{array}$ & 1x per year \\
\hline 8 & & $\begin{array}{l}\text { Inverter preventive maintenance for [ ] inverters per } \\
\text { manufacturer's operating guidelines }\end{array}$ & See below \\
\hline 9 & & Clean inverter cabinet air vents. & $1 \mathrm{x}$ per year \\
\hline 10 & & $\begin{array}{l}\text { Clean and change inverter air filters, if present, per } \\
\text { manufacturer's warranty requirements. }\end{array}$ & $1 \mathrm{x}$ per year \\
\hline 11 & & $\begin{array}{l}\text { Clean/remove dust from inverter heat sinks per } \\
\text { manufacturer's warranty requirements. }\end{array}$ & $1 \mathrm{x}$ per year \\
\hline 12 & & $\begin{array}{l}\text { Check torque marks and re-tightening appropriate wiring } \\
\text { connections to design specification torque force per } \\
\text { manufacturer's guidelines. }\end{array}$ & $1 \mathrm{x}$ per year \\
\hline 13 & & $\begin{array}{l}\text { Inspect roof penetrations to ensure sealant is applied } \\
\text { properly and not degrading. }\end{array}$ & $1 \mathrm{x}$ per year \\
\hline 14 & & PV array module maintenance for [ ] modules & See below \\
\hline 15 & & $\begin{array}{l}\text { Wash all panels with water with no chemicals in a method } \\
\text { approved by the Owner. }\end{array}$ & $\begin{array}{l}\text { 1x per year or } \\
\text { per study }\end{array}$ \\
\hline 16 & & $\begin{array}{l}\text { Perform infrared scan of [ ] } \% \text { of modules for two types of } \\
\text { circuitry connections: cells on the front and junction boxes } \\
\text { on the back. }\end{array}$ & $1 \mathrm{x}$ per year \\
\hline
\end{tabular}




\begin{tabular}{|c|c|c|c|}
\hline \multicolumn{4}{|c|}{ Service Schedule } \\
\hline Item & $\begin{array}{l}\text { Services } \\
\text { included } \\
\text { (only if } \\
\text { checked) }\end{array}$ & Service Description & $\begin{array}{l}\text { Frequencyl } \\
\text { Response } \\
\text { Time }\end{array}$ \\
\hline 17 & & $\begin{array}{l}\text { Remove any sprouting seeds or vegetation, bird nests, } \\
\text { leaves or debris, etc. }\end{array}$ & $1 \mathrm{x}$ per year \\
\hline 18 & & $\begin{array}{l}\text { Document details of preventive maintenance work, such } \\
\text { as condition observations, work performed, meter } \\
\text { readings, thermal images, and system testing results. }\end{array}$ & As performed \\
\hline 19 & & $\begin{array}{l}\text { Include non-conformance reports to identify potential } \\
\text { short-term and long-term power production issues. }\end{array}$ & $1 \mathrm{x}$ per year \\
\hline \multicolumn{4}{|c|}{ Service Support } \\
\hline 20 & & $\begin{array}{l}\text { Contractor will make available a } 24 \times 7 \times 365 \text { Technical } \\
\text { Support. }\end{array}$ & Ongoing \\
\hline 21 & & $\begin{array}{l}\text { Dispatch commitment: dispatch resources in response to } \\
\text { alarms and alerts/service requests received by Contractor } \\
\text { from Owner. }\end{array}$ & See below \\
\hline 23 & & $\begin{array}{l}\text { Alarm: means loss of one inverter's production. The } \\
\text { dispatch time incurs a fee of } \$ X X X \text { per alarm, in addition to } \\
\text { the fees in non-covered services schedule, including } \\
\text { alarms that require warranty service. }\end{array}$ & $\begin{array}{l}\text { Dispatch in } \\
<\text { [specify } \\
\text { required } \\
\text { response } \\
\text { time] }\end{array}$ \\
\hline 24 & & $\begin{array}{l}\text { Alert/service request: means noticeable anomaly or loss of } \\
\text { power, but inverter in question is still operating. This } \\
\text { dispatch time incurs a fee of } \$ X X X \text { per alert/service } \\
\text { request, in addition to the fees in non-covered services } \\
\text { schedule, including alerts/service requests that require } \\
\text { warranty service. }\end{array}$ & $\begin{array}{l}\text { Dispatch in } \\
<[\text { ] specify } \\
\text { time }\end{array}$ \\
\hline
\end{tabular}




\section{Example Description of Maintenance Services for Commercial Ground Mount Installations}

As of the Commencement Date, Contractor shall provide the Services marked below at the frequency indicated in accordance with the terms and conditions of Maintenance Agreement.

\begin{tabular}{|c|c|c|c|}
\hline \multicolumn{4}{|c|}{ Service Schedule } \\
\hline Item & $\begin{array}{l}\text { Services } \\
\text { included } \\
\text { (only if } \\
\text { checked) }\end{array}$ & Service Description & $\begin{array}{l}\text { Frequency / } \\
\text { Response } \\
\text { Time }\end{array}$ \\
\hline \multicolumn{4}{|c|}{ Preventive Maintenance } \\
\hline 1 & & $\begin{array}{l}\text { Visual inspection of Solar Facility's general site conditions, } \\
\text { PV arrays, electrical equipment, mounting structure, fence, } \\
\text { shading, trackers, vegetation, animal damage, erosion, } \\
\text { corrosion, and discolored panels. }\end{array}$ & $1 \mathrm{x}$ per year \\
\hline 2 & & $\begin{array}{l}\text { Visual inspection and correction of Solar Facility for loose } \\
\text { electrical connections and ground connections. }\end{array}$ & $1 \mathrm{x}$ per year \\
\hline 3 & & $\begin{array}{l}\text { String-level open-circuit voltage, DC operating current } \\
\text { tests, and I-V curve traces on [ ]\% of [ ] strings. }\end{array}$ & $1 \mathrm{x}$ per year \\
\hline 4 & & $\begin{array}{l}\text { [ ] switches and disconnects test to ensure they are not } \\
\text { jammed. }\end{array}$ & $1 \times$ per year \\
\hline 5 & & $\begin{array}{l}\text { Infrared scans on all [ ] combiner and re-combiner boxes; } \\
\text { tighten connections; report broken terminal blocks. }\end{array}$ & $1 \mathrm{x}$ per year \\
\hline 6 & & $\begin{array}{l}\text { [ ] sensors and meters, including pyranometers, } \\
\text { anemometers, and tilt sensors }\end{array}$ & $1 \mathrm{x}$ per year \\
\hline 7 & & $\begin{array}{l}\text { Turn off and on to ensure they are communicating and } \\
\text { ensure battery backups are working. }\end{array}$ & $1 \mathrm{x}$ per year \\
\hline 8 & & $\begin{array}{l}\text { Exchange units with Owner's spares for calibration per } \\
\text { manufacturer's instructions. Report serial numbers of } \\
\text { exchanged units. Calibration costs are non-covered } \\
\text { services. }\end{array}$ & [ ] \\
\hline 9 & & $\begin{array}{l}\text { Inverter preventive maintenance for [ ] inverters per } \\
\text { manufacturer's operating guidelines }\end{array}$ & See below \\
\hline 10 & & Clean inverter cabinet air vents. & $1 \times$ per year \\
\hline 11 & & $\begin{array}{l}\text { Clean and change inverter air filters, if present, per } \\
\text { manufacturer's warranty. }\end{array}$ & $1 \times$ per year \\
\hline 12 & & $\begin{array}{l}\text { Clean and remove dust from inverter heat sinks per } \\
\text { manufacturer's warranty requirements. }\end{array}$ & $1 \mathrm{x}$ per year \\
\hline
\end{tabular}




\begin{tabular}{|c|c|c|c|}
\hline \multicolumn{4}{|c|}{ Service Schedule } \\
\hline Item & $\begin{array}{l}\text { Services } \\
\text { included } \\
\text { (only if } \\
\text { checked) }\end{array}$ & Service Description & $\begin{array}{l}\text { Frequency / } \\
\text { Response } \\
\text { Time }\end{array}$ \\
\hline 13 & & $\begin{array}{l}\text { Check torque marks and re-tightening appropriate wiring } \\
\text { connections to design specification torque force per } \\
\text { manufacturer's guidelines. }\end{array}$ & $1 \mathrm{x}$ per year \\
\hline 14 & & $\begin{array}{l}\text { If tracked, perform tracker verification and preventive } \\
\text { maintenance per manufacturer's owner manual. }\end{array}$ & $1 \times$ per year \\
\hline 15 & & PV array module maintenance for [ ] modules & See below \\
\hline 16 & & $\begin{array}{l}\text { Wash all panels with water with no chemicals in a method } \\
\text { approved by the Owner. }\end{array}$ & $\begin{array}{l}\text { 1x per year or } \\
\text { per study }\end{array}$ \\
\hline 17 & & $\begin{array}{l}\text { Perform infrared scan of [ ] \% of modules for two types of } \\
\text { circuitry connections: cells on the front and junction boxes } \\
\text { on the back. }\end{array}$ & $1 \mathrm{x}$ per year \\
\hline 18 & & Vegetation mitigation within the fenced area & $1 \times$ per year \\
\hline 19 & & $\begin{array}{l}\text { Document details of preventive maintenance work, such } \\
\text { as meter readings, thermal images, and system testing } \\
\text { results. }\end{array}$ & As performed \\
\hline 20 & & $\begin{array}{l}\text { Include non-conformance reports to identify potential } \\
\text { short-term and long-term power production issues. }\end{array}$ & $1 \times$ per year \\
\hline \multicolumn{4}{|c|}{ Service Support } \\
\hline 21 & & $\begin{array}{l}\text { Contractor will make available a } 24 \times 7 \times 365 \text { Technical } \\
\text { Support. }\end{array}$ & Ongoing \\
\hline 22 & & $\begin{array}{l}\text { Dispatch commitment: dispatch resources in response to } \\
\text { alarms and alerts/service requests received by Contractor } \\
\text { from Owner/Offtaker. }\end{array}$ & See below \\
\hline 23 & & $\begin{array}{l}\text { Alarm: means loss of one inverter's production. The } \\
\text { dispatch time incurs a fee of } \$ X X X \text { per alarm, in addition to } \\
\text { the fees in non-covered services schedule, including } \\
\text { alarms that require warranty service. }\end{array}$ & $\begin{array}{l}\text { Dispatch in } \\
<[\text { ] specify } \\
\text { time }\end{array}$ \\
\hline 24 & & $\begin{array}{l}\text { Alert/service request: means noticeable anomaly or loss of } \\
\text { power, but inverter in question is still operating. This } \\
\text { dispatch time incurs a fee of } \$ X X X \text { per alert/service } \\
\text { request, in addition to the fees in non-covered services } \\
\text { schedule, including alerts/service requests that require } \\
\text { warranty service. }\end{array}$ & $\begin{array}{l}\text { Dispatch in } \\
<[\text { ] specify } \\
\text { time }\end{array}$ \\
\hline
\end{tabular}




\section{Example Description of Operations Services}

As of the Commencement Date, Contractor shall provide the Services marked below at the frequency indicated in accordance with the terms and conditions of Operations Agreement:

\begin{tabular}{|c|c|c|c|}
\hline \multicolumn{4}{|c|}{ Service Schedule } \\
\hline Item & $\begin{array}{l}\text { Services included } \\
\text { (only if } \\
\text { checked) }\end{array}$ & Service Description & $\begin{array}{c}\text { Frequency/Response } \\
\text { Time }\end{array}$ \\
\hline \multicolumn{4}{|c|}{ Operations Administration } \\
\hline 1 & & $\begin{array}{l}\text { Input and or checking of monthly } \\
\text { production data }\end{array}$ & Monthly \\
\hline 2 & & $\begin{array}{l}\text { Preparation and submission of any } \\
\text { declarations or notification requested by } \\
\text { GSE, LAGIE, or other regulatory bodies }\end{array}$ & When needed \\
\hline 3 & & $\begin{array}{l}\text { Check and approval of in-bound and out- } \\
\text { bound invoices, as well as verification } \\
\text { with contracts, proper and correct } \\
\text { invoicing, settlement }\end{array}$ & $\begin{array}{l}\text { Continuous and on } \\
\text { demand }\end{array}$ \\
\hline 4 & & $\begin{array}{l}\text { Management of any SPV contract } \\
\text { obligation and relationship with SPV } \\
\text { counterparties }\end{array}$ & $\begin{array}{l}\text { Continuous and on } \\
\text { demand }\end{array}$ \\
\hline 5 & & $\begin{array}{l}\text { Continuous check and reporting on } \\
\text { relevant regulations }\end{array}$ & $\begin{array}{l}\text { Continuous and on } \\
\text { demand }\end{array}$ \\
\hline 6 & & $\begin{array}{l}\text { Advise on necessary actions /adaptations } \\
\text { of the plant to change in law }\end{array}$ & $\begin{array}{l}\text { Continuous and on } \\
\text { demand }\end{array}$ \\
\hline 7 & & $\begin{array}{l}\text { Periodic renewal of the insurance } \\
\text { contracts and revision of the terms and } \\
\text { conditions }\end{array}$ & Upon deadline or yearly \\
\hline 8 & & $\begin{array}{l}\text { Incident intervention, based on data } \\
\text { gathered through operational } \\
\text { performance monitoring }\end{array}$ & When needed \\
\hline
\end{tabular}




\begin{tabular}{|c|c|c|c|}
\hline \multicolumn{4}{|c|}{ Service Schedule } \\
\hline Item & $\begin{array}{l}\text { Services included } \\
\text { (only if } \\
\text { checked) }\end{array}$ & Service Description & $\begin{array}{c}\text { Frequency/Response } \\
\text { Time }\end{array}$ \\
\hline 9 & & $\begin{array}{l}\text { Insurance claim handling and settlement } \\
\text { that comes with it, using data gathered } \\
\text { through operational performance } \\
\text { monitoring }\end{array}$ & $\begin{array}{c}\text { When needed, up to } 2 \\
\text { events per year }\end{array}$ \\
\hline 10 & & $\begin{array}{l}\text { Support to legal consultant in relation to } \\
\text { ongoing litigation }\end{array}$ & On demand \\
\hline 11 & & $\begin{array}{l}\text { General administrative support for project } \\
\text { compliance }\end{array}$ & When needed \\
\hline 12 & & Liaising with authorities on behalf of SPV & When needed \\
\hline 13 & & $\begin{array}{l}\text { Formal correspondence (authorities or } \\
\text { contractual third parties) }\end{array}$ & When needed \\
\hline 14 & & Managing general compliance events & When needed \\
\hline 15 & & Managing insurance policies & When needed \\
\hline 16 & & Managing land leases & When needed \\
\hline 17 & & Managing telecommunications contracts & When needed \\
\hline 18 & & $\begin{array}{l}\text { Managing security contracts (ARC, O\&M, } \\
\text { key holding) }\end{array}$ & When needed \\
\hline 19 & & Managing electricity supply agreements & When needed \\
\hline 20 & & Managing PPAs (non-technical) & When needed \\
\hline 21 & & $\begin{array}{l}\text { Managing data storage and backup } \\
\text { contracts }\end{array}$ & When needed \\
\hline
\end{tabular}




\begin{tabular}{|c|c|c|c|}
\hline \multicolumn{4}{|c|}{ Service Schedule } \\
\hline Item & $\begin{array}{l}\text { Services included } \\
\text { (only if } \\
\text { checked) }\end{array}$ & Service Description & $\begin{array}{c}\text { Frequency/Response } \\
\text { Time }\end{array}$ \\
\hline 22 & & $\begin{array}{l}\text { Managing document storage (hard and } \\
\text { soft) }\end{array}$ & When needed \\
\hline 23 & & Production register books & When needed \\
\hline 24 & & $\begin{array}{l}\text { Justification and calculation of liquidated } \\
\text { damages (O\&M) }\end{array}$ & When needed \\
\hline 25 & & $\begin{array}{l}\text { Assessment on the calculation of } \mathrm{PR} \text { and } \\
\text { availability according to O\&M contracts }\end{array}$ & Yearly \\
\hline 26 & & $\begin{array}{l}\text { Control, follow-up, and settlement of the } \\
\text { guarantees and penalties using data } \\
\text { gathered through the operational } \\
\text { performance monitoring }\end{array}$ & Yearly \\
\hline \multicolumn{4}{|c|}{ Monitoring } \\
\hline 1 & & Historical data import & Upon handover \\
\hline 2 & & $\begin{array}{l}\text { Data acquisition from the current SCADA } \\
\text { installed \& storage }\end{array}$ & Daily \\
\hline 3 & & $\begin{array}{l}\text { Check on data communication, security } \\
\text { signal and production and escalation to } \\
\text { Service Provider }\end{array}$ & Daily \\
\hline 4 & & Plant data management, storage, backup & Daily \\
\hline \multicolumn{4}{|c|}{ Reporting } \\
\hline 1 & & $\begin{array}{l}\text { Actual Irradiance vs Expected @ P50, } \\
\text { P75, P90 }\end{array}$ & $\begin{array}{l}\text { Monthly / Quarterly / Bi- } \\
\text { Annual / Yearly }\end{array}$ \\
\hline
\end{tabular}




\begin{tabular}{|c|c|c|c|}
\hline \multicolumn{4}{|c|}{ Service Schedule } \\
\hline Item & $\begin{array}{l}\text { Services included } \\
\text { (only if } \\
\text { checked) }\end{array}$ & Service Description & $\begin{array}{c}\text { Frequency/Response } \\
\text { Time }\end{array}$ \\
\hline 2 & & $\begin{array}{l}\text { Actual Production vs Expected @ P50, } \\
\text { P75, P90 }\end{array}$ & $\begin{array}{l}\text { Monthly / Quarterly / Bi- } \\
\text { Annual / Yearly }\end{array}$ \\
\hline 3 & & $\begin{array}{l}\text { Actual Revenues vs Expected @ P50, } \\
\text { P75, P90 }\end{array}$ & $\begin{array}{l}\text { Monthly / Quarterly / Bi- } \\
\text { Annual / Yearly }\end{array}$ \\
\hline 4 & & Actual Availability vs guaranteed & $\begin{array}{l}\text { Monthly / Quarterly / Bi- } \\
\text { Annual / Yearly }\end{array}$ \\
\hline 5 & & Actual Performance Ratio vs guaranteed & $\begin{array}{l}\text { Monthly / Quarterly / Bi- } \\
\text { Annual / Yearly }\end{array}$ \\
\hline 6 & & $\begin{array}{l}\text { Delta Production and Revenues vs } \\
\text { Expected @ P50, P75, P90 }\end{array}$ & $\begin{array}{l}\text { Monthly / Quarterly / Bi- } \\
\text { Annual / Yearly }\end{array}$ \\
\hline 7 & & $\begin{array}{l}\text { Analysis on performance and } \\
\text { benchmarking against similar plants }\end{array}$ & Bi-Annual / Yearly \\
\hline 8 & & $\begin{array}{l}\text { O\&M preventive and corrective } \\
\text { maintenance services during the current } \\
\text { month and expected for the following } \\
\text { month }\end{array}$ & $\begin{array}{l}\text { Monthly / Quarterly / Bi- } \\
\text { Annual / Yearly }\end{array}$ \\
\hline 9 & & $\begin{array}{l}\text { Main incidents recorded, incidents } \\
\text { handling and resolution times }\end{array}$ & $\begin{array}{l}\text { Monthly / Quarterly / Bi- } \\
\text { Annual / Yearly }\end{array}$ \\
\hline 10 & & $\begin{array}{l}\text { Corporate, administrative and contractual } \\
\text { tasks executed during the current month } \\
\text { and expected for the following month }\end{array}$ & $\begin{array}{l}\text { Monthly / Quarterly / Bi- } \\
\text { Annual / Yearly }\end{array}$ \\
\hline 11 & & $\begin{array}{l}\text { Analysis of all performance data of the } \\
\text { plants to ensure optimal performance } \\
\text { and detect any areas for improvement. }\end{array}$ & Bi-Annual / Yearly \\
\hline
\end{tabular}




\begin{tabular}{|c|c|c|c|}
\hline \multicolumn{4}{|c|}{ Service Schedule } \\
\hline Item & $\begin{array}{l}\text { Services included } \\
\text { (only if } \\
\text { checked) }\end{array}$ & Service Description & $\begin{array}{c}\text { Frequency/Response } \\
\text { Time }\end{array}$ \\
\hline 12 & & $\begin{array}{l}\text { Pro-active intervention, proposal of } \\
\text { improvements and coordination of action } \\
\text { items }\end{array}$ & Bi-Annual / Yearly \\
\hline 13 & & $\begin{array}{l}\text { Operations committees, presentations } \\
\text { and assistance }\end{array}$ & $\begin{array}{l}\text { Quarterly / Bi-Annual / } \\
\text { Yearly }\end{array}$ \\
\hline \multicolumn{4}{|c|}{ Daily Plant Operations } \\
\hline 1 & & Real-time data analysis & Daily \\
\hline 2 & & Root-cause analysis & Daily \\
\hline 3 & & Event notification management & Daily \\
\hline 4 & & Alert notification management & Daily \\
\hline 5 & & Proactive intervention & Daily \\
\hline 6 & & Incident management & Daily \\
\hline 7 & & Trouble ticket creation & When needed \\
\hline 8 & & Trouble ticket management & When needed \\
\hline \multicolumn{4}{|c|}{ Field Service Management } \\
\hline 1 & & $\begin{array}{l}\text { Issue work order for preventive } \\
\text { maintenance services }\end{array}$ & $\begin{array}{c}\text { Quarterly or when } \\
\text { needed in major events }\end{array}$ \\
\hline 2 & & $\begin{array}{l}\text { Issue work order for corrective } \\
\text { maintenance services }\end{array}$ & $\begin{array}{c}\text { Quarterly or when } \\
\text { needed in major events }\end{array}$ \\
\hline
\end{tabular}




\begin{tabular}{|c|c|c|c|}
\hline \multicolumn{4}{|c|}{ Service Schedule } \\
\hline Item & $\begin{array}{l}\text { Services included } \\
\text { (only if } \\
\text { checked) }\end{array}$ & Service Description & $\begin{array}{c}\text { Frequency/Response } \\
\text { Time }\end{array}$ \\
\hline 3 & & $\begin{array}{l}\text { Check incident handling \& resolution } \\
\text { times }\end{array}$ & $\begin{array}{c}\text { Quarterly or when } \\
\text { needed in major events }\end{array}$ \\
\hline 4 & & Spare parts management & $\begin{array}{c}\text { Quarterly or when } \\
\text { needed in major events }\end{array}$ \\
\hline 5 & & Site visits with specific site visit reports & Bi-Annual / Yearly \\
\hline 6 & & $\begin{array}{l}\text { Verification of the services relating to } \\
\text { health \& safety, security, quality and } \\
\text { environment management plans }\end{array}$ & When needed \\
\hline 7 & & $\begin{array}{l}\text { Supervision and management of the } \\
\text { contract with the surveillance service } \\
\text { provider }\end{array}$ & When needed \\
\hline 8 & & $\begin{array}{l}\text { In case of under-performance, check, } \\
\text { monitoring and evaluation of the services } \\
\text { to be performed by the Service Provider } \\
\text { to identify the causes of the issue and to } \\
\text { correct the issue }\end{array}$ & When needed \\
\hline 9 & & Trouble ticket management & When needed \\
\hline 10 & & $\begin{array}{l}\text { Major maintenance works assessment } \\
\text { and solutions implemented }\end{array}$ & When needed \\
\hline
\end{tabular}




\section{Appendix F. Using Model PV System Availability Terms for Contracted O\&M}

This appendix outlines the foundation for developing language that can be utilized in model equipment availability terms typically included in an O\&M services agreement for a PV system and between a plant owner, operator, and an O\&M services provider. The availability of the components for function is the foundation of system management and will require planned and corrective maintenance at times, regardless of size. Tracking this availability (or unavailability) provides transparency into the equipment reliability state to all parties involved in an O\&M services contract.

In most PV operation contracts, energy will be the driving factor of whether the system is operating as expected. EPC guarantees, operator guarantees, owner measure of ROI, and other considerations for a contract are mostly based on whether the system produced energy as it was expected to. By itself, the availability terms are not sufficient; energy performance over the life of the system should be calculated separately and according to contract terms defined for failure to meet those numbers. In addition, energy losses associated with unavailability will play a key role in contractual language and whether a system is producing as expected. Both energy and availability are necessary metrics for assessing PV systems.

If the stakeholders involved in a contract are most interested in energy production, and if the contract holds parties responsible for energy production, then it is crucial that energy losses associated with unavailability and system performance are accounted for. Crucial is the separation of losses due to unavailability from losses due to performance issues. The stakeholders do not want any losses accounted for twice, and they do not want any losses missed.

To further complicate the issue, stakeholders should classify energy losses by category and the party responsible for losses in each category. While nobody wants to accept any losses, sometimes it is not the fault of any stakeholders who are a party to the agreement. In these instances, knowing about the losses and how they are categorized are very important, but blame or claim may not be justified against any party to the contract.

It is also important to note that while mitigation of losses is usually the goal of most stakeholders, sometimes it is good to give credit where credit is due, mostly as an incentive to exceed expectations whenever possible. If a certain energy production is expected, and that production is consistently exceeded, the beneficiaries will realize the benefits. Sharing those unexpected gains among all parties may be an incentive for all parties to make it happen.

The IEC has specific standards on these topics and for a rigorous treatment on this topic are advised to consider their use for information and/or implementation.

IEC 61724-1 Photovoltaic system performance - Part 1: Monitoring

IEC 61724-2 Photovoltaic system performance - Part 2: Capacity evaluation method

IEC TS 61724-3 Photovoltaic system performance - Part 3: Energy evaluation method 
IEC 63019 Information Model for Availability (pending).

Starting with definitions modified from IEEE 762:

The Available state is where a unit can provide service per specification, regardless of whether it is in service and regardless of the capacity level and other capabilities that can be provided.

Equipment is in an Unavailable state when the equipment is not capable of operation to specification due to equipment failures, external restrictions, testing, maintenance, or other plant work being performed or some adverse condition. The unavailable state persists until the unit is made available for operation by being synchronized to the system in service state.

Note in the definitions that there are clarifying thoughts regarding capacity and reasons why equipment may not be capable. There are many reasons for downtime and the simplest is that the solar irradiance at night will not power a PV system. In IEC 63019, categories of causes include full capability, partial capability, services set points, out of environmental specification, requested shutdown, scheduled maintenance, planned corrective actions, forced outages (faults and failures), suspended, and force majeure. These are presented in tabular form in the model, are adjustable, and may need greater specificity that IEC 63019 will provide. Many of these are external to management control of the plant, but of course, some are instrumental in the internal operation and asset management activities of O\&M. Inclusions and exclusions should be determined by the scope of contract services sought.

To successfully understand the various categories of conditions that reduce availability, the system requires a time series DAS that tracks operating conditions and durations of outages. If such information is not available, some categories may require manual tracking of events. Examples of the myriad events include faults, interruptions due to grid disturbances, owner/customer interruptions, weather impacts, bio-fouling (e.g. bird droppings), and force majeure events. These will need to be identified in the service agreement for inclusion or exclusion, but generally, these items may fall into internal or external events or control actions. The attached model contract clause includes an equation by which to calculate time-based total PV power station capacity availability. 


\section{Model Equipment Availability Terms}

Capacity is a physical property of the PV system and installed components. Capacity will only be reduced when a component integral to power production fails (and becomes unavailable). Individual components will also have capacities associated with them. The total of all component capacities will comprise the plant capacity. Capacity can then be used as an input to compute full PV system availability, as that is an expected usual goal. With that, use the following formula:

$$
\underset{\text { Availability }}{\text { PV System }} \quad=1-\frac{1}{\mathrm{H}_{\text {tp }} \times K W_{n p}} \times\left(\sum_{\text {Incident }}\left(H_{u n} K W_{d r}\right)\right)
$$

Where:

Theoretical total production time (Http):

The hours in the period when sufficient sunlight exists to allow the inverters to reach the input voltage needed to operate.

Nameplate power (KWnp):

The nameplate power rating of the entire solar generating facility determined by the sum of each module's nameplate $\mathrm{kWp}$ rating.

Component unavailability hours (Hun):

The hours in the period when solar irradiance is sufficient to power the inverters, yet a component within the facility is not available to generate power due to an equipment fault.

Derated system power (KWdr):

The value for unavailability derated system power will be calculated by the amount of unavailable DC nameplate capacity for the period and is determined by sum of each module's nameplate $\mathrm{kWp}$ rating for that given unavailable component.

Incident:

Every outage incident during the measurement period.

Note 1: KWdr describes the fractional capacity reduction (not due to degradation).

Note 2: This calculation does not consider cumulative degradation, which should be calculated and tracked separately along with energy production. 


\begin{tabular}{|c|c|c|c|c|c|c|c|c|c|c|c|c|c|c|}
\hline \multirow[b]{2}{*}{$\begin{array}{l}\text { MEANING } \\
\text { COLORS: } \\
\text { GREEN = included in } \\
\text { period hours as } \\
\text { available }\end{array}$} & \multicolumn{12}{|c|}{ Mandatory - Information categories } & \multicolumn{2}{|c|}{$\begin{array}{c}\text { Availability }= \\
1-\text { unavailability }\end{array}$} \\
\hline & 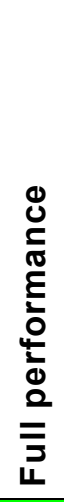 & 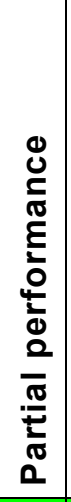 & 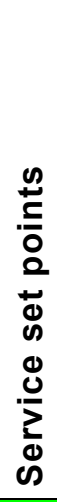 & 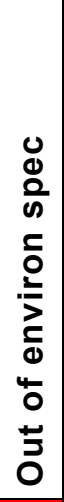 & 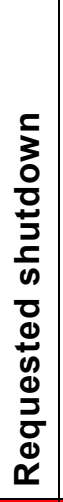 & 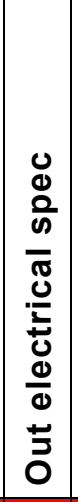 & 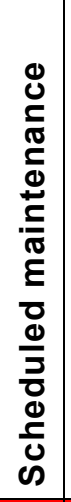 & 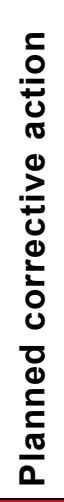 & 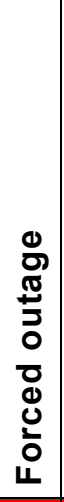 & 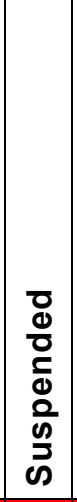 & 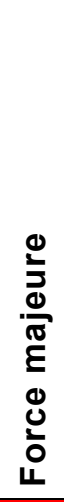 & 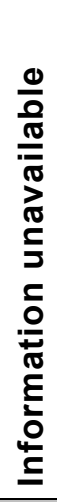 & 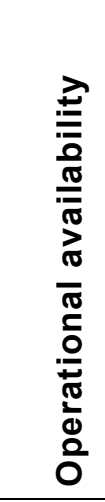 & 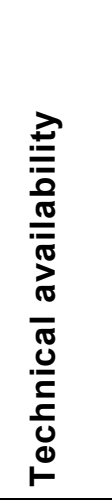 \\
\hline $\begin{array}{l}\text { Operational } \\
\text { availability }\end{array}$ & & & & & & & & & & & & & $\mathbf{X}$ & \\
\hline Technical availability & & & & & & & & & & & & & & $\mathbf{X}$ \\
\hline
\end{tabular}

Example: Assignment of downtime events to information categories.

Operational availability is the fraction of a given period (e.g., month) in which a PV system is generating. This is primarily an operator's, user's, or owner's view of a PVPS and measures how often the asset was generating power. This may also be known as "raw" or "all-in" availability.

Technical availability differs from operational availability in that categories generally beyond the control of the PVPS systems, subsystems, components, or subcomponents are excluded from consideration. For instance, system performance is not being evaluated during hours where the operator has requested a shutdown, an electrical connection is not available, or a force majeure event has occurred.

(Typical contract terms are not provided in the Model Equipment Availability Terms, and items such as liquidated damages, warrantee procedures, exceptions and inclusions, and other contract terms will need to be added.)

Figure F-1. Model Availability Terms

This approach is a tool, and the users can deviate from the listed inclusions and exclusions as appropriate and further identify and define them for purposes of the contract.

Stated simply, unavailability events must be tracked, and the capacity reduction expressed as a percentage is the availability for the duration of the period respective outages. Care must be taken to avoid double counting, and this should be reflected in the contract terms. IEC 63019 will have guidance for prioritizing outages (i.e., grid outage concurrent at the time of an inverter outage), which usually prioritizes keeping components available (internal) versus external factors of control of the operator.

For contracts, a table used to summarize, calculate, and categorize contract exclusions, energy gains, and losses due to performance; energy gains and losses due to availability; and associated contract penalties or rewards may be useful. By using a summary table, the parties may easily calculate offsets of losses in one area with gains in another. 